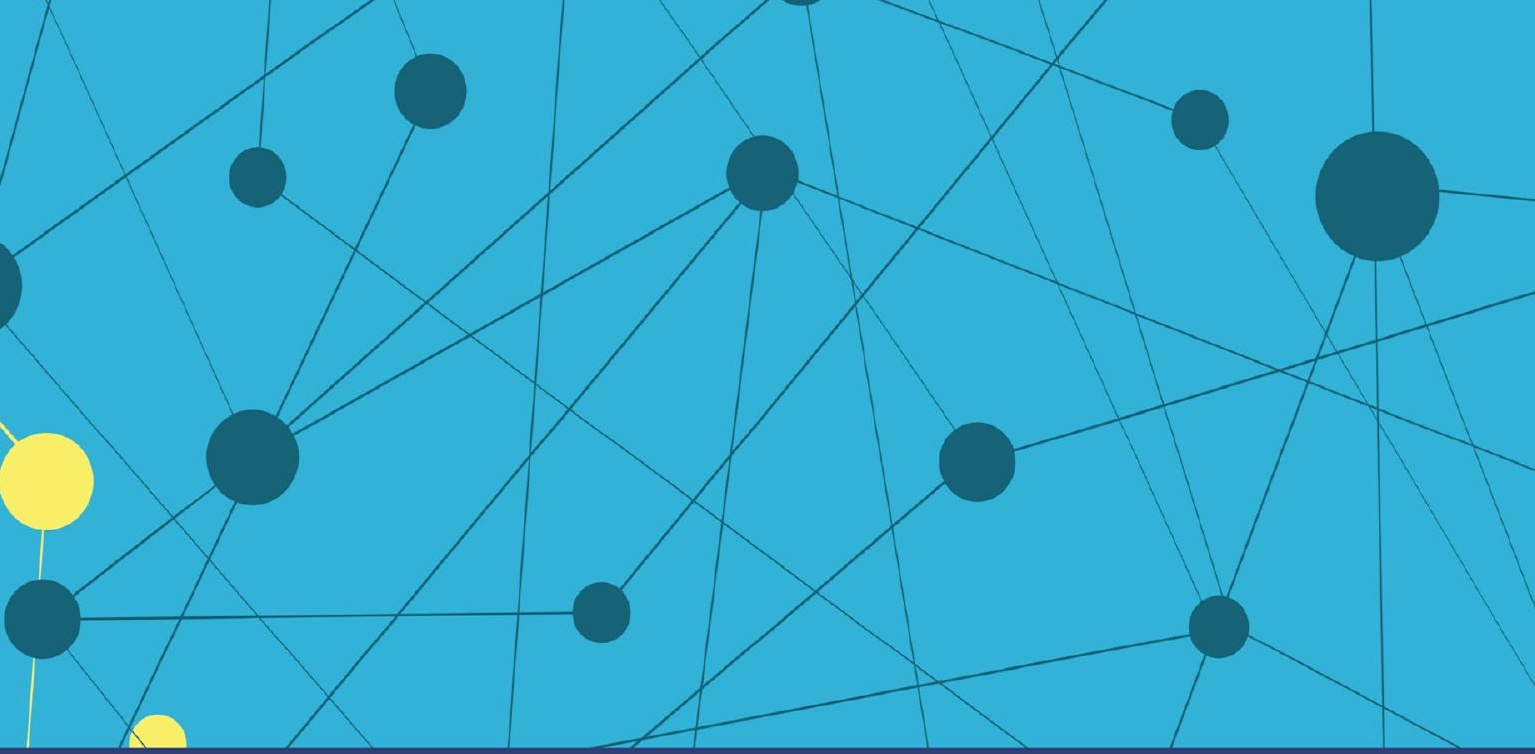

Chinese Perspectives on Journalism and Communication

\title{
SCIENCE IN MOVEMENTS
}

KNOWLEDGE CONTROL AND SOCIAL CONTESTATION IN CHINA'S HYDROPOWER, GMO AND NUCLEAR CONTROVERSIES

Hepeng Jia

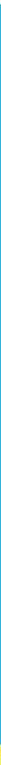




\section{Science in Movements}

This book analyzes and compares the origins, evolutionary patterns and consequences of different science and technology controversies in China, including hydropower resistance, disputes surrounding genetically modified organisms and the nuclear power debate.

The examination combines social movement theories, communication studies, and science and technology studies. Taking a multidisciplinary approach, the book provides an insight into the interwoven relationship between social and political controls and knowledge monopoly, and looks into a central issue neglected by previous science communication studies: why have different controversies shown divergent patterns despite similar social and political contexts? It is revealed that the media environment, political opportunity structures, knowledge-control regimes and activists' strategies have jointly triggered, nurtured and sustained these controversies and led to the development of different patterns. Based on these observations, the author also discusses the significance of science communication studies in promoting China's social transformation and further explores the feasible approach to a more generic framework to understand science controversies across the world.

The book will be of value to academics of science communication, science and technology studies, political science studies and sociology, as well as general readers interested in China's science controversies and social movements.

Hepeng Jia is a professor of communication at Soochow University, Suzhou, China. He has worked as a leading science journalist for 20 years and is also a pioneering researcher in the field of science journalism and communication in China. 


\section{Chinese Perspectives on Journalism and Communication}

Series Editor: Wenshan Jia is a professor of communication at Shandong University and Chapman University.

With the increasing impact of China on global affairs, Chinese perspectives on journalism and communication are on the growing global demand. This series focuses on theory and research-oriented scholarship on journalism and communication broadly defined from Chinese perspectives, aided by a variety of methods, and informed by indigenous, interdisciplinary, intercultural or global approaches.

Titles in this series currently include:

From Cyber-Nationalism to Fandom Nationalism

The Case of Diba Expedition in China

Hailong Liu ed.

\section{Propaganda}

Ideas, Discourses and its Legitimization

Hailong Liu

\section{Convergent Journalism}

Chinese Approaches

Woody Bing Liu

\section{Chinese Internet Buzzwords}

Research on Network Languages in Internet Group Communication Zhou Yan

\section{Science in Movements}

Knowledge Control and Social Contestation in China's Hydropower, GMO and Nuclear Controversies

Hepeng Jia

For more information, please visit https://www.routledge.com/Chinese-Perspectives-on-Journalism-and-Communication-Series/book-series/CPJC 


\section{Science in Movements}

Knowledge Control and Social

Contestation in China's Hydropower,

GMO and Nuclear Controversies

\section{Hepeng Jia}


First published 2022

by Routledge

2 Park Square, Milton Park, Abingdon, Oxon OX14 4RN

and by Routledge

605 Third Avenue, New York, NY 10158

Routledge is an imprint of the Taylor \& Francis Group, an informa business

(C) 2022 Hepeng Jia

The right of Hepeng Jia to be identified as author of this work has been asserted by him in accordance with sections 77 and 78 of the Copyright, Designs and Patents Act 1988.

Trademark notice: Product or corporate names may be trademarks or registered trademarks, and are used only for identification and explanation without intent to infringe.

The publication of this open access book is funded by Soochow University.

The Open Access version of this book, available at www.taylorfrancis.com, has been made available under a Creative Commons Attribution-Non Commercial-No Derivatives 4.0 license.

British Library Cataloguing-in-Publication Data

A catalogue record for this book is available from the British Library

Library of Congress Cataloging-in-Publication Data

Names: Jia, Hepeng, 1972- author.

Title: Science in movements : knowledge control and social contestation in China's hydropower, GMO and nuclear controversies / Hepeng Jia.

Other titles: When science controversies encounter political opportunities

Description: Abingdon, Oxon ; New York, NY : Routledge, 2022. |

Series: China perspectives | Revision of author's dissertation

(doctoral)--Cornell University, 2019, titled When science controversies

encounter political opportunities : comparing GMO, hydropower and nuclear power contentions in contemporary China. |

Includes bibliographical references and index.

Identifiers: LCCN 2021006436 (print) | LCCN 2021006437 (ebook) |

ISBN 9780367749095 (hardback) | ISBN 9780367765293 (paperback) |

ISBN 9781003160212 (ebook)

Subjects: LCSH: Communication in science--China. | Science and

state--China. | Science--Social aspects--China. | Social movements--China.

Classification: LCC Q223 .J52 2022 (print) | LCC Q223 (ebook) |

DDC 306.4/509510905--dc23

LC record available at https://lccn.loc.gov/2021006436

LC ebook record available at https://lccn.loc.gov/2021006437

ISBN: 978-0-367-74909-5 (hbk)

ISBN: 978-0-367-76529-3 (pbk)

ISBN: 978-1-003-16021-2 (ebk)

DOI: $10.4324 / 9781003160212$

Typeset in Times New Roman

by Taylor \& Francis Books 
To Haiyan, Jay and Daniel. 
$\Longrightarrow$ Taylor \& Francis

Taylor \& Francis Group

http://taylorandfrancis.com 


\section{Contents}

List of illustrations viii

Acknowledgements $\quad \mathrm{x}$

List of abbreviations xii

1 Science controversies encounter political opportunities 1

2 Research method and data 19

3 Science controversies in transitional China 36

4 Hydropower, fragmentation and knowledge-making 66

5 GMO controversy: How orthodox science lost control 101

6 The nuclear power debate in a narrow political opportunity $\begin{array}{ll}\text { structure } & 135\end{array}$

7 Why are science controversies so different? 168

8 Synergy of different theoretical traditions in a comparative lens 184

9 Conclusion 188

$\begin{array}{lr}\text { Appendix } & 192\end{array}$

References $\quad 202$

$\begin{array}{ll}\text { Index } & 226\end{array}$ 


\section{Illustrations}

\section{Figures}

1.1 The intersecting elements of social movements 8

4.1 Hydropower reporting by the four sampled Chinese media (1980-2017) 72

4.2 High-impact BBS posts focused on hydropower (2003-2017) 79

4.3 Google search trends (2004-2018) 79

4.4 Combined hydropower reporting by four sample Chinese media (2004-2017)

5.1 Number of the four sampled media's combined articles on GMO in China (1995-2016)

5.2 Attitude of sampled media articles to GMOs in China 1995-2016 109

5.3 Percentage of sampled media articles adverse to GMOs in China 1995-2016

5.4 Baidu media index of GMOs in China (2011-2018) 110

5.5 Baidu search index for GMOs in China (2011-2018) 111

5.6 Google search index for GMOs in China (2004-2018) 111

5.7 High-impact BBS posts on Tianya (2003-2017) 112

5.8 Political opportunity structure, framing and mobilization in China's anti-GMO activism

6.1 Number of the sampled media articles on nuclear power in China (2000-2017)

6.2 Combined four sampled Chinese media nuclear power articles (2010-2017)

6.3 Chinese media articles mentioning nuclear power searched through Baidu Index (2011.01-2019.01)

6.4 Baidu users' online search of the keyword "nuclear power" (2011-2018)

6.5 Google Trend showing the online search of the keyword "nuclear power" (in Chinese and China) (2004.01-2019.01) 
6.6 The frequency of high-impact BBS posts on "nuclear power" (in Chinese) on Tianya.com (2003-2017)

6.7 Narrow political opportunity structure, unfriendly framing and low mobilization for China's anti-nuclear activism

\section{Tables}

1.1 Characteristics of hydropower, nuclear power and GMO, and controversies surrounding them

2.1 Downloaded media articles and their publishing time

2.2 Mass media theme coding of the three studied subjects

4.1 SW's hydropower articles between 2000 and 2017 and their attitudes

4.2 XEN's hydropower articles between 2002 and 2017 and their attitudes

4.3 PD's hydropower articles between 2000 and 2017 and their attitudes

4.4 The main themes of SW and XEN's hydropower articles 76

4.5 Some of CPPCC or NPC's actions against hydropower since $2003 \quad 85$

4.6 Hydropower controversies through the lens of social movement theories

4.7 Themes of the People's Daily hydropower articles between 1980-1999

4.8 Main themes of the four sampled media's hydropower articles, article attitude, visibility of controversies and their percentage

4.9 Noticeable public intellectuals against hydropower (excluding ENGO members)

5.1 Main themes, article attitude, visibility and percentage of coverage of the four sampled media's GMO articles

5.2 Analysis of Cui Yongyuan's recent anti-GMO tweets (12/20/201801/06/2019)

5.3 Major GMO controversial events in China in recent years

6.1 XEN's nuclear power coverage (2002-2017)

6.2 People's Daily nuclear power coverage (2000-2017)

6.3 China Science Daily nuclear power coverage (2007-2017)

6.4 Southern Weekend nuclear power coverage (2002-2017)

6.5 Main themes of the sampled media articles on nuclear power in China (2000-2017)

7.1 Different patterns of hydropower, GMOs and nuclear power controversies 


\section{Acknowledgements}

This book is based on my doctoral dissertation resulting from a challenging 7-year academic journey. For the journey, I am so lucky to have worked with my advisor and committee chair Professor Bruce Lewenstein, who has offered everything needed to allow me to start a new era in my academic life.

I started my doctoral studies at a time when I had achieved a certain level of professional excellence as a science journalist. However, professional excellence soon proved to be a significant burden to my academic pursuit. A thriving science journalism career had made me focus on analyzing specific sociopolitical factors for my news stories while an academic career forced me to pursue cross-cultural generalizability. This tension is particularly true in American communication scholarship, where the Chinese landscape has always been dimmed. For the first two years of my doctoral studies, I struggled between the objectives.

In the situation, I should say special thanks to Professor Lewenstein, who was always generous in sharing his instructions and insights with me. As a result, I gradually marched to a clearly-tasked, yet balanced zone for academic research. My committee members, Prof. Katherine McComas, and Prof. Stephen Hilgartner from Cornell and Prof. Fa-ti Fan from SUNY Binghamton, also offered great support to me. Among them, Prof. Hilgartner has been particularly helpful. He guided me to begin my research from social movement theories during an independent study course with him. The independent study finally shaped my dissertation direction. Prof. Fan and Prof. McComas, on the other hand, offered tremendous help by instructing me on how to link my research to China and risk communication.

In my academic shift from a working journalist to a science communication scholar, the essential supports of several tutors have played fundamental roles. I would particularly thank Prof. Xue Lan of Tsinghua University, who always created unique opportunities and instructive suggestions for me - from referring me to work for SciDev.Net's science communication initiatives to starting doctoral work. The late Harvard Prof. Calestous Juma, who himself was an exemplary model of journalist-turned-scholar, also gave me tremendous help. Professor Caroline Wagner, my advisor at the Ohio State University, where I 
studied science policy before moving to Cornell, is also on the list of those lifelong mentors.

Many Chinese collaborators' supports are crucial to my project and should be acknowledged. Professor Deng Lifeng of Sun Yat-sen University has generously shared his contacts and insights on China's nuclear power controversy. Sun Yat-sen University also gave a small grant to help my field study in China. Dr. Liu Kai of Beijing Jiaotong University has offered decent data supports to my dissertation during his visit to Cornell. I have made repeated consultation with Dr. Miao Weishan of the Chinese Academy of Social Sciences, my long-time friend and collaborator, on the dissertation outline and many detailed data analyses. Dr. Li Yang of Tsinghua University munificently provided her unpublished social network analysis data on China's GMO debates. Many others supported me either by receiving my interview or providing critical information during my field study. Due to ethical consideration, I cannot disclose their names.

Then, for turning my dissertation into the current book, I am particularly grateful to Professor Jia Wenshan of Shandong University, whose encouragement and recommendation made this book possible. Lian Sun and Xiaoyin Feng, two editors at Taylor \& Francis China, helped me streamline the revision of the book. The three anonymous reviewers' suggestions also played a crucial role in guiding me to go through the book proposal. My employer Soochow University's generosity should also be mentioned and thanked. The university funded the open-access publication of this book, so that more people are able to access to the book and many of its insights.

Finally, but perhaps most importantly, my wife Haiyan's great sacrifice, understanding, and support are the unreplaceable resource I have always had in finishing my Ph.D. training and academic shift. Without her tolerance, I really could not have completed this trip. 


\section{Abbreviations}

$\begin{array}{ll}\text { AEC } & \text { Atomic Energy Commission } \\ \text { AMMS } & \text { Academy of Military Medical Sciences } \\ \text { Bt } & \text { Bacillus thuringiensis } \\ \text { CAAS } & \text { Chinese Academy of Agricultural Sciences } \\ \text { CAE } & \text { Chinese Academy of Engineering } \\ \text { Caltech } & \text { California Institute of Technology } \\ \text { CAMS } & \text { Chinese Academy of Medical Sciences } \\ \text { CAS } & \text { Chinese Academy of Sciences } \\ \text { CAST } & \text { China Association for Science and Technology } \\ \text { CCP } & \text { Chinese Communist Party } \\ \text { CGNPC } & \text { China General Nuclear Power Corporation } \\ \text { China CDC } & \text { Chinese Center for Disease Control } \\ \text { CIAE } & \text { China Institute of Atomic Energy } \\ \text { CNEA } & \text { China Nuclear Energy Association } \\ \text { CNNC } & \text { China National Nuclear Corporation } \\ \text { CNS } & \text { China Nuclear Society } \\ \text { CNTA } & \text { China National Tourism Administration } \\ \text { CPPCC } & \text { Chinese People's Political Consultative Conference } \\ \text { CRAES } & \text { Chinese Research Academy of Environmental Sciences } \\ \text { CSD } & \text { China Science Daily, published by the Chinese Academy of } \\ & \text { Sciences } \\ \text { CSHE } & \text { China Society for Hydropower Engineering } \\ \text { CTGC } & \text { China Three George Corp } \\ \text { CUSBEA } & \text { China-US Biochemistry Examination and Application } \\ \text { DRC } & \text { Development Research Center of the State Council } \\ \text { EIA } & \text { Environmental impact assessment } \\ \text { ENGOs } & \text { Environmental non-governmental organizations } \\ \text { EPA } & \text { The U.S. Environmental Protection Agency } \\ \text { EPR } & \text { European Pressurized Reactor } \\ \text { FDA } & \text { (US) Food and Drug Administration } \\ \text { GDP } & \text { Gross domestic project } \\ \text { HGP } & \text { Human Genome Project } \\ \text { HUST } & \text { Huazhong University of S\&T } \\ & \end{array}$




$\begin{array}{ll}\text { HZAU } & \text { Huazhong Agricultural University } \\ \text { IAEA } & \text { International Atomic Energy Agency } \\ \text { IHEP } & \text { Institute of High-energy Physics, Chinese Academy of Sciences } \\ \text { IRRI } & \text { International Rice Research Institute } \\ \text { ITER } & \text { International Thermonuclear Experimental Reactor } \\ \text { IWHR } & \text { China Institute of Water Resources and Hydropower Research } \\ \text { MEE } & \text { Ministry of Ecology and Environment of China } \\ \text { MEP } & \text { Ministry of Environmental Protection } \\ \text { MOA } & \text { Ministry of Agriculture of China (Renamed to Ministry of } \\ & \text { Agriculture and Rural Affairs in 2018) } \\ \text { MOAR } & \text { Ministry of Agriculture and Rural Affairs } \\ \text { MOH } & \text { Ministry of Health of China } \\ \text { MOST } & \text { Ministry of Science and Technology of China } \\ \text { MWR } & \text { Ministry of Water Resources of China } \\ \text { NDRC } & \text { National Development and Reform Commission of China } \\ \text { NEA } & \text { National Energy Administration of China } \\ \text { NFA } & \text { National Forestry Administration of China } \\ \text { NIRP } & \text { National Institute for Radiological Protection under the } \\ & \text { Chinese Center for Disease Control } \\ \text { NNSA } & \text { National Nuclear Safety Administration of China } \\ \text { NPC } & \text { National People's Congress of China } \\ \text { NPP } & \text { Nuclear power plant } \\ \text { NRC } & \text { Nuclear Regulatory Commission } \\ \text { OECD } & \text { Organization for Economic Co-operation and Development } \\ \text { ORNL } & \text { Oak Ridge National Laboratory } \\ \text { PD } & \text { People's Daily } \\ \text { PIOs } & \text { Public information officers } \\ \text { PR } & \text { Public relations } \\ \text { PUS } & \text { Public understanding of science } \\ \text { PWR } & \text { Pressurized water reactor } \\ \text { R\&D } & \text { Research and development } \\ \text { RUC } & \text { Renmin University of China } \\ \text { SACH } & \text { State Administration of Cultural Heritage of China } \\ \text { SASTIND } & \text { State Administration of Science, Technology, and Industry for } \\ & \text { National Defense of China } \\ \text { SEPA } & \text { State Environmental Protection Administration of China; } \\ & \text { Renamed in 2008 to Ministry of Environmental Protection } \\ & \text { (MEP), and then reshuffled to become the Ministry of Ecology } \\ \text { TGP } & \text { and Environment (MEE) in 2018 } \\ \text { TNC } & \text { State Nuclear Power Technology Corporation } \\ \text { SNWTP } & \text { South-North Water Transfer Project } \\ \text { SOEs } & \text { State-owned enterprises } \\ \text { SW } & \text { Theuthern Weekend } \\ \text { The Nature Conservancy } \\ \end{array}$


xiv Abbreviations

UIBE University of International Business and Trade

USTC University of Science and Technology of China

VPN Virtual private network

WCD World Commission on Dams

WTO World Trade Organization

WWF World Wildlife Fund

XEN

Xinmin Evening News (Shanghai-based metropolitan tabloid) 


\section{Science controversies encounter political opportunities}

\subsection{Introduction}

Science and technology (S\&T) controversies are an essential research topic in science communication scholarship (Lewenstein, 2017). However, despite the effort to systemize scientific controversy studies (Martin, 2014), two critical dimensions remain underexplored. First, why have different controversies shown divergent patterns? Second, most controversy studies were performed in Western democracies, which are insufficient for us to understand scientific controversies in broader social and political contexts.

Indeed, S\&T controversies have been spreading worldwide, including in authoritarian regimes like China where science traditionally enjoys an ideologically paramount status (Cao, 2014; Ding, 2014). Since February 2016, when I began to prepare the current project, more than a dozen major science-related controversies have flooded the Chinese media and Internet. They ranged from the role of nonprofessional researchers in observing gravitational waves (Y. Tang \& Wang, 2016) and the replicability of a dubious cutting-edge genome editing technology (Cyranoski, 2017) to new developments of long-lasting controversies surrounding genetically modified organisms (GMOs) (Financial Times, 2016), hydropower projects (J. Li, 2016) and nuclear power (Buckley, 2016a). The most recent one is the well-publicized genomic editing of babies manipulated by Chinese scientist He Jiankui at Shenzhen-based Southern University of S\&T (SUSTech).

As in Western contexts, S\&T controversies in China demonstrate highly divergent evolution patterns, ranging from the massive and long-lasting public rejection of genetically modified (GM) foods to the collective efforts of environmental non-governmental organizations (ENGOs) to resist hydropower development and the low-profile internal elite strife surrounding nuclear power. How should we understand the high frequency of S\&T controversies and their different patterns? Have social, political and economic factors contributed to their occurrence and development? The current project tries to answer these questions by combining different theoretical traditions empirically.

In addition to science communication scholarship, science and technology studies (STS) utilize controversies to reveal science's hidden operation rules

DOI: $10.4324 / 9781003160212-1$ 


\section{Science controversies}

(Pinch, 2015; Pinch \& Leuenberger, 2006). However, while STS intensively explores the central status of knowledge in scientific controversies, it has under-investigated macro-political factors which play a crucial role in influencing the development of such disputes (Jasanoff, 2017), particularly in developing countries (F.-t. Fan, 2007).

Social movement theories, particularly the political process theory proposed by McAdam, Tarrow and Tilly (2001), seems to have a powerful advantage in exploring the divergent patterns of the widespread S\&T controversies in China, where specific political opportunity structures, a central theoretical component of the political process theory, open up in some disputes, leading them to break out and become sustained, but not in others.

However, as STS scholars point out, social movement theories ignore knowledge and epistemic issues (Breyman, Campbell, Eubanks \& Kinchy, 2017; Hess, Breyman, Campbell \& Martin, 2008; Martin \& Groth, 1991), resulting in a crucial neglect of the social and political order science co-produces with its epistemic authority (Jasanoff, 2004b, 2017).

Absorbing science communication scholarship, STS, social movement theories, East Asian probes into the science-society-state interaction (W. Anderson, 2012; F.-t. Fan, 2012; Fu, 2007), and studies on China's sociopolitical transitions, this book examines and compares controversies surrounding GMOs, hydropower development and nuclear power. Based on intensive field studies and multilevel data analysis, I will reveal a wide range of communication, sociopolitical and knowledge factors contributing to the occurrence and sustaining of controversies despite science's ideological importance in China.

\subsection{Literature review}

\subsubsection{S\&T controversies in science communication landscape}

According to sociologist Dorothy Nelkin (1987), growing concerns over the social, moral or religious implications of scientific advances, tensions between environmental value and technological development, worries about health hazards of emerging technologies, and declining public trust in scientists and public institutions have contributed to the surging number of controversies of this kind in the public domain. In a sense, the public debates on these technologies are fundamentally controversies over political control (Nelkin, 1995).

Like Nelkin, Brian Martin has systematically studied scientific controversies. In his Controversy Manual, Martin (2014) summarized the main dynamics underlying controversies, including actors' (scientists, the media and activists) confirmation bias, their vested interests, the repeated reinforcement of assumptions, and the debated nature of scientific evidence. For example, in the GMO controversy, several studies (Cook, Pieri \& Robbins, 2004; Cuppen, Hisschemöller \& Midden, 2009) found biotechnology scientists generally thought public resistance to GMO was because of their ignorance, their naïve requirement of the impossible "zero risks" and their heavy reliance on emotion to make decisions. 
But structural differences between science communities, the media and the public also contribute to scientific controversies. Flipse and Osseweijer (2013) found scientists and the biotechnology industry's often slow response to GMO-related controversial events resulted in their having a far lower presence in the media than challenging activists. When they did respond, the media attention to the events decreased, and most of the public did not have a chance to learn the mainstream scientific conclusions through the media.

Science communication scholars have also intensively investigated the role of the media in controversies. Cook, Robbins and Pieri (2006) found the UK media have widely cited public representatives and NGOs to counterbalance scientists' and the government's effort to frame GMO in S\&T terms. The second dimension is to reveal how the media's pursuit of dramatic effects intensifies controversies. For example, studies have demonstrated that the media's efforts to balance scientific consensus on climate change with climate skepticism create opportunities for skeptics to speak out (Antilla, 2005; Boykoff \& Boykoff, 2004).

A third dimension is to show the effect of media reporting on public attitudes to the controversial technologies. Bauer (2002) found that the media trend of favoring medical biotechnology more than agricultural biotechnology is significantly associated with the European public's divergent opinions on the two biotechnologies while Frewer, Miles and Marsh (2002) demonstrated evidence to support the social amplification of risk framework, which claims that different amplifier stations including media determine the consequences of a risk event.

Overall, the media selection of information and their preference of conflicts have increased public rejection of controversial S\&T (Mazur, 1981; M. C. Nisbet \& Huge, 2006). Mazur (2016) further claimed that it is the amount of media coverage of S\&T controversies rather than its frames or contents that determines the public rejection of the controversial technologies.

Science communication scholars have also traced how S\&T controversies are staged in the media arena (Hilgartner \& Bosk, 1988) and how the media facilitate controversy development (Brossard, 2009; Lewenstein, 1995). They found that the media, instead of being a passive platform to deliver controversy actors' voices, actively promoted the process of the controversies.

A large body of science communication literature investigates public attitudes to controversial technologies and the social, psychological and cognitive factors that shape individual attitudes. There is no substantial evidence to support the assumption that more knowledge leads to stronger support for disputed S\&T items (Akin \& Scheufele, 2017). Compared with knowledge, trust (or more accurately, trust in scientific institutions) is a much stronger predictor of people's positive attitude to S\&T, especially in controversial setting (Chryssochoidis, Strada \& Krystallis, 2009). Other cultural cognitive constructs like political ideology have been found to cause people's biased selection of information and biased attitude to controversial S\&T (Kahan, Jenkins-Smith \& Braman, 2011). 


\section{Science controversies}

Although science communication scholarship has identified and measured a wide variety of social, organizational, communication and individual factors that affect people's attitudes to science controversies, it has not done enough to examine the dynamics of scientific debates. As a result, we don't know why, in similar situations, people reject science A but keep silent on equally controversial science B. Why have some controversies lasted while others were short-lived?

To answer all these questions, one needs to take a more in-depth view of the controversies, a critical examination of its actors and a comparative approach across nations, political systems and cultures.

\subsubsection{Epistemic roots of $S \& T$ controversies}

\section{From social institution to epistemic constructionism}

Relying on the epistemological relativism suggested by Bloor's (1991) Strong Program, sociology of scientific knowledge (SSK) scholars have widely examined science controversies. The so-called strong program symmetrically treats all knowledge claims, scientific or unscientific, true or false, and mainstream or marginalized.

Absorbing the essence of SSK but stepping out of its lab settings, other STS scholars have investigated public science controversies with constructionist approaches. In his study on the controversy surrounding the HIV-AIDS link, Epstein (1996) showed in his Impure Science that Peter Duesberg's unsuccessful challenge of the orthodoxy of the link between HIV infection and AIDS became salient partly because of the campaigns by AIDS activists who were still young and active when diagnosed with viral infections. The challenge was finally rejected because the "viral hypothesis satisfied the interests of various players, both 'insiders' and 'outsiders"' (p. 321). Combining resource mobilization theory (McCarthy \& Zald, 1973, 1977) and STS, Impure Science initiated the endeavor to investigate science controversies as a social movement, though the effort has not been widely followed among either social movement or STS scholars (Breyman et al., 2017).

In her seminal book Design on Nature (2011), Sheila Jasanoff demonstrated how different cultures, risk regulations and science-government-business links shaped divergent biotechnology governances in the United States, United Kingdom and Germany. The US style of relying on experts, numbers and its distrust of the public constitutes a risk governance regime sharply different from those of Britain and Germany, which either employ an experience-based consultation (Britain) or focus on rationality, ethics and experts' professional skills (Germany).

\section{From civic epistemology to knowledge-control regime}

In Design on Nature, based on the comparative analysis of the policymaking process, Jasanoff proposed the idea of civic epistemology, which "refers to 
these culturally specific, historically and politically grounded, public knowledge-ways" (2011, p. 249). The concept, advancing Irwin and Wynne's (1996/2003) effort to justify layman knowledge to confront the monopoly of experts' views, stresses that 'convergence in scientists' understanding of the facts is not the same thing as public assent to those understandings" (Jasanoff, 2011 b, p. 129). The public knowledge-ways is not to understand the mainstream scientific truth as imagined by the public understanding of science (PUS) model, but to "yield to the social reality of sciences that are more problem-driven and politically accountable" (Jasanoff, 2011b, p. 130).

Civic epistemology is a concept highly relevant to public S\&T controversies because, in the controversy setting, activists or the general public often raise issues well beyond the mainstream scientific conclusions. The concept of civic epistemology allows an in-depth analysis into the contexts in which these anti-establishment "knowledge-ways" were brewed.

Although Jasanoff raised the idea of civic epistemology in the Western democracy setting, there is no reason to question the concept's applicability in authoritarian regimes like China where political control, the political importance of S\&T and civil understanding of them coexist, just like in the West (J. Y. Zhang, 2015). This similarity is indicated by many studies that have explored how orthodox scientists and unscientific laymen epistemically treat controversial S\&T in China in different means (Cao, 2018; L. Deng \& Jia, 2019; Hansen, 2017b). Based on these studies, it is also clear that political power and the politics-science alliance have played a more significant role in shaping civic epistemology in China than in the West. This book will clarify the science-politics union.

Meanwhile, in addition to macro politics, it is also essential to understand what other factors have differentiated controversy actors in making their knowledge-ways. One such differentiating factor - often unnoticed - could be cultural characteristics, such as the idea of national sociotechnical imaginaries Jasanoff and Kim (2009, 2015) raised while analyzing the different fates of nuclear power in South Korea and the United States. The concept represents a national memory and imagination on the role of specific technologies in influencing a nation's historical development and steering its future. Jasanoff and Kim demonstrated that nuclear power is imagined as significant S\&T progress and national pride in South Korea while mostly an uncontrollable monster needing to be contained in the United States. Despite its broad scholarly impact, the idea has not yet been systematically used to examine different science controversies.

The current book attempts to assess the applicability of the concept by treating the imaginaries as resources for civic epistemology. For science controversies, the other side of the coin is social control revealed in epistemic form. Following Michel Foucault's concept of biopower which refers to modern states' regulation of their subjects through numerous and diverse techniques to subjugate bodies and control populations (Foucault, 1978), many scholars have explored how social institutions such as medication and 


\section{Science controversies}

public health realized political control (Conrad, 1992). Epistemically advancing the ideas, Jasanoff (2004b) developed the concept of "co-production" of knowledge and social order which argues that how the world is known and how social relations are disciplined are deeply interconnected, and the change of established social orders has to undergo processes in which knowledge and social relationships mutually adjust each other.

Absorbing Jasanoff's idea of co-production, Hilgartner (2017) advanced the concept of "knowledge-control regimes" in his book Reordering Life to analyze the formation and evolution of the Human Genome Project (HGP). According to Hilgartner (2017, p. 9), a knowledge-control regime can be defined as "a sociotechnical arrangement that constitutes categories of agents, spaces, objects and relationships among them in a manner that allocates entitlements and burdens pertaining to knowledge." Such regimes allocate epistemic authority, distribute credit, create a property, spread knowledge, ensure quality, construct professional jurisdictions, and even protect national security.

There are many regimes for such knowledge-controls, which constitute modes of control that apply to specific actors, entities and jurisdictions, but they vary in the extent to which they are formally codified. Hilgartner (2017, p. 12) also argued that the conceptual structure of a knowledge-control regime is encoded as a "governing frame," which promotes an official viewpoint that endows agents with specific entitlements and burdens pertaining to other agents or to control over spaces, objects and actions.

Knowledge-control regimes should be considered a regular type of epistemic management. A journal publication process is a typical example of such a scheme. Authors must abide by a series of norms, such as blinding author information, to submit their papers. These papers, then, are sent to peer reviewers to decide academic originality. It is expected that the author will not release the paper before journal publication. These and other expectations are part of the knowledge-control regime. In the process described here, journal editors implement multiple controls of the knowledge contained in the paper.

In publicly controversial science, dissenting scholars and activists have to try to break such knowledge-control regimes, while mainstream scientists try to maintain them with all means, including laws, rules, authority, norms and institutionalized arrangements. But a knowledge-control regime does not necessarily mean an intentional effort to hide the truth. A central tenet of the concept is that specific knowledge presented in social life is always a result of the interaction between epistemic management and multiple social, political and institutional factors. While the epistemic management in some areas might be stronger than in other regions, the knowledge-control regime is embedded in a networked social context which prevents us from saying the knowledge-control regime in one sector is stronger (or weaker) than in another. What makes the difference is the effect of such control regimes, whose strength varies across different schemes. 
In his study on the HGP case, Hilgartner did not specifically analyze "knowledge-control regimes" in the public controversy setting, which is the goal of this current monograph. Meanwhile, the dynamic interaction between politics and knowledge-making will also be probed.

\section{Exploring state power in $S \& T$ controversies}

Although multilevel knowledge-control regimes cover the state's jurisdiction power, like other STS scholars who examined "movements" in science and medicine (Epstein, 2008; McCormick, 2006, 2007a; K. Moore, 2009; Schurman \& Munro, 2010), Hilgartner's central interest lies in knowledge making. Generally, STS scholars pay much more attention to the role of knowledge, expertise and expert-layman alliances/tensions and "often seek changes in institutions beyond the state" (Breyman et al., 2017, p. 299), but the constructionist approach of science studies has understudied political power or the so-called macropolitics (Jasanoff, 1996, 2017). This negligence is an apparent flaw for studies into science-society relationships in nonWestern settings, where government and political leaders often have a more significant say in science issues (Jasanoff \& Kim, 2009). The emerging East Asian STS scholarship may offer a chance to fill the gap (W. Anderson, 2012; F.-t. Fan, 2012).

In term of macropolitics, East Asia has manifested a strong interplay between government and knowledge. In Japan, techno-nationalism used to drive its nuclear power program (Kelly, 2015) just like in South Korea (Jasanoff \& Kim, 2009). In the latter, the representation of macropolitics is linked to a robust S\&T nationalism, as evidenced by Hwang Woo-Suk's stem cell research scandal (Hong, 2008; T.-H. Kim, 2008; Leem \& Park, 2008). In China, a strong sense of techno-nationalism and the inadequate research capacity in the 1980 s jointly pushed scientists to explore supernatural human functions as a possible route to scientific breakthroughs (Palmer, 2007).

These unique aspects of East Asian STS scholarship contribute to and expand our understanding of S\&T controversies. Besides, East Asian STS scholars are actively involved in socially heated S\&T controversies. For example, while highlighting the inherent capitalistic feature of epidemiology whose stress on traceable causal links between illness and environmental factors naturally disfavors victims and the working classes $(\mathrm{H} .-\mathrm{H}$. Chen, 2011; Y.-P. Lin, 2011), Taiwanese STS scholars allied with the disadvantaged workers suffering from their former employer's toxic pollutant emission in their juridical fights.

While macropolitics has been brought into East Asian STS, political science theories, such as those about social movements, have not been present. As a result, East Asian STS scholarship so far has failed to trace the dynamic processes of $S \& T$ controversies and their sociopolitical roots. 


\section{Science controversies}

\subsubsection{S\&T disputes from the perspective of social movement theories}

\section{From resource mobilization to political opportunity}

Since the 1960s, three major types of rational choice theories of social movements - resource mobilization theory (McCarthy \& Zald, 1973, 1977), framing and collective identity theory (Snow, 2013), and the political process approach - have been developed.

Tilly, Tarrow and McAdam developed the political process approach (McAdam, 1982; Tarrow, 1994; Tilly, 1978), which focuses on the idea of political opportunity structures proposed by Tarrow (1994, 1996, 2011). "Structure of political opportunities" means "consistent - but not necessarily formal or permanent - dimensions of the political environment that provide incentives for people to undertake collective action by affecting their expectations for success or failure" (Tarrow, 1994, p.85). As shown in Figure 1.1, three intersecting elements - political opportunities and threats, cultural artifacts and frames, and mobilization networks and organizations - were proposed as the most important ones for social movements to happen (Tarrow, 2011).

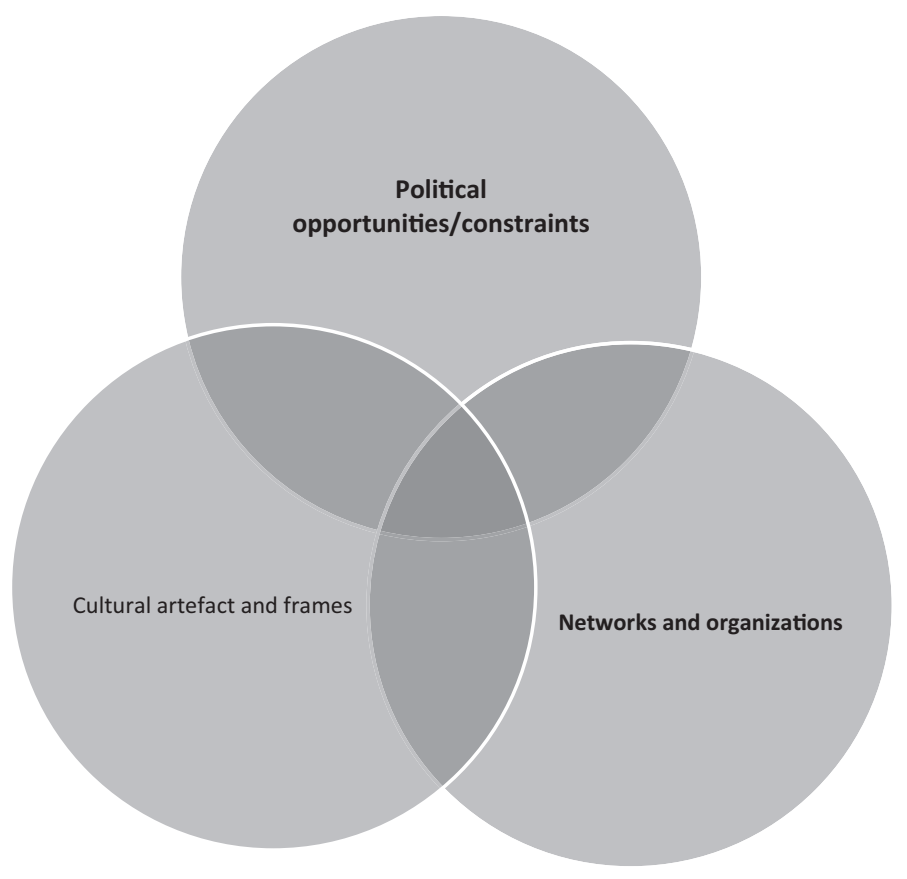

Figure 1.1 The intersecting elements of social movements

Source: Drawn by the author; Tarrow, 2011, p.121 
Tarrow and colleagues (2001) also traced interaction mechanisms underlying social movements. To Tilly and Tarrow (2015), mechanisms mean a class of changes that alter relations among specified sets of elements in identical or closely similar ways over a variety of situations (Tilly \& Tarrow, 2015, Kindle Locations 685-686). The most common mechanisms in social movements are brokerage, diffusion and coordinated action. Others include social appropriation, boundary activation, certification/decertification and identity shift.

\section{Social movement theories' relevance for analyzing $S \& T$ controversies}

The dynamic process examined by Tarrow and colleagues can be beneficial for investigating the outbreak, development, intensification and closure of S\&T controversies. As discussed above, current science communication and STS approaches to science controversies often fail to answer why some potentially disputable technologies become publicly controversial while others do not, or why some debates last longer than others. With the dynamic analysis, we can say the outbreak of S\&T controversies may be associated with certain kinds of [political] opportunity structure. For example, the continued food safety crisis in Europe in the late 1990s offered an opportunity structure for activists to mobilize the public against GMOs (Bonny \& Sylvie, 2003). But the United States has not provided such an opportunity structure due to its product-based risk regulatory preference and stronger industry-government alliance (Jasanoff, 2011b; Schurman \& Munro, 2010).

In addition to political opportunity structures, political scientists like Ronald Herring (2008, 2010a, 2010b) have adopted mechanisms like brokerage, framing and diffusion to explain public resistance to GMOs. However, only limited science communication and STS studies (Delborne, 2008; Martin, 1998, 2004, 2010, 2014; Martin \& Groth, 1991) have examined mechanisms (and certainly not those mentioned by Tarrow) involved in S\&T controversies.

The resource mobilization approach can also help understand the strength of activism. Epstein's study of activists' efforts to change the clinical trial process for HIV drugs, in his Impure Science (1996), is an excellent example of combining constructionist epistemic examinations and the resource mobilization approach.

Another useful approach is to adopt social movement framing to analyze S\&T controversies. The four framing mechanisms - frame bridging, frame amplification, frame extension and frame transformation - identified by Snow and colleagues (Snow \& Benford, 1988; Snow, Rochford Jr, Worden \& Benford, 1986) can be used to observe and analyze $S \& T$ controversies.

But for my purposes, social movement theories do have limits. Scholars in the field do not pay much attention to S\&T controversies and the role of knowledge or issues of expertise (Hess et al., 2008; Martin \& Groth, 1991). The latter is often a crucial factor influencing such controversies. As I will show in this monograph, actors' dominance of knowledge-making or 
their capacity to produce alternative, yet credible knowledge affects the political opportunities available to them. Besides, like mainstream STS scholarship, most social movement theories are based on Western democratic contexts, neglecting southern or Asian experiences (Fadaee, 2016) or adopting a stereotype of these countries' situations, such as losing sight of the dynamic public sphere in an authoritarian state like China (Y.-W. Lei, 2018).

\subsubsection{Understanding $S \& T$ controversies in transitional China}

S\&T enjoy an ideologically paramount and unquestionably important status in China (Cao, 2014). Since the 1980s when the country began its opening-up, however, there have been consistent S\&T controversies in public discourse ranging from the gigantic Three Gorges Dam Project (TGP) (Lee, 2013a) and Qigong (a type of mystical exercise to strengthen and control spiritual force (Palmer, 2007)) to GMOs (Cao, 2018) and trash incineration (Lang \& Xu, 2013). After the 2000s, the controversies involved more and more actors, including ENGOs, academics, journalists and often contingently organized citizen groups.

The authoritarian regimes often more tolerated scientific or technological debates in China. In the 1980s, S\&T controversies, including harsh discussions on the TGP, emerged from the country's budding liberalism (H. L. Miller, 1996). The situation necessitates an investigation of the political structure of these S\&T debates in the country.

\section{From fragmented authoritarianism to consultative authoritarianism}

A classic model developed by political scientists to understand the tension between China's authoritarian rule and public protests or resistance to policies is "fragmented authoritarianism" (FA), which argues that differently-tasked government departments and their conflicts result in policy results and delay (Lieberthal \& Lampton, 1992). Adopting the model, Mertha (2008) has convincingly examined China's anti-dam protests. Among the three anti-dam cases examined by him, the protest in Dujiangyan that could mobilize more support from the fragmented ruling system while framing itself as a cultural contention succeeded, while the rally without any endorsement from the ruling group was clamped down.

Facing the booming Chinese civil society and more diversified political players, Mertha (2009) introduced a modified FA (fragmented authoritarianism 2.0) framework, which allows more actors such as journalists and NGOs to play a role in the model. Others, noticing that FA seldom considered scientists and scientific knowledge, tried to introduce these elements into the framework (e.g. Hansen, 2017b). Some observers also maintained that the Chinese Communist Party (CCP) leadership remains tightly controlling and can frequently adapt to the situation despite bureaucratic fragmentation (Mertha \& Brødsgaard, 2017; Shambaugh, 2008). 
Despite these modifications, there remain some loopholes in the FA framework. Given the existing fragmentation within the Chinese bureaucracy, what types of fragmentation can lead to social protests and their success? What external conditions are needed? Is there a threshold value of fragmentation in the FA framework to break the rule?

Besides, a dimension neglected in current studies that use the FA framework is the central-local government relationship, which is considered a crucial aspect of Chinese politics (Hao, Lin \& Chung, 1994; Zheng, 2007; Zhong, 2015). When and in what conditions will the tension between central and local governments lead to social movements? How does this centralregional tension affect public S\&T controversies? Another less discussed aspect in FA scholarship is the rise of new leftism in China. Should we be able to identify an ideological FA framework? These questions will be empirically addressed through Chapters 3 to 5 .

The observation that some social protests achieved their goals in China due to policymakers' apparent encouragement of different opinions led Teets (2014) to conclude that the Chinese system would be better consistent with a consultative authoritarianism in which authorities try to seek professional expertise from organizations and individuals outside the official system, such as ENGOs (F. Wu, 2009; J. Y. Zhang \& Barr, 2013).

Rejecting State- and market-centered causal effect explanations, G. Yang (2005) found that the development of ENGOs accompanied four institutional factors including changing political conditions, the media, the Internet and international NGOs expanding in China. In the process, Chinese academics have played a vital role, working as ENGO organizers, policy entrepreneurs or sometimes brokers (J. Y. Zhang \& Barr, 2013).

Both diversification (and partial liberalization) of traditional media and the penetration of the Internet are associated with China's civil society takeoff. For traditional media, the professionalization of investigative journalism (H. Wang, 2016), revenue-seeking through attention-grabbing, and harsh media competition (Y.-W. Lei, 2011) all cause the expansion of the public sphere, which, due to political censorship, tend to evolve in the environmental protection areas (G. Yang \& Calhoun, 2007).

The Internet has been hailed as providing an online public sphere for the nation's activists, fueling opinionated citizens (Y.-W. Lei, 2011) and overcoming the regime's tight control on traditional media (DeLuca, Brunner \& Sun, 2016). Social media, ranging from blogs to Weibo to WeChat, expanded the contentiousness of the online public sphere (Harwit, 2016; Leibold, 2011; Lu \& Qiu, 2013; Rauchfleisch \& Schäfer, 2015).

Amidst the selective censorship on social media by the Chinese regime (Cairns, 2017; King, Pan \& Roberts, 2013), many subjects on social media have to be apolitical (Sullivan, 2012) but contentious enough to attract attention (Y.-W. Lei, 2018). Censorship avoidance should make science and environmental controversies welcomed topics by news portals and social media editors. 


\subsection{GMO, hydropower and nuclear controversies in China}

\subsubsection{Theoretical case selection}

The above sections reviewed various theoretical traditions and approaches to studying S\&T controversies. It is necessary to compare these aspects across different S\&T disputes. Studies have found that contemporary S\&T debates in China demonstrate quite different patterns. For example, opposition to trash incineration (Lang \& Xu, 2013) has spread across Chinese cities but most of them were spontaneous local activities without nationwide organization while in other controversies, such as the anti-hydropower movement, ENGOs are the main actor (H. Han, Swedlow \& Unger, 2014; T.-c. Lin, 2007).

The case selection was based on theoretical necessity and the relevance to studied targets: they should all involve debates on science and technology, they should have relatively broad or perceivable social impacts, they should have lasting duration, and they should have public policy impacts. When doing case studies, researchers want their research subjects highly typical in the studied aspects (Small, 2009). They should examine the theoretical relevance of the case they choose in various perspectives as the situation unfolds (R. K. Yin, 2009). Meanwhile, constant comparison is critical for conceptual development (Glaser \& Strauss, 2009).

Based on my personal experience as a science journalist in China in the past 20 years and online search of topical news stories, I selected a batch of candidate cases, which are all socially impactful and related to S\&T issues, including Qigong and the supernatural human function debate, food safety scandals (particularly food additive disputes), the GMO controversy, the antidam movement, public protests against Paraxylene (PX) (Jia, 2014a), collective resistance to trash incineration facility building, the nuclear power debate and the air pollution control controversy (particularly the sources of PM2.5 (Jia \& Wang, 2017)). I screened media coverage and social media mentions. I consulted Chinese peer scholars, journalists and activists to help avoid my personal bias in the initial selection. They agreed that these selected cases could be considered significant enough and related to contention on S\&T issues in the public domain.

Many cases, such as the public protest against Paraxylene (PX) (Jia, 2014a), collective resistance to trash incineration facility building, and food additive disputes, were stochastic and lacked constancy. Therefore, I eliminated them from consideration.

After extensive consultation, I decided to choose the GMO controversy, the anti-dam movement and anti-nuclear power conflicts. They all had milestone impacts on Chinese society since China began to adopt opening-up in the 1980s. Meanwhile, these controversies displayed knowledge contention and involved political powers. These characteristics enabled them to be readily defined as social movements. I also tried to pursue international comparison so that the 
theoretical findings of my case studies could have a more extensive theoretical application.

For example, GMOs have suffered massive public rejection in China, with $73 \%$ of people opposing GMOs used as foods (G. He, Liao, Shi, Zhang \& Zhao, 2017). This attitude echoed the resistance to the technology in both the developed world (Motta, 2014; G. D. Stone, 2010) and developing countries (Scoones, 2008). The anti-hydropower movement can be traced to the harsh debate on whether to construct the Three Gorges Project (TGP) to build a massive dam in Three Gorges in the mid-Yangtze River in the 1980s. Recently, scholars have widely examined anti-hydropower activities to study emerging Chinese civil societies and ENGOs (Buesgen, 2008; F. Wu, 2009; G. Yang, 2005). For the nuclear power controversy (Jia, 2016a), two recent NIMBY activities led to the suspension of nuclear fuel recycling facilities proposed for Guangdong Province's Jiangmen (J. Dai, Zeng \& Huang, 2015) and Jiangsu Province's Lianyungang (Buckley, 2016a). Earlier, another proposed nuclear power plant in Shandong Province's Rushan was also suspended due to local resistance (Zeng, Dai \& Wang, 2015).

\subsubsection{Divergent patterns of selected cases}

While the three examples - GMO controversy, anti-hydropower debates and nuclear power disputes - satisfy the criteria for theoretical orientation, they demonstrate very varying patterns. The hydropower and nuclear industries and biotechnology research also show different characteristics.

For example, despite the harsh citizen outcries against GM foods and Greenpeace's highly successful campaign to reverse the commercialization of GM crops in China, nearly no domestic ENGO is involved (see Chapter 5 of this monograph). For nuclear power, as a whole, public support for the technology remained high even after the Fukushima accident (Y. Wu, 2017) in spite of sporadic NIMBY protests. Unlike in Europe and the United States where anti-nuclear campaigns had been widespread, sparking national coalitions of environmental groups (Kasperson, Berk, Pijawka, Sharaf \& Wood, 1980), there was no nationwide anti-nuclear campaign and no single Chinese organization, including local branches of international NGOs like Greenpeace, committed to anti-nuclear power activism (see Chapter 6).

The hydropower controversy showed a different landscape. Indeed, there is no other science-related dispute in China like anti-hydropower activism that has lasted so long and promoted such unified voices from ENGOs and their joint protests (see Chapter 4).

The cases of GM crops/food, nuclear power and hydropower that are contested in contemporary China each have a set of different characteristics. Table 1.1 below lists their geographic locations, history and heritage, different media presentations of the industries/sector, relationship to the public, and the time, scale and actors of the controversies. 


\section{Science controversies}

Table 1.1 Characteristics of hydropower, nuclear power and GMO, and controversies surrounding them

\begin{tabular}{|c|c|c|c|}
\hline & Hydropower & Nuclear power & $G M O$ \\
\hline Locations & $\begin{array}{l}\text { TGP: in central } \\
\text { China } \\
\text { Contended dams in } \\
\text { the 2000s: south- } \\
\text { western China }\end{array}$ & $\begin{array}{l}\text { Mostly in eastern and } \\
\text { southern coastal } \\
\text { areas near major } \\
\text { cities }\end{array}$ & Nationwide \\
\hline History & $\begin{array}{l}\text { Long debated across } \\
\text { Chinese history }\end{array}$ & $\begin{array}{l}\text { No history of open } \\
\text { contention }\end{array}$ & $\begin{array}{l}\text { Technology is new, } \\
\text { but food supply } \\
\text { concerns are a } \\
\text { long-standing issue } \\
\text { in history. }\end{array}$ \\
\hline $\begin{array}{l}\text { Industrial } \\
\text { legacy and } \\
\text { strength }\end{array}$ & $\begin{array}{l}\text { Dominantly State- } \\
\text { owned sector; lack of } \\
\text { publicity tradition }\end{array}$ & $\begin{array}{l}\text { Completely State- } \\
\text { owned sector; strong } \\
\text { publicity tradition } \\
\text { both in military } \\
\text { weapon and civil } \\
\text { technology develop- } \\
\text { ment eras }\end{array}$ & $\begin{array}{l}\text { Fragile industry; } \\
\text { lack of publicity } \\
\text { tradition }\end{array}$ \\
\hline Military link & $\begin{array}{l}\text { Part of the origin of } \\
\text { the industry due to } \\
\text { the involvement of } \\
\text { engineering troops. } \\
\text { No connection now }\end{array}$ & $\begin{array}{l}\text { Originated from atom } \\
\text { bomb development; } \\
\text { remaining an active } \\
\text { link }\end{array}$ & $\begin{array}{l}\text { Completely civil. No } \\
\text { military link }\end{array}$ \\
\hline $\begin{array}{l}\text { Relationship } \\
\text { to the pub- } \\
\text { lic's daily life }\end{array}$ & Low & Low & High \\
\hline $\begin{array}{l}\text { Media } \\
\text { presentation }\end{array}$ & Moderate & Moderate & High \\
\hline $\begin{array}{l}\text { Time of } \\
\text { controversy }\end{array}$ & $\begin{array}{l}\text { The } 1980 \text { s, then } 2003 \\
\text { through mid-2010s }\end{array}$ & $\begin{array}{l}2008 \text { and then from } \\
\text { after Fukushima to } \\
\text { now }\end{array}$ & $\begin{array}{l}\text { From the early } 2000 \text { s } \\
\text { to now }\end{array}$ \\
\hline $\begin{array}{l}\text { Scale of } \\
\text { controversy }\end{array}$ & $\begin{array}{l}\text { National, but few } \\
\text { southwestern locals }\end{array}$ & $\begin{array}{l}\text { Primarily selected } \\
\text { media platforms and } \\
\text { internal debates }\end{array}$ & $\begin{array}{l}\text { Nationwide, various } \\
\text { media, social media } \\
\text { and online portals }\end{array}$ \\
\hline $\begin{array}{l}\text { Actors of } \\
\text { controversy }\end{array}$ & $\begin{array}{l}\text { For: Energy sector, } \\
\text { hydropower industry; } \\
\text { Against: ENGOs, } \\
\text { ecological \& environ- } \\
\text { mental experts, envir- } \\
\text { onmental agencies; } \\
\text { Various media and } \\
\text { journalists; CPPCC } \\
\text { (China's upper house) }\end{array}$ & $\begin{array}{l}\text { For: Energy sector, } \\
\text { nuclear power } \\
\text { industry; mainstream } \\
\text { scientists; } \\
\text { Against: Small circle } \\
\text { of dissenting experts } \\
\text { and activists; Limited } \\
\text { residents against } \\
\text { nuclear fuel recycling } \\
\text { projects }\end{array}$ & $\begin{array}{l}\text { For: Mainstream } \\
\text { scientists; science } \\
\text { communicators; } \\
\text { foreign companies } \\
\text { Against: Various } \\
\text { anti-GMO activists; } \\
\text { non-science experts; } \\
\text { STS scholars; } \\
\text { Maoists; and many } \\
\text { of the general public }\end{array}$ \\
\hline
\end{tabular}

(Source: Author's categorization) 


\subsubsection{From pattern difference to the theoretical comparison}

Selecting GMOs, hydropower and nuclear controversies does not exclude the importance of other S\&T disputes, such as the widespread public protest against Paraxylene (PX) (Jia, 2014a) and trash incineration (Lang \& Xu, 2013; Standaert, 2017). But compared with the three selected controversies, the other cases are either too China-specific or lacking scientific relevance, so that temporal and international comparisons are hardly possible.

For the three selected controversies, different theoretical traditions reviewed above can each offer intriguing explanations. As indicated in Chapter 6, these theoretical explanations are entirely consistent across the various disputes. No doubt the individual characteristics of these controversies should contribute to the difference in the theoretical account. For example, the widespread concern about food safety distinguishes the GMO controversy from hydropower and nuclear power contentions in terms of the level of public attention. But this does not mean the characteristics per se can replace theoretical probing or illegitimate theory-oriented comparisons between cases. Instead, these characteristics need to interact with other factors which will be theoretically analyzed in the following chapters.

For example, people's everyday concern with food safety is one factor leading to the GMO controversy's longevity and widespread expansion, but the fear has to be combined with other social movement and knowledge factors, such as activists' negative framing and orthodox knowledge's low credibility, to initiate and intensify the controversy.

On the other hand, not every item raising people's daily concern will lead to widespread public controversy. For example, the debut of China's highspeed train was accompanied by a disastrous crash that killed at least 38 people and injured 192 in Wenzhou in July 2011 (Branigan, 2011). The public anger against high-speed train management and the government's cover-up, however, soon gave way to applause for China's S\&T achievement in becoming world leaders in high-speed train development. Similarly, despite sporadic protests against (improper use of) food additives, they have never evolved into an extensive public controversy.

Besides this, although the three controversy cases primarily examined in this book have different characteristics, they still share many common features. For example, both hydropower and nuclear power are low-carbon energies dominantly invested by State-owned enterprises (SOEs). Therefore, comparing their different evolution pattern is meaningful in revealing their theoretical difference.

My study is not a mechanical comparison of different controversies. To have a holistic understanding of public S\&T controversies, one must more systematically observe and compare them. This synthetic approach is particularly crucial to studying China's S\&T controversies, because while the profound political interference in social life necessitates an analysis on variables like political opportunities, the paramount status of S\&T in China calls for an integration of 
science communication and STS scholarship in our understanding of people's perception and utilization of such political opportunities. Thus, S\&T controversies cannot be solely examined with structural sociopolitical factors.

\subsection{Research questions}

Based on the above theoretical review and the proposed synthetic approach to analyze S\&T controversies in China, I asked a series of working research questions. The first set of research questions addresses how science communication scholarship can help us understand the selected controversies. They ask:

- Research Question 1a (RQ1a): What are the communication elements, such as the media, Internet and public attitudes to science, involved in the process for GMOs, hydropower and nuclear power to become controversial?

- Research Question 1b (RQ1b): How do the communication elements, such as the media, spur and/or maintain the controversies of GMOs, hydropower and nuclear power?

- Research Question 1c (RQ1c): Have the communication elements, such as the media, caused the controversies of GMOs, hydropower and nuclear power to develop differently?

The second set of research questions addresses how social movement and other political theories can be integrated into our understanding of the selected controversies. It will look at the science-politics relationship, and the communication elements asked above.

- Research Question 2a (RQ2a): Can political opportunity structures explain the different patterns of controversies surrounding GMOs, hydropower and nuclear power in China and why?

- Research Question 2b (RQ2b): Can networks and mobilization explain the different patterns of controversies surrounding GMOs, hydropower and nuclear power in China?

- Research Question 2c (RQ2c): Can cultural artifacts and frames explain the different patterns of controversies surrounding GMOs, hydropower and nuclear power in China?

- Research Question 2d (RQ2d): Can fragmented authoritarianism explain the different patterns of controversies surrounding GMOs, hydropower and nuclear power in China?

The third and last set of research questions explores STS components of the selected controversies that have been analyzed politically. These questions link STS, science communication and political process theory. 
- Research Question 3a (RQ3a): Have knowledge-control regimes influenced the patterns of GMO, hydropower and nuclear power controversies in China?

- Research Question 3b (RQ3b): What are the sociotechnical imaginaries related to GMO, hydropower and nuclear power controversies in China?

- Research Question 3c (RQ3c): How has civic epistemology regarding GMOs, hydropower and nuclear power impacted the evolution of controversies in China?

These questions were not final tasks for this monograph to address. Instead, they were set as roadmaps for me to organize the book and as reminders for readers to grasp central components amidst the colorful and intricate scenes of the studied controversies that have lasted 30 years or longer.

\subsection{Book outline}

My book consists of nine chapters, with this opening chapter focused on the theoretical review and the concluding chapter exploring a dynamic social model for scientific controversies combining different theoretical perspectives. The second chapter presents research methods, data, and analysis process. The third chapter is a summary of China's major S\&T controversies. This chapter also summarizes the social, political, economic and media factors that contributed to them. The three following chapters then address hydropower, GMO and nuclear controversies respectively.

Chapter 4 is focused on China's anti-hydropower movement. Among the three subjects, it is first dealt with because it is one of the earliest S\&T controversies in contemporary China, first breaking out surrounding the construction of the Three Gorges Project. As the project was finished long before this study was launched, the debate surrounding the project was mostly treated as a background, but it has paved an essential way to the later concentrated efforts by ENGOs to oppose southwestern hydropower projects. The anti-dam cases show different patterns, yet they jointly demonstrate features specific to hydropower controversies, such as the difficulty to control knowledge by hydropower groups and the effective mobilization by ENGOs.

Chapter 5 deals with the GMO controversy. Combining media content analysis and interview data, I reveal the fragile alliance between science and the state, the struggle among scientists, the politicization of the issue and the vast mobilization of various anti-technology groups that eventually successfully halted the commercial farming of GM crops.

Chapter 6 studies the nuclear power controversy. While the military background and scientific progress frame (or national sociotechnical imaginaries) of the nuclear industry seemed to quench initial public suspicion, the monopoly of research on the health consequence of radiation by limited players results in less open discussions on nuclear power safety. But to some elite anti-nuclear 


\section{Science controversies}

campaigners, the political opportunity could still be explored, though not a straightforward utilization of the fragmented governance system.

In the seventh to eighth chapters, based on the above studies, I compare science communication, sociopolitical and knowledge factors across the three controversies. A table summarizing their different theoretical components and predicting variant consequences is presented. Chapter 8 summarizes the main findings and examines the interactions among different theoretical frameworks.

The concluding chapter, which is Chapter 9, explores this study's generalizations and discusses its data and theoretical limitations. I also briefly discuss my further study plan both to overcome the current limitations and to realize the academic contribution more fully. 


\section{Research method and data}

\subsection{Introduction}

The primary research method of this book is a qualitative case study. Qualitative research is inherently multi-method (Flick, 2009). My study is a multi-approach, multi-method endeavor. According to R. K. Yin (2009), the case study logic implies each case can help us gradually improve our understanding of our research questions.

In each case I studied, I adopted theoretical sampling (Glaser \& Strauss, 1967) to assure its validity. Theoretical sampling is the process of data collection for generating theory whereby the analyst jointly collects and analyzes his/her data and decides what data to collect next and where to find them, to develop his/her theory as it emerges. For qualitative scholars, the criterion to judge when to stop sampling is whether they have reached theoretical saturation for the researched/observed cases (Adler \& Adler, 1994). Theoretical saturation represents the phase of qualitative data analysis where no new information appears, and all concepts in the theory are well developed. In my case studies, I stopped searching for further evidence when I believed all the possible theoretical explanations had been explored with the available evidence. In reality, there were always gaps that I thought I could not solve with my current data access. For example, I cannot reach China's top leadership to interview their policy intentions regarding $\mathrm{S} \& \mathrm{~T}$ controversies.

Following the suggestions of Creswell (2007, p. 126) and Lofland, Snow, Anderson and Lofland (2006) on evidence collection, I sampled and reached actors/events/cases with maximum variance and/or extreme or deviant cases to improve the project's validity (Maxwell, 1996). With this logic, I identified cases/events/actors/evidence reflecting various theoretical components such as political opportunity, framing, mobilization (strategies), technoscience institutions, national sociotechnical imaginaries and fragmented authoritarianism. I also mainly looked at how science \& technology (S\&T) information was produced, transmitted, learned and used in the process of controversies for certification of actors, the transgression of the disputes, allying with partners/campaigners, and mobilizing participants.

DOI: $10.4324 / 9781003160212-2$ 


\section{Research method and data}

Within the broad category of case studies, I adopted semi-structured interviews with various actors involved in the GMO, nuclear and hydropower controversies, documentation and content analysis of media coverage, social media postings and policy documents of these technologies and participatory observation of ongoing disputes, and triangulation of different data sources and various types of evidence (Maxwell, 1996, pp. 86-98).

\subsection{Data collection and description}

\subsubsection{Triangulation and qualitative interviews}

I interviewed different actors so that interviews from different informants could be used to verify each other, the primary sense of triangulation. Triangulation also happened between interview transcripts and media coverage. There was also triangulation between media coverage and policy documents.

In the past three years' field studies (including US-based telephone and WeChat interviews), I conducted intensive interviews. Due to my lengthy journalistic background, I first sought help from former journalist colleagues while interviewing them. With their assistance, I was able to reach a good number of activists and dissenting experts who usually are more open to journalists and researchers. As studies reveal, many activists in China originally were journalists (H. Wang, 2016).

Using the snowball method, I asked interviewed activists to recommend others they thought relevant and open to talk. My science journalistic background also enabled me to question many scientists and experts involved in each controversy. I also obtained help from peer Chinese scholars who had studied individual subjects falling in my research scope. Through them, I was able to reach many industrial figures, particularly people in China's nuclear industry.

However, despite my links, I was not as successful at reaching Chinese officials, who are generally cautious of talking with journalists and international scholars, even though I was familiar with some of them. As a result, most officials I reached refused to speak with me or only shortly briefed me about some basic situations.

Eventually, I interviewed 107 informants, including 26 journalists and former journalists, 24 activists, 21 scientists, 10 industry representatives, 4 government officials and former officials, 17 STS, communication and policy scholars who have studied some relevant aspects of the subjects I was researching for this project, 2 science communication practitioners and 3 public information officers (PIOs). In the above categorization, for those having multiple roles, I only chose their role most relevant to my research subjects.

Most in-depth interviews took about 1.5 to 2 hours, while some other discussions, particularly those with my former journalist peers, took highly flexible forms, such as face to face interview plus WeChat (a Chinese social media platform) and telephone follow-up talks. For the shorter interviews, the primary research purpose was to get or verify information. A detailed list of interviewee 
characteristics (with names and affiliation intentionally deleted) is provided in Appendix A, and in this book I use information from interviews like an in-text citation. I give an abbreviation INT plus date (in yyyy $+m m+d d$ format) after using interview information or quoting informants. When on the same date there were multiple interviews, I use the letter " $\mathrm{a}, \mathrm{b}$ or c" at the end of the date number to alphabetically distinguish different interviews.

The Cornell University IRB approved this research method on 27 September 2016. The protocol number was 1608006557.

\subsubsection{Mass media coverage data}

\section{Sampled newspaper data}

In addition to interviews, I collected several types of media data. The first type is the mass media coverage of GMOs, nuclear power and hydropower by four representative newspapers. Two of them - the People's Daily (PD), which is the official party newspaper of CCP, and the Southern Weekend (SW), which is the most liberal Chinese newspaper published per week from Guangzhou - are widely adopted as sample newspapers to study contemporary China (e.g. Y.-W. Lei, 2018). A third newspaper is the Shanghaibased Xinmin Evening News (XEN), which is known as a relatively high-end metropolitan tabloid. The fourth newspaper is China Science Daily (CSD), published daily by the Chinese Academy of Sciences (CAS) from Beijing. CSD, formerly Science Times, is widely considered to demonstrate the most professional science journalism in China. ${ }^{1}$ Combined, the four sampled newspapers represent a representative portfolio of typical Chinese newspapers.

Contents from PD, SW and XEN were retrieved from Wise Search, the most comprehensive full-text newspaper database in China, while materials from CSD were from the newspaper's website (password-protected), as its contents had not been included in Wise Search or another full-text Chinese newspaper database CNKI before 2008 (CNKI is the most famous for its Chinese academic paper database). Both Wiser and CNKI began to collect full-text newspaper data from the early 2000s (the starting time for different newspapers varied). As most controversies studied in this book took place after the year 2000, the time range is excellent for my purposes. But because the TGP debate, the main hydropower controversy, mainly took place in the 1980s, it was also necessary to trace media reporting before stories were collected and archived to the full-text databases. Among the four sampled newspapers, only PD has such a full-text database. So, I also downloaded PD articles from the 1980s.

All the newspaper articles were searched and downloaded by different groups of China-based partners with keywords decided after our discussions and trials. For the hydropower controversy, sample articles were examined with the Chinese keywords meaning "hydropower" (水电或水 能), “hydroelectricity” (水电或水能), “hydraulic" (水利), “big dam” (大坝), “TGP” (三峡工程), “Nu River” (怒江), and “dam controversy” (建坝争论、 


\section{Research method and data}

争坝). In English, "hydropower" is almost identical to "hydroelectricity," but in Chinese, the literal translation of "hydropower" (水能: shuineng or water energy) is seldom used, and hydroelectricity (水电: literally shuidian or water electricity) is a much more popular term. However, there was significant ambiguity in the Chinese context, as hydroelectricity (水电: shuidian or water electricity) can also mean "water and electricity," which is used in a large amount of household utility-related media stories, which are irrelevant to this research. Manual cleaning was therefore essential.

After the articles were found and downloaded, I manually skimmed all of them and excluded the irrelevant stories. After data cleaning, there were 138 relevant articles for hydropower in SW, 343 in XEN, 319 in CSD and 1,211 in PD. Taken together, there were 2,011 sample newspaper articles on hydropower for analysis.

For GMOs, sample articles were searched with the Chinese keyword “GMO" (转基因), as this is a highly specific word without any significantly noticeable ambiguity. Such items were downloaded from PD after 1995, from SW after 2004, from XEN after 2007 and from CSD after 2000. After the articles were found and downloaded, I manually skimmed all of them and excluded the irrelevant pieces. After data cleaning, there were 36 relevant articles for GMOs in SW, 97 in XEN, 321 in CSD and 152 in PD. Together, there were 606 sample newspaper articles on GMOs for analysis.

For nuclear power, sample articles were searched with the Chinese keywords “nuclear power” (核电), “atomic power” (原子能), “nuclear energy” (核能), and “nuclear science and technology" (核科技), Due to the Chinese partners lack of access to CSD's own site, the data set could only obtain CSD contents for nuclear from WISE after 2007. After data cleaning, I obtained 1,916 sample newspaper articles on nuclear power for analysis (619 in PD, 74 in SW, 604 in XEN and 619 in CSD).

Table 2.1 below shows the downloaded media articles across three controversies after sample cleaning. Their publishing time range is also provided.

\section{Other media articles}

Besides the full-range media coverage data from the sampled newspapers, relevant media contents were collected, mostly when interviewees or social

Table 2.1 Downloaded media articles and their publishing time

\begin{tabular}{lllr}
\hline PD & Hydropower & GMO & \multicolumn{1}{c}{ Nuclear power } \\
\hline PD & $1,211(1980-2017)$ & $152(1995-2012)$ & $619(2000-2017)$ \\
SW & $138(2000-2017)$ & $36(2004-2016)$ & $74(2000-2012)$ \\
XEN & $343(2002-2017)$ & $97(2007-2016)$ & $604(2002-2017)$ \\
CSD & $319(2003-2017)$ & $321(2000-2016)$ & $619(2007-2017)$ \\
\hline
\end{tabular}

(Source: Author's calculation) 
media discussions mentioned them. What's more, with the decline of traditional print media and the rise of online media, such as WeChat-based smartphone publications, I collected relevant articles from smartphone publications. They were primarily used for information purposes and triangulation.

\section{Media coverage and public reaction patterns}

Besides collecting and analyzing sampled media stories, I also explored the overall model of media coverage of the studied subjects. In our digital era, a reliable method to trace the pattern is to look at the frequency of media reporting of the topics through Internet tools such as Google Trends and its Chinese equivalent Baidu Index. With thousands of mass media and news sites accessed by its news search engine, Baidu Index can show the frequency of media coverage of specific keywords.

Google Trends or Baidu Index also offer a pathway to examine public reactions to hot social events through its function to trace people's online search results. It has been found that the public's interest in science as represented by their Google searches is associated with media reporting of relevant subjects (Baram-Tsabari \& Segev, 2011; Segev \& Baram-Tsabari, 2012). My method for examining people's interests in the three target controversies hydropower, GMOs and nuclear power - is as follows. Using the same keywords to search relevant stories in the four sampled newspapers and Baidu Index (for news coverage frequency), I examined the Baidu keyword search trends. I chose Baidu instead of Google because Google has been blocked in China since 2009. My purpose in this book is not to examine the statistical association between news coverage frequency and people's online searches but to qualitatively shed light on the general media and public reactions to the controversies to supplement the methodological insufficiency of merely relying on elite discourses reflected by interviews and sampled media reporting.

\subsubsection{Social media data}

Social media contents were also collected. Unlike mass media, social media and information transmission channels enable observation of the communication patterns of the studied controversies and people's reaction to them (Brossard, 2013). Mass media often only allow elite discourses, no matter whether they are from leading scientists, senior officials or activism leaders. But social media can significantly expand the platform for debates, particularly in controversial issues such as GMOs and climate change (A. A. Anderson \& Huntington, 2017; Davies \& Hara, 2017; Smith, Zhu, Lerman \& Kozareva, 2013). Different social media platforms play different roles in transmitting the debates on science and technology controversies.

Throughout this book, I categorize BBS (bulletin board systems), blogs and social network sites like Facebook or Twitter as social media platforms due to their common function to empower users to interact with their audiences 


\section{Research method and data}

(Obar \& Wildman, 2015). BBS is more suitable than the other two major social media platforms in China - WeChat and Twitter-like Weibo. WeChat posts are open only to friends, and although Weibo is an open platform, its operator only allows one ID to download 1,700 tweets ${ }^{2}$ for any single search, which for research purposes are too few as compared with all postings in the social media platform. Therefore, I collected BBS posts with appropriate debate/discussion contents (conveniently defined as having 100 following posts) regarding GMOs, nuclear power and hydropower in the most popular Chinese BBS website Tianya, and individual Weibo and blog posts by main actors involved in the controversies.

Using a web crawler software, which can automatically search online contents, I downloaded Tianya posts regarding GMOs, nuclear power and hydropower using the same keywords used in the mass media search with multiple purposes. One purpose was to record the number of the hot BBS posts (technically defined as the original posts followed by more than 100 comments by the time of data collection) each year to triangulate the communication trends and patterns found in mass media content and people's online searching behavior.

$B \log S$

Blogs are much longer and more abundant in information than BBS or Weibo. For this book, blog data are instrumental, because they can supplement and triangulate interview data and serve the purpose of comparative studies. I mainly searched three blog sites - Sina Blog, BlogChina.com and ScienceNet.cn. Sina Blog, operated by China's once largest online portal Sina.com.cn which also operates Weibo, is the largest blog site in China. BlogChina.com was a very active blog site, but due to the overall decline of the blog as a communication vehicle, it is no longer active enough; however, for historical reasons, it was still adopted as a sampled blog site. ScienceNet.cn, operated by the Chinese Academy of Sciences, is a leading website primarily targeting scientists but also publicly accessible. Typical blogs of main actors were downloaded and analyzed. The results are reported in individual chapters.

\section{Weibo data}

With its deep and wide penetration into everyday life and its public sphere role (Rauchfleisch \& Schäfer, 2015), Weibo could potentially be an excellent platform to observe the public representation of science controversies (J. Fan, Jia, Peng \& Zhang, 2013). I analyzed the attitudes and behaviors of individual actors involved in the dispute as a substitute when interviews were unavailable. Due to Weibo's access and download restrictions, I could only access a limited number of recent tweets. Therefore, Weibo search was not systematic, focusing on more typical tweets, including those suitable for external software analysis. 
For GMOs, former TV anchor Cui Yongyuan, a main anti-GMO actor, regularly produced high-impact Weibo posts. His Weibo tweets became my main research target. Besides, I retrieved data presented in my previous studies on Weibo transmission of GMO controversy in China for analysis (J. Fan et al., 2013; Jia, Fan \& Peng, 2014; Jia, Fan \& Yan, 2015).

For nuclear power, three Weibo searches in May and August 2018 and January 2019 resulted in about 1,500 tweets, a small number which indicated an indifferent public reaction to the nuclear power issue. Few anti-nuclear actors opened or regularly updated Weibo accounts. Among the first 600 sampled Weibo tweets (the first 200 tweets from each search), I only identified four tweets meeting the benchmark analysis criterion of 30 forwards set by the external tool Weiboreach.com (conveniently defined as high-impact tweets here). To overcome the gap, I expanded my search to topics (with hashtag \#) including the keyword "nuclear power" (核电), which resulted in nearly 2,000 such issues. Among the first 200 topics of my searched results, only 29 topics had a readership of more than 10,000 and were worth further analysis. I also searched posts by known anti-nuclear activists to identify qualified tweets for external analysis.

I did not specifically search Weibo tweets for hydropower, as most controversies on dam buildings had ceased or declined when Weibo became popular in China in 2011. Even though there were Weibo tweets related to the last collective protest surrounding Chongqing's Xiaonanhai dam, Weibo's search engine did not support searching for tweets posted several years ago.

\section{WeChat data}

Chinese people have become deeply immersed in WeChat, which has more than 1 billion active users, more than the number of smartphones in China (China Internet Network Information Center (CNNIC), 2017). But unlike Weibo or Twitter, where people can "follow" any individual account, joining a friend's circle (like Facebook's wall), WeChat is mostly private and viewing a person's posts requires the permission of that person (Harwit, 2016).

WeChat has two more functions for "publicness." Any individual or organization can publish a public account (standard translation is "official account"), which can be considered a smartphone-based publication, without a license that is essential for traditional media in China. Any user can subscribe to the smartphone publication.

The second publicness function is WeChat's group chat. Each group allows up to 500 members. Information from a WeChat public account can be transmitted quickly by being posted into a chat group, and then it can be transferred to other chat groups by overlapping group members (X. Wang \& Gu, 2016). As I was involved in multiple relevant chat groups, I observed the dialogues in the groups and summarized some patterns in the following chapters, but I did not record and report any personally identifiable information. 


\section{Research method and data}

Meanwhile, using external online tool QS Data (www.qsdata.com), which ranks WeChat articles and public accounts, one can obtain the ranking (ranked in terms of views) of public account articles and access them. I collected three types of WeChat data. The relevant public account articles I randomly encountered or intentionally traced when alerted; highly ranked public account articles related to the studied subjects - hydropower, GMOs and nuclear - obtained through QS Data, and unidentifiable chat group posts for observation.

I downloaded, coded and analyzed from QS Data the first 50 articles distributed through a WeChat public account (a free-of-charge user can access to a maximum of 100 materials posted in the past three months) for each of the three subjects. As indicated above, due to high literary disambiguation necessary for hydropower, I obtained such public account articles by searching the same keywords as in mass media and then cleaned the combined results. For GMO and nuclear power articles, I only used the single keyword to search in QS Data due to their low level of ambiguity. Because WeChat articles on nuclear power were highly homogenous in their attitude to the power, I also supplemented the search with activists' names as keywords.

\subsubsection{Partisan website data}

Unlike news sites which boast their neutrality, partisan websites (and their WeChat-based public accounts) promote politically biased viewpoints. Because of China's officially recognized socialism ideology and its active censorship, sites openly promoting Western democracy are virtually nonexistent within China. On the other hand, in recent years, Maoist leftism ${ }^{3}$ has grown in Chinese society and the online world rapidly (L. Ma, 2012). With the fast development of online populism in China, the number of leftist websites quickly expanded (Fang \& Repnikova, 2017; A. Y. Hu, 2006). Given the situation, it is necessary to examine whether the rising left-wing populism has influenced science controversies.

Examining the political polarization of science controversies is a common research topic, particularly looking at climate change (Kahan, Jenkins-Smith \& Braman, 2011; E. C. Nisbet, Cooper \& Garrett, 2015). A standard method is to measure one's political attitude from right to left (conservative to liberal), but tracing partisan websites has also been adopted (Schuldt, Konrath \& Schwarz, 2011). Due to the lack of a full spectrum of political ideology in China's public sphere, tracing partisan websites may be considered a partial proxy to calculate partisan attitudes among the public.

Based on my long-time observation, the anti-GMO position is often linked to leftism political appeals, but I haven't found evidence for similar trends in the case of hydropower and nuclear power. So I only examined GMO articles across several selected Maoist websites, including Utopia (Wuyou zhixiang: wyzxwk. com), Chawang (cwzg.cn) and Red Song Club (szhgh.com). The observation time was August 2018. Using the Chinese keyword GMO (转基因), I found 
4,340, 234 and 45,778 articles. Unfortunately, I did not have enough resources to analyze all these articles, so I only downloaded and analyzed the first 50 articles ranked by relevance identified from each of these sites.

\subsubsection{Other documentation data}

Another type of information is various government documents, including the annual government work reports delivered to the plenary meeting of the National People's Congress by the Prime Minister, different five-year plans (五年计划: including comprehensive plans, energy development plans and plans for specific fields such as nuclear power) and the national middleand long-term S\&T plan (and such plans in subfields, such as the middle- and long-term plan for agricultural S\&T). There were also many government circulars relevant to my research. I primarily used these documents for informational purpose. Some typical materials were also used to analyze some STS concepts, such as sociotechnical imaginaries.

In addition to government documents, I also analyzed books and journal papers written by the main actors of the studied controversies. A significant purpose for examining these documents was to look at the knowledge contests between main actors and the possible sources of alternative knowledge. Meanwhile, for the TGP controversy in the 1980s, three books written during the debate - Treatises on Macro Policymaking on the Three Gorges Project (F. Tian, Lin \& Ling, 1987), Second Collection of Treatises on Macro Policymaking on the Three Gorges Project (F. Tian, 1989) and Yangtze, Yangtze: Debates on the Three Gorges Project (Q. Dai, 1989) - were the primary data sources for this topic due to the lack of other materials.

The multiple sources' documentation provided a solid basis for triangulation which also existed between interviews, documentation and participatory observation. The multiple triangulation not only enhanced the study's reliability but also created chances to explore new theoretical findings through the constant comparison suggested by grounded theorists (Glaser \& Strauss, 2009).

\subsection{Multilevel data analysis}

\subsubsection{Analyzing interview data}

I adopted what R. K. Yin (2009, pp. 136-160) described as the five case study analysis techniques, including pattern matching (comparing an empirically based pattern with a predicted case), explanation building (analyzing case study data by building an explanation), time-series analysis, logic models and cross-case synthesis (aggregating findings across a series of individual case studies). Another method is constant comparison, which combines data coding and analysis to generate theory systematically. It is designed to aid analysts in producing a theory that is consistent, plausible, close to the data 


\section{Research method and data}

and at the same time is in a form clear enough to be readily, if only partially, operationalized for testing in quantitative research (Glaser \& Strauss, 1967, 1771-1773 Kindle Location).

Concretely, I first developed a timeline of the three selected controversies and then analyzed different data for different purposes. For example, interview transcripts were used for: 1) clarifying and verifying the "truth" and details of individual controversies; 2) finding theoretical components involved; and 3) comparing and matching patterns of these controversies.

Unlike the common practice in qualitative case studies, I did not use software to code all interview transcripts systematically. Instead, I read all interview transcripts (commonly immediately after my interviews), compared them with my interview notes which had highlighted some points either theoretically meaningful or essential to story developments to decide the crucial quotes I would use. Because I made all interviews myself and had some strong impressions when there was vital information, the comparison between notes and transcripts was more efficient than formal coding for identifying important messages both for theories and for book details. To address the possible neglect of other essential clues and theoretical components, I also carefully read relevant transcripts (from interviewees who were essential figures in controversies) to identify meaningful contents further.

\subsubsection{Analyzing mass media data}

I coded media reporting collected from the above four sampled newspapers for framing analysis and tracing the media's frequency of attention. I also analyzed media to form a triangulation with my interviews with journalists. Based on literature (M. C. Nisbet \& Lewenstein, 2002) and the trial analysis, I developed a coding system consisting of three aspects - themes, attitude and whether controversy can be identified (dispute visibility).

What I define as themes here is similar to frames: significant aspects of social life covered by the media stories. Frames have been widely used in the relevant literature, and when they were used in environmentally relevant studies (Gamson \& Modigliani, 1989; M. C. Nisbet \& Lewenstein, 2002), they have often been linked to specific established meanings, such as S\&T progress and Pandora, which were sometimes directional. Thus, I preferred to use the term "theme," by which I referred to more objectively and neutrally defined areas of human activities related to the studied topic. For example, one story may report the business or economic aspects of nuclear power while another news article deals with the environmental issues of hydropower development. A simple reason for me to prefer the straightforward aspects of studied topics is it is easier to code. Besides, coding sampled media articles with these straightforward aspects as themes allows me to make cross-over analysis between article themes and other features such as article attitude and controversy visibility. 
I fully absorbed the previous frame analysis work such as those by M. C. Nisbet and Lewenstein (2002), which proposed the following framing typology for biotechnology:

- Progress: Celebration of new development, breakthrough; the direction of history; the conflict between progressive/conservative-reactionary

- Economic prospect: Economic potential; prospects for investment and profits; R\&D arguments

- Ethical: Call for ethical principles; thresholds; boundaries; distinctions between acceptable/ unacceptable risks in discussions on known risks; dilemmas. Professional ethics.

- Pandora's box: Call for restraint in the face of the unknown risk; the opening of flood gates warning; unknown risks as anticipated threats; catastrophe warning

- Runaway: Fatalism after the innovation; having adopted the new technology/products, a price may well have to be paid in the future; no control any more after the event

- Nature/nurture: Environmental versus genetic determination; inheritance issues

- Public accountability: call for public control, participation, public involvement; regulatory mechanisms; private versus public interests

- Globalization: call for global perspective; national competitiveness within a global economy; opposite: splendid isolation

(Copied from M. C. Nisbet and Lewenstein (2002, p. 372))

I took the aspects of human activities M. C. Nisbet and Lewenstein (2002) described in their framing typology but split values (e.g., progress, Pandora's box, etc.) attached to these frames as much as possible to form some trial article themes. Then I read about 100 sample media articles for each of the three studied controversies to test the applicability of these themes in the Chinese context. I expanded, dropped and adapted the trial themes when reading sample media articles to finalize the themes finally used in this book. Some themes were adjusted in the formal coding process. Eventually, I developed either 10 or 11 themes for each of the three studied controversies.

For the media stories on hydropower, I identified ten major themes. They included business \& economy; S\&T; environment \& ecology; floods, dam safety \& water management; engineering; history \& culture; politics, activism \& national interests; regulatory \& public accountability; immigrant affairs; and development \& social welfare.

Among the themes, engineering was different from S\&T because the former was more related to industrial practice rather than research done by scientists. The theme "regulatory affairs \& public accountability" was also separated from "politics, activism \& national interests," which covered articles on political decisions, political leaders' involvement (where the items do not have 


\section{0}

Research method and data

other clear themes), public participation and activism, and national interest frames, which are common in China (Jia \& Liu, 2014; Jia \& Liu, 2009).

For the media stories on GMOs, 11 primary themes were identified, including seven themes equal to those in hydropower stories - S\&T; business \& economy; culture \& history; development \& social welfare; environment \& ecology; politics \& national interests; and regulatory affairs \& public accountability. Besides, the media articles on GMO specifically covered the themes of food safety; ethical issues; conspiracy; and science communication \& popularization. I added a "science communication \& popularization" theme because due to the ongoing GMO controversies, a large group of science communicators emerged, and science communication activities were organized to defend biotechnology. As a result, two types of media articles including non-news popular science articles to defend GMOs and a kind of news story specifically on science communication activities - emerged and cannot easily be included into other themes.

The media stories on nuclear power also included seven themes used to code GMO and hydropower stories - S\&T; business \& economy; culture \& history; development \& social welfare; environment \& ecology; politics \& national interests; and regulatory affairs \& public accountability. Besides, science communication \& popularization; conspiracy; nuclear safety; and engineering themes were covered. An additional theme specific to nuclear power is international nuclear non-proliferation negotiation and potential military use of nuclear energy. Although when cleaning data, I have cleared most nuclear articles solely about military purposes, such as the North Korea or Iran nuclear crises, there were still some articles about both nuclear power and international nonproliferation negotiation, such as those on the international negotiation of Iran's civil nuclear power plant.

Ethics \& Pandora is a frequently used frame in environmental or biotechnology stories (M. C. Nisbet \& Lewenstein, 2002), so initially, I kept the ethics \& Pandora theme. But I dropped the theme after the first 400 article coding did not find any such item.

Table 2.2 indicates the mass media themes of the three studied subjects.

For the science communication \& popularization theme, I sometimes coded secondary themes based on the main contents being communicated or popularized, but there were also articles discussing science communication of the studied subjects per se. In this case, I did not make a secondary theme code. For nuclear power articles, the theme "history and culture" was mostly related to the glorified history of China's nuclear weapon or industry. Secondary themes were also coded following the concrete historical contents.

The sampled media stories' attitude to research subjects was coded at a three-level scale, from a negative attitude (-1) to neutral (0) and then to a positive attitude $(+1)$. Positive attitude typically meant straightforward praise that could be identified with keywords like progress, honorable, nationally significant, glorious, independent innovation and benefit (to nations, people or environment), while negative attitude represented clear denunciations or 
Table 2.2 Mass media theme coding of the three studied subjects

\begin{tabular}{|c|c|c|c|}
\hline & Hydropower & GMOs & Nuclear power \\
\hline $\begin{array}{l}\text { Common themes } \\
\text { across the three } \\
\text { subjects }\end{array}$ & $\begin{array}{r}\text { Dev } \\
\text { Politics } \\
\text { Regulator }\end{array}$ & $\begin{array}{r}\text { S\&T } \\
\text { Business \& } \\
\text { Culture \& } \\
\text { elopment \& s } \\
\text { Environment } \\
\text { national inte } \\
\text { y affairs \& pr }\end{array}$ & $\begin{array}{l}\text { onomy } \\
\text { istory } \\
\text { cial welfare } \\
\text { ecology } \\
\text { ests \& activism } \\
\text { lic accountability }\end{array}$ \\
\hline \multirow[t]{4}{*}{$\begin{array}{l}\text { Specific themes in } \\
\text { different subjects }\end{array}$} & Engineering & $\begin{array}{l}\text { Ethics \& } \\
\text { Pandora }\end{array}$ & Engineering \\
\hline & $\begin{array}{l}\text { Floods, dam safety } \\
\& \text { water } \\
\text { management }\end{array}$ & $\begin{array}{l}\text { Food } \\
\text { safety }\end{array}$ & Nuclear safety \\
\hline & Immigrant affairs & Conspiracy & $\begin{array}{l}\text { International nuclear non- } \\
\text { proliferation negotiation } \\
\text { and military use }\end{array}$ \\
\hline & & \multicolumn{2}{|c|}{ Science communication $\&$ popularization } \\
\hline
\end{tabular}

(Source: Author's coding)

warnings against the subject. The benchmark to determine the tone, however, may vary per the media. For example, PD, a Party propaganda mouthpiece, was the most generous in using positive keywords while SW always tried to show journalistic balance. Thus, a story defined as neutral in PD may be positive in SW.

Then, during my pretest, the idea to mark the visibility of controversy emerged. Although I have not found any previous study to set dispute visibility as a variable for coding, there is a long tradition to trace identifiability of disputes in media articles (Lewenstein, 1995; Mazur, 1981; Nelkin, 1995). The purpose here is to know what types of media themes and what attitudes are related to the media's framing of controversies and uncertainty. Although media's balancing efforts can naturally create a general controversiality and uncertainty (Boykoff \& Boykoff, 2004), this indicator is meaningful in China, as propaganda-styled science news in the country is highly positive (Jia \& Liu, 2009) tending to erase such controversiality and uncertainty, particularly in official media. The visibility of controversy was conveniently coded as " 0 " (debate invisible) and "1" (controversy visible).

Due to the enormous number of media articles (about 5,000), I did not have technical and financial resources to hire independent coders. I asked the help of an independent Chinese peer researcher for a reliability test. The researchers' primary research method is a media content analysis. We separately analyzed about 100 articles in each of the three studied subjects hydropower, GMOs and nuclear power - after I delivered my intentions and strategies. The intercoder reliability test was quite high, more than 0.8 across 


\section{Research method and data}

the three subjects. We discussed the difference and reached consensus on coding accuracy. Then I coded all of the media articles myself for their themes, attitude and dispute visibility.

I did not code media articles (including WeChat public account articles) I collected during interviews and through various occasions such as WeChat chat groups. Instead, aiming to explore the typicality (Small, 2009), I carefully read these articles, most of which were relevant to recent dialogues, in search of relevant information. Various findings will be reported in the individual chapters on particular subjects.

In the individual chapters on researched subjects, I present the mass media data in tables to show the analysis results of coding (frames, attitude, controversy visibility). The results of media reporting frequency and keywords search amounts are also graphed in corresponding chapters.

\subsubsection{Analyzing social media data}

As described above, my social media data include BBS, blogs, Weibo and WeChat public account articles. I counted the annual number of the original BBS posts (the first post that is followed by others to form a debate) to support, clarify and verify communication trends found in mass media content analyses and the examination of other data. In terms of Weibo and blog data, I mainly observed some typical tweets and blogs of actors to triangulate and supplement my interview data.

For Weibo data, I used an external, fee-charged Weibo analysis tool Weiboreach.com to calculate typical individual tweets' coverage, number of comments and retweets. Then I analyzed and estimated these tweets' communication structure and their effects. Due to the Weibo data restriction, the Weiboreach.com analysis was more for demonstration than for systematic examination. Weiboreach.com's threshold criterion is at least 30 forwards, which is conveniently defined by the tool as high-impact tweets.

For WeChat articles, I modified the mass media coding rubrics by adding criteria like whether the analyzed public account was published by an established media source (including both print media and traditional online news portals such as sina.com.cn), whether the account belonged to an individual or an organization, the types of account publisher (see below), and the number of people reading. Whether the account belonged to an individual is an essential criterion because theoretically, all print media outlets are stateowned but individual persons can publish WeChat public accounts as a factual mobile media. For public account types, there was a slight difference across the three studied fields. For example, for GMOs, it is necessary to have an independent category of food-related business (including cuisine, food planting, food distribution and travel food) split from the general type of business and economy entities. The finalized coding rubrics for the themes of public account articles in GMO setting were: News stories (from conventional media); science issues; business and economy articles; food business; societal 
and public welfare; culture and history; political and national interest; environment; health; opinion; entertainment; military; and religion. These codes may overlap with each other. In this case, the articles were multiply coded.

After examining nuclear power articles downloaded from WeChat-based public accounts, I decided it was unnecessary to develop systematic coding. The materials were highly homogenous in their attitude to nuclear power, sources and the types of publishing accounts, so that finding heterogenous articles (e.g., articles with nuclear-negative tone) already reached my academic goal.

In addition to using QS Data for the top read WeChat public account articles, I also collected and read articles randomly distributed in chat groups in each of the subjects - hydropower, GMOs and nuclear power - for content analysis. I did not code these public account articles but carefully read them to identify useful information.

\subsubsection{Analyzing data from other sources}

I also skimmed the articles on the three targeted controversies - hydropower, GMO and nuclear power - on Maoist partisan websites. I only analyzed the first 50 most read articles downloaded from each of the three sampled partisan sites (Utopia (Wuyou zhixiang: wyzxwk.com), Chawang (cwzg.cn) and Red Song Club (szhgh.com)). I first coded their attitudes to GMO (positive, neutral and negative). A standard intercoder reliability test was not performed, but when I was uncertain about an article's attitude, I asked my Chinese colleagues who studied communication to help. In all cases, we had a quick consensus.

Analyzing government documents was often done with framing analysis techniques, though I did not code them with frames due to lack of systematic collection of government documents. Analyzing these documents can offer a pathway to trace national sociotechnical imaginaries, which match but are different from the media framing (Jasanoff \& Kim, 2009). Detailed analyses were reported in these chapters wherever necessary.

I reported and analyzed the results in both tables and graphs. Some general working research questions associated with the media content analysis include how did different types of Chinese media report and frame various science controversies? What types of frames were associated with the story's attitude and the visibility of debate? Have hot events driven Chinese media coverage of controversies?

\subsection{Ethical considerations}

Ethical issues are crucial to social and behavioral sciences, particularly to qualitative studies; as Sieber (1997, p. 127) argues, "unethical applied researchers are likely to harm themselves and their research as well as those they study." My research is impacted by ethical considerations because China is an authoritarian nation where free debates are not encouraged, and open 
protests against controversial technologies might be potentially punished. Nearly all investigated controversial technologies - GMOs, hydropower and nuclear - are supported by the government or some branches of it. Protesting these technologies is often thought of as challenging government authority.

Second, Chinese scientists and officials are particularly reluctant to speak out partly due to political control and partly because of a less open scientific culture in the country (Y. Shi \& Rao, 2010). In this situation, scientists who discuss scientific controversies with "outsiders" are not appreciated by peers. This situation can be considered reputational damage to them even though they may never be punished.

Facing the ethical challenges, a common strategy is to prepare for them (Sieber, 2009). Cornell IRB approved my research in 2016, and I also studied various ethical regulations. The central principle of moral consideration is to do no harm, including the intentional effort to limit the potential damage as far as possible (Ellis, 2007).

To ensure no harm, I stuck to two principles - confidentiality and voluntary research participation. During my interviews, besides having the regular informed consent process in which I stressed the privacy and voluntary involvement, I discussed with most in-depth interview informants the possible consequences of our talk and my research.

In this monograph, I almost universally maintain anonymity for my interviewees, even though this may cause some narrative inconsistency. Sometimes, for example, the names of activists whom I interviewed were widely known in open protests and widely reported by media. In this situation, I used some real names but always avoided hiding the clue that can be used to reveal which real-name person was interviewed by me. Besides keeping anonymity, when presenting my findings, I deleted personally identifiable information of informants as much as possible.

Ethical consideration goes beyond anonymity in impacting my study. For example, with various independent interviews and my personal experience as a former Chinese science communication organizer dependent on international funding, I believed most major Chinese environmental non-governmental organizations (ENGOs) relied on international financial support during my studied period. However, revealing this may threaten these organization's credibility, and hence their existence in the current Chinese situation, in which the use of international grants is severely limited.

Therefore, while listing foreign funding as a general sociopolitical factor (political opportunity) fueling China's environmental activism, I avoided exploring funding issues for any individual ENGOs, even anonymously.

\section{Notes}

1 For full disclosure: I was the founder of Science News Magazine, affiliated to the CSD, and served as its editor-in-chief from 2008 to 2010. 
2 Because Weibo is very similar in structure and usage to Twitter, I use the words "tweet" and "retweet" throughout this book to describe Weibo posts.

3 In the Chinese context, the left or leftism is entirely different from the West. Leftism in the daily context can be understood as Maoism. 


\section{Science controversies in transitional China}

\subsection{Introduction}

As mentioned in Chapter 1, the Chinese leadership has long granted critical importance to the ideological role of S\&T (Cao, 2014; X. Deng, 1988/1993b; Chunfa Wang, 2017), but there has never been a shortage of S\&T controversies in the history of the People's Republic. While the current book uses the typical anti-hydropower movement, GMO controversy and nuclear power disputes for a comparative study, it is necessary to trace the history of major S\&T controversies in the socialist regime. Besides offering background information to readers who are not familiar with China's contemporary history, the narrative in this chapter also sums up the fundamental economic, social and, in a sense, political changes occurring in China since the 1980s when the country began its opening-up.

The S\&T controversies took place well before Deng Xiaoping's opening-up policy. It can be traced back to the 1950s' Three Gorges Dam Project (TGP) debate in Chairman Mao Zedong's era. Since the 1980s there have been more S\&T controversies - ranging from the renewed debate on TGP to GMOs and trash incineration - in the public discourse. Initially, a dispute burst out about Qigong and other supernatural phenomena when orthodox scientists disapproved of the so-called magical power by Qigong masters. These masters, in many cases, were supported by retired revolutionary politicians and, sarcastically, by some top science leaders such as Qian Xuesen, who is the father of China's space program (Palmer, 2007). The renewed TGP debate occurred at the same time (Lee, 2013a). After it came to the 2000s, when China increasingly became an essential player in the world economy with its entry into the World Trade Organization (WTO) in 2001, S\&T controversies became intensified, covering GMOs, building chemical plants, food safety, landscape management, hydropower and nuclear power. The disputes involved more and more actors, including ENGOs, academics, journalists, and often contingently organized citizen groups.

Indeed, China observers have identified how S\&T controversies in the 1980s interacted with the country's budding liberalism, which was veiled in the slogan of making policy-making scientifically sound (H. L. Miller, 1996). The other side of the coin is that policy disputes can be reflected in scientific

DOI: $10.4324 / 9781003160212-3$ 
controversies, as in the West's situation (Nelkin, 1995). The unprecedentedly severe controversy surrounding the feasibility of TGP in the 1980s can be considered such an example (Lee, 2013a). Therefore, a historical narrative of China's S\&T controversies starting from TGP is necessary chronologically and theoretically.

\subsection{Hydropower, nuclear power and GMO controversies in China}

\subsubsection{Three Gorges Dam controversy}

Modern China's hydropower controversies began in the decades-long debate on TGP. Sun Yat-sen (1866-1925), the founder of modern China, proposed building TGP as early as the 1920s (Y.-s. Sun, 1920/2014) but could not realize the plan. It is noticeable that Sun described the TGP plan in his famous Guidelines for Nation Building, an indication of what scholars call a State-making effort (Tilt, 2014) or modernist developmentalism (Lee, 2013a). The nationalist government that ruled China in the first half of the 20th century did conduct some feasibility surveys in preparation for TGP, chaired by the US-trained mining engineer Sun Yueqi (1893-1995), the then Chairman of the Resources Committee.

After the communist party expelled the nationalist government to Taiwan in 1949, Chairman Mao Zedong began to brew the TGP plan. In 1958, he convened a national hydroengineering meeting in the southern Chinese city of Nanning, intentionally bringing in Party officials and experts of different opinions on the issue to debate. Fierce debates on the construction cost, settlement of relocated residents, and the total capacity of TGP to prevent flood broke out between Lin Yishan (1911-2007), the then minister of water resources, and Li Rui (1917-2019), the then director of the Bureau of Hydropower under the then Ministry of Electrical Industry. Li was one of Mao's professional secretaries responsible for industry affairs.

Despite the disputes, Mao did not hide his strong desire to build TGP as a remarkable feat. Feasibility study began in late 1958, involving 10,000 scientists and engineers nationwide. However, the study had to be halted in 1960 when China began to suffer the Three-Year Great Famine (H. Chen, Yang \& Xiang, 2006), responsible for the death of an estimated 36 million people (J. Yang, 2012).

The massive controversy surrounding TGP broke out again in 1985 after the Chinese government finished drafting a feasibility plan to build a 150-meter-high dam in Three Gorges, the so-called low-dam plan, under the instruction of Deng Xiaoping. The disputes about the TGP in the 1980s involved more actors, though still among elites, and lasted several years until the government made a final decision in 1989 to build a 185-meter-high dam to enable heavy cargo ships to access Chongqing. The higher the dam, the more water in the upstream waterway behind the dam, supporting ships of more significant tonnage. 
The debates on TGP were quite institutionalized despite China's authoritarian regime. CPPCC - many of its members being senior scientists, engineers and scholars, including Sun Yueqi - convened two extensive inspections of the planned dam site and its upper and lower river regions. Most of the team members, including many leading scientists, such as former Peking University President Zhou Peiyuan (1902-1993), opposed the immediate start of TGP.

In addition to Li Rui and CPPCC members, other scholars and Party officials were involved in debating against the immediate implementation of TGP. Among them, Cornell-trained Tsinghua hydrology professor Huang Wanli (1911-2001) was the most noted. Huang wrote three petitions to the then central committee of CCP against TGP based on his theoretical belief that stone sediments from the upstream Yangtze River would eventually fill the reservoir, forcing to blast TGP to avoid big floods. With TGP having been completed for nearly two decades, Huang's warning seemed highly implausible, though it was adopted as talking points of anti-dam campaigns again and again.

The main arguments to resist the immediate start of TGP were economic feasibility, the risk of sediments that might block the dam's overflow outlet, the priority to build smaller upper river dams, and the real numbers of relocated residents and the capacity to resettle them. Although one team was responsible for possible environmental pollution in the feasibility study, the environment did not become a significant theme during the debate (INT20161222).

Searching PD, few open debates on TGP can be found across the 1980s, though many journalists were actively devoted to reporting the opposing voices. Interviews with two involved journalists indicated that critical coverage of the debate was censored (INT20161102, INT20161208), but journalists published a compiled book containing those unpublished articles and interviews (Q. Dai, 1989). TGP opponents also published several books to collect articles questioning TGP.

By spring 1989, the government plan had been dominated by TGP supporters, who received the patronage of Premier Li Peng, a Soviettrained hydropower engineer. Opponents were far from being convinced. However, the bloody clampdown in Tiananmen Square in June 1989 and the subsequent arrest of a leading TGP opponent, famous journalist Dai Qing who was also involved in the democratic protests, silenced the opposing voices against TGP. In 1992, under the new communist leadership headed by Party Secretary Jiang Zemin and Premier Li Peng, NPC's annual plenary meeting passed the initiative to build TGP. With the project completed with a total investment of US $\$ 31.7$ billion in the late 2000 s, organized opposition faded away. The installed generation capacity at the Three Gorges Project (TGP) reached 18 million kilowatts, the world's largest. Although articles and posts questioning TGP often appear online, the controversy has mostly been closed. 


\subsubsection{From TGP to anti-dam in southwestern China}

\section{A threat to the world's heritage?}

After the open TGP controversy was silenced, hydropower debates disappeared in China's public sphere for about 14 years until 2003, when the protest against hydropower companies' escalated efforts to develop southwestern hydroelectricity projects primarily in Sichuan and Yunnan provinces suddenly broke out. Unlike in the TGP controversy, environmental and ecological issues dominated the agenda, and ENGOs and their supporters became main actors.

ENGO did not become full-fledged across the 1990s. China's first legally registered ENGO, the Friends of Nature, was formally established in 1994, and after that, NGOs began to proliferate in China, reaching 71 in 2001 (G. Yang, 2005). Wang Yongchen, a former environmental journalist at China National Radio who founded the Green Earth volunteers, is the center of the antihydropower campaign.

In April 2003, Wang was invited to report to an expert meeting discussing the proposed Yangliuhu Hydraulic Facility in Sichuan's southwestern province. With a low dam of 23 meters, Yangliuhu was designed to adjust the downriver water supplies to the Zipingpu Dam, which began construction in 2001. The major controversy about Yangliuhu was that its construction would destroy the authenticity of the UNESCO heritage site Dujiangyan, a hydraulic project built more than 2000 years ago, located less than 2 kilometers away from the proposed Yangliuhu dam.

With Wang's reporting and her effort to mobilize other journalists, the Yangliuhu controversy rapidly became a nationwide hot media event. More than 180 national media outlets reported the disputes (Y. Yan, 2009). The flooding media coverage exerted massive pressure on both the central and local governments. In August 2003, the Ministry of Construction, which supervised China's compliance with UNESCO heritages, asked Sichuan Province to be highly cautious in decision-making, avoiding any impact on the authenticity of Dujiangyan as a UNESCO heritage site. In the same month, Sichuan provincial government announced the suspension of the Yangliuhu project.

\section{Fighting dams proposed for $\mathrm{Nu}$ River}

While celebrating their victory in Yangliuhu, perhaps the first in the history of Chinese environmental protests, activists soon transferred their anti-dam endeavors to the far southwestern province of Yunnan Province. This time, however, the struggle was initiated from within the government. In August 2003, the National Development and Reform Commission (NDRC), China's most powerful government agency, passed the plan to build 13 dams in the middle and upper $\mathrm{Nu}$ River. According to the program, the dams' economically feasible generation capacity could reach 21.3 million kilowatts, higher 
than TGP, yet with only half of the construction cost of TGP. Most dams were to be built in the $\mathrm{Nu}$ Prefecture, the most impoverished region in Yunnan. Direct tax revenues from electricity generation were estimated to be 8 billion yuan (US\$1.3 billion), several times the prefecture's current tax revenue. At a joint governmental meeting held between August 12 and 14, the representative of the State Environmental Protection Administration (SEPA, upgraded to the Ministry of Environmental Protection (MEP) in 2008 and reshuffled to become the Ministry of Ecology and Environment (MEE) in 2018) was surprised to learn of the Nu River plan and found he was the only government official at the meeting disagreeing with the program (Q. Deng, 2013). The SEPA official refused to sign to endorse the plan. Meanwhile, on September 1, 2003, the new Environmental Impact Assessment (EIA) Law was to take effect. SEPA insisted that significant dam projects must pass EIA before they were constructed.

Due to its relatively low hierarchic status, SEPA did not have the authority to revoke NDRC's decision. Instead, it convened on September 3 an expert seminar discussing the unique cultural and biological diversity in $\mathrm{Nu}$ River, involving many leading environmental journalists. The meeting produced a batch of articles calling for preserving the $\mathrm{Nu}$ River, including a highly influential essay in the People Daily (PD), "Preserving an ecological river for offspring," authored by its senior environmental journalist Zhao Yongxin. Due to PD's unique status as the CCP's official organ, it was quickly picked up by dozens of other media outlets. Anti-dam activists claimed building dams would destroy the rich local biodiversity and cultural diversity, and that many dams planned for Nu River were built on risky seismic belts.

The media campaign once again placed colossal pressure on hydropower companies and particularly Yunnan local governments, which had thought hydropower development could drive away their poverty. Yunnan provincial bureau of environmental protection rejected the accusation that $\mathrm{Nu}$ River dams would destroy biodiversity, saying species in the dam region only accounted for a small percentage of the biodiversity-rich $\mathrm{Nu}$ prefecture. Most seismologists, not just those in Yunnan, rejected activists' claims that Nujiang dams were planned on seismic belts.

Activists did not forget to lobby top leaders. It was reported that a petition was submitted to Premier Wen Jiabao, a geologist by training, through channels I will analyze later. Premier Wen commented on the $\mathrm{Nu}$ River hydropower development plan in February 2004: "To those major hydropower projects with close public attention and environmental disputes, [we] should cautiously study and scientifically make decisions" (Y. Yan, 2009).

Since the 2003/2004 debate, Nu River has become an emblem of China's hydropower controversies. For example, in 2011, four retired geologists sent a petition to the State Council (through an unknown channel), calling for $\mathrm{Nu}$ River hydropower development suspension because the proposed dams will be built in an active seismic belt (Q. Deng, 2013). 
The petition was soon taken up by the media as an active part of their new round to cover the resumed plan to develop $\mathrm{Nu}$ River, which appeared in the 12th Five-Year Energy Development Plan (2011-2015).

The new round of media campaigning seemed to play a role. In the 12th Five-Year Plan period, no new dam construction was resumed. In 2015, when the draft outline of the 13th Five-Year Energy Development Plan was published for public opinion, ENGOs once again strongly opposed the $\mathrm{Nu}$ River dam development proposed in the plan. In June 2016, seven ENGOs, including Green Watershed, Green Earth Volunteer, Friend of Nature, Green Hanjiang, Hengduan Mountain Research Institute, Chengdu Urban Rivers Association, and Green Zhejiang, jointly published an open letter urging the government to abandon $\mathrm{Nu}$ River development. Surprisingly, the Nu River hydropower development plan was dropped from the 13th Five-Year Energy Development Plan announced in late 2016.

However, interviews with insiders suggested the abandonment of the $\mathrm{Nu}$ River development was not merely because of civil society's protests (INT20161120, INT20161223, INT20170106). Instead, the severe oversupply of electricity has resulted in the massive abandonment of the outputs of unstable energy sources - including hydropower, wind power and solar power.

\section{Fighting for Tiger Leaping Gorge dam}

With just four months' truce, environmentalists launched an offensive against another proposed dam - Longpan Dam - above the famous tourist site Tiger Leaping Gorge, after NDRC approved the Mid-Jinsha River hydropower development plan, which is the upstream river of the Yangtze, also in Yunnan Province. This time, in addition to arguing against the dam's environmental and ecological impacts and its influences on another UNESCO heritage site, Three Parallel Rivers of Yunnan (Jinsha, Lancang or Mekong, and Nu or Salween rivers), its destruction of the tourism site as well as the scale of residents and area of land to be relocated became the focus of contentions.

The media's involvement soon spread to other targets. NDRC had approved an eight-dam cascade starting at Tiger Leaping Gorge in the portion of Jinsha River. None of them had gone through the EIA process. Investigative reporting by Southern Weekend (SW) soon found one of the eight dams was already being built without obtaining EIA approval. The wave of media coverage provided SEPA an excuse to get involved in high profile, suspending these dams' construction. Meanwhile, SEPA funded and invited many journalists to dam sites close to the Tiger Leaping Gorge, apparently to justify its decision (INT20161016).

To date, the Longpan Dam construction on Tiger Leaping Gorge has not been recovered though some of the eight dams below it have been completed (J. Liu, 2013). Starting from the controversy on Tiger Leaping Gorge dam, activists' call for public participation in decision making on dams, as required by the EIA law in principle, became a "standard" contest procedure. 
The dam on Tiger Leaping Gorge was designed to adjust water supplies to TGP, which had then entered its final construction stage. The first batch of electric generators had already been put into operation. However, none of the southwestern dam debates was extended to the TGP project. On the other hand, nearly no major actors in the TGP contention joined the southwestern dam controversies about 15 years after the TGP debate was over.

Time and age are certainly one factor. Most of the main actors were already in their 70s in the TGP debates, and many of them had died or were not physically active 15 years later. Southwestern dam controversies were dominated by environmental issues and the corresponding reproach of hydropower companies' immorally trading environment for monetary interests. Still, none of them were highlighted during the TGP debates.

During the southwestern hydropower controversies, hydropower companies adopted a passive stance at the very beginning, seldom responding to activists' challenges. Zhang Boting, vice-secretary general of Beijing-based China Society for Hydropower Engineering, became the only spokesperson for the industry. Senior scientist He Zuoxiu and leading science writer Fang Shimin supported Zhang. Fang was famous for his website New Thread which whistle-blowed scientific misconducts.

Confronting Zhang is a large, divergent, yet loose, group of "environmentalists," including ENGOs - many of whose members are former (and working) journalists and scholars. Some of them were equipped with professional science training - ecologists, conservation scientists, cultural study scholars, a limited number of environmental scientists, and a large number of so-called crank researchers (indicating those self-claimed researchers who have not received professional science training and often would not abide by scientific norms (S. Tian, 2003)). Although there weren't top officials and scientists involved on the activists' side, as Li Rui and Zhou Peiyuan did in the TGP debate, the anti-dam front seems to have convened much broader allies, though it is short of native community members who have suffered the most impact of hydropower development.

Environmental activists indeed involved some indigent residents, at least technically. In late October 2004, the United Nations Symposium on Hydropower and Sustainable Development was held in Beijing. Activists managed to bring several hydropower immigrants, mostly from communities relocated by the Manwan Hydropower Station in Lancang/Mekong River, which was completed in 1995, to hold a side meeting. Both sides claimed their victories. Activists argued that they made the hydropower victims' voices heard by UN experts for sustainable development. In contrast, hydropower supporters said they used the chance to check with the immigrants, smashing the rumors linked to hydropower development (INT20161225, INT20170106).

\section{Fighting for the fish}

One of the major causes for the anti-dam campaigns in southwestern China was hydropower facilities' impact on biodiversity. To most of the Chinese 
public, biodiversity remained remote and obscure. But the fate of fish in the Yangtze River provided a concrete example of biodiversity conservation. Facing the impacts of TGP completion and other planned dams in the upper river Yangtze on fish and other aquatic species, the Chinese government set up a Yangtze upper river fish conservation zone. The zone covered the Yangtze river, parts of Chongqing Municipality and parts of Sichuan, Guizhou and Yunnan provinces in 1995. The newly established reserve, administered by the Ministry of Agriculture (MOA), covered 1,162 kilometers length of the Yangtze. It banned dams and other major engineering projects in its core area within the 1,162 kilometers. However, the reserve policy neglected that in the Mid and Upper Yangtze Development Plan approved by the State Council, China's cabinet, in 1990, three major dams had already been planned in the area.

The planned Xiaonanhai (literally Small South China Sea) hydropower station, among the three, is located in Chongqing's jurisdiction, and since 2009 Chongqing government has been pushing the start of Xiaonanhai construction to relieve the power shortage of the fast-growing municipality. Since then, controversies have erupted. The impact of the hydropower station, the legal priority of different government plans, and the proper measures to reduce the effects have been internally debated. The main force opposing the Chongqing government includes the MOA, SEPA, and scientists at Wuhan-based CAS Institute of Hydrobiology headed by Cao Wenxuan, a renowned CAS academician famous for systematic studies on edible fishes (INT20161227).

In 2009, with continued lobbying by the Chongqing government headed by its ambitious Party Secretary Bo Xilai, a political star having the potential to challenge Xi Jinping for the Party head, MOA agreed to adjust the coverage of the natural reserve. The following year, the Ministry of Environment Protection (MEP, upgraded from SEPA in 2008) reportedly gave up its firm stance against Xiaonanhai. The hydrobiology scientists "surrendered" too on the condition that Chongqing agreed to commission them to design a fish protection plan. In March 2012, Chongqing held the launch ceremony for the dam construction. Around that time, however, ENGOs became involved. Utilizing the media, they promoted several rounds of media reporting of the Xiaonanhai controversy (INT20161120). It is worth mentioning that Bo was put on home arrest in Beijing in that month for alleged corruption (Jacos, 2012).

In August 2013, MOA Fishery Resources Management Committee and World Wildlife Fund (WWF) jointly organized a scientific field inspection of the fish species in Upper Yangtze. The assessment found that upper Yangtze fisheries were on the verge of collapse (Fishery Resources Management Committee (China) \& World Wide Fund for Nature, 2013). Although cautiously avoiding mentioning Xiaonanhai, the report called for strengthening natural reserves in the upper Yangtze and for the State Council, rather than individual ministries, to implement the abovementioned $\mathrm{Mid}$ and Upper Yangtze Development Plan. Although WWF China has regularly made Yangtze fishery investigations, the 2013 report was unusual. The international 
organization collaborated with a government agency to produce a scientific report related to a hotly controversial issue. The survey only took 12 days, ending in late June, and the report was published in August.

The WWF report caused a new round of media reporting, warning of the threat to fish diversity from hydropower dams in the upper Yangtze. In 2015, in a decision widely applauded by ENGOs, MEP finally denied Xiaonanhai dam to violate natural reserve. Yet, several sources suggested the MEP's final decision was also because of the fall of Bo (INT20161120, INT20161227) (M. Moore, 2012). Although Bo was a local government Party chief, as a CCP Politburo member and a potential candidate for the Politburo's standing committee, he was much more potent in the Chinese political hierarchy than ministers of individual agencies.

\section{Dam building and earthquake triggering}

The 8.0-magnitude Wenchuan Earthquake in 2008 that killed some 80,000 persons provided new ammunition for geological concerns (Hansen, 2017b). Christian Klose, a geophysical hazards researcher at Columbia University, claimed that Zipingpu Dam, just 500 meters from the fault and 5.5 kilometers from the quake's epicenter, could have triggered Wenchuan Earthquake. $\mathrm{He}$ initially raised the point during his session talk in December 2008 at the American Geophysical Union's Fall Meeting in San Francisco, California (Klose, 2008). The possibility was soon confirmed by a journal paper mainly authored by Chinese scientists, which calculate that the reservoir impoundment in Zipingpu could have brought a nearby fault to the point of failure to trigger a quake (X. Lei, Ma, Wen, Su \& Du, 2008).

Fan Xiao, former chief engineer at the Sichuan Geology and Mineral Bureau in Chengdu who has been joining ENGOs and other environmentally conscious experts, claimed that the Zipingpu dam had triggered the big earthquake (X. Fan, 2009) (INT20161222). After Science magazine reported the studies on the link between Zipingpu and Wenchuan earthquake in January 2009 and interviewed Fan to comment on the survey (Kerr \& Stone, 2009), he became widely known and received many interviews with both domestic and international media. Science also conducted a follow-up interview with Fan. However, he did not publish papers in internationally recognized journals, which Chinese scientists usually consider to have higher quality than domestic journals (R. Stone, 2009).

The Science articles provoked a hot debate among seismologists on whether the Zipingpu Dam has triggered the earthquake, later extending to whether the dams built in southwestern China's earthquake-prone regions can resist a significant quake. Unlike previous argumentation against dams by ENGOs, the debate took an entirely professional mode. Seismologists and geologists disagreed with each other on the role played by mass change caused by reservoir impoundment in triggering the earthquake, and the debate has led to some published articles in academic journals and discussions (Y. Chen, 
2009; Gahalaut \& Gahalaut, 2010; Ge, Liu, Lu, Godt \& Luo, 2009; Jackson, 2012; Klose, 2012, 2013; X. Lei, 2011; X. Lei et al., 2008).

Chinese mass media were not actively involved except Xinhua's official tone to reject the claim (C. Wang, 2009. cited from Hansen 2017b). There was a reported government ban on openly discussing a link between Zipingpu and Wenchuan Earthquake in the Chinese media (Berkow, 2009; J. Shi, 2009). However, with their comprehensive field studies on river topography in the southwestern mountainous region, Fan and another nonprofessional researcher Yang Yong supported the claim, even though neither had received formal seismology training. Yang launched an ENGO Hengduan Mountain Research Institute and obtained wide recognition in the area of environmental protection but not in academic geology.

\subsubsection{Ongoing debate on Poyang Lake water project}

The most recent controversy regarding hydraulic facilities is taking place in Poyang Lake in Jiangxi Province, located in the lower Yangtze River. While the debate repeated the earlier repertoire - dissident experts raising the issue followed by ENGOs' organization of events and critical media coverage - the Poyang Lake Hydro Junction Project differed from previous hydropower controversies. None of the established ENGOs that had partially grown with the anti-dam movement were involved. What was protested was not a moneydriven hydropower dam but an officially-claimed ecological project to protect Poyang Lake from losing water to the Yangtze River.

Poyang Lake, the largest freshwater lake in China, is connected with the Yangtze River, and the Yangtze regularly supplements its water body. However, after TGP began to store water, the Yangtze had a lower water level, particularly during winter, which caused water to flow from Poyang Lake into the Yangtze. More seriously, after TGP began to intercept water and sediments, water in lower Yangtze became clearer, which flows much quicker than before, consistently cutting runaway and lowering Yangtze's riverbed. The massive quarrying in the Yangtze River further lowered its bed. The lower riverbed increased pressure on Poyang Lake to output water to the Yangtze. As a result, Poyang Lake has suffered severe droughts in recent years.

The Jiangxi provincial government in the late 2000s proposed setting up low dams to prevent Poyang Lake from losing water to the Yangtze. Initially, the low dam plan included some hydroelectricity capacity, but this was soon given up due to strong protests from environmental experts and groups. However, the reduced hydroelectricity capacity has not won support. Environmental activists worry that the dam will block the free migration of the finless porpoise, an endangered rare species which is a remote freshwater member of the dolphin family. Activists also claim that with the proposed dam to contain water in Poyang Lake, the water level in the wetland of the lake will be much higher, making it hard for aquatic birds to find food. 
Unlike ENGOs that actively conserved the $\mathrm{Nu}$ River and other southwestern rivers, environmental groups involved in Poyang Lake hydraulic facility were all new domestic organizations focused on animal protection (INT20161217). With its committed goal to conserve Yangtze River animals, WWF was also rather outspoken, rare for international NGOs in China, to protest Jiangxi provincial government's proposed move.

On the other hand, after abandoning the hydropower facility, the provincial government would not make more concessions. Insisting on the hydro junction project's necessity to save Poyang Lake ecology and solve the problem of insufficient drinking water, the local government forcibly advanced to lobby the NDRC to approve the project (INT20170109). Environmental groups and some experts rejected the government's solution, saying a set of integrated management measures, such as strengthening fishery management and forbidding excavation of sand, rather than a simple engineering solution, should be adopted. They noted that the Poyang Lake project might create a terrible precedent (solely relying on engineering methods to reach goals) to solve environmental woes.

In early 2021, the Jiangxi provincial government once again announced that the Poyang Lake project had been listed as a 2020-2022 national key water project, and it would soon be started (Diao, 2021). Once again, the decision was strongly protested by a group of experts organized by China Biodiversity Conservation and Green Development Foundation (CBCGDF), an ENGO with official background (CBCGDF, 2021).

The Poyang Lake controversy is unusual because it was not a developmentalism versus conservationism debate but a dispute between different solutions to an environmental problem. At the time that this book was drafted, the controversy was still in a deadlock. NDRC has not finally approved the project (but has agreed on the implementation feasibility study). MEP, which often sits together with ENGOs against hydropower companies, seemed to avoid expressing its attitude (INT20170111).

Separate from the Poyang Lake controversy, since late 2016, hydropower companies seem to have lost their momentum, and banks became reluctant to offer loans to hydropower companies to build new dams because of an oversupply of hydroelectricity.

Correspondingly, since late 2016, hydropower controversies have dramatically declined in the Chinese public sphere.

\subsubsection{Emerging anti-nuclear power campaigns}

\section{China's nuclear dream}

To examine China's nuclear controversy, one cannot separate the earlier history of atom bomb development and the contemporary civil use of nuclear power, as the A-bomb, together with the H-bomb and satellites, has been considered a matter of national pride - hence one of the deeply cherished 
national sociotechnical imaginaries (Jasanoff \& Kim, 2009) - both by State leaders and the ordinary public. For example, Deng Xiaoping stated in 1988 that "without the A-bomb, H-bomb and satellites successfully developed in the 1960s, China cannot be called an internationally influential power and enjoy its current international status" (X. Deng, 1988/1993a, p. 279).

In 1955, Mao Zedong decided to develop China's A-bomb. In 1959, with the split between China and the Soviet Union, Mao decisively resolved to create an A-bomb independently. A large number of scientists and engineers, many overseas trained, including former Cornell professor Guo Yonghuai (1909-68) and his Caltech (California Institute of Technology) Ph.D. cohort Qian Xuesen (1911-2009) who became the chief scientist for China's atom bomb and satellite programs, were recruited into the secret plan. Enormous resources were mobilized to support it (T. Jiang, 2013). Top Chinese institutions, particularly CAS and Tsinghua University, prioritized nuclear physics training and research. CAS Institute of Modern Physics, established in 1950, was later split out to become the China Institute of Atomic Energy (CIAE) under China National Nuclear Corporation (CNNC). It is essential to mention that CIAE has cultivated more than $60 \mathrm{CAS}$ or CAE academicians, the highest honored scientists in China.

In 1964 and 1967, an A-bomb and H-bomb were successfully exploded in the northwestern desert. It was immediately portrayed as the biggest ever scientific development in China, enabling "the Chinese people to stand up." Nuclear scientists became national heroes. For example, the sudden death of Guo, whose body was found to closely huddle his guards to protect the newly obtained H-bomb data contained between their bodies after an air crash, became a widespread patriotic story.

It was against this background that China decided to develop civil nuclear power in the mid-1970s. In 1974, domestic atomic power players, which later became CNNC, began to independently design Qinshan NPP in coastal province Zhejiang, which was put into operation in 1994. Meanwhile, in the 1980s, with its newly-adopted opening policy, China purchased French technologies to build Dayawan NPP near Guangdong Province's Shenzhen. Neighboring Hong Kong, Shenzhen has now become the most developed Chinese city and enjoys a reputation as China's high-tech capital. Dayawan began to generate electricity to the grid in 1994. Based on French technologies and the Dayawan plant, China General Nuclear Power Corporation (CGNPC, formerly called China Guangdong Nuclear Power Corporation), the second-largest nuclear power firm, was established in 1994. Unlike CNNC, which keeps some military nuclear functions, CGNPC is a complete civil atomic power operator, with its early engineers trained in France with expertise including public communication skills (INT20161023).

In 1994, China began to launch its second stage of moderate nuclear power development, introducing French, Canadian and Russian technologies to build eight reactors in Guangdong, Zhejiang and Jiangsu, all coastal and the richest Chinese provinces. It is worth noting that the second stage of Qinshan 
consisted of two locally-developed reactors based on the domestically renovated version of French technologies used in Dayawan.

In 2006, nuclear power marched to an accelerating development stage. The State Council, China's cabinet, released the Mid- and Long-term Development Plan for Nuclear Power (2005-2020), which positively announced nuclear power development. While enabling the ongoing construction of NPPs to spread across the country, including inland areas, the document began to brand atomic power as a symbol of independent innovation. Meanwhile, at this stage, China became the only country to simultaneously host all three major types of the so-called third-generation pressurized water reactor (PWR) technologies - French EPR (European Pressurized Reactor), the US AP1000, and Russia's VVER1000 (WWER in English: water-water energetic reactor). The Generation III reactor is the practically newest development of nuclear reactor designs with improved fuel technology, superior thermal efficiency, significantly enhanced safety systems (including passive atomic safety), and standardized procedures for reduced maintenance and capital costs.

China also began to construct its third-generation technology Hualong (HPR 1000) and developed a Chinese modified version of AP1000 CAP1400. After a period of controversies, which I will discuss later in this chapter, in the summer of 2018, both AP1000 and EPR reactors were put into commercial operation for the first time in the world in Guangdong Province's Taishan (EPR), Zhejiang Province's Sanmen (AP1000), and Shandong Province's Yangjiang (AP1000). In contrast, due to the combined factors of industrial decline, higher cost and local resistance, no EPR and AP1000 reactors were finished outside China, including in these technologies' home countries.

HPR 1000, mostly free of controversies, will soon be commercialized in the third and fourth reactors of Fuqing NPP in Fujian, a coastal province opposite Taiwan across the Taiwan Straits. China also began to export HPR1000 to Pakistan, Argentina and the UK, which the State media portrayed as a proud national technological development (X. Yan, 2015).

One key element of the above institutional arrangement and adjustment is to place the National Nuclear Safety Administration (NNSA) under SEPA/ MEP from the then Ministry of Nuclear Industry and State S\&T Commission in 1998, a crucial factor resulting in few organized anti-nuclear campaigns. The publicly announced reason for the arrangement was to improve nuclear safety by separating it from the nuclear industry and introducing third-party control (Z. Sun, 2013).

\section{Emerging anti-nuclear protest}

Despite its political support and the long-time nuclear power dream, nuclear power has not been free from controversies and local protests. However, the degree to which it has been hindered is far less than other controversial projects such as trash incineration or PX and much lighter than in the West. In 
1986, after the Chernobyl accident, more than 1 million residents in Hong Kong protested the neighboring Dayawan NPP. Deng Xiaoping decisively insisted on continuing the plant while urging the nascent nuclear power industry to increase public communication efforts. Correspondingly, CGNPC dispatched a group of experts to communicate with and appease Hong Kong residents and set up one of the earliest public relations (PR) departments in China.

On the Chinese mainland, the earliest protest took place in Rushan, a coastal city in Shandong Province, 20 years later, though the protest was not by "local" residents. Since the early 2000 s, Rushan has built many retirement properties to attract inland residents to spend their retirement life in the coastal city. The local government simultaneously invited the proposed Rushan NPP invested by CNNC to boost the economy. However, newly settled retirees became so upset about the incoming NPP neighboring them, and they launched a campaign against it. Unlike a regular local campaign, there was no street politics, partly because opponents were not local. But despite their fewer number, many of the active retirees have broad social and political connections (INT20161227). They set up a website and frequently used BBS to post anti-nuclear messages and mobilize "local" partners (INT20161011). Finally, the nuclear project was abandoned by CNNC without a formal announcement.

Zeng et al. (2015) interpreted the Rushan case as the nuclear power side's failure to deal with risk communication. However, sources from the atomic industry would not recognize it. They either thought the anti-nuclear activists succeeded in lobbying central policymakers or stressed that in the Mid- and Long-term Development Plan, the Rushan plant site was not finalized, so it should be understood as an active retreat by the industry (INT20161023, INT20161227). One source even reflected that he received an army veteran representing Rushan's original residents to complain that the Rushan site was abandoned, costing many local jobs (INT20161227). Although Chinese commercial media are zealous in reporting local protests, it is strikingly noticeable that the Rushan case was seldom reported, even though the 2000 s were their heyday.

Before Fukushima, the Rushan case was the only public protest against an NPP in China. The Fukushima accident in 2011, however, changed the situation. While in the West, the disaster's impact was primarily on public risk perception on nuclear power, in China, Fukushima began to motivate intellectuals' anti-nuclear mood, activate local resistance and protests, and mobilize actors to anti-nuclear activities, even though the mobilization effect was often temporary.

Soon after Fukushima, a book allegedly written by a former engineer of Fukushima Daiichi NPP before his cancer death caused by nuclear radiation became a bestseller in China (Hirai, 2011). The book depicted how the nuclear power industry, including Fukushima Daiichi, tried to profit by lowering safety investment and surveillance. It was prefaced by Jiang Xiaoyuan, a leading historian of science at Shanghai Jiaotong University and an intellectual leader against technologies including GMOs. Jiang's preface, appealing to people to give up co-existence with the demon of nuclear power which they had thought 
necessary, became a famous article among intellectuals, receiving nearly no resistance or refutation from the nuclear power industry.

As elsewhere globally, the Fukushima accident immediately forced China to suspend ongoing nuclear power construction, halt the further development of proposed power stations, including all inland NPPs, and perform a nationwide safety inspection. In spring 2012, the authorities loosened the restrictions, announcing the examination had resulted in much-improved safety measures. The government greenlights, however, were soon followed by a grassroots anti-nuclear campaign. One of the proposed inland NPPs, Pengze NPP invested by State Nuclear Power Technology Corporation (SNPTC), became the first target.

Pengze NPP was located in Pengze County of Jiangxi Province, along the lower Yangtze River. The local government enthusiastically embraced it as a project to solve Jiangxi's power shortage, boost the laggard local economy, and create jobs. But across the Yangtze River, Wangjiang county in Anhui Province began to mobilize against the nuclear project in 2012. The county government officials began to communicate with their Pengze counterparts, either directly or through its higher provincial government but received a cold response.

A dramatic scene arose in late 2012 when a resident of Wangjiang complained online that Wangjiang local government was powerless in failing to resist Pengze NPP. Noticing the message and stung by the slight humiliating wording, Wangjiang magistrate asked a subordinate to "accidentally" post a red-stamped document denouncing Pengze nuclear project issued by Wangjiang county government on Weibo, equivalent to Twitter. The red-stamped file has been claimed as a historically first publicized document from one local government to criticize another government openly. Its release immediately attracted media interest. Due to China's authoritarian political culture, incumbent local officials avoided meeting the media. Instead, four retired county leaders the former chairman of the county's CPPCC branch, a former county judge, the former deputy director of County People's Congress, and a former director of the bureau of water resources - were arranged to receive visiting media in the name of a newly established non-official organization Wangjiang Environmental Protection Association. The debut of the four retired officials - widely respected as the Wangjiang Four Seniors - became a dramatic plot due to imperial China's long tradition of local autocratic rule by renowned gentlemen (Fairbank \& Goldman, 2006). Across the second half of 2012, dozens of media outlets sent reporters to Wangjiang to report the event and Wangjiang's official anti-nuclear movement.

The retired "gentlemen" proved highly capable. The Four Seniors concentrated their investigation on procedural faults of the Pengze nuclear project. They claimed that the latter intentionally under-calculated the Wangjiang County site's population to meet the atomic safety rules (which requires that the population within an NPP's 10-kilometer radius must be below 100,000). They also argued that the nuclear operator neglected local seismological records (to 
meet geological safety requirements) and abused the required public opinion survey by offering surveyees high valuable gifts to bribe them. The Four Seniors' comprehensive media coverage attracted the attention of a top CAS scientist He Zuoxiu and his former doctoral student Wang Yinan, a senior research fellow at the government's leading think tank Development Research Center of the State Council. Wang later became China's leading anti-nuclear power activist.

He is a CAS academician and theoretical physicist who won his academic fame in his early years of atomic bomb research and his public fame as an antipseudoscience campaigner. Due to his comprehensive publications, he was also a doctoral advisor in the philosophy of science at Peking University. Together with Fang Zhouzi, he bitterly criticized anti-hydropower and anti-GMO activism and allied with established experts in these fields. Since the late 2000s, he has begun to doubt nuclear power to be economically feasible due to the high expected nuclear waste processing cost. However, his anti-nuclear voice was seldom reported by the media, even after Fukushima.

After visiting Wangjiang in July 2012, He and Wang submitted a policy petition to Premier Wen Jiabao, appealing for high levels of caution when planning inland nuclear power projects. Three months later, the newly released Mid- and Long-term Development Plan for Nuclear Power (2011-2020), signed by Premier Wen, suspended all inland nuclear power projects during the 12 th Five-Year Plan period (2011-2015). The coastal NPPs continued (Luo, 2014). The Wangjiang Four Seniors achieved a vital victory in their anti-nuclear power campaign.

Soon after the petition to Premier Wen, Wang began to emerge as a prominent public anti-nuclear power figure with series of commentary articles criticizing the energy published in China Economic Weekly, which is affiliated to the People's Daily, CCP's mouthpiece. Until May 2018, she published more than ten blockbuster articles questioning inland NPPs. These articles opposed the building of NPPs in the Bohai Sea (which is surrounded by metropolises like Beijing and Tianjin), reproached the manipulation by Westinghouse (the world's primary nuclear technology developer and supplier) of China's nuclear market, warned of nuclear regulatory loopholes and highlighted the potential risks of AP1000's fuel loading (the final step before an NPP's formal operation). They also admonished nuclear power technologies controlled by the United States after the US government's punitive measures to halt supplies to ZTE, the world's fourth and China's second-largest telecom equipment producer, in 2018. The actions were for ZTE's violation of the US sanction to sell equipment to North Korea and Iran. A source confirmed that most of Wang's articles were published in the media after her internal policy reports were viewed by top state leaders (INT20171221).

Although Wang has highlighted the series of what she claimed to be deadly shortfalls of nuclear power, she claimed she was not an anti-nuclear activist. Instead, she opposed the great leap forward of nuclear power and was particularly against inland NPPs. 
Despite the "reservation," Wang's articles were widely redistributed online, causing immense pressure on the nuclear power industry. After some impromptu reactions by individual, often anonymous atomic experts, the nuclear industry began to implement organized responses. In March 2016, five months after Wang published another article targeting inland NPPs (Y. Wang, 2015b), China Nuclear Energy Association (CNEA) published a paper authored by CNEA President Zhao Chengkun and three other senior nuclear experts (Chengkun Zhao, Zhou, Mao \& Wang, 2016). The article cautiously rejected Wang's ten questions and proposed inland NPP to be restarted during the 13th Five-Year Plan (2016-2020). The CNEA response started the momentum for the nuclear industry to address Wang's replies. The effort involved senior officials from the National Nuclear Safety Administration (NNSA), newly launched mobile media outlets in the nuclear power industry, State Administration of Science, Technology and Industry for National Defense (SASTIND) leaders, top academicians and several individual industry engineers. A face-to-face debate was also convened in 2015, involving Wang, a dissenting scientist whose specialism is computational physics, and a dozen nuclear industry experts and academicians. They did not reach any consensus, and no media outlet was involved.

Despite her articles being posted by many commercial Internet news portals, Wang's accusations and the counterarguments she received were limited to elite circles. A more extremist tone of grassroots public intellectual rose and absorbed professional knowledge raised in Wang's articles. In 2015, Wu Hui, a Maoist junior agricultural college teacher in Hunan Province, published online an article "Nuclear power will destroy China." On top of the high cost of nuclear decommissioning and nuclear waste processing, which was all mentioned by Wang, was added more "fresh" gunpowder - one of the central policy targets of the United States was to dump its nuclear waste to China. The conspiracy material proved to attract more attention than Wang's scholarly argumentation. According to $\mathrm{Wu}$, the article "Nuclear power will destroy China" grabbed five million visit overnights before it was censored from China's top visiting news portal Tencent.com (which, together with the most widely used social media platforms QQ and WeChat, belongs to the Internet giant Tencent Corp) (H. Wu, 2018).

The initial response of the nuclear power industry to Wu's article was claiming it as nonsense, but encouraged by the victory in attracting attention, $\mathrm{Wu}$ wrote and posted several anti-nuclear articles online (primarily in his blogs) and compiled a book focused on anti-nuclear energy solutions (in which he proposed to give up industrialization and return to an agricultural civilization). Still, no media outlets and news portals published his articles again, and no publisher accepted his book. He opted to print the book himself and sold it online, with minimal sales (INT20161127).

Although excluding any direct dialogue with $\mathrm{Wu}$, the nuclear industry was grasped by his title. Tang Bo, the NNSA department director for nuclear safety surveillance, notably wrote an article "How will nuclear power not 
destroy China," published in industrial media and widely distributed among the industry staff. The article examined points ranging from reasonable risk assessment to China's powerful nuclear safety management (B. Tang, 2017).

The elite debate on nuclear power seemed separate from local movements against NPP. In recent years, China witnessed two local street protests, though there were other non-street protesting campaigns like the one in Wangjiang. In July 2013, after Jiangmen residents in Guangdong Province learned that the city had won a bid to construct a billion-dollar nuclear fuel recycling facility in its affiliated Heshan city, they rushed to the streets, besieged the municipal government, and protested the facility jointly invested by CNNC and CGNPC. The three-day impromptu demonstration forced the municipal government to give up the project (C. Yang, 2013). There was no evidence that local protesters widely read anti-nuclear articles authored by Wang and others. Instead, an examination of public opinion revealed that many residents did not distinguish between the nuclear fuel recycling facility and an NPP (INT20170915). A similar street protest occurred in Jiangsu Province's Lianyungang against another proposed atomic fuel processing plant in 2016 (S. Han, 2016). During the demonstration, local protesters widely distributed and read Wu's abovementioned article "Nuclear power will destroy China" (INT20161011).

None of the two local street protest participants were found to belong to the small anti-nuclear elite network, which, in addition to $\mathrm{He}$, Wang, Wu and the dissenting computational physicist, also absorbed a limited number of new members, including retired nuclear engineers, a billionaire operating in an industry not connected to nuclear power who is also a CPPCC delegate, one hydropower engineer who launched a small NGO in central China, and a dozen of individual Maoism-prone environmentalists. Based on my three years' field observation, no established NGO was found to connect with the network in any form.

Despite the small numbers involved in anti-nuclear activism, its appeals, particularly Wang's internal policy petition submitted to top State leaders via various channels, which I will explore later, seemed to have resulted in effects to policy. In November 2016, the 13th Five-Year Plan of Power Industry was released by NDRC and NEA, without mentioning inland NPPs. In 2016 and 2017, no construction permits were issued to any new NPP. More strikingly, the two NPPs - Haiyang in Shandong Province and Sanmen in Zhejiang Province adopting AP1000 technology - postponed their fuel loading scheduled in July 2017, at a cost of tens of millions of yuan losses, according to industry sources. In January 2018, Wang was invited to participate in an internal policy meeting to discuss the prospect of nuclear power with a group of industry experts before top leaders in charge of energy.

However, in March 2018, the policy tone toward nuclear power suddenly became positive. NEA announced new construction permits could be issued to six to eight reactors. In April, a license to load fuels in the abovementioned two AP1000-equipped NPPs and Taishan NPP adopting French EPR 
technology were issued. In particular, the Taishan license was published in the presence of President Xi Jinping and visiting French President Emmanuel Macron. In June 2018, CNNC and Russian state nuclear company Rosatom agreed to build four VVER-1200 atomic reactors at the Tianwan Nuclear Plant in Lianyungang and Xudapu nuclear plant in Northeast China's Liaoning Province. The No. 3 and No. 4 reactors at the Xudapu plant will use Russian technology, and construction may start before reactors No. 1 and No. 2, which will use the AP1000 technology designed by Westinghouse (D. Chu, 2018). Most activists suspended their efforts to challenge the nuclear power sector when the policy advances delivered a clear signal of the resumed support for nuclear power development by China's top leadership.

On January 30 2021, CNNIC put the first reactor using HPR1000 technology into commercial operation. By then, with 49 reactors and 52 million kilowatts installed capacity, China was ranked the world's third-largest player in both nuclear power reactors in operation and installed generation capacity.

There are no data to show whether there is an evident attitude change from China's top state leaders. But considering the long-time suspension of inland nuclear power projects at the cost of atomic power investors' tens of millions of yuan in early-stage investment and the two-year freeze in issuing new reactor construction permits, the nuclear controversy in China indeed had its policy impact.

\subsubsection{GMO falls to disputes}

China began to plant GM tobacco in the 1980s even before the government knew the type of crops needed to be licensed. In 1997, the Chinese government approved Bt (Bacillus thuringiensis, an insect-killing bacterium) cotton's commercialization to fight the uncontrollable bollworm. Since then, China has only approved a type of anti-virus GM papaya. The other two types of approved GM crops in China - tomato and sweet peppers genetically engineered to lengthen their storage period - were abandoned because they were uneconomic in the market. In 2017, China planted 2.8 million hectares of GM cotton and papaya, accounting for $1 \%$ of the total global area of biotech crops (189.8 million hectares) and $0.29 \%$ of its 956-million-hectare whole arable land. Among the 10 top GM crop-planting countries, China was ranked 8th in 2017 in terms of the acreage used for such crops.

The early years of GM crop development in China were free from controversy. It was hailed as a significant national S\&T progress in the media. In 2001, the Chinese government enacted a set of State Council (China's cabinet) safety regulations on transgenic agricultural products, apparently to prepare China for the impact from the expected import surge of US agricultural products upon its imminent entry to the World Trade Organization (WTO) (INT20161118). The regulation was followed by two regulations of the Ministry of Agriculture (MOA): one on labeling GM foods sold in the Chinese market and another on the safety management of GM product imports, requiring all imported GM products to be certified by MOA. In 2002, the Ministry of Health (MOH) 
enacted Hygiene Regulation for GM foods, which also required such foods to be labelled.

Although Chinese scientists, the scientific community working on biotechnology, and the governmental agencies were unaware of their impact, the 2001 series of rules started the journey to alienate GM foods. Activists, headed by Greenpeace, rose to the GMO controversy stage.

The initial campaigns against GMOs in China were all launched and organized by Greenpeace. Greenpeace set up its East Asia office in Hong Kong in 1997. Soon after this, the organization launched its China operation by setting up an affiliated working office under the then National Forestry Administration (NFA) to help the agency manage natural reserves. However, it was its anti-GMO campaign that made Greenpeace quickly noted and established in mainland China. In 1999-2000, Greenpeace launched its first round of attack, spreading a report to claim that China's GM cotton had caused some ecological threats. Although Chinese scientists angrily rejected the claim, the claimed threat to biodiversity by GM crops caused little media and public attention (INT20161215).

In 2003, Greenpeace dramatically changed its anti-GMO campaigns to focus on GMO regulation's public accountability and transparency (INT20160926, INT20161122). The timing corresponded to China's SARS (severe acute respiratory syndrome) crisis. The SARS virus killed more than 800 infected patients. The Chinese government's initial cover-up of the intense situation (Tai \& Sun, 2007) ignited a nationwide call for government accountability and transparency. In 2003, Greenpeace supported a Shanghai consumer Zhu Yanling to sue Nestle for not labeling GMO ingredients in its baby rice products. The first genetic test offered by a German genetic test firm long linked to Greenpeace proved Zhu's claim. Still, the second test appointed by the court, using MOA's standards at an MOA-affiliated testing organization, did not identify any GMO ingredients from Nestle's samples. Zhu lost the lawsuit.

For many Chinese, the widely reported case was the first time they heard the term GMO. The labeling policy offered an excuse for the public's transparency call, though, at this time, the Chinese consumers accepting GM food outnumbered those rejecting it (J. Huang, Qiu, Bai \& Pray, 2006a). Meanwhile, Chinese scientists and policy advisors increased their efforts to lobby the government to commercialize GM rice. By mid-2004, GM rice was already on China's commercialization threshold (Jia, Jayaraman \& Louët, 2004).

A Greenpeace-supported investigative story published in the popular liberal newspaper Southern Weekend (SW) in December 2004 suddenly halted the commercialization process. The article claimed that scientists commercialized GM rice for their interests despite the uncertainties. The national GMO safety committee under MOA, which was responsible for offering experts' views on GMO commercialization and safety certificate, was full of rent-seeking biotech experts (Jianqiang Liu, 2004). The article was reposted thousands of times in emerging Internet sites and raised substantial public protests, effectively halted GM rice commercialization in China (INT20161118). 
The SW coverage unfolded the offensive against GMOs in China, still dominated by Greenpeace, supported by many scholars, mostly social science researchers including several leading STS professors and agricultural economists. In 2005, Greenpeace found farmers illegally planted the GM rice seed developed by Wuhan-based Huazhong Agricultural University (HZAU) in Hubei. Greenpeace exposed the scandal, causing another wave of critical media reporting.

In the mid-2000s, another organized anti-GMO campaign was formed in China. The campaign consisted of Maoist intellectuals, activists, some maverick scientists, and a Maoist website Nowhere (http://www.wyzx.com). They held that GMOs are a symbol of capitalism and the American imperialists' conspiracy to control China. Embracing Chairman Mao Zedong and opposing GMOs became the two high-profiled slogans to unite Maoists, according to its theorist Li Beifang (2016). Bo Xilai and many other princelings of the first generation of Chinese communist leaders supported the new Maoist movement and its anti-GMO stance.

However, to the delight of plant scientists, Premier Wen Jiabao publicly showed his support for GMOs in 2008. The Chinese government launched a gigantic funding program to support GM seeding research, among the country's 16 mega research projects (R. Stone, 2008). According to an ecology professor who had mildly questioned GMOs, the mega funding program silenced many scientists who had been conservative in GMO development to obtain funding. In 2009, the national GMO safety committee issued a biosafety certificate - the premise for commercialization - to two GM rice varieties developed by HZAU. The diploma to a GM corn variety was developed by scientists at the Chinese Academy of Agricultural Sciences (CAAS).

The excellent news to plant scientists soon proved to be their nightmare. The issuance of GM rice biosafety certificates raised a nationwide protest against GMOs and the policies to commercialize them. In a move rare in authoritarian China, more than 100 leading Chinese scholars, with CAS botanist Jiang Gaoming as the only scientist among them, submitted a protesting petition to NPC's annual plenary meeting in March 2010. As we will show later, the media massively criticized and questioned the policies to commercialize GM rice (though in reality, there is a long way between issuing biosafety certificates to GM rice varieties and commercializing them).

Since 2010, so-called GMO safety incidents have been repeatedly discovered, pushing the media to report. Although none of these events were identified by professional scientists and published in journals, MOA had to dispatch four inspection teams to investigate them, further kindling national panics. Around 2010, several professional anti-GMO activists completely independent from Greenpeace and mostly isolated from the Maoist campaigns debuted. Although some of them had a little scientific training, none of them studied modern biology. However, first using blogs and social media such as Weibo, these professional anti-GMO activists outvoiced scholars and scientists. They have provided endless resources, real or false, against GMOs' scientific claims and any government initiatives to support transgenic crops. 
Greenpeace did not go quiet. In 2012, Greenpeace exposed through the media a scandal of a Tufts University professor who unethically fed Chinese children with genetically modified golden rice without proper informed consent in a nutritional study. Once again, public anger and protest against GMOs were ignited.

Biotechnology scientists did not sit idle either. Since the 2004/2005 anti-GMO campaign by Greenpeace, these scientists began to promote scientific knowledge and the scientific consensus on the controversial technology. Many science writers now chose to popularize GMO topics, endorsing its safety and economic promises. In late 2013, 61 CAS and CAE academicians, the country's top scientific elites, submitted a petition to the State Council to support GMOs.

The pro-GMO momentum, however, was soon overwhelmed by the expanding anti-GMO front. In late 2013, Cui Yongyuan, a famous TV talk show anchor, joined the movement against GMOs. With his substantial public influence, penetrating language arts, status as a CPPCC delegate, and strong mobilization capacity through social media, Cui became a new center of China's anti-GMO campaign. The maverick scientists against GMOs quickly converged behind him. Supported by them, Cui made an investigative TV documentary to reflect the "real" situation of the American public's attitude to GMOs. Citing a group of US-based anti-GMO researchers, Cui smashed the United States' image as a GMO friendly country.

In 2016, Cui exited from pursuing anti-GMO as his central business. But his influence can still be felt. When I began to draft this chapter, any sporadic comments on GMOs by Cui on social media would create thousands of following words and supportive emojis.

Meanwhile, in 2015, China's propaganda department began to cool down media coverage of GMO issues. However, my interviews with several journalists and web editors indicated that none of their media outlets received an explicit ban against reporting GMO issues. Instead, the tone was to avoid sensationalizing GMO issues (INT20160919, INT20170725). Given the Chinese government's regular censorship and the ban on its disfavored news, the style to prevent sensationalizing itself indicated the central leadership's hesitant and obscure GMO attitudes.

In 2014, pro-GMO scientists tried to persuade Chinese leader Xi Jinping to show his supports for GMO technologies publicly. Xi inspected a leading local agribiotech company's R\&D center in Beijing (but did not speak out to support immediately commercializing GM food). With Xi's speech, plus the propaganda department's move to downplay media reporting of GMO controversy, the antiGMO media situation was reversed. Still, anti-GMO activists had largely shifted their battlefields to social media.

The 13th Five-Year S\&T Development Plan (2016-2020) revised the roadmap of agricultural biotechnology. The new plan prioritized commercializing non-staple food GM crops (GM corn and GM soya) while suspending GM rice's commercialization. However, up to the end of 2020, the third year of the Five-Year Plan, there has been no sign of commercialized GM corn. Although since 2016, few significant scandals/safety events about GMOs have 
been reported in the media, the public continued their disfavor of GM foods in several nationwide surveys (Cui \& Shoemaker, 2018; G. He et al., 2017; Ren, Gao \& Huang, 2016).

Summarizing the course of China's GMO controversy, several patterns are worth mentioning. As compared with other scientific disputes, GMO contention was the most sustained, and most widely engaging. Today, any social media conversation about GMOs will immediately attract ample attention and following comments.

Then, consistent with the trend, GMO debates were highly polarized. Both pro-GMO scientists and science communicators, and anti-GMO activists tried to attack the other side with extreme claims and often emotional expression. The increasing political polarization trend strengthened the sharp conflict.

Third, many intellectuals of different backgrounds are involved in anti-GMO campaigns, which have been highly diversified. But on the other hand, few civil society organizations, including nearly all local ENGOs, have not actively joined the debates on GMOs. Besides Greenpeace, the main actors are loosely connected Maoists (which I am reluctant to define as civil society groups), individual activists, and a small group promoting the idea of food sovereignty. Several organic food organizations (either in the form of NGOs or commercial companies) played a supplemental, though not inessential, role in the anti-GMO front. I will explore the implications of the organizational structure later in this chapter.

Finally, the media have shown an extraordinary enthusiasm to raise GMO issues. Even after the propaganda department's warning against sensationalizing GMOs, journalists have spared no effort to report GMO-related events. But social media has increasingly replaced traditional media to become the main arena for such debates.

\subsection{Other noted public disputes related to S\&T}

The controversies surrounding hydropower, nuclear power and GMOs are not isolated in China. Social contestations on trash incineration, PX (para-xylene) manufacturing facilities and other potentially polluted factories have spread across China. Unlike the global discourses about hydropower, nuclear power and GMO disputes, the public protests against these projects are more focused on local communities. They reflect typical features of local NIMBY (Not In My Backyard) activities.

Although local protests are not always about science and technology, they often question the authoritative explanation and official discourses about targeted projects' safety and potential risks. In other words, they are about the credibility of knowledge, a central concern of S\&T controversies. Thus, it is also necessary to briefly describe some of these local activities from the perspective of scientific debates. This section will explore these activities' socioeconomic situation to contribute to a general understanding of the social and economic changes underlying China's S\&T controversies. 


\subsubsection{Anti-incinerator movement}

The anti-incinerator movement in China represented a series of public protests against industrial waste incinerators. Up to 2018, 54 anti-incinerator public demonstrations had been reported nationwide (Johnson, Lora-Wainwright \& $\mathrm{Lu}, 2018$ ). The movement is generally treated as a typical local protest (Liang, Guo \& Wang, 2019). The anti-incinerator movement can be traced back to the 2006 Liulitun protest in Beijing's Haidian district. The Liulitun plant protest succeeded in indefinitely postponing the proposed incinerator. Its success encouraged many other protests against incinerator plants across China, with Guangzhou, Wujiang and Panguanying being the most widely reported, beginning around 2009 (Lang \& Xu, 2013).

In Guangzhou, inhabitants of the residential Panyu district began opposing plans to construct a municipal waste incinerator in their area. By the end of 2011, the Guangzhou city government canceled the project. In Pingwang, a town located outside Wujiang city in China's Jiangsu province, residents began opposing the construction of a nearby incinerator plant that was already nearing completion. Their collective actions, including a large street demonstration, resulted in the plant's construction being halted (Lang \& Xu, 2013). However, ten years later, a much larger (with six times the investment) waste incinerator facility was being constructed in Wujiang, expected to be completed by the end of 2021. No environmental protest was reported again (Mei, 2021).

In the same year, in Panguanying, a small rural village in China's Hebei province, villagers received assistance from environmental NGOs and urban activists from Beijing. With these professional supports, the local government suspended the proposed incinerator, although it hasn't made a final decision (Johnson et al., 2018). Although there seemed to be fewer street protests under Xi Jinxing's iron-hand rules, public contestations and demonstrations against waste incinerators can still be heard. The most recent one took place in Yangluo, a residential zone of Wuhan, the capital city of the central province of Hubei (Zhuang, 2019).

In each anti-incinerator protest, a variety of individuals were involved. In the 2006 Beijing Liulitun protest, participants were primarily made up of scholars and science or engineering professionals from nearby universities and high-tech firms in Haidian District. Protesters claimed that incinerator plants, especially those from earlier generations, produced various noxious byproducts containing dioxins (H. Hu, Li, Nguyen \& Kavan, 2015). During the Panyu protest in Guangzhou, residents of the newly developed district showed concern for their health and the proposed plant's potential environmental impact. Protesters were uniquely assisted by professionals residing in the area, many of whom were journalists and retired government bureaucrats (Steinhardt \& Wu, 2016).

Throughout the reported protests, local government and official environmental research organizations argued that burning trash would not produce enough toxins to threaten human health if appropriately operated. Indeed, most published scholarly papers supported the official tone. But protesters 
cited research on excessive pollution emission from Chinese incinerators and claimed that dereliction was widespread in China and it is hardly possible to ensure incinerators' proper operation. Another more persuasive evidence is the different composition of China's living wastes from those of the West. They said that the high percentage of kitchen waste in China resulted in increased water content, making the burning more readily produce dioxin.

Various ENGOs have gotten involved and supported protesters, including the Beijing-based Nature University, Friends of Nature, and the Guangzhou-based Eco Canton (Steinhardt \& Wu, 2016). These anti-incinerator protests used online discussion and mobilization, conducted public demonstrations and utilized media attention. Most of these tactics involved using China's emerging commercial media (Y. Chen, 2010) and Internet platforms ranging from the earlier BBS and blogs to Weibo and later WeChat (R. Huang \& Sun, 2015).

Protesters widely utilized the Internet to criticize the incinerator plants and mobilize protests against them. However, the online mobilization led thousands of residents to the streets in many reported anti-incinerator cases. Some protesters also sought prominent environmental lawyers, who connected them with various environmental activist groups.

By contrast, the supporters for the trash incinerator project seemed to lack a united strategy. In most cases, the parties most responsible for advancing the incinerator projects were the local government and their urban development subordinates. Although there were external investors, they seemed highly reliant on local government to solve the conflicts. Although local governments generally ordered the media affiliated with them to avoid reporting the public protests, media from other geographical jurisdictions were often involved. The booming Internet-based online communication channels such as Weibo, WeChat and various We Media accounts played active roles.

\subsubsection{Social protests against PX plants}

Like the anti-incinerator movement, public protest opposing the para-xylene (PX) project in China was also a typical local activity. Since 2007, protests have occurred in Xiamen, Dalian, Ningbo, Kunming and Maoming, where PX plants were being planned.

Para-xylene is a common chemical used to produce terephthalic acid, which is used to manufacture polyester. The chemical has low toxicity, and there are very few reports worldwide of environmental harm from PX plants. Despite this, PX has become a common target for public protest in China since December 2007 when Xiamen's government suspended the construction of a PX factory with a planned investment of billions of yuan. Since then, PX projects have been halted in Dalian, Ningbo and Kunming due to public discontent.

As in anti-incinerator movements, the anti-PX plant's initial success in Xiamen also planted a seed of open public protests. In fact, except in antiincinerator and anti-PX movements, few other social contestations in China have gathered so many participants and such high attention. 
Like in the Beijing Liulitun protest, the Xiamen PX protesters were led by scholars at Xiamen University. Protesters were headed by an environmental chemist at Xiamen University, significantly improving the anti-PX movement's credibility. Although the anti-PX side did not demonstrate enough scientific credibility as the protests advanced, the initial credibility increased the anti-PX activities' legitimacy.

Following the Xiamen incident, a series of protests against PX projects in China broke out in Kunming (Chang, 2013), Shifang, Ningbo, Dalian and Maoming between 2010 and 2014. The Maoming protest was the most severe. After several open public protests, the local government in Maoming seemed well aware that the PX proposal could be controversial. A month before the latest protest began, it launched an extensive public education campaign on chemical and PX safety. According to local media, petrochemical workers, family members and public school students were required to sign a letter of support for the PX project. The forced petition triggered public protests as it was seen as a sign that the PX plant had received the go-ahead. In late March 2014, thousands of residents in Maoming, Guangdong Province - a city with a thriving petrochemical industry - took to the streets and burned cars in protest at a proposed PX plant. After the demonstration, the Maoming government announced that the 3.5-billion-yuan PX project was not finalized and maintained that it was safe and essential for the local economy.

In short, earlier anti-PX protests spawned subsequent ones, underpinning a movement continuity against the PX project in China. Despite censorship, commercial media has played an essential role in legitimatizing citizens' activities and facilitating the Internet (Chin-Fu, 2013; J. Liu, 2016). Specifically, the online debate regarding PX's toxicity, a phenomenon unheard of in anti-incinerator activities, has become a hallmark of the PX contestation.

Amid the Chinese public's increasingly fierce resistance to chemical plant construction, young chemists are coming to the industry's defense. The street protests in Maoming were accompanied by an online campaign that saw environmentalists change the entry on PX's toxicity in Baidu Baike, the Chinese equivalent of Wikipedia, from "low" to "highly toxic." However, on April 2, while millions of people were still posting supportive tweets for the collective action in Maoming, a group of chemical engineering students at the prestigious Tsinghua University corrected the PX entry. The effort led to a running battle over the Baike entry until a Baidu Baike employee finalized the PX entry as "low toxicity."

While agreeing that PX is not particularly toxic, a professor of fine chemicals at a southeastern university said the movement to defend PX has gone to the other extreme (INT20160309). "It might be true that per some indicators, PX is no more toxic than alcohol. But you cannot drink PX even though you can drink alcoholic beverages," said the interviewee, arguing that PX's low toxicity is touted to support the political goal of clamping down on dissidents. He said that a better way to convince the public of PX plants' safety is to let chemical industry leaders live next to their factories. 
Another expert said that what the public opposed was not the science or the chemical itself but how plants are built and managed (INT20161128). He cited an explosion in the only PX plant built in recent years - the plant in Gulei Peninsula that was initially earmarked for Xiamen - as evidence that poor management was what people fear.

\subsubsection{Debating the sources for PM2.5}

In addition to anti-incinerator and anti-PX movements, there is public contestation on the sources for PM2.5, the primary polluting particle contributing to the thick haze in northern China in the winter. Also known as ultrafine particulates, PM2.5 consists of solids and liquids. Its sources include black carbon from incomplete combustion as well as sulfates and nitrates. Levels of such ultrafine particles surpassed $500 \mu \mathrm{g}$ per cubic meter of air in both recent incidents in China (Jia \& Wang, 2017).

Although it is generally agreed that PM2.5 was a primary culprit for the thick haze, where it mainly came from was a focal point for debate. On certain occasions, the discussion also evolved into a public science controversy.

On December 26 2013, the Institute of Atmospheric Physics (IAP) under the Chinese Academy of Sciences (CAS) posted on its website the news release of a study published in July 2013 in the top journal Atmospheric Chemistry \& Physics (ACP) (R. Zhang et al., 2013). The study, with lead author Renjian Zhang from IAP and participating authors from different Chinese and overseas institutions, claimed six primary sources for PM2.5 had been identified, ranging from traffic and waste incineration emission (3\%), biomass burning $(13 \%)$, coal combustion $(14 \%)$, soil dust $(16 \%)$ and secondary inorganic aerosol $(26 \%)$ to industrial pollution $(28 \%)$.

When local media like the Beijing Times published the Xinhua wire news on December 31, they highlighted less than 4\% of traffic emissions' contribution to PM2.5. The story immediately aroused widespread public protests in social media and online forums against the Chinese capital city's strict car control policy (Jia, 2014b).

The basis for interpretative flexibility - meaning scientists employ discretion as they decide what counts as reliable scientific facts and claims (Collins, 1981) existed in the study. The data provided by R. Zhang et al. (2013) implied that traffic emission's actual contribution to PM2.5 could be much larger than the claimed less than 4\%. However, current technologies cannot accurately identify the origins of the so-called secondary inorganic aerosol that was formed through complicated chemical reactions between primary polluting emissions.

Orthodox scientists harshly rejected Zhang et al. (2013). Beijing Municipal Environmental Protection Bureau and CAS administration organized two separate urgent news conferences on January 2 to refute this study's conclusions. Meanwhile, the news release of the study was withdrawn from CAS and IAP websites. However, the tones of the official news conferences were very mild. Spokespeople at the two news conferences admitted the uncertainty of 
determining traffic emissions' contribution to atmospheric PM2.5, but highlighted Zhang et al.'s sampling location, the types of instruments, inaccurate calibration and unaccepted range of variance. Both individual scientists' initial rejection of R. Zhang et al. (2013) as having excessive uncertainty and CAS news conference's effort to accept the study per se but reject its inappropriate uncertainty range represented an endeavor to maintain mainstream scientists' epistemic privilege.

In the science controversy regarding the sources of PM2.5, the science-media relationship has institutionally corroborated science's image of credibility and suppressed the public visibility of interpretative flexibility. Metropolitan media journalists did not have the interest and capacity to deeply explore the scientific uncertainty involved in the PM2.5 source apportionment controversy. While professional science journalists accessed and managed uncertainty to increase their stories' dramatic effect, they eventually bent to orthodoxy conclusions.

In mid-2014, Beijing environmental protection bureau officially released "authoritative" data - car emission contributed to 31\% of Beijing's PM2.5. The controversy initiated by the ACP paper seemed to close quickly. However, disputes on the composition of China's atmospheric pollutants continued. Based on the contrast between dramatically reduced PM2.5 concentration due to China's clean air moves and the remaining haze in the northern part of the country, several environmental groups, such as International Fund for China's Environment, continued questioning the definitive conclusion on the pollutant composition. However, these debates have seldom drawn the media's attention.

\subsection{General observation of S\&T controversies in China}

In addition to the abovementioned cases, there were other public controversies related to S\&T. The most notable was the series of debates on the efficacy of traditional Chinese medicine (TCM) (Q. Zhu \& Horst, 2019). The discussion can be traced back to the early 20th century when China ended the Qing Dynasty. Occasionally, internal debates within the science community, such as whether China should host the next generation supercollider (Jia, 2016b), can also become a public science controversy after the media reported the debate.

Another controversy was about the increased public concerns about their health and food safety and their decreased trust in experts, particularly in these areas. Periodically, there was media reporting or popular social media posting of potential food or medical risks, which reflected public disbelief of experts' assurance of existing practice safety, such as iodized salt or fluoridated toothpaste.

But the pattern was different from the West. In the West, heterodox experts professionally raised evidence questioning the orthodox practice. For example, Andrew Wakefield's (1998) controversial The Lancet paper (retracted in 2010) claimed a link between MMR vaccine (vaccine against measles, mumps and rubella) and autism (Flaherty, 2011). In China, the public effort to 
question mainstream health and food practice often lacked professional support. Experts reportedly expressing suspicion of the established practice repeatedly denied their reported claims, accusing the media of misinterpretation. As a result, individual public controversies regarding food safety and existing medical practice were often short-lived.

So far, we have described typical S\&T controversies in China in the past half-century. During the period, China underwent a dramatic transition. Its social, economic, political and media system all experienced tremendous change. It is against this background that the S\&T controversies we examined above occurred. They include long-lasting hydropower disputes, widespread GMO resistance, elitist debate on nuclear power, local community-based anti-incinerator and anti-PX movements, and public suspicion of the official interpretation of the atmospheric pollutants. It is necessary to reveal their general patterns. Although examining the mechanism underlying these controversies is the task of the whole book, for the moment, I attempt to summarize these patterns and the sociopolitical environment nurturing the evolution of these controversies. In a sense, the current section is not theoretically driven. Instead, the observation can be considered raw stuff sorted out for theoretical development in the subsequent chapters.

The first observation here is despite China's authoritative rule and S\&T's crucial importance in China's official ideology, S\&T controversies have thrived, particularly after the opening-up in the 1980s. But even before the opening-up, the big debate on GDP under the encouragement of Mao Zedong indicated that even Mao's totalitarian regime could tolerate some S\&T controversies for a specific purpose.

Second, S\&T controversies seemed a product of social diversification, which was speeded up after Deng's opening-up policy. The 1950s' debate on TGP was a highly controlled process. If the public's involvement is necessary to define a science controversy, the 1950s' TGP debate could hardly own such a name. Even the 1980s' TGP debate was highly elitist (H. L. Miller, 1996). But as the Chinese society became increasingly diversified, S\&T controversies concentratedly appeared in China.

Media reform and commercialization played an essential role in promoting S\&T controversies. As I will demonstrate in the following chapters, China's S\&T controversies cannot receive public attention or become public events without media involvement. The role the Chinese media has played is strategic. The liberalizing and market-oriented media reform (L. L. Chu, 1994) pushed many media to snatch public attention. Reporting controversies was an ideal option. On the other hand, Chinese journalists, such as Green Earth's Wang Yongchen, became the first generation of activists. They have played an enormous networking role in mobilizing experts' voices against the establishment. The greater tolerance that the Chinese media enjoyed in the 1990s and 2000s also drove the media's increasing reporting of controversial issues. 
Under Xi Jinxing's reign, the CCP leadership strengthened the media control, and the media industry suffered significant impacts from social media so that their support for investigative journalism dramatically decreased. Social media, including their earlier formats such as BBS and blogs, became increasingly critical in fueling S\&T controversies in China. As demonstrated in multiple cases, Weibo and WeChat have become the tool to convene public opinion against the mainstream scientific conclusions and mobilize collective actions (R. Huang \& Yip, 2012; J. Liu, 2016; Wen, Hao \& Han, 2016). The rising public accounts on the WeChat platform replaced traditional media to present public contestation against official conclusions.

Accompanying the rising public disputes of definitive S\&T conclusions is the falling public trust in scientific experts. Science continues to enjoy the most trustable status, and scientists are the most trusted professions in China (Xiang, Chu \& Jin, 2015). However, scientific experts were bitterly criticized for reportedly distorting science for official purposes in each of the disputed cases. In some cases, such as the GMO dispute, biotechnology scientists were demonized as a malicious vested interest group. In still other cases, scientists were thought to be ignorant of the real situation, such as industry malpractice, such as during the debates on waste incinerators and PX plants.

When faced with controversial scientific issues, most scientists in China keep silent, while China's industrial associations and academic societies often dodge their responsibility to timely inform, educate and listen to the public. As a result, the public has become increasingly wary of S\&T projects in China.

Finally, in some cases, political fragmentation in the Chinese regime seems to have played a role in certain controversies such as hydropower and nuclear power. There will be theoretical discussions on this aspect across our case studies in the following chapters. Right now, I am satisfied with pointing out this as an observable phenomenon.

While the above patterns can be identified in nearly all S\&T controversies in contemporary China, some disputes had a quick closure and did not last long. But others are widespread, long-lasting, and consistently showed certain aspects that are worth a theoretical examination. Hydropower controversy, nuclear power dispute, and public resistance to GMOs are the most typical ones. Now let's move to these cases for more in-depth investigation. 


\section{Hydropower, fragmentation and knowledge-making}

\subsection{Introduction}

Chinese civilization is closely linked to hydraulic engineering projects, whose centralized disposal of labor and resources led Wittfogel (1957) to raise the concept of Oriental Despotism. Disputes regarding water utilization, however, have never ceased, even after the People's Republic founded in 1949 effectively silenced most intellectuals.

From the 1980s, when China began to adopt the opening-up policy, hydropower controversies ranging from the debate on the gigantic Three Georges Project (TGP) to the protest against dams in the Nu River (Salween River in Southeast Asia) once again topped the public agenda. Hydropower also became one of the few issues that China's emerging ENGOs joined their hands to reject (T.-c. Lin, 2007) despite the country's record speed in building dams. According to the International Commission on Large Dams, by the end of 2013, China had built 38,000 big dams (higher than 15 meters), accounting for $55.9 \%$ of the world's total (China Energy News, 2015).

Why has the hydropower controversy evolved into such a central issue in the Chinese environmental movement and how is it different from other disputes GMOs and nuclear power - investigated in this book? This chapter traces the development of the hydropower controversy in China in the past 40 years, and then examines the dispute in the landscapes of contemporary media transitions, social movement theories and several STS concepts.

\subsection{1 "Thick" dikes and dams}

Because of the universal importance of water, it is natural that hydraulic projects across the world are designed, developed and implemented according to their specific historical, cultural and political tradition. Bijker (2007) used "dikes and dams, thick with politics" to describe how the difference between the Netherlands' dike and storm surge barriers and the coastal levees in the United States was a result of their different political traditions in dealing with risks. Meanwhile, these coastal engineering projects also shaped political and cultural practices of their hosting countries. For this reason, France developed

DOI: $10.4324 / 9781003160212-4$ 
hydropower capacities in its North African colonies in the 19th and early 20th centuries to demonstrate its technological progress and to realize imperial control (Pritchard, 2012) and tamed the Rhône River to recover its national pride after the Second World War (Pritchard, 2011).

China's massive hydropower development and its social and political implications have not escaped scholarly attention (Rogers \& Crow-Miller, 2017). Using the concept of developmentalism and authoritarian control, scholars have examined the modernistic efforts behind the grand ambitions to build TGP (Lee, 2013a, 2014) and the gigantic South-North Water Transfer Project (SNWTP) to transfer water from southern China to the arid north 1000 miles away (Rogers, Barnett, Webber, Finlayson \& Wang, 2016; Webber, Crow-Miller \& Rogers, 2017). According to Lee (2013a), Deng Xiaoping's desperate endeavor to build the TGP despite massive opposition was to use the discourse of developmentalism to justify his leadership as well as his orthodox inheritance from Chairman Mao. The dam also asserted the power of the central state by, for example, unifying power grids in China, replacing a system that was focused on individual or small groups of provinces with a national network of electricity production and distribution (Webber, 2012).

Launched while TGP was being constructed, China's SNWTP was supposed to solve environmental problems. But by prioritizing an engineering solution, the SNWTP showed the common policymaking logic: Authoritarians can accommodate growing public concern for the environment without fundamentally altering existing structures of power (S. M. Moore, 2014; Webber et al., 2017). In fact, besides TGP and SNWTP, all major dam constructions and their corresponding relocation of impacted residents reflect China's state-making efforts, which entails an essential faith in the power of human knowledge systems including science, technology and policy - to achieve better and better futures (Tilt, 2014).

The rich body of literature introduced above highlights the crucial importance of water projects, their symbolic meanings, and the hydraulic technologies deeply embedded in specific sociopolitical contexts. Then it is natural to assume that hydropower controversies are not just about protests against these facilities. Instead, they can reflect resistance to the social meanings embodied by these water projects.

\subsubsection{Social movements against hydropower}

Given the crucial importance of water utilization to society, anti-dam movements have been intensively studied globally. The focal location for the research is in the global south where transnational anti-dam movements were booming in the 1990s (Khagram, 2004). The social movements against dams are considered as civilians' collective actions against capitalist greed. These movements are underreported and underrepresented by local media (Da Silva \& Rothman, 2011), however they have received the aid of international organizations which have formed transnational activism networks, providing 
funding, international media attention, professional knowledge and organizational experience to local activists (Khagram, 2004; Lee, 2013b; McCormick, 2010).

In China, H. L. Miller (1996) found that the Party's call for scientific policymaking as an effort to correct Chairman Mao's capricious policy-making in the 1980s empowered senior scientists to openly express their concerns about TGP through improved institutions for elites' political participation, such as the Chinese People's Political Consultative Conference (CPPCC, China's Upper House). Interestingly, a Chinese STS journal, Journal of Dialectics of Nature, became the main platform to convene reformist scientists and their voices questioning TGP, reflecting Chinese STS scholars' tradition of active participation in social activism.

A decade after the TGP debates, China's ENGOs flourishing in the 2000s became the main actors in the subsequent hydropower controversy. Studies have examined the role of ENGOs as policy entrepreneurs, who have expanded China's hydropower policymaking structure, enabled more voices and interests to be heard (H. Han, 2013), and raised political concern for the social problems of forced migration and the public distrust of the business alliance between power companies and local governments (Vermeer, 2011). This type of coalition is particularly evident in the $\mathrm{Nu}$ River controversy erupting in late 2003 and lasting until now. ENGOs and allied scholars successfully blocked the grandiose State plan to build 13 dams in the upper $\mathrm{Nu}$ River.

They have mobilized institutional resources. In addition to the abovementioned international activism whose aid became possible after China opened its door for international NGOs to set up local offices (Lee, 2013b), ENGOs' capacity to facilitate the enaction of new environmental laws - particularly the rules on environmental impact assessment (EIA) and public participation in the process - and to mobilize open public debates have been discussed in the scholarly literature (Magee \& McDonald, 2006; Teets, 2014). In a more recent study, an essential yet hidden factor for ENGOs to be able to play their policy entrepreneurship role - the utilization of their supervisory agency - has been noticed (Teets, 2018). To increase its control of civil society, the Chinese government requires that an NGO must have both a governing government body (usually the Ministry of Civil Affairs and its local branches) with which it is registered and a sponsoring agency, which must be either a government agency or a public research organization. The design of the dual registration was aimed at better supervising NGOs, but as Teets noticed, some sponsors became the channels for NGOs to deliver their policy suggestions to top policymakers.

As mentioned in Chapter 1, other scholars adopted the fragmented authoritarianism (FA) framework to examine why some of China's antihydropower movements were successful while others were clamped down (Mertha, 2008). While Mertha has correctly pointed out the importance of bureaucratic fragmentation and the involvement of various public actors such as intellectuals and the media in leading to the successful opposition to Yangliuhu Water Facility near Dujiangyan, a UNESCO (United Nations 
Educational, Scientific and Cultural Organization) World Heritage site, the FA framework relies too much on the structural differences of agencies and their leniency to activism, without further exploring other factors, such as the channel to top policymakers (Teets, 2018) and the role of scientific knowledge and scientists (Hansen, 2017b).

\subsubsection{Knowledge-control regime and hydropower controversy}

Tracing the debate on the relationship between the Zipingpu Dam in Sichuan Province and the Wenchuan Earthquake in 2008, Danish STS scholar Hansen (2017b) argued that the FA framework is too rigid to account for scientists' different positions within the bureaucracy. He hence proposed including an epistemic community (seismologists in this case) as the fourth category of policy entrepreneurs, thus adding to the three types already included by Mertha in his FA framework 2.0, which includes bureaucrats, activists and journalists (Mertha, 2009).

While Hansen correctly proposed combining FA and STS, the lack of a detailed analysis of social movement elements in his studies has resulted in a limited understanding. Elsewhere, STS scholar McCormick (2007a) used the Habermasian concept of scientization of social order and the corresponding scientization contest movements to describe Brazilian anti-dam campaigns. She considered the latter as an effort to democratize science, which is the process through which lay understandings are taken into account when scientific knowledge production is used to make political decisions.

In another study applying the Habermasian concept of communicative action, McCormick (2006, 2007b) argued that the Brazilian hydropower governance regime is highly capitalistically driven, as evidenced by the fact that hydraulic information is organized to facilitate hydroelectricity development, without considering the indigenous knowledge of the rivers and the social, cultural or much of the ecological impacts of hydropower projects.

But McCormick failed to examine knowledge as a social mobilization resource and did not consider the institutional roles of actors. For example, why have the sympathetic experts collaborated with local activists? How can their alternative knowledge be accepted by the public and policymakers so that it can work as a weapon against hydropower developers? We need to address all these questions in a synthetic approach combining science communication, social movement theories and the knowledge-control regimes concept which I proposed in the introductory chapter.

\subsection{Contemporary hydropower controversies in China}

As shown in Chapter 3, modern China's hydropower controversies started with decades-long debates on the feasibility of TGP. After the disastrous Cultural Revolution, a controversy surrounding TGP broke out again in the 1980s. Eventually, TGP supporters won the debate. But after some years' 
dormancy, hydropower controversy revived in the early 2000s and became the focus of China's emerging environmentalism. Chapter 3 described typical debates surrounding hydropower controversy in the past 20 years, ranging from public resistance to a dam threatening a World Heritage Site to ENGO's joint rejection of dams in cultural and natural conservation zones. Geological stability, natural beauty, ethnic minority groups' pristine living style and biodiversity preservation became excuses for rejecting dam building. The anti-hydropower movement also spread to eastern China's Poyang Lake water adjustment.

One of the major causes for the anti-dam campaigns in southwestern China is hydropower facilities' impact on biodiversity which is mainly embodied as fish and other aquatic species in the Chinese public sphere. The plan to build Xiaonanhai (literally Small South China Sea) hydropower station, located in the jurisdiction of Chongqing, ignited another public debate in the mid-2000s, shortly after controversies surrounding the $\mathrm{Nu}$ River and dams near Tiger Leaping Gorge began to fade away. The debate was about whether the Xiaonanhai dam destroys the Yangtze upper river fish conservation zone. The debate lasted about ten years, ending in MEP's final rejection of Xiaonanhai's EIA. By providing scientific opinions and organizing a scientific field study, a group of senior hydrobiological scientists and international organizations such as World Wildlife Fund (WWF) sat with ENGOs to protest or resist Chongqing municipal government's dam-building plan.

Besides aquatic biological conservation, anti-dam activists and experts also challenged hydropower development by linking earthquake triggering to dam building. The contention was escalated in 2008 when the 8.0-magnitude Wenchuan Earthquake in 2008 that killed 80,000 persons induced a debate on whether Zipingpu Dam, just 500 meters from the seismic fault and 5.5 kilometers from the quake's epicenter, triggered the disastrous earthquake (Hansen, 2017b). After Science Magazine reported on the claim of the possible link between Zipingpu and Wenchuan earthquake (Klose, 2008) and the corresponding modeling studies (Kerr \& Stone, 2009; R. Stone, 2009), the debate spread across international seismological and geological communities (Y. Chen, 2009; Gahalaut \& Gahalaut, 2010; Ge et al., 2009; Jackson, 2012; Klose, 2012, 2013; X. Lei, 2011; X. Lei et al., 2008), though most of the discussions were censored in the Chinese media. Activists, such as Fan Xiao, former chief engineer at the Sichuan Geology and Mineral Bureau in Chengdu, actively participated in the debate (X. Fan, 2009) (INT20161222).

With southwestern dam building slowing down, minor eastern and northwestern water projects also became centers of contention, such as the Hydro Junction Project in Poyang Lake in the eastern province of Jiangxi, which, as China's largest freshwater lake on the lower Yangtze River, experienced severe impact after TGP reportedly reduced Yangtze River water flow. The hydro junction project which aimed to stop Poyang Lake from losing water to the Yangtze received strong resistance from the new generation of ENGOs (not the ones active in southwestern hydropower controversy) focused until then 
on animal protection. A sharp difference from the previous southwestern anti-dam movement is that the Poyang Lake project is not a commercial one but aims at conserving local ecology. Therefore, what activists resisted is an ecological engineering solution (INT20161217, INT20170111).

These various hydropower controversies have witnessed collective involvement of China's emerging ENGOs and consistent media highlights, which, often occurring after an ENGO convened dissenting experts, have formed intense public pressure, suspending most targeted controversial projects. Comparing what looked like an easy mobilization of dissenting experts, hydropower companies adopted a passive strategy. Zhang Boting, vice-secretary general of the Beijing-based China Society for Hydropower Engineering (CSHE), became the only public spokesperson for the industry. In front of Zhang is a large, divergent, yet loose, group of "environmentalists," including ENGOs, with tiny involvement of local communities impacted by dams (Tilt, 2014). The collective action, experts' participation, adoption of counter-knowledge, media involvement and relatively high success rate are the subject of the theoretical discussions in the following sections.

\subsection{Communication patterns of hydropower controversy}

\subsubsection{Examining the media's role in hydropower controversies}

Except for the TGP controversy in the 1980s when the Chinese media were not accustomed to critical reporting (but Chinese journalists began to attempt it, as analyzed below), most controversies regarding hydropower development in southwestern, northwestern and eastern China started with the media's critical reporting of planned dams. The media's critical environmental coverage was encouraged by editors and central government leaders as a way for them to supervise environmentally illegal moves by local governments, according to one senior journalist of an official newspaper (INT20170830). Compared with the official media, market-driven liberal presses devoted more energy to produce investigative stories. "We thought at that time that supervising these hydropower projects is a right way to safeguard public interests," said a senior journalist at one of China's most influential liberal newspapers (INT20161022).

Media content analysis supported the claims of journalist interviewees. As shown in Figure 4.1, across the four sampled media outlets, hydropower coverage was event-driven, with 2003, the birth year of southwestern hydropower controversy, experiencing a record high number of media articles. The Yangtze River interception at TGP in 2003 also resulted in a much higher number of media stories on hydropower than in other years. The 2006 and 2009 environmental regulation storms (when SEPA/MEP intensified EIA implementation) and the 2008 Wenchuan Earthquake all created more media coverage of hydropower. After 2012, with both declining new dam building and controversial projects, media coverage of hydropower declined with the 
72 Hydropower, fragmentation, knowledge-making

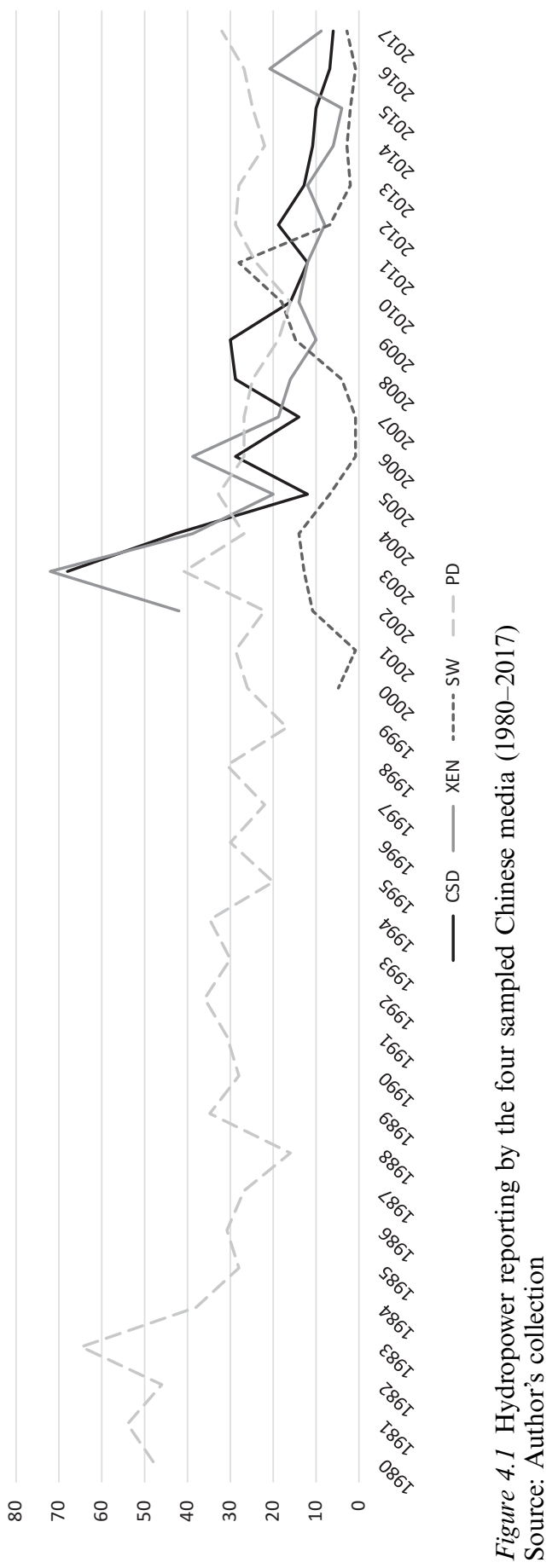


exception of PD, which began to report more international hydropower projects constructed by Chinese companies often with loans from the Chinese government.

Between 2000 and 2017, Southern Weekend (SW) published 136 stories and comments primarily about hydropower projects. One hundred articles, or $81 \%$ of them, negatively or critically reported hydropower development and its impacts on relocated residents.

Table 4.1 to Table 4.3 summarize the main themes of the sampled media's hydropower stories and their attitude to hydropower developments. While SW is famous for its critical investigative reporting, Xinmin Evening News (XEN), an urban tabloid usually reluctant to report negative news, also regularly dedicated negative stories to hydropower, particularly in 2003 when the Yangliuhu and $\mathrm{Nu}$ River controversies were hot social issues. As mentioned above, PD, the CCP mouthpiece dominantly serving the Party's propaganda, did not hesitate to negatively frame the first dam building drives, especially between 2003 and 2007, the years witnessing escalated debates on southwestern hydroelectricity projects.

Table 4.1 SW's hydropower articles between 2000 and 2017 and their attitudes

\begin{tabular}{lclccc}
\hline Year & $\begin{array}{c}\text { Total hydro- } \\
\text { power articles }\end{array}$ & Positive tone & Neutral & Negative & $\begin{array}{c}\text { Articles with visi- } \\
\text { ble controversies }\end{array}$ \\
\hline 2000 & 5 & 1 & 4 & 0 & 4 \\
2001 & 1 & 0 & 0 & 1 & 1 \\
2002 & 11 & 0 & 9 & 2 & 11 \\
2003 & 13 & 0 & 5 & 8 & 12 \\
2004 & 14 & 0 & 7 & 7 & 14 \\
2005 & 7 & 0 & 0 & 7 & 7 \\
2006 & 1 & 0 & 1 & 0 & 1 \\
2007 & 1 & 0 & 0 & 1 & 1 \\
2008 & 4 & 0 & 1 & 3 & 3 \\
2009 & 15 & 0 & 4 & 11 & 14 \\
2010 & 18 & 2 & 10 & 6 & 18 \\
2011 & 28 & 2 & 7 & 19 & 27 \\
2012 & 7 & 0 & 0 & 7 & 7 \\
2013 & 2 & 0 & 0 & 2 & 2 \\
2014 & 3 & 0 & 0 & 3 & 3 \\
2015 & 2 & 0 & 0 & 2 & 2 \\
2016 & 1 & 0 & 0 & 1 & 1 \\
2017 & 3 & 0 & 2 & 1 & 2 \\
Total & 136 & 5 & 81 & 130 \\
\hline & & 0 & & \\
\hline
\end{tabular}

(Source: Author's coding) 
74 Hydropower, fragmentation, knowledge-making

Table 4.2 XEN's hydropower articles between 2002 and 2017 and their attitudes

\begin{tabular}{lccccc}
\hline Year & $\begin{array}{l}\text { Total hydro- } \\
\text { power articles }\end{array}$ & $\begin{array}{l}\text { Positive } \\
\text { tone }\end{array}$ & Neutral & Negative & $\begin{array}{l}\text { Articles with visible } \\
\text { controversies }\end{array}$ \\
\hline 2002 & 41 & 26 & 15 & 0 & 0 \\
2003 & 72 & 44 & 22 & 6 & 4 \\
2004 & 39 & 18 & 18 & 3 & 1 \\
2005 & 20 & 4 & 14 & 2 & 3 \\
2006 & 39 & 20 & 16 & 3 & 3 \\
2007 & 19 & 3 & 12 & 4 & 2 \\
2008 & 16 & 3 & 9 & 4 & 2 \\
2009 & 10 & 2 & 7 & 1 & 2 \\
2010 & 14 & 6 & 5 & 3 & 2 \\
2011 & 12 & 3 & 7 & 2 & 6 \\
2012 & 8 & 2 & 4 & 2 & 1 \\
2013 & 12 & 1 & 5 & 6 & 5 \\
2014 & 6 & 3 & 1 & 2 & 1 \\
2015 & 4 & 0 & 1 & 3 & 2 \\
2016 & 21 & 2 & 10 & 9 & 12 \\
2017 & 10 & 3 & 4 & 3 & 3 \\
Total & 343 & 140 & 150 & 53 & 49 \\
\hline
\end{tabular}

(Source: Author's coding)

Consistent with these tables, except SW, most Chinese media outlets as represented by PD and XEN still reported more positive and neutral stories about hydropower than negative ones. But in a society where traditional media outlets were tasked to propagandize positive socialistic values, the frequent appearance of negative stories per se indicates hydroelectricity projects have been recognized as controversies. In terms of circulation, the high subscription of SW among intellectuals and urban middle classes represents a more significant social impact, and any adverse reporting in PD, China's politically most prestigious newspaper (its editor-in-chief is equivalent to the level of a minister in the hierarchic political system), causes typically significant political pressure. One veteran anti-hydropower activist recalled with a comforting smile during my interview: "In the period, any media outlet which has not reported hydropower controversy seemed to be environmentally unfriendly" (INT20161225).

In addition to (and often parallel to) adverse reporting, the Chinese media in the 2000s began to make controversies about hydropower visible in their reporting, even in stories with a generally positive tone. Scholars have long recorded balancing different views to create drama and for environmental stories to attract readers (Boykoff \& Boykoff, 2004; Corbett \& Durfee, 2004), but in China, lack of mentioning disputing views as a result of the media's long-time propaganda tradition may have reduced the attractiveness of 
Table 4.3 PD's hydropower articles between 2000 and 2017 and their attitudes

\begin{tabular}{cccccc}
\hline Year & $\begin{array}{l}\text { Total hydropower } \\
\text { articles }\end{array}$ & $\begin{array}{l}\text { Positive } \\
\text { tone }\end{array}$ & Neutral & Negative & $\begin{array}{l}\text { Articles with visible } \\
\text { controversies }\end{array}$ \\
\hline 2000 & 26 & 8 & 18 & 0 & 0 \\
2001 & 28 & 5 & 23 & 0 & 2 \\
2002 & 22 & 10 & 12 & 0 & 0 \\
2003 & 41 & 25 & 14 & 2 & 4 \\
2004 & 26 & 7 & 16 & 3 & 8 \\
2005 & 33 & 11 & 15 & 7 & 18 \\
2006 & 27 & 6 & 14 & 7 & 9 \\
2007 & 27 & 6 & 19 & 2 & 7 \\
2008 & 25 & 6 & 19 & 0 & 8 \\
2009 & 19 & 8 & 8 & 3 & 2 \\
2010 & 16 & 6 & 9 & 1 & 5 \\
2011 & 26 & 7 & 15 & 4 & 7 \\
2012 & 29 & 8 & 21 & 0 & 3 \\
2013 & 28 & 16 & 12 & 0 & 2 \\
2014 & 22 & 10 & 8 & 4 & 8 \\
2015 & 25 & 13 & 10 & 2 & 5 \\
2016 & 27 & 13 & 13 & 1 & 6 \\
2017 & 32 & 17 & 13 & 2 & 6 \\
Total & 479 & 182 & 259 & 38 & 100 \\
\hline & & & & & \\
\hline
\end{tabular}

(Source: Author's coding)

science and environmental stories (Jia, 2007; Jia \& Liu, 2009). We can also say that media stories highlighting the presence of controversy surrounding hydropower may have created an atmosphere where it was possible to question the validity of building dams.

While the media have played an essential role in facilitating the hydropower controversy in China, interviews (INT20161016, INT20161022, INT20161215, INT20161219) revealed that during the Nu River and Tiger Leaping Gorge controversies, media reporting either was initiated by the environmental agency or received its support in terms of easy access to comments from environmental officials, among others. Table 4.4 shows that the leading theme of SW hydropower stories was regulatory issues.

Among the $40 \mathrm{SW}$ stories framed as reporting regulatory issues, 31 negatively reported hydropower projects, mostly investigative stories about the dam developers' irregular actions or the expected negative impacts. Most of these stories quoted either SEPA/MEP officials or environmental/public policy experts. Comparatively, Shanghai-based XEN, as an urban tabloid based in a metropolitan center, did not report so many regulatory stories. In the sampled period (2002-2017), the completion of TGP and other major dams also 
Table 4.4 The main themes of SW and XEN's hydropower articles

\begin{tabular}{lcc}
\hline & $S W$ (2000-2017) & XEN (2002-2017) \\
\hline Floods, dam safety \& water management & 5 & 59 \\
S\&T & 5 & 11 \\
Regulatory affairs \& public accountability & 43 & 2 \\
Politics \& national interests & 5 & 16 \\
Immigrant affairs & 7 & 21 \\
History \& culture & 6 & 17 \\
Engineering & 5 & 112 \\
Environment \& ecology & 31 & 40 \\
Development \& social welfare & 7 & 5 \\
Business \& economy & 11 & 60 \\
\hline
\end{tabular}

(Source: Author's coding)

resulted in more positive reporting of hydropower construction's engineering achievements. However, XEN reported more environmental stories (as well as stories on floods and their impacts) about hydropower, partly because Shanghai, located in the downstream Yangtze, is more likely to be subject to the possible environmental impacts of the upstream dams, such as salt sea water's incursion due to reduced Yangtze water flow caused by dams. Among XEN's 40 hydropower stories reporting environmental issues, 28 were negative.

Table 4.4 also reveals the alternative frames the media used in challenging hydropower projects that were often portrayed as engineering achievements and beneficial to social development. But in the controversial settings, the media more frequently reported the environmental and regulatory aspects of hydropower development.

\subsubsection{Media morphology, Internet and public attention in hydropower controversies}

While producing a large number of critical stories against hydropower developments, Chinese media also demonstrated a unique morphology in such reporting, as evidenced by the diversified authorship structure and unique source layout. My interviews with many journalists indicated that besides a small group of energy journalists who covered the beat of hydropower or power industry in general, many science, environmental, cultural and business reporters reported hydropower issues without constraints (INT20160816, INT20160925, INT20161016, INT20160921a). A large portion of hydropower stories were authored by environmental reporters, who, with environmental reporting increasingly considered by editors as politically safe yet widely welcomed critical stories, enjoyed more and more salient roles within 
Chinese media outlets. The situation is similar to the association between the deployment of journalists to different topics and the media's overall tendency revealed by M. C. Nisbet and Huge (2006).

Another apparent morphology in Chinese media's reporting of hydropower is the high frequency of dissenting experts primarily in the loosely defined environmental and ecological field. As media theme analysis in the previous subsection revealed, most environmental and ecological stories reported hydropower development negatively. My random analysis shows that negative reporting was often supported by citing critical experts' views and unbalanced treatment of anti-hydropower experts as against pro-hydropower experts. A detailed quantitative analysis is beyond the scope of the current book, and the availability of many dissenting experts is also a knowledge control issue to be explored in the STS section of this chapter. What can be said here is that through their continuous field investigation involving both journalists and experts such as Jianghexing (Yangtze and Yellow rivers trips), activists, many of whom had earlier been journalists like Wang Yongchen, helped mobilize a dissenting expert network ready to equip environmental journalism challenging hydropower.

Hydropower developers and supporters, by contrast, have made few effective communication and public relation (PR) efforts, which as a result encouraged journalists and activists not to hesitate to raise new controversial issues against hydropower (INT20170106). In 2009, when I was a Chinese science journalist, Lu Youmei, former president of China Three Gorges Corporation (CTGC) who led the construction of TGP, told me that during the dam's construction process, an international PR firm came to the company for business but it was rejected because the company's management thought it was unnecessary to make PR for a project the State was determined to accomplish. Lu later felt very regretful of the decision, which he considered a cause leading to later years' continued hydropower controversies in China.

An STS scholar who has long studied hydropower history in China thought two factors might contribute to the industry's poor reactions to hydropower controversies. The industry, dominated by hydropower engineers, has long defined itself as implementing the State's will, and the industry's primary operation location was often in remote mountainous areas so that it saw little necessity to communicate to the public (INT20170715).

In addition to the print media, the rising Internet in the 2000s also fueled the spread of controversies regarding hydropower. The rise of Internet news portals in the period has dramatically promoted the impact of sensational, often antagonistic news stories in China (Qian \& Bandurski, 2011; L. Tang \& Sampson, 2012; Xiao, 2011). My study also revealed similar patterns. The leading news portals in China, such as Sina.com.cn, 163.com, sohu.com and QQ.com, have all produced individual webpages/columns on each major hydropower controversy from the debated Yangliuhu dam proposal to the controversial Xiaonanhai project. Most leading Chinese Internet news portals do not have the right to report news independently (L. Tang \& Sampson, 
2012). But their market dominance has enabled them to obtain free access quickly to impactful stories from conventional media. The lack of the right to independent reporting drove these news portals to concentrate highly impactful print media stories into a single column, significantly increasing the topic's impact. "Normally people (meaning Internet users) do not care too much about hydropower issues, but when a controversy [about hydropower] broke out, visits to our special columns [on the hydropower controversy] surged dramatically," one former news portal editor told me (INT20170109).

He was echoed by another former news portal editor who said some journalists-turned environmental activist such as Wang Yongchen often shared with her and her colleagues important news about environmental issues and involved them in planning investigative news reporting of environmental woes (INT20170114). Hence, activists expertly dominated the media agenda, both online and offline. This situation is consistent with previous scholarly observations on the institutional role of the Internet in fueling China's green politics (G. Yang, 2005, 2009; G. Yang \& Calhoun, 2007).

In addition to news portals, various types of social media also played an essential role in fueling hydropower controversy. As discussed in Chapter 2, this book adopts a broad definition of social media, including BBS, blogs, Weibo and WeChat. Below is the frequency of high-impact BBS posts about hydropower retrieved from Tianya.com, China's largest BBS site.

BBS became popular only after 2003, so BBS posts did not share the earlier pattern of mass media's reporting frequency of hydropower, particularly the intensified media coverage of hydropower in 2003. However, in the following years, the rate of high-impact BBS posts gradually became similar to those of our sampled print media, particularly between 2010 and 2011, when the strengthened implementation of EIA by MEP pushed higher media coverage of hydropower issues.

I did not systematically collect Weibo and blog posts on hydropower due to the difficulty of data collection and analysis. As Weibo was introduced only in 2009 when the hydropower controversy had relatively faded, the lack of Weibo data should not constitute a significant challenge to the validity of my media data analysis. Nonetheless, my interview with a researcher on new media who interned at a leading Chinese ENGO for her dissertation on social media and activism revealed that Chinese ENGOs have adopted a flexible strategy to combine the use of different social media platforms (blogs, Weibo and WeChat) (INT20170109). Often, their opponents - local government departments and State-owned enterprises (SOEs) - failed to adopt such a strategy.

Media reporting of hydropower controversies mobilized by activists have significantly increased public attention to the disputes occurring in the far southwest. The high-impact BBS posts plotted in Figure 4.2 provided partial evidence. Another form of proof is Google search results obtained from Google Trends (https://trends.google.com). Figure 4.3 reflects the search trend. Figure 4.4 shows the combined hydropower reporting by the four sampled Chinese media, whose long-term trend was graphed in Figure 4.1, for the period starting in 2004 for comparison. 


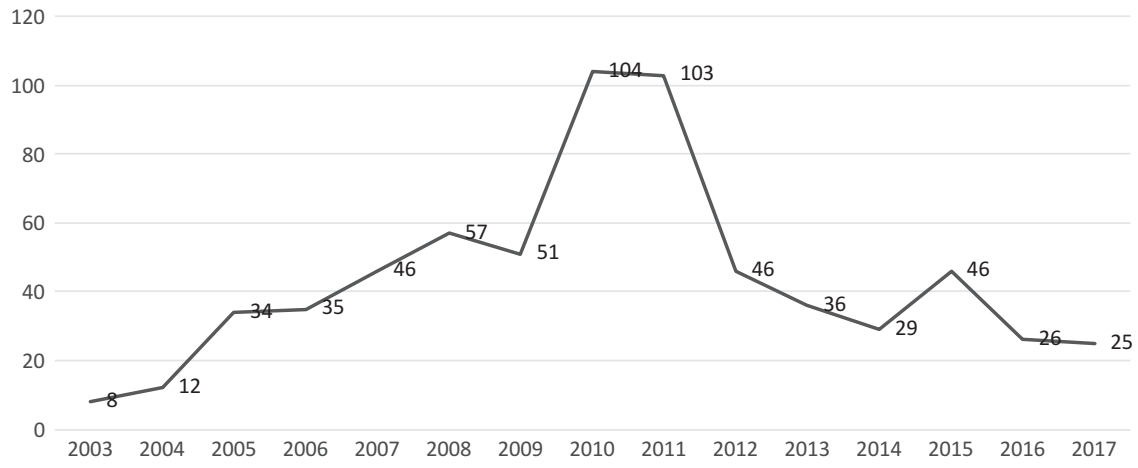

Figure 4.2 High-impact BBS posts focused on hydropower (2003-2017)

Source: Data downloaded from Tianya.com by courtesy of Kai Liu on May 8, 2018

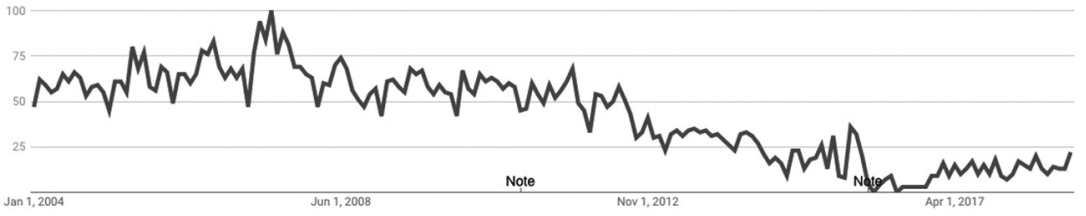

Figure 4.3 Google search trends (2004-2018)

Source: Data downloaded from Google Trends on December 25, 2018, by the author

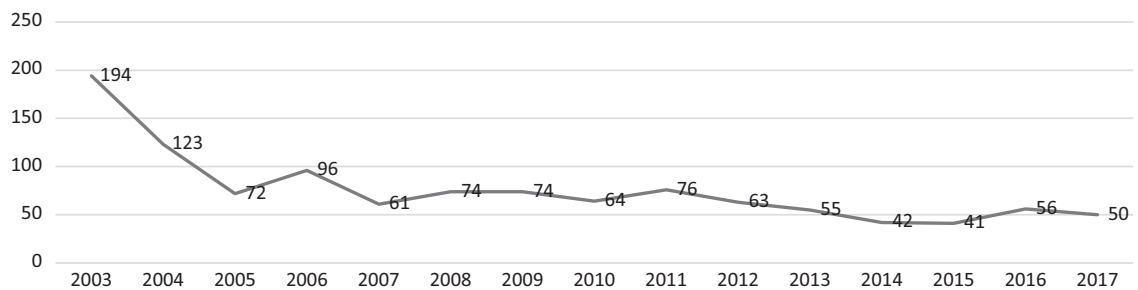

Figure 4.4 Combined hydropower reporting by four sample Chinese media (20042017)

Source: Author's collection 
Although due to the difference in units (media reporting was calculated in years while Google Trends data is calculated daily), the two graphs cannot be directly compared, we can notice that they roughly share a similar pattern. BBS posts and Google search trends seem to indicate that public reactions to hydropower were primarily driven by, or at least correspond to the media reporting events, though these media stories may be not only about controversies. Another critical point is that Google began to withdraw from China in 2010, but visits to it were not wholly blocked until May 2014 (Wikimedia, 2018). Therefore, Google search data can still be considered as an analysis reference.

The above analysis demonstrates the active and institutional role the media and Internet played in triggering and facilitating China's hydropower controversy. However, only revealing such a role is not enough for us to fully understand the controversies of hydropower and other S\&T issues. For example, why did the media not quote orthodox experts to counterbalance activists' arguments against hydropower in their controversial reporting? Why, as we will indicate in the later chapters in this book, did the media treat different controversial topics differently?

It is necessary to further explore these issues both through the social movement theory framework and through STS-oriented theories. In the next section, I will examine the components of social movement theories - particularly of political process theory and FA framework - underlying China's hydropower controversies. Following that, STS concepts such as knowledge-control regime (Hilgartner, 2017), sociotechnical imaginaries (Jasanoff \& Kim, 2013, 2015) and civic epistemology (Jasanoff, 2011b) will be probed.

\subsection{Social movement interpretation of hydropower controversy}

Although the debate on dam building in China was covered in professional terms and concerns, a political dimension is visible during the controversy. In the early dispute on TGP, dissenters took advantage of the newly opened political opportunity structure (Meyer \& Minkoff, 2004) created by China's liberalizing reform in the 1980s while ENGOs' struggles against the southwestern hydropower projects were linked to the rise of the government's environmental protection agencies. When fighting the plan to build dams, the disobedient intellectuals and activists consciously or unconsciously attempted to expand the privileged political freedom in S\&T issues and the legitimacy of civil society.

\subsubsection{Examining political opportunity structure for TGP debates}

Hot debate against the TGP broke out in the mid-1980s among CPPCC members. Three books published during the debate - Treatises on Macro Policymaking on the Three Gorges Project (F. Tian et al., 1987), Second Collection of Treatises on Macro Policymaking on the Three Gorges Project 
(F. Tian, 1989) and Yangtze, Yangtze: Debates on the Three Gorges Project (Q. Dai, 1989) are the main data sources used in this book. Wordings of the articles reflected the emerging political opportunity structure - an atmosphere to encourage academic debates as a way to move toward political democracy - and actors' desire to utilize the opportunity.

In his preface to the first book, Zhou Peiyuan (1902-1993), former Peking University president and a leading physicist, argued that the debates on TGP were to implement and expand the Party's encouragement of scientific policymaking. Zhou's "political correctness" was shared by nearly all authors of the three books who appealed for scientification and democratization of policymaking about TGP. Sun Yueqi (1893-1995), a former top official of Kuomintang government in charge of the mining industry who was long marginalized after he surrendered to the communist government in 1949, told a journalist whom I interviewed, "it is time to (publicly) say something. TGP [debate] is where I should be able to speak safely." (INT20161208a)

It is unfair to say that the authors argued against TGP simply for the sake of free speech. They demonstrated meaningful concerns about the sediment of sandstone (the main concern of Cornell-trained Huang), the insufficiency of TGP in flood prevention (particularly its role in preventing metropolitan Wuhan from flooding), the funding shortage, the major challenge to relocate the 1 million residents whose homes were to be flooded by rising Yangtze water level, and the project's impact on other hydropower projects which had to be suspended for the shortage of funding due to TGP's huge investment. Environmental and ecological impacts, the main arguments against hydropower projects in later controversies were mentioned (F. Guo, 1987; Hou, 1987) but were not taken as the main issue during the debate.

Although the media did not widely report the 1980s' TGP debates, they indeed played a crucial role in disseminating the opinions of dissenting scholars. The publication notes of the second Treatises claimed that 26 national and international media outlets had reported the controversy. One senior journalist recalled that when she had a chance to attend a CPPCC meeting discussing TGP, she and peer journalists were enthusiastically welcomed with applause (INT20161102).

Journalists' effort to cover the TGP debate itself was a signal of the increasingly liberalizing sociopolitical environment, which is also part of the political opportunity structure. A journalist said she was involved in reporting TGP because, since the mid-1980s, she had opened a column in her news outlet to interview one or two intellectuals with fresh ideas per week. Targeted interviewees were often obtained through a snowballing recommendation. Gradually her interviewees involved more and more people challenging the TGP plan (INT20161208a).

The Chinese government took a very tolerant stance at the early stage of the debate, which can be considered another sign of political opportunity in such an authoritarian regime. The Central Propaganda Department, the supreme master for media censorship, allowed professional discussions on TGP at CPPCC and in professional journals, but disfavored such debates in 
the mass media (B. Zhang, 2011). During the four years of debates, Science Daily (which later became China Science Daily, our sampled media outlet) and Guangming Daily (mainly covering intellectuals), as well as professional journals like Journal of Dialectics of Nature published by Chinese Academy of Sciences (CAS) and Science and Technology Review published by China Association for Science and Technology (CAST), were actively involved in publishing debating articles.

To summarize, we find that even though the Chinese media had not marched toward marketization in the 1980s - which many scholars believed was linked to a certain degree of political freedom (Price, Rozumilowicz \& Verhulst, 2003; Shirt, 2011) - they became the agents to facilitate controversies, frame the justifiable features of the anti-TGP campaign and mobilize support. The involvement of publications like Journal of Dialectics of Nature represented another early sign of China's S\&T controversies - the presence of socially active STS scholars in debates regarding S\&T.

\subsubsection{Southwestern dam debates and fragmented authoritarianism}

The TGP controversy can be considered a result of the emerging political opportunity structure created by China's liberalization trend in the 1980s. Although the political liberalization trend was halted due to the 1989 Tiananmen Square bloody clampdown, the rapid economic progress continued to fuel social and political diversification, fueling bureaucratic fragmentation, the very basis for the FA framework.

As discussed in the introductory chapter, the FA framework can be loosely considered part of the political opportunity structure. Mertha (2008) listed a group of governmental organizations whose interests or goals conflicted with hydropower developers and their official sponsors like NDRC and the Ministry of Water Resources (MWR, which was the Ministry of Water Resources and Electricity during the 1980s' TGP debate). These agencies included SEPA and its updated version MEP, the Ministry of Construction in charge of urban water supplies, and State Administration of Cultural Heritage (SACH), as many cultural and historical relics could be overwhelmed by dams.

In the cases of China's southwestern hydropower controversies, what is in conflict is not only jurisdictions of agencies but also their institutional missions. This conflict can be seen in the Nu River controversy. The breakout point was the abovementioned SEPA meeting on September 3, 2003, which produced the PD article critical of $\mathrm{Nu}$ River hydropower development. It is interesting to note that the PD story did not mention the SEPA seminar, apparently to avoid an impression of bureaucratic conflicts.

"In nearly every hydropower controversy, MEP was behind ENGOs and the media. In Chinese political regime, it is inconvenient for one agency to challenge another and State-owned conglomerates," one hydropower industry expert said (INT20170106), an opinion shared by another interviewee closely linked to the industry (INT20161229). 
While bureaucratic fragmentation constitutes a political opportunity structure for triggering controversy, societal fragmentation has contributed to the more prominent and more sustainable debates. During the $\mathrm{Nu}$ River controversy, few journalists visited the planned dam-building site in $\mathrm{Nu}$ River (INT20161215, INT20160816, INT20161016), so they heavily relied on experts critical of hydropower development to produce their stories. After initial media coverage of the $\mathrm{Nu}$ controversy, Wang collected signatures from over 50 public figures at a national cultural study conference held in October in a petition to preserve the $\mathrm{Nu}$ River, facilitating another wave of media reporting. Journalists' reliance on experts for the authority and legitimacy of their reporting has been well documented (Albæk, 2011) and sympathizing experts were a primary source of anti-establishment science controversies including those in hydropower (McCormick, 2006, 2007a). Many of the experts interviewed by journalists, such as He Daming, an ecology professor at Yunnan University, attended the SEPA September 2003 seminar on $\mathrm{Nu}$ River preservation.

$\mathrm{Yu}$ Xiaogang, the founder of Yunnan-based ENGO Green Watershed and then a research associate at Yunnan provincial academy of social sciences, submitted a policy report on the poverty and hardship of hydropower-relocated residents based on his dissertation field study through Yunnan provincial branch of Xinhua Agency ${ }^{1}$. The official acknowledgment of Yu's report led Yunnan provincial academy of social sciences to pay great importance to Yu's research and allow him to set up a self-funded institute, the precursor to Green Watershed, within the academy (INT20161225).

Some activists admitted that SEPA/MEP officials supported their actions while others denied they were simply a proxy agent of the government agency. "Some SEPA officials would come to support our actions because Pan Yue (then deputy administrator of SEPA who was a former environmental journalist) was friendly to ENGOs in his effort to launch the so-called Environmental Governance Storm. This tone made the rank-and-file officials tend to work with ENGOs." (INT20170515)

Others took advantage of the accommodating institutions too. After the media launched the anti-hydropower campaign regarding the $\mathrm{Nu}$ River, they reportedly managed to submit a signed petition to Premier Wen Jiabao through a retired air force general who was an environmental volunteer. Interviews suggested the activists sent similar reports or petitions through environmentally conscious leaders of the government's think tanks (INT20161215), quite similar to Teets' (2018) finding that ENGOs utilized their sponsoring organizations as a policy petition channel.

Most activists I interviewed could find internal channels to submit petitions to senior leaders at the central government. ${ }^{2}$ These channels include official news outlets such as Xinhua Agency and the People's Daily and their local branches, state-affiliated think tanks such as the academies of social sciences at various levels, research institutions such as CAS, senior scientists such as CAS/Chinese Academy of Engineering members, science management bodies 
such as China Association for Science and Technology (CAST), and some privileged academic societies such as the old scientists' association (X. Zhu, 2013) (INT20161221). The diversified channels that activists can utilize to access to the central leadership are evidence that the regime was fragmented in ways that accommodated China's rising environmental activism, or we can consider them as a political opportunity structure favoring a specific type of activism.

Due to China's authoritarian regime, the annual plenary meetings of NPC, the Chinese legislature and CPPCC are usually occasions when various elites express their political loyalty to the top leadership and their policy agenda, but these events also provide a forum for dissenting professionals to show their complaints and protests against policy, governance and technical issues (Saich, 2011). Table 4.5 shows critical CPPCC proposals appearing at annual plenary meetings of CPPCC (held in March each year) and other CPPCC events since the 2000s.

Discussions at CPPCC's annual plenary meetings, or occasionally NPC, attract media attention more easily and legitimate the media's reporting of controversial issues. Hydropower thus became a target for such technical criticism.

\subsubsection{Institutions and experts fueling hydropower controversies}

In addition to bureaucratic fragmentation, rising ENGOs and the media, other social actors also played facilitating roles underlying hydropower controversies. International organizations, such as UNESCO, International Rivers, World Wildlife Fund (WWF), Oxfam, Conservation International and The Nature Conservancy (TNC), are such players. International ENGOs' role in transnational anti-dam movements has been well recorded (Khagram, 2004; Lee, 2013b; McCormick, 2010). Most domestic activists I interviewed admitted they had received various types of funding from international charity groups or their foreign counterparts (INT20170310). Together with funding, international ENGOs were significant sources of expertise needed by their Chinese counterparts. International ENGOs were also suppliers of knowledge to Chinese government officials. This situation may explain the fact that even some highly antagonist foreign NGOs like Greenpeace can be allowed to have a legal presence in China (Teets, 2013).

International and domestic experts and scientists, particularly those who study biodiversity, fishing resources, sediments, dams' geological impacts, and relocation of impacted residents, can be considered another element influencing hydropower debates. Brødsgaard (2017) and Hansen (2017a) argued that scientists should be regarded as a central component of the FA framework. For example, Cao Wenxuan, a renowned CAS academician famous for his systematic studies on Chinese carp, was the primary opponent of the proposed Xiaonanhai dam in Chongqing (INT20161227).

With coordination by ENGOs, environmental and ecological research organizations and scientists were widely mobilized against dam building. Since the debut of the southwest anti-hydropower movement in Dujiangyan, 
Table 4.5 Some of CPPCC or NPC's actions against hydropower since 2003

\begin{tabular}{ll}
\hline Year & Details \\
\hline May 2004 & $\begin{array}{l}\text { In May 2004, Vice-chairman of CPPCC Li Meng led a delegation to } \\
\text { inspect environmental and ecological protection in TGP and lower } \\
\text { Jinsha River. }\end{array}$ \\
Mar. 2005 & $\begin{array}{l}\text { CPPCC members and a senior scientist at the CAS Institute of Geo- } \\
\text { graphy and Natural Resources Liang Jiyang submitted a proposal to } \\
\text { criticize that hydropower development negatively impacted the health of } \\
\text { Chinese rivers. }\end{array}$
\end{tabular}

Mar. 2007 Six CPPCC members submitted a proposal and talked with the media on disordered hydropower development.

Aug. 2007 CPPCC formed a hydropower inspection team to investigate the impact of small hydropower projects.

Sept. 2008 Shao Bingren, deputy director of CPPCC's environmental committee, claimed the overdevelopment of hydropower in upper Yangtze River and organized a team to investigate.

Mar. 2009 CPPCC members discussed the negative aspects of hydropower development and its exclusion from a State economic boosting plan (with a total investment of 4 trillion yuan) to fight the financial crisis.

Jun. 2009 SEPA suspended two hydropower projects for their failure to pass EIA. CPPCC organized a delegation to investigate.

Mar. 2010 CPPCC members submitted a proposal to protect wetlands against hydropower development.

Mar. 2011 CPPCC members submitted a proposal to protect rural water facilities (appealing for the State to invest more money in rural water facilities, which would reduce the investment in hydropower developments).

Mar. 2012 CPPCC members submitted a proposal to strengthen water resource management (from disordered storage of water by hydropower projects).

Mar. 2012 CPPCC members submitted a proposal, appealing to abolish the construction plan of Xiaonanhai hydropower station.

Mar. 2013 CPPCC members submitted a proposal, appealing to strengthen water management of hydropower and hydraulic reservoirs.

May 2013 Shao Bingren, deputy director of CPPCC's environmental committee, stressed at a CPPCC standing committee meeting that hydropower development must be scientifically planned.

Jun. 2013 Xie Qingsheng, a CPPCC standing member, appealed to have special legislation on Yangtze River hydropower development.

Jul. 2013 Xie Qingsheng, a CPPCC standing member, led a delegation to inspect upper Yangtze hydropower developments and appealed that they must be reasonably planned.

Mar. 2014 CPPCC members submitted a proposal, suggesting that the overdevelopment of hydropower and other new energies will increase the abandoning electricity produced from these sustainable sources.

Mar. 2014 CPPCC members mainly from Yunnan Province submitted a proposal, appealing to restart $\mathrm{Nu}$ River hydropower development. Other members bitterly criticized the plan. 
Table 4.5 (Cont.)

\begin{tabular}{|c|c|}
\hline Year & Details \\
\hline Mar. 2015 & $\begin{array}{l}\text { CPPCC members submitted a proposal, appealing to keep the original } \\
\text { faces of Nujiang from hydropower development. }\end{array}$ \\
\hline Mar. 2015 & $\begin{array}{l}\text { CPPCC members submitted a proposal, appealing to strengthen legal } \\
\text { stipulation of wetland protection (including protecting wetlands from } \\
\text { losing water to hydropower facilities). }\end{array}$ \\
\hline Mar. 2016 & $\begin{array}{l}\text { The CPPCC members from China Democratic Progress Party submitted } \\
\text { a proposal, appealing to pay attention to the } 3.7 \text { million dam refugees } \\
\text { who were still in poverty. }\end{array}$ \\
\hline Mar. 2016 & $\begin{array}{l}\text { CPPCC members discussed the policies to clear (many illegal) small } \\
\text { hydropower facilities in Nu River. }\end{array}$ \\
\hline Jun. 2016 & $\begin{array}{l}\text { CPPCC members made an inspection delegation to upper Yangtze } \\
\text { River against the overdevelopment of hydropower. }\end{array}$ \\
\hline Mar. 2017 & $\begin{array}{l}\text { CPPCC members submitted a proposal, appealing to strengthen water } \\
\text { resource management in the Yangtze River basin. }\end{array}$ \\
\hline Mar. 2018 & $\begin{array}{l}\text { CPPCC members submitted a proposal, appealing to strengthen wet- } \\
\text { land protection in upper Yangtze River. }\end{array}$ \\
\hline Mar. 2018 & $\begin{array}{l}\text { CPPCC members in different regions jointly appealed to strengthen the } \\
\text { management of smaller hydropower facilities, after the National Audit } \\
\text { Office concluded in an audit report that small hydropower facilities have } \\
\text { cut out water flows of } 333 \text { rivers in China. }\end{array}$ \\
\hline
\end{tabular}

(Sources: Collected by the author from the media reporting and CPPCC website)

the $\mathrm{Nu}$ River and Tiger Leaping Gorge, convening dissenting environmental, cultural conservation and animal protection experts to organize seminars widely attended by journalists had become the main tactic to question dam building. Through these seminars, experts' views were unified to an anti-dam tone which was quickly amplified by the media.

Following these earlier events, Wang Yongchen and her Green Earth Volunteers organized numerous Yangtze and Yellow river journalist inspections (jianghexing) (annual events for more than 15 years), each of which was headed and joined by environmental, geological and animal protection experts. A mobilization network of activists-experts-journalists-environmental officials provided firm and consistent public opinion pressure against the hydropower side. Like the earlier experts' seminar that raised anti-dam activism in Dujiangyan, Nujiang and Tiger Leaping Gorge, many of the subsequent journalists' inspections had one or two concentrated targets, resulting in intense pressure on hydropower developers.

Hydropower developers and supporters, as mentioned above, have made few effective counterattacks. Hence, an alliance composing of the fragmented bureaucratic agencies, local and international ENGOs, active academics and the media was formed. Fueled by the institutional accommodation of activism caused by China's social and economic transformation, the alliance outweighed the communication of the apprehensive hydropower industry and its weak local government allies, at least in the battle to win public opinions, 
leading to everlasting controversies surrounding hydropower development, and often forcing the latter to suspend the targeted projects.

\subsubsection{Understanding hydropower controversies with social movement theories}

In this subsection, I made a table to link major hydropower disputes with features suggested by social movement theories. Based on the table, I summarized generic factors contributing to these disputes.

Per Table 4.6, we can make several observations. First, these controversies can be understood through the FA framework and political process theories. They became controversial not merely because of conflicting scientific claims, but because they involved many political actors, particularly the government agencies, ENGOs and the mass media.

Second, based on the involvement of these actors, the outcomes, development process and consequences of the controversies are different. For example, the hydropower EIA (environmental impact assessment) storm in Jinsha River (shown in the table) only involved SEPA and the hydropower industry with the media only playing a supplemented role, so that the solution came fast and eventually the resistance to the dams in question was cleared.

Third, although both the FA framework and political process theory have a durable explanatory power to analyze China's hydropower controversies, they have a different focus. The FA framework is superb in exploring micro-political structures while the political opportunity structure can cover some macro trends and environment for actors to seek justification.

But despite the FA framework and political process theory's explanatory power, they are insufficient in fully explaining S\&T controversies, for both neglect the role of knowledge, how people use their knowledge, and sometimes the perceptual background on which actors rely to exert their influence. The next section of this chapter will examine the interaction between knowledge, power and institutional/structural issues in China's hydropower controversies. Then, I will briefly analyze the political implications of the controversies.

\subsection{Conceptualizing hydropower debates in the STS landscape}

While the previous sections examined communication and social movement components of China's hydropower controversies, it is necessary to push the investigation further to understand how hydropower as an S\&T issue may make the controversies different from a typical social movement case such as a peasant uprising or a worker's strike. As an S\&T issue, hydropower has been naturally linked to knowledge to justify relevant actions or mobilize allies.

\subsubsection{Knowledge contention and civic epistemology in hydropower controversies}

Opponents in the TGP debate in the 1980s included several hydraulic and sediment authorities such as Huang Wanli (1911-2001), Lu Qinkan (1911-2011) 


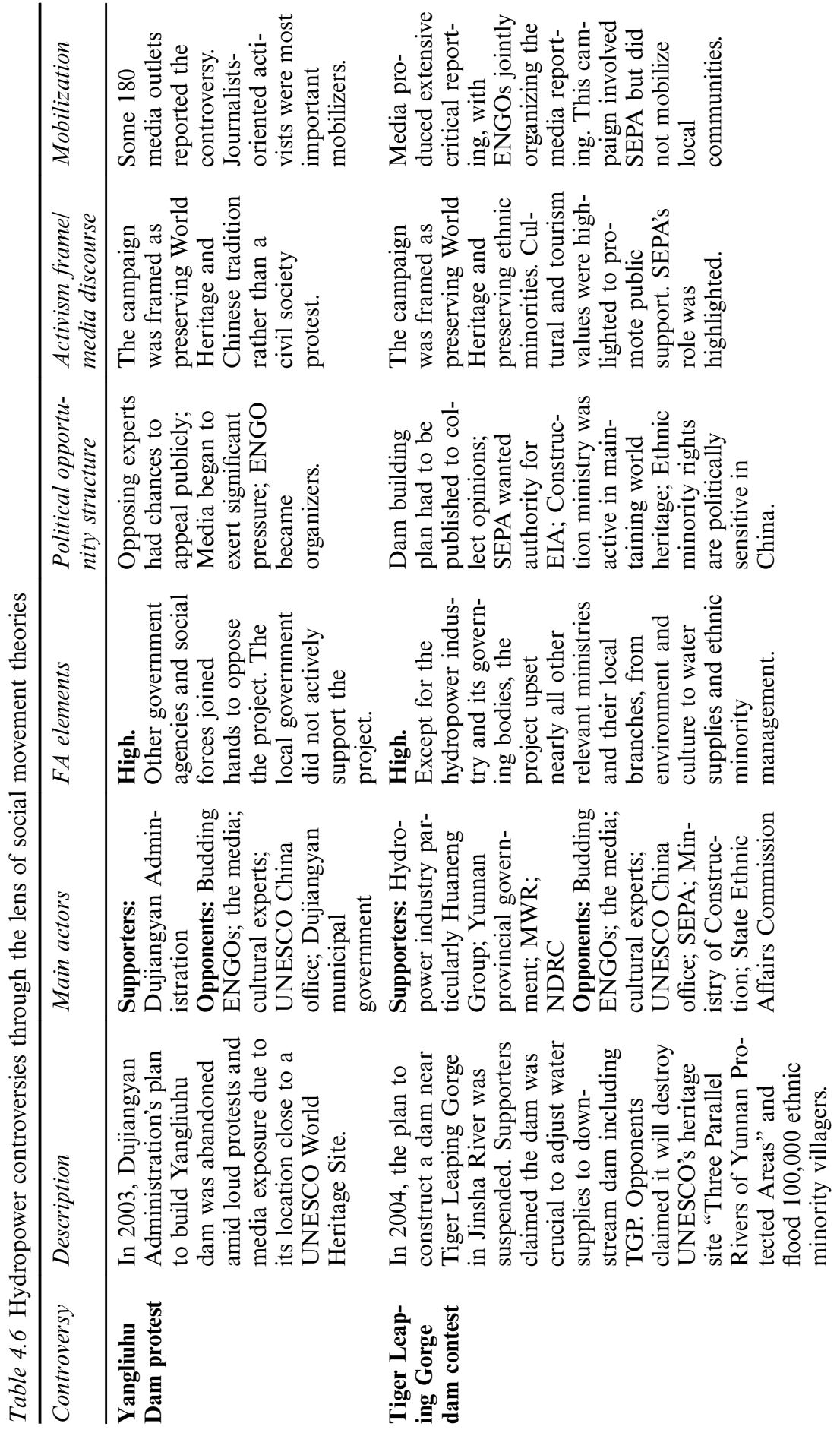




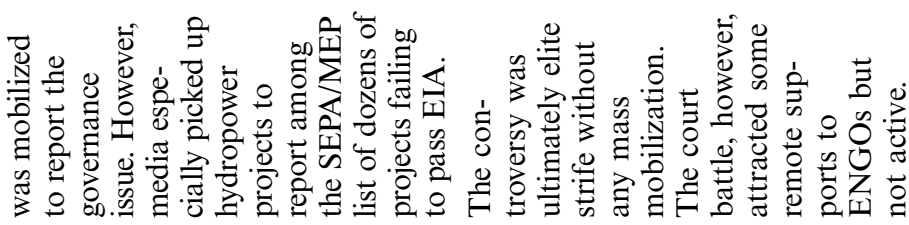

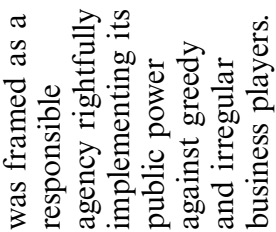

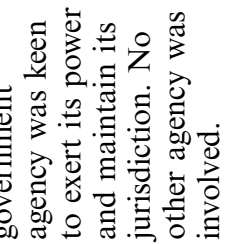

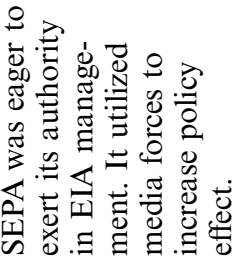

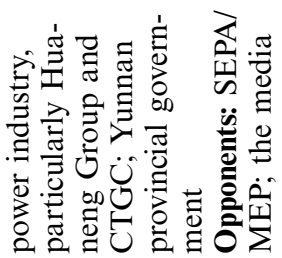

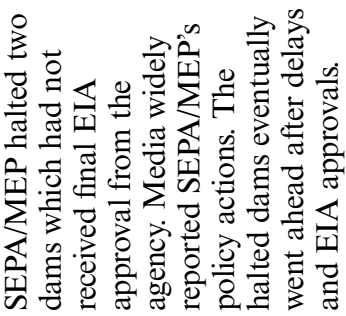

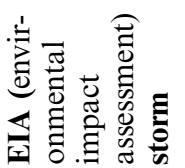

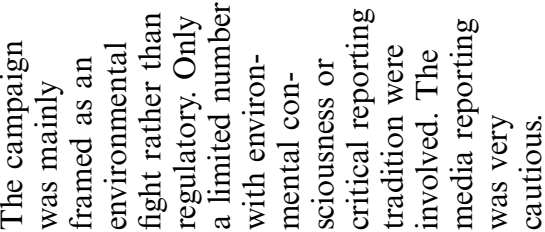

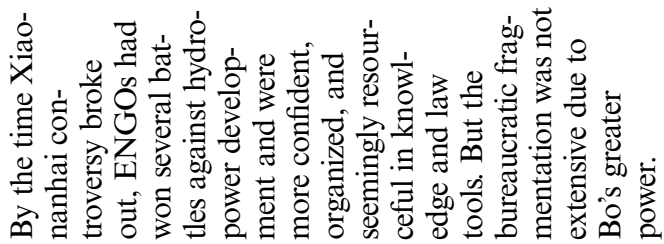

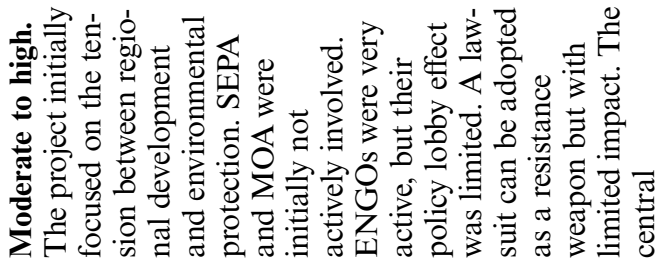

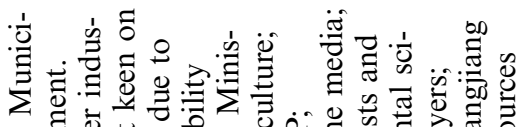

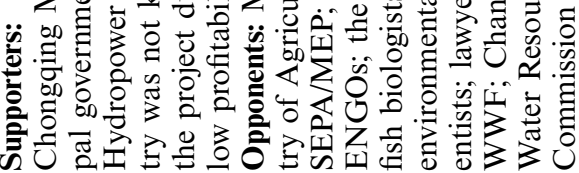

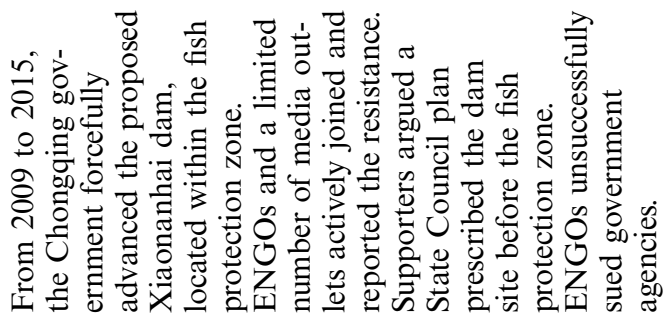

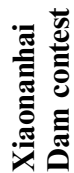


90 Hydropower, fragmentation, knowledge-making

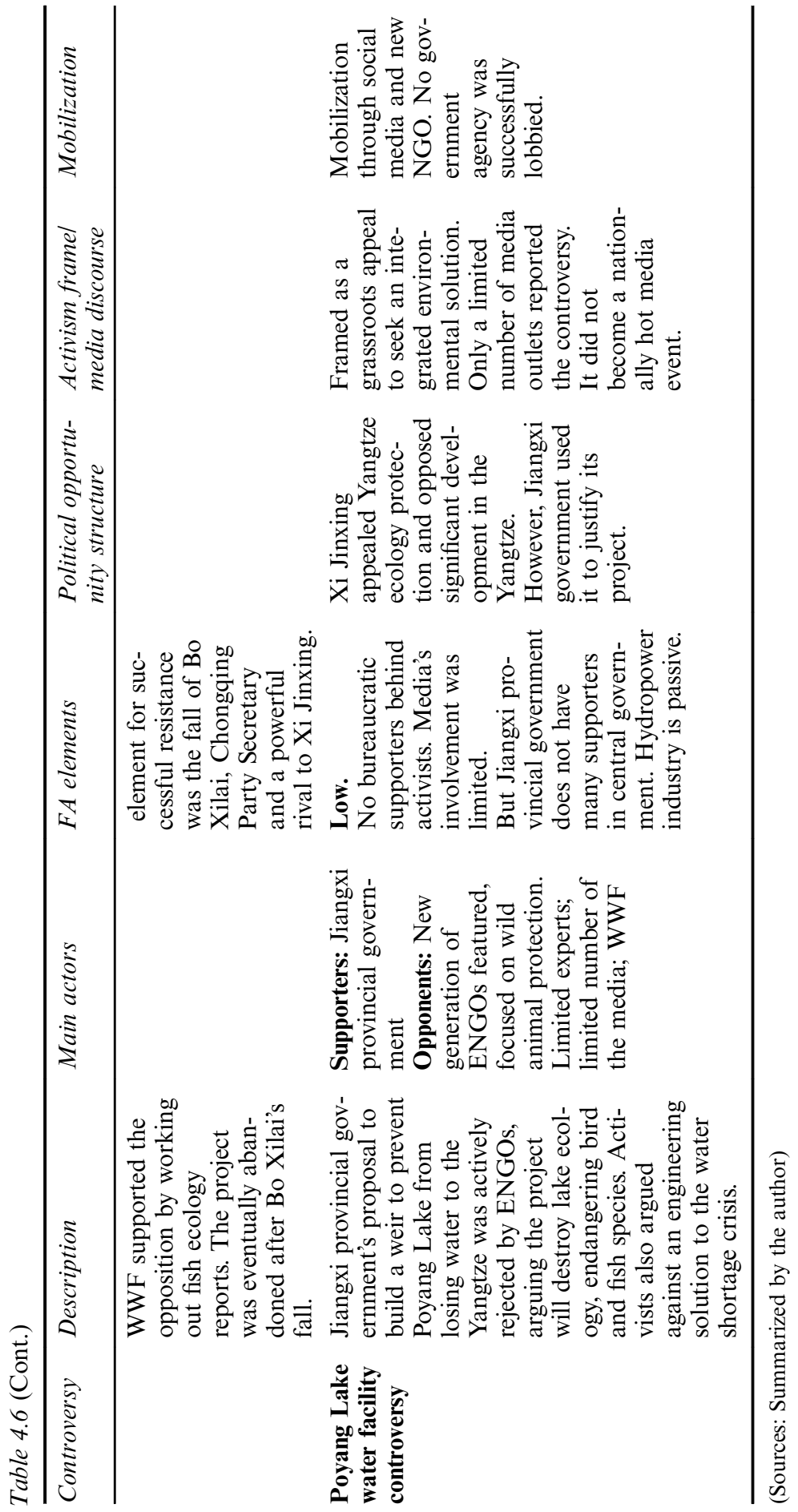


and Fang Zongdai (1911-1991), cherished as founders of China's modern hydraulic engineering or sediment science. By contrast, nearly all activists involved in the southwestern hydropower controversies lacked professional training in hydraulic science or hydroengineering. However, they did not fear to debate with hydropower experts because they successfully extended the focus of debate to environment, ecology and resident resettlement.

Yang Yong, the founder of ENGO Hengduan Mountain Society and an anti-dam environmentalist, said he made a month-long field inspection every year to report the factual water flow and geological situation and then provided the knowledge to other activists to corroborate their counterarguments against official figures cited in the hydropower facilities' feasibility reports (INT20161221). Fan Xiao, the former chief engineer at the Sichuan Geology and Mineral Bureau in Chengdu, actively raised the issue of dams triggering earthquakes, several years before the Wenchuan Earthquake (INT20161222). $\mathrm{Yu}$ Xiaogang focused on hydropower governance, the impact of hydropower projects on local communities, and residents' participation in hydropower policymaking (INT2016125). Yu also introduced to China the World Commission on Dams (WCD) report Dams and Development: A New Framework for Decision-Making (2000), a classic document widely cited by worldwide activists in their struggle against dam construction.

Other activists, particularly those from more established Chinese ENGOs, avoided debate using S\&T terms even though initially they framed their rejection of dams as scientific debates. Instead, "we did not stress science. We debated with hydropower developers on regulatory issues," said a former head of an established Chinese ENGO (INT20170515). The regulatory issues he mentioned mainly referred to the EIA procedure governed by SEPA/MEP (INT20161120).

In addition to the WCD report, various alternative knowledges outside mainstream hydraulic scholarship/engineering, such as hydropower projects' environmental, ecological and geological impacts, fish data monitored by MOA's surveillance network and WWF's field trips, resident relocation and ethnic minority groups' specific cultural heritage were also distributed among activist groups, dissenting experts and SEPA/MEP. Most of these bodies of knowledge were outside orthodox hydraulic science and engineering scholarship, but they were used to enrich the argumentation against hydropower development's benefits and even to expand reviewing perspectives adopted in EIAs. For example, after the years-long Xiaonanhai controversy focused on whether dam construction would jeopardize the fish protection zone, MEP finally denied in 2015 the dam's EIA based on updated criteria taking into account the impact on fish (INT20161227).

This knowledge contention can be understood in terms of civic epistemology, which "refers to these culturally specific, historically and politically grounded, public knowledge-ways" (Jasanoff 2011b, p. 249). Although the hydropower sector was dominant in hydraulic engineering knowledge and the economic side of dams, activists did not challenge dam building from these 


\section{2}

Hydropower, fragmentation, knowledge-making

perspectives. Rather, they contested the knowledge of dams' environmental and social impacts, which activists framed as more relevant public knowledge. Following evidence presented above, one may find that "politically grounded" is also a necessary condition, because without a sponsoring agency and/or CPPCC, the public knowledge-ways to produce and distribute alternative knowledge were hardly possible during the hydropower controversies.

Another component of civic epistemology "historically grounded public knowledge-ways" raises the necessity of examining the concept of national sociotechnical imaginaries, an imagination with a role in shaping a nation's history and future (Jasanoff \& Kim, 2009). It seems that the hydropower sector failed to fully enjoy the benefits of positive national sociotechnical imaginaries which it had struggled to create. Since the 1980s, official Chinese media ceaselessly reported the engineering advances of hydropower construction, framing it as the means to promote development. Table 4.7 summarizes the main themes of the PD's coverage of hydropower in the 1980s and 1990s. For the period, PD is the only newspaper available for analysis.

However, as environmental awareness continued to grow in the 2000s, activists were primarily dedicated to toppling the nation's dominant developmentalism (Lee, 2014), rejecting the sociotechnical imaginaries of the engineering solution to managing water and the political control and corruption associated with this solution. "Chinese ENGOs' concentration in anti-hydropower in the early 21 st century was because dams can provide a black-and-white symbol for social mobilization. The regime's corruption associated with dam building was also a factor leading to broad public participation in the [anti-dam] movement by ENGO members," said a former ENGO leader (INT20170515). SEPA/MEP, the environmental agency, no doubt helped strengthen the imaginaries unfavorable to hydropower.

Table 4.7 Themes of the People's Daily hydropower articles between 1980-1999

\begin{tabular}{lcc}
\hline & $1980-1989$ & $1990-1999$ \\
\hline Engineering & 153 & 144 \\
Development & 152 & 37 \\
Economy and business & 37 & 44 \\
Politics \& national interests & 23 & 18 \\
Floods, dam safety \& water management & 10 & 5 \\
Environment / ecology & 7 & 15 \\
Science & 2 & 6 \\
History and culture & 1 & 2 \\
Regulatory & 1 & 0 \\
Immigrant issues & 0 & 3 \\
Total & 386 & 274 \\
\hline
\end{tabular}

(Source: Collected and coded by the author) 
Knowledge becomes knowledge not only because it is created by scientists and other "qualified" producers but also because people and policymakers accept it in concrete settings with necessary imaginaries. Now we can say certain knowledge become legitimate by the socially constructed qualified knowledge community, but this does not mean other knowledge considered illegitimate or excluded by this community does not count. Rather, adoption, legitimacy and imaginaries in the policymaking setting are not solely decided by the "qualified knowledge community" but by relevant agencies whose political authority can empower them with the privilege of knowledge selection. Relevant agencies also empower or authorize activists or dissenting experts to produce and distribute alternative knowledge. In this sense, Chinese hydropower controversy has enriched our understanding of the concept of civic epistemology.

\subsubsection{Knowledge-control regimes and disintegrated knowledge making}

While people can have their own "public knowledge-ways," whether such public knowledge-ways can be legitimately and saliently adopted to challenge orthodox knowledge supported by the state (at least by relevant government agencies) and industry relies on the level of social and epistemic control the orthodox side can realize. Hilgartner's (2017) "knowledge-control regime," which refers to "a sociotechnical arrangement that constitutes categories of agents, spaces, objects and relationships among them in a manner that allocates entitlements and burdens pertaining to knowledge" $(2017$, p. 9) can be a powerful explanatory tool, though the concept has not been tested in public science controversies since its debut.

According to Hilgartner (2017, p. 12), for specific knowledge, while multiple knowledge-control regimes are relevant, which can control objects, jurisdiction and relationships, there is a "governing frame," which promotes an official viewpoint that endows agents with specific entitlements and burdens pertaining to other agents or to control over spaces, objects and actions. In line with this idea, we can suggest that due to continued and concentrated controversies, the hydropower sector may suffer a weak governing frame in the public sphere to control knowledge production, distribution and acceptance, at least in the specific fields closely connected to debates. The suffering of the hydropower sector may both result from political factors that I discussed in the previous section (e.g., FA reduces hydropower supporters' control over jurisdiction) and be produced by the nature of the specific type of knowledge. In this case, it is loosely defined environmental sciences.

During my interview with an industry expert, he repeatedly stressed, by citing new literature, that ecology should be adapted rather than stationary, only highlighting the unalterable nature. Hence, ecologists should consider the benefits dams have brought to the ecosystem rather than merely insisting on the value of the so-called authenticity of original biodiversity (INT20170106). So, a representative of the dominant mainstream/orthodox hydropower 
knowledge became an outsider of another type of expertise, appealing to the latter to make appropriate adjustment. Hence, when the "unadjusted" ecology becomes a necessary part of the knowledge to support environmental assessment policies and implementation, partly through the channels created and expanded by anti-dam activists, the strength of orthodox hydropower knowledge as reflected in the industry plan drafting made by NDRC/NEA is weakened in the EIA policy-making and implementation process.

By nature, all types of knowledge should have the same problem, but, in accordance with the trading zone metaphor (Galison, 1997), there are many types of "harmonized" knowledge in which the potentially differentiating or even conflicting elements/paradigms may have reached consensus through negotiations and/or interest exchange. However, data collected in this book shows that when appearing in the public sphere, environmental, ecological, fishery and agricultural experts continuously challenged dams. This knowledge contention can be seen in Table 4.8, which outlines themes of hydropower in the four sampled Chinese media and the summative statistics of associated article attitudes and whether controversial/debatable contents are visible in these articles.

Per Table 4.8, among all themes, regulatory and environmental/ecological themes see the two highest association of negative media articles. The two types of articles also show the highest ratio of negatively reported media stories. The high percentage of negative reporting and visible controversies in environmentally-framed stories indicate that the hydropower sector had a low capacity to control knowledge of this type (environment, ecology, fish protection, sedimentation, and so on). Comparatively, stories with an engineering theme had the lowest rate of negative reporting and the second lowest percentage of visible controversies, representing that the hydropower sector had a much stronger control in this type of knowledge. The media analyses show that at least in the public sphere, the orthodox hydropower knowledge community cannot rein in the environmental sector in their effort to promote hydropower development.

This failure may reflect the fact that the hydropower sector's original "technology complex," using the terminology of Pietz (2015), has failed to integrate modern environmental, ecological and biological sciences adequately. In the sense of knowledge-control regimes, besides hydropower sector's insufficient jurisdiction control due to bureaucratic fragmentation, this is also related to the sector's failure to control space or objects due to most dams and reservoirs' normally open geographical conditions that make environmental and ecological impact data easily accessible even for ordinary external researchers.

On the other hand, due to China's environmental woes, ecological and environmental sciences are enjoying an increasingly privileged status in the country, and environmental knowledge production itself is connected with activism, as the environmental movements showed in the West decades ago (Eyerman \& Jamison, 1989). The increasingly salience and privilege of environmental knowledge makes the field a fertile land in producing public figures, 
Hydropower, fragmentation, knowledge-making 95

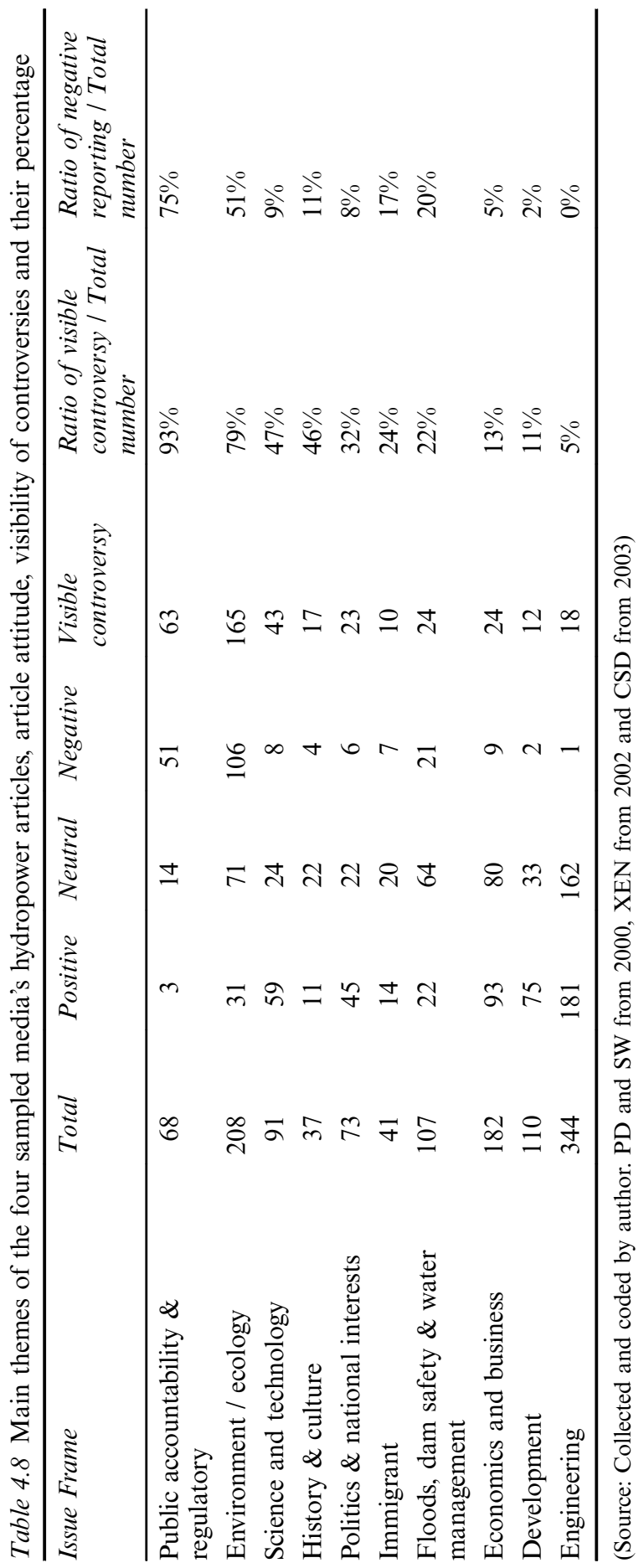


ranging from vice environmental minister Pan Yue (currently executive vice president of the Central Academy of Socialism in Beijing) to various anti-dam public intellectuals. Table 4.9 summarizes some of the prominent public intellectuals (primarily through the media), not including professional activists mentioned above, against hydropower in chronological order.

The above table shows that anti-hydropower experts were dispersed across fields such as environment, ecology, fishery and seismology. Although many of them were not consistent anti-dam activists, their identity and expertise were utilized by ENGOs and other activists to form a strategic front against hydropower developments periodically.

Scientists, scholars and experts are not the only group of people regularly and habitually questioning the knowledge of hydropower. Government agencies such as SEPA/MEP and MOA are these actors too. But unlike the analysis suggested by political frameworks such as FA, the knowledge-control regime analysis shows that these agencies compete with hydropower developers and their government sponsors (NDRC, MWS and NEA) not just for jurisdictional power, but also over knowledge issues.

For example, a hydropower industry expert pointed out that implementing EIA is only part of the story for SEPA/MEP to always "trouble" hydropower industry. "MEP and hydropower industry had a basic divergence. A major indicator to evaluate MEP's work achievements is to reduce chemical oxygen demand (COD). Building dams will certainly reduce water flow speed and increase COD" (INT20170106).

The claim was not confirmed by people linked to or familiar with SEPA/ MEP, but the agency's effort to collect, learn, organize and distribute knowledge that can resist hydropower is apparent. After SEPA officials learned about the WCD report from Yu Xiaogang in 2003, the agency invited him to Beijing to give its staff a detailed presentation on the report and its possible application in China and commissioned him to translate the WCD report. Yu was also invited to brief SEPA officials at its internal workshops about the report, which, for quite a long period, became a knowledge weapon for various individuals and organizations questioning dams (INT20161225).

According to Hilgartner (2017, p. 9), knowledge-control regimes "play a central role in regulating the production and use of knowledge," and they have a "lawlike structure, which constitutes specific means of controlling knowledge objects, disciplining actors and bringing order to specific jurisdictions." Based on the empirical data presented above, it seemed that the hydropower sector failed to regulate the production and use of the increasingly salient environmental knowledge. In this field, regarding hydropower projects' environmental impacts and consequences, hydropower companies lacked a lawlike structure that would enable them to control knowledge objects, discipline actors and bring order to specific jurisdictions, at least in the public controversy settings.

Of course, the hydropower sector's insufficient control of environmental knowledge production in the public sphere did not mean it became a weak 
Table 4.9 Noticeable public intellectuals against hydropower (excluding ENGO members)

\begin{tabular}{|c|c|c|c|}
\hline Name & Affiliation & $\begin{array}{l}\text { When and where to get } \\
\text { involved }\end{array}$ & $\begin{array}{l}\text { Level of } \\
\text { involvement }\end{array}$ \\
\hline $\begin{array}{l}\text { Lu } \\
\text { Qinkan }\end{array}$ & A senior hydraulic scientist & During TGP debates & High \\
\hline Lü Zhi & $\begin{array}{l}\text { Conservation biologist at } \\
\text { Peking Univ. }\end{array}$ & $\begin{array}{l}\text { As a head of ENGO of } \\
\text { the conservancy, Lü has } \\
\text { continuously been } \\
\text { involved in debates. }\end{array}$ & High \\
\hline Tian Song & $\begin{array}{l}\text { STS scholar at Beijing } \\
\text { Normal Univ. }\end{array}$ & $\begin{array}{l}\text { In the mid-2000s when } \\
\text { the southwestern hydro- } \\
\text { power controversy } \\
\text { became a hot event }\end{array}$ & Low \\
\hline $\begin{array}{l}\text { Liu } \\
\text { Huajie }\end{array}$ & STS scholar at PKU & $\begin{array}{l}\text { In the mid-2000s when } \\
\text { the southwestern hydro- } \\
\text { power controversy } \\
\text { became a hot event }\end{array}$ & Low \\
\hline $\begin{array}{l}\text { Weng } \\
\text { Lida }\end{array}$ & $\begin{array}{l}\text { Yangtze River Water } \\
\text { Resources Protection Bureau }\end{array}$ & $\begin{array}{l}\text { Consistently opposed to } \\
\text { southwestern dams in } \\
\text { upper Yangtze River }\end{array}$ & High \\
\hline $\begin{array}{l}\text { Chen } \\
\text { Guojie }\end{array}$ & $\begin{array}{l}\text { Chengdu-based Institute of } \\
\text { Mountain Hazards and } \\
\text { Environment (IMHE), CAS }\end{array}$ & $\begin{array}{l}\text { Involved against TGP } \\
\text { and later became a lead- } \\
\text { ing opponent to south- } \\
\text { western dams }\end{array}$ & High \\
\hline $\begin{array}{l}\text { Cao } \\
\text { Wenxuan }\end{array}$ & $\begin{array}{l}\text { Wuhan-based CAS Institute } \\
\text { of Hydrobiology }\end{array}$ & $\begin{array}{l}\text { Involved against south- } \\
\text { western dams for fish pro- } \\
\text { tection since the mid-2000s }\end{array}$ & Moderate \\
\hline $\begin{array}{l}\text { Bai } \\
\text { Daming }\end{array}$ & Yunnan University & $\begin{array}{l}\text { Involved against south- } \\
\text { western dams for ecology } \\
\text { in the early } 2000 \mathrm{~s}\end{array}$ & Moderate \\
\hline Xu Daoyi & $\begin{array}{l}\text { Retired scientist at Institute } \\
\text { of Geology, China Earth- } \\
\text { quake Administration, }\end{array}$ & $\begin{array}{l}\text { Involved against south- } \\
\text { western dams for their } \\
\text { possibly triggering earth- } \\
\text { quakes in the early } 2010 \mathrm{~s}\end{array}$ & Low \\
\hline $\begin{array}{l}\text { Sun } \\
\text { Wenpeng }\end{array}$ & $\begin{array}{l}\text { Retired scientist at Beijing } \\
\text { Research Institute of Ura- } \\
\text { nium Geology }\end{array}$ & $\begin{array}{l}\text { Involved against south- } \\
\text { western dams for their } \\
\text { possibly triggering earth- } \\
\text { quakes in the early } 2010 \text { s }\end{array}$ & Low \\
\hline Zhu Ming & $\begin{array}{l}\text { Retired scientist at Beijing- } \\
\text { based Institute of Geology } \\
\text { and Geophysics, CAS }\end{array}$ & $\begin{array}{l}\text { Involved against south- } \\
\text { western dams for their } \\
\text { potentially triggering } \\
\text { earthquakes in the early } \\
2010 \text { s }\end{array}$ & Low \\
\hline $\begin{array}{l}\mathrm{Li} \\
\text { Dongxu }\end{array}$ & $\begin{array}{l}\text { Retired scientist at China } \\
\text { University of Geosciences }\end{array}$ & $\begin{array}{l}\text { Involved against south- } \\
\text { western dams for their } \\
\text { possibly triggering earth- } \\
\text { quakes in the early } 2010 \mathrm{~s}\end{array}$ & Low \\
\hline
\end{tabular}


Table 4.9 (Cont.)

\begin{tabular}{|c|c|c|c|}
\hline Name & Affiliation & $\begin{array}{l}\text { When and where to get } \\
\text { involved }\end{array}$ & $\begin{array}{l}\text { Level of } \\
\text { involvement }\end{array}$ \\
\hline $\begin{array}{l}\text { Jiang } \\
\text { Gaoming }\end{array}$ & Institute of Botany, CAS & $\begin{array}{l}\text { A botanic scientist occa- } \\
\text { sionally against hydro- } \\
\text { power publicly }\end{array}$ & Low \\
\hline $\begin{array}{l}\text { Yu } \\
\text { Kongjian }\end{array}$ & $\begin{array}{l}\text { A famous gardening scholar } \\
\text { at Peking University }\end{array}$ & $\begin{array}{l}\text { Sometimes against hydro- } \\
\text { power publicly }\end{array}$ & Low \\
\hline $\begin{array}{l}\text { Huang } \\
\text { Wanli }\end{array}$ & A senior hydraulic scientist & $\begin{array}{l}\text { During TGP debates } \\
\text { became a symbol of the } \\
\text { anti-dam movement }\end{array}$ & Low \\
\hline $\begin{array}{l}\text { Liu } \\
\text { Shukun }\end{array}$ & A senior hydraulic scientist & $\begin{array}{l}\text { Occasionally against } \\
\text { hydropower publicly }\end{array}$ & \\
\hline $\begin{array}{l}\text { Zhou } \\
\text { Jianjun }\end{array}$ & $\begin{array}{l}\text { A hydraulics professor at } \\
\text { Tsinghua University }\end{array}$ & $\begin{array}{l}\text { Occasionally against } \\
\text { hydropower publicly }\end{array}$ & Moderate \\
\hline $\begin{array}{l}\text { Liu } \\
\text { Dehong }\end{array}$ & $\begin{array}{l}\text { Deputy director for sea } \\
\text { affairs at the Ministry of } \\
\text { Communications and a } \\
\text { CPPCC member }\end{array}$ & $\begin{array}{l}\text { Stood up to question } \\
\text { southwestern hydropower } \\
\text { projects in } 2005 \text { as a } \\
\text { CPPCC members }\end{array}$ & Low \\
\hline $\begin{array}{l}\text { Yang } \\
\text { Zunwei }\end{array}$ & $\begin{array}{l}\text { A CPPCC member and a } \\
\text { senior engineer at China } \\
\text { Harbor Engineering Corp }\end{array}$ & $\begin{array}{l}\text { Stood up to challenge } \\
\text { southwestern hydropower } \\
\text { projects in } 2005 \text { as a } \\
\text { CPPCC members }\end{array}$ & Low \\
\hline Lu Renda & $\begin{array}{l}\text { A CPPCC member and a } \\
\text { deputy chief engineer of } \\
\text { China Road \& Bridge Corp }\end{array}$ & $\begin{array}{l}\text { Stood up to question } \\
\text { southwestern hydropower } \\
\text { projects in } 2005 \text { as a } \\
\text { CPPCC members }\end{array}$ & Low \\
\hline $\begin{array}{l}\text { Zhang } \\
\text { Zhikai }\end{array}$ & $\begin{array}{l}\text { A CPPCC member and wife } \\
\text { of Politburo member Yu } \\
\text { Zhengsheng }\end{array}$ & $\begin{array}{l}\text { Stood up to challenge } \\
\text { southwestern hydropower } \\
\text { projects in } 2005 \text { as a } \\
\text { CPPCC members }\end{array}$ & Low \\
\hline Zhu Shou & $\begin{array}{l}\text { A CPPCC member and vice- } \\
\text { president of China General } \\
\text { Association for Light } \\
\text { Industries }\end{array}$ & $\begin{array}{l}\text { Stood up to question } \\
\text { southwestern hydropower } \\
\text { projects in } 2005 \text { as a } \\
\text { CPPCC members }\end{array}$ & Low \\
\hline $\begin{array}{l}\text { Li Xiao- } \\
\text { dong }\end{array}$ & $\begin{array}{l}\text { A CPPCC member and vice- } \\
\text { chairman of CPPCC Shaanxi } \\
\text { branch }\end{array}$ & $\begin{array}{l}\text { Stood up to challenge } \\
\text { southwestern hydropower } \\
\text { projects in } 2005 \text { as a } \\
\text { CPPCC members }\end{array}$ & Low \\
\hline $\begin{array}{l}\text { Zhao } \\
\text { Yimin }\end{array}$ & $\begin{array}{l}\text { Director of MOA Office for } \\
\text { Yangtze River Fishery }\end{array}$ & $\begin{array}{l}\text { Involved against south- } \\
\text { western dams for fish pro- } \\
\text { tection since the late } 2000 \mathrm{~s}\end{array}$ & Moderate \\
\hline
\end{tabular}

(Sources: Collected by the author from the media reporting)

actor. Despite the debates, the government's energy and economic planning agencies such as NDRC and the National Energy Administration (NEA) continued to approve hydropower development plans. The orthodox hydropower knowledge community, including various evaluation committees to 
back up these agencies' decisions, continued rejecting the alternative knowledge and its producers. Although nearly all publicly disputed dams were suspended or suffered remarkable delays, most of the undisputed dams were constructed without too strong resistance.

To summarize this section on STS perspectives on hydropower controversies, one can safely conclude that thanks to a civic epistemology that prioritizes environmental, ecological and societal consequences of hydropower development, activists have triumphed over the developmentalism discourse of the hydropower sector. Despite the hydropower sector's firm control over engineering knowledge and the development agenda, its knowledge-control regime failed to contain production and distribution of environmental knowledge - which became more salient public knowledge due to an alliance between the media and activism - due to both epistemic factors and political struggle over jurisdiction. Neither civic epistemology nor knowledge-control regimes were static but dynamically developed in the process of hydropower controversies, in which the choices of main actors, such as juridically powerful agencies like SEPA/MEP, can significantly shape either civic epistemology or relevant knowledge-control regimes. While civic epistemology and the knowledge-control regime have durable explanatory power in the context of China's hydropower controversy, applying them here also helped enrich the meanings of the two concepts while widening our understanding of knowledge production process.

\subsection{Chapter conclusion}

This chapter investigates China's hydropower controversy, particularly the southwestern hydropower controversies since the 2000s, with the analytical frameworks of communication scholarship, social movement theories and STS concepts. Each of these frameworks can explain some aspects of the occurrence and development of hydropower controversies, but none of them can solely cover the whole picture. For example, media commercialization and China's political censorship drove journalists to choose politically safer, yet technically sensational environmental issues for their negative reporting and this has boosted and strengthened hydropower controversies. But the reporting needs sponsorship from government agencies and support from experts. Bureaucratic fragmentation as a political opportunity structure resulted in such sponsoring agencies and the rising environmental knowledge that escaped the hydropower sector's knowledge-control regime offered supporting experts for the media. On the other side, both social movement mobilization and negative framing of hydropower projects were highly depended on the media. The press was also a vehicle to convey civic epistemology and a catalyst to break knowledge-control regimes of the hydropower sector, at least in environmental knowledge and regulatory aspect of hydropower projects.

On the other hand, factors derived from different theoretical frameworks interacted with each other frequently. Journalists turned to activists in the environmental sector, linking the media and activism; SEPA/MEP resisted 
hydropower development from its policy consideration (e.g., controlling COD), but also sought alternative knowledge from activists, partly legitimatizing the latter in the public sphere regarding the controversy.

Combining all these factors, we can find the hydropower sector, despite its tens of billions of yuan assets, was positioned in a relatively disadvantaged political and epistemic position. The hydropower sector suffered from media opposition, bureaucratic fragmentation, and the relatively weak knowledge-control regime in environmental knowledge, which became salient knowledge in the public sphere. It did not enjoy glorious national sociotechnical imaginaries to offset the disadvantages. As a result, although most hydropower projects were on schedule, partly due to the sector's firm knowledge-control regime in engineering and development agenda, nearly all publicly controversial dams were halted.

In applying the different theoretical frameworks in explaining China's hydropower controversy, this chapter also developed and enriched these theoretical traditions. For example, it introduced contested knowledge into social movement theories and borrowed fragmented authoritarianism to understand knowledge issues such as civic epistemology. These theoretical developments will be discussed and compared across different cases in the concluding chapters (Chapters 7 through 9).

\section{Notes}

1 He submitted the report to then-Premier Zhu Rongji. Chinese official media have long been empowered to reflect local situations directly to the central leadership without going through the local bureaucratic hierarchy in the form of so-called Internal Reference (Neibu Caokao, or simply Neican) (Nathan, 1986, pp. 152-171).

2 China has an established system to accept calls and petitions from people in the lower administrative jurisdiction. At the central government level, there is a State Bureau of Letters and Calls, and each government department is required to set up such an office or provide a similar function. However, letters and petitions submitted from these regular channels are at most processed by rank-and-file employees, with little chance to reach a senior official, let alone a minister or even a prime minister. 


\section{GMO controversy: How orthodox science lost control}

\subsection{Introduction}

In the past 40 years, disputes over genetically modified (GM) foods and crops have been spreading worldwide (Schurman \& Munro, 2010). China is no exception. Public support for GM foods has seen a steady decline in the past 15 years, and resistance to them has grown significantly (Cui \& Shoemaker, 2018). As a result, China has not approved any new GM variety since 2006 when the government gave the green light to an anti-virus version of GM papaya.

The GMO controversy has received the broadest scholarly attention in revealing social psychological elements leading to the public perception of the technology (Gupta, Fischer \& Frewer, 2012). Other studies have analyzed social disputes over it (Motta, 2014), activists' strategies to demonize agricultural biotechnology (Herring, 2008, 2010b) and communication factors associated with the controversy (M. C. Nisbet \& Huge, 2006; M. C. Nisbet \& Lewenstein, 2002).

However, few studies have integrated communication, STS and social movement scholarship to reveal the broader sociopolitical and epistemic landscape underlying the world's most sustained S\&T controversies. In addition, despite intensive local studies in China on public attitudes and an in-depth monograph on the issue's policy implications (Cao, 2018), no research has examined with a theoretical lens how anti-GMO activism, social and political transformation, and epistemic factors have co-evolved in China, the world's largest importer of GM crops (GM soy and corn). Combining different theoretical traditions for a meaningful explanation of China's GMO disputes is the objective of the current chapter.

\subsubsection{Social, psychological and political roots of GMO contentions}

From the 1970s, biotechnology has been frequently debated in mass media (Schurman \& Munro, 2006). Protests have followed a series of food scares, such as mad cow disease (Irwin, 2001). The British government's initial coverup and poor reactions shook the public confidence in its S\&T regulations (Bonny \& Sylvie, 2003).

DOI: $10.4324 / 9781003160212-5$ 
Indeed, public trust in institutional actors like government often strongly predicted support for GMOs (Einsiedel, 2002; Gupta et al., 2012; Pin \& Gutteling, 2009; Pin, Gutteling \& Kuttschreuter, 2009; Priest, 2001; Qiu, Huang, Pray \& Rozelle, 2012; Siegrist, 1999). Scholars believe institutional trust is based on value similarity - meaning whether people think that institutional players like government officials share the same values as them (Siegrist et al., 2000; Siegrist et al., 2012). Brossard and Nisbet (2007) argued that deference to scientific authority, a value long rooted in the American public, was a powerful predictor to explain trust in scientific institutions and the corresponding support for agricultural biotechnology in the United States.

Anti-GMO campaigns have consistently framed GMO as risky, uncertain, and sometimes unethical (Cook et al., 2006; Levidow \& Boschert, 2011). These observations are consistent with Herring's $(2008,2010 \mathrm{~b})$ more analytical assessment of anti-GMO activists' framing strategies. Although both medical and agricultural biotechnologies rely on genetic modification, activists have effectively branded the latter as "one ominous category: GMOs" (Herring, 2008, p. 459).

On the other hand, biotechnology and other mainstream scientists have been mediocre at engaging the public and mistreated its risk perceptions, thinking the public resistance to GMO was because of its naïve requirement of impossible "zero risks" (Cook et al., 2004; Cuppen et al., 2009). Scientists generally describe risk in a quantitative, measurable way, while the public tends to view it in a qualitative way (McInerney, Bird \& Nucci, 2004).

\subsubsection{The role of the media in the GMO controversy}

Although Europe's opinion-leading media's earlier coverage was positive to agricultural biotechnology (Gutteling et al., 2002), their attitude has changed since the mid-1990s. For example, Frewer et al. (2002) found European media tended to emphasize the negative impacts of GMOs and concentrated in reporting GMO safety studies. In their review of the UK media's reporting of its 2003 national debate, "GM Nation?" (Barbagallo \& Nelson, 2005), Cook et al. (2006) found the UK media widely cited public representatives and NGOs to counterbalance scientists and the government's effort to frame GMO in science and technology terms. Augoustinos, Crabb, and Shepherd (2010) further demonstrated that the UK media's GMO coverage during the 2003 national debate was full of semiotic signs and metaphors linked to the ongoing Iraqi war. Meanwhile, European media continued to treat medical biotechnology positively but reported agricultural biotechnology negatively (Marks, Kalaitzandonakes, Wilkins \& Zakharova, 2007).

The United States elite media were very favorable to biotechnology (M. C. Nisbet \& Lewenstein, 2002). In their analysis of TV evening news of GMO reporting over more than two decades, Nucci and Kubey (2007) found US TV (evening news) coverage of GMO was slight and mostly positive. Compared with the national press, US community newspapers included a more comprehensive 
range of concerns (Crawley, 2007), indicating that the biotechnology-friendly environment in the United States is most likely a result of elite support at the national level.

As a whole, when reporting agricultural biotechnology, US media adopted a cost/benefit frame more frequently while British media stories often used the frame of environmental risks (Marks, Kalaitzandonakes, Allison \& Zakharova, 2003). Listerman (2010) found that science and economic frames dominated the US media, German media had an active ethical discourse, whereas British media were inclined to link agricultural biotechnology to a public agenda.

According to M. C. Nisbet and Huge (2006), the GMO controversy was regularly assigned to science journalists rather than political or general assignment journalists in US elite media outlets and appeared mainly in science or environmental pages instead of front and political pages. Flipse and Osseweijer (2013) found that the science community, government and biotechnology industry's slow response to GMO-related controversial events resulted in their far lower presence in media than anti-GMO activists. When they did respond, media attention to the events had decreased, and most people did not have a chance to read or hear positive perspectives.

\subsubsection{Civic epistemology and knowledge control in GMO controversy}

Similarly to many authors cited above, Sheila Jasanoff also examined the national differences in biotechnology governance across the Atlantic (2005; 2011b). But she explored the more fundamental knowledge-making ways in which biotechnology is understood in the United States, Britain and Germany and their interaction with policymaking. According to Jasanoff (2011b), the United States (as a result of its habitual use of quantifiable risk assessments and its distrust of public roles in regulation) implemented an early and quicker exclusion of non-scientific voices in assessing biotechnology to form an interest group and market-driven, product-focused, scientific authority-seeking, and litigation-relying risk regulation system, smoothing the advancement of GMOs.

In examining the different policymaking processes, Jasanoff proposed the concept of civic epistemologies, which are the stylized, culturally specific ways in which the public expect the state's expertise, knowledge, and reasoning to be produced, tested and put to use in decision-making (Jasanoff, 2011b). This concept is particularly important in understanding how the GMO controversy featured a sharp tension between mainstream scientists' acceptance and the public's rejection (Rainie, Funk \& Anderson, 2015).

The conflict was captured by Schurman and Munro (2010) by using a concept developed by Schutz and Luckmann (1973) in sociology, "lifeworld", which "comprises a stock of culturally transmitted background knowledge that people bring to a situation and that provides them with a common cognitive and normative frame of reference" (Schurman \& Munro, 2010, Kindle Locations 252253). They argued that the conflicts between the scientist-industry lifeworld on the safety and efficacy of GMOs and the activists' lifeworld on their evilness 
explain the emergence of GMO controversies, its bitter disputes, the tactics each side used, and the social struggle changes across time (Schurman \& Munro, 2010, pp. 188-192).

The challenge of civic epistemology to orthodox genetic science and the conflicts of the two lifeworlds raise the question of knowledge control, explored by Hilgartner's (2017) "knowledge-control regimes" concept, which, though proposed through Hilgartner's study on the Human Genome Project (HGP), is still very useful for us to explore the emergence, sustainability and degree of GMO controversies. Using this framework, we may say that the US science-industry-government alliance (and, to a lesser degree, such partnerships in Canada, Australia, and Brazil) better controls the biotechnology knowledge production and distribution than the activist alliance, and that their control prevents activists and other citizens from comprehensively stigmatizing biotechnology.

In China, scholarly examinations of the GMO controversy are limited to measuring public attitudes (Cui \& Shoemaker, 2018; G. He et al., 2017; J. Huang, Qiu, Bai \& Pray, 2006b; Qiu et al., 2012) or the nominal appeals (mostly by Chinese STS scholars) to increase public participation in the policymaking process (C. Fan, 2010; X. Jiang, 2014; S. Tian, 2010, 2012). This chapter is an effort to fill the gap in our understanding of GMO controversy in the sociopolitical context in China.

\subsection{Contemporary GMO controversies in China}

Since 1997 when China commercialized Bt cotton, the country has experienced rapid growth in both biotechnology research and application. In 2019, China planted 3.2 million hectares of GM cotton and papaya, accounting for $1.7 \%$ of the total global land for biotechnology crops, ranking 7 th in the world in terms of the acreage used for such plants (ISAAA, 2021).

As described in Chapter 3, the first batch of campaigns against GMOs in China were all launched and organized by Greenpeace. In the late 2000s, another organized anti-GMO force was formed in China. The campaigners, consisting of Maoist intellectuals, activists, and some maverick scientists, organized around a Maoist website Wuyouzhixiang (literally meaning "Nowhere": http://www.wyzx.com and wyzxwk.com ${ }^{1}$ ), held up GMOs as a symbol of capitalism and the American imperialists' conspiracy to control China. The issuance of GM rice biosafety certificates in 2009 sparked a nationwide protest against GMOs and the policies to commercialize them. Meanwhile, GMO and plant scientists continued lobbying top Chinese leaders including Xi Jinping. But the pro-GMO front received a heavy blow in late 2013 when Cui Yongyuan, a famous TV talk show anchor, joined the movement against GMOs. With his substantial public influence, penetrating language skill, status as a CPPCC (the Chinese People's Political Consultative Conference, equivalent to China's upper house) delegate and strong mobilization capacity through social media, Cui became a new figurehead of China's anti-GMO campaign. 
In its recent policy agenda, China's science authorities (MOST and MOA) revised the roadmap of agricultural biotechnology, prioritizing the plan to commercialize non-staple food GM crops (GM corn and GM soya) in the 13th Five-Year S\&T Development Plan (2016-2020). However, by the end of 2020, there was no news on the final approval of any new GM crop in China. Several nationwide surveys continued to show public disfavor (Cui \& Shoemaker, 2018; G. He et al., 2017; Ren et al., 2016).

The above summary shows that with lots of media enthusiasm, contention about GMOs was prominent, sustained, and widely engaging science controversy in China. Both pro-GMO scientists and science communicators and anti-GMO activists tried to attack the other side with extreme claims and often emotional expression. A large number of intellectuals of different backgrounds were involved in anti-GMO campaigns which have been highly diversified. But on the other hand, few civil society organizations, including nearly all local ENGOs, have actively joined the debates on GMOs.

\subsection{Media landscape of GMO controversy in China}

\subsubsection{Media liberalization and scientists' communication failure}

Tracing China's GMO controversy lasting nearly 20 years, one can identify a crucial role the media has played. Since the very beginning of China's GMO controversy, presenting the technology's uncertainties and disputes in the press was a vital task of Greenpeace, which initiated China's anti-GMO campaigns and dominated their agenda until 2013-2014 when popular TV anchor Cui Yongyuan became the central actor.

Greenpeace fully utilized China's ongoing media commercialization and partial liberalization (Chan \& Qiu, 2002). It hired at the very beginning of its China operation active journalists from liberal media outlets like SW to work as its public relations staff (INT20160926, INT20161122), consistently attracted the liberal media's attention to its campaigns ranging from anti-GMO and tracing chemical pollution to fighting climate change, and effectively helped the media frame these events as defending public interests.

Media commercialization and partial liberalization have driven the Chinese media to attract public attention through sensational news reporting. GMOs are one of such topics. The mass media's impactful reporting initiated nearly every anti-GMO wave in China. Figure 5.1 records the increasing number of annual articles on GMOs published in the four sampled Chinese press outlets. The trend was reversed after 2015 when the propaganda department began to interfere with the reporting, according to sources (INT20160919, INT20160925).

Liu Jianqiang, the writer of the aforementioned 2004 SW article, told me in a 2008 interview that when Greenpeace proposed to him an investigative story option, he knew nothing about GMOs and had no interest in reporting scientific issues about it. However, the theme that highly respectful scientists may violate public interest for their profits had attracted him (Yi \& Jia, 2008). 


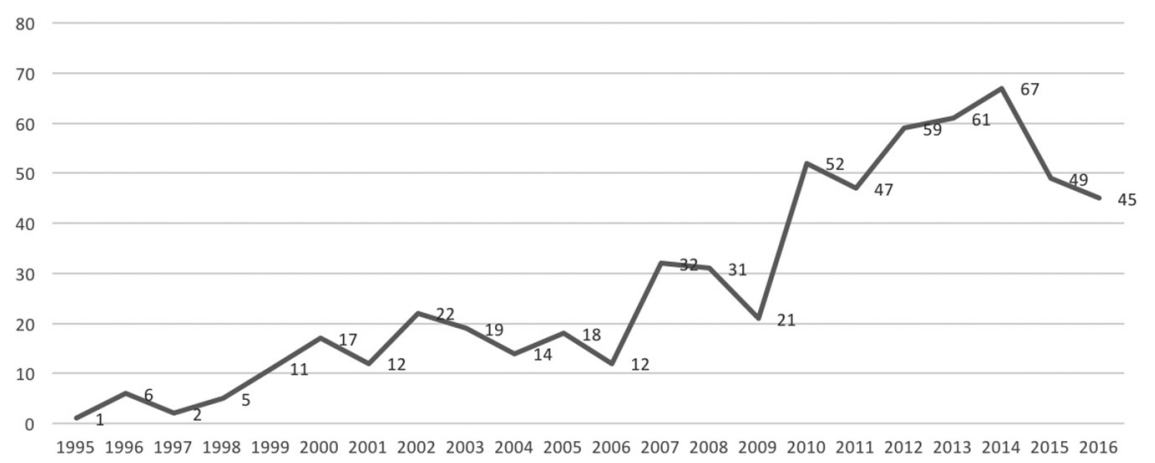

Figure 5.1 Number of the four sampled media's combined articles on GMO in China (1995-2016)

Source: Collected and cleaned by the author; PD: 1995-2016; SW: 2004-2016; XEN: 2007-2016; CSD: 2000-2016

Separate interviews with leading journalists of the liberal media confirmed the motivation to maintain public interest from the "infringement" by GMOs (INT20161022, INT20161219). Media content analysis confirmed the interview data. Table 5.1 summarizes the main themes of GMO-related stories among the four sampled media outlets. As in the case of hydropower, public accountability and regulatory issues became a significant frame in terms of the number of articles. That frame highlighted visible controversies and contained more negative reporting than positive ones. In fact, in the late 1990s, while the domestic newsroom of $\mathrm{PD}$, as a top propaganda outlet, unanimously praised Chinese advances in agricultural biotechnology as a significant scientific achievement, its international pages shared no efforts to introduce the surging international controversies and debates on GMOs.

Compared with the few environmental frames, the Chinese media, especially urban tabloids such as WEN, more often framed GMO stories as food safety issues. Accompanying the high dissatisfaction with public accountability were the repeated outbreaks of food scandals such as the 2008 baby milk contamination in which food producers added the industrial chemical melamine to increase the indicator for protein content of milk falsely, and public confidence in food safety crashed (Lam, Remais, Fung, Xu \& Sun, 2013; Y. Ma \& Zhao, 2009; Y. Yan, 2012). One possible reason for the widespread public rejection of GMO is that ordinary people thought of it as food contamination (P. Ho, Vermeer \& Zhao, 2006; Vermeer \& Ho, 2004). Hence, the widespread public concerns on food safety could be easily transferred to public rejection of GM food, just as in Europe (Bonny \& Sylvie, 2003; Frewer et al., 2004), particularly after continued media reporting made the GMO dispute a salient science controversy in contemporary China. 
Table 5.1 Main themes, article attitude, visibility and percentage of coverage of the four sampled media's GMO articles

\begin{tabular}{|c|c|c|c|c|c|c|}
\hline & Total & $\begin{array}{l}\text { Neg- } \\
\text { ative }\end{array}$ & $\begin{array}{l}\mathrm{Neu}- \\
\text { tral }\end{array}$ & $\begin{array}{l}\text { Posi- } \\
\text { tive }\end{array}$ & $\begin{array}{l}\text { Visible } \\
\text { controversy }\end{array}$ & $\begin{array}{l}\text { Ratio of visible } \\
\text { controversy / } \\
\text { Total number }\end{array}$ \\
\hline Food safety & 65 & 5 & 21 & 39 & 50 & $76.9 \%$ \\
\hline Business \& economy & 34 & 3 & 11 & 20 & 12 & $35.3 \%$ \\
\hline $\begin{array}{l}\text { Development \& } \\
\text { welfare }\end{array}$ & 6 & 0 & 0 & 6 & 1 & $16.7 \%$ \\
\hline $\begin{array}{l}\text { Environment \& } \\
\text { ecology }\end{array}$ & 14 & 8 & 5 & 1 & 13 & $92.9 \%$ \\
\hline $\begin{array}{l}\text { Science comm \& } \\
\text { popularization }\end{array}$ & 13 & 0 & 1 & 12 & 7 & $53.8 \%$ \\
\hline Ethics \& Pandora & 1 & 0 & 1 & 0 & 1 & $100.0 \%$ \\
\hline Politics \& policy & 16 & 3 & 4 & 9 & 13 & $81.3 \%$ \\
\hline $\begin{array}{l}\text { Public accountability } \\
\text { \& regulatory }\end{array}$ & 159 & 35 & 95 & 29 & 145 & $91.2 \%$ \\
\hline S\&T progress & 256 & 8 & 40 & 208 & 62 & $24.2 \%$ \\
\hline
\end{tabular}

(Source: Coded by the author; PD: 1995-2016; SW: 2004-2016; XEN: 2007-2016; CSD: 2000-2016)

As in the environmental reporting, a small group of journalists, such as Jin Wei, currently a leading journalist at financial newspaper Huaxia Times, also worked as a prominent anti-GMO activist, though unlike their environmentalist colleagues who set up formal ENGOs, the anti-biotechnology journalists did not form any formal organization. In the heyday of China's anti-GMO moments in 2010 and 2011, Jin and colleagues reported the false news that after eating GM corn and GM soya, sows suffered miscarriages while mice disappeared, causing public panic (Wei, 2013).

Besides the media's effort to promote debates and uncertainties, as in the West, scientists' poor reaction to activists' challenges and public concerns were other factors underlying the biotechnology controversy (Cook et al., 2004; Cuppen et al., 2009; McInerney et al., 2004). Chinese scientists shared their Western counterparts' disdain for the public. "At an academic meeting at the time when GMO first became a controversial topic, we even sneered at the one who tried to persuade the public that GMO is harmless," said a senior biotechnology scientist during an interview (INT20161118). "Without popularizing to the public, [agricultural] scientists only wanted to persuade top leaders. Now the GMO controversy has become a serious barrier [to the commercialization of GM crops]," said one senior agricultural journalist (INT20170723).

Since 2009, when GMOs became a national controversy, Chinese scientists have been acting to increase their popularization efforts. The \$3.5-billion mega-GM seed initiative (R. Stone, 2008) also offered a subsidiary grant to 
support such risk communication activities, in which I was involved to advise HZAU, then a lead implementer of the grant-supported communication projects. They composed popular science books, launched popular websites or webpages for biotechnology, and set up several exhibition rooms - all classic "deficit" model activities.

The propaganda-oriented public science information system in China (Jia \& Liu, 2009) increased the problem of poor communication. Two PIOs (public information officers) of the Chinese Academy of Science (CAS) institutes and one member of staff from China Association for Science and Technology (CAST) admitted they would intentionally avoid talking about GMOs and other hot public science controversies to avoid upsetting their audience and offending their institutional leaders (INT20160925c, INT20160928, INT20160821).

Scientists plus the biotechnology industry indeed increased their efforts to "educate" the media after the GMO controversy became intensified. Every year, the Chinese Society of Biotechnology, China branches of Monsanto and industry organizations like CropLife, and local biotechnology firms like Beijing Dabeinong Technology organized a couple of media workshops on GMOs, involving hundreds of media journalists. Based on my observations, participating journalists were pro-GMO or technology-savvy, but many stories questioning biotechnology were reported by their colleagues absent from the event or by media not reached by the training. In the heyday of GMO controversies (roughly 2010-2014), Chinese media showed a very high diversification of authorship (INT20161110) because the high public interest in the topic involved reporters of many different beats. Although I was not able to implement for this study a systematic empirical comparison, the media structure for supporting greater diversification of authorship looked more diversified than in the hydropower reporting mentioned in the previous chapter and contrary to (and theoretically consistent with) the low participation in biotechnology reporting that M. C. Nisbet and Huge (2006) revealed among US media workers.

The diversification also existed across different media outlets. Figure 5.2 shows that the four sampled media outlets generally had more positive than negative news stories on GMOs.

But among them, the more impactful non-official media source Southern Weekend (SW) published many more negative stories than positive ones (Negative: neutral: positive $=17: 9: 9$ ). Also, negative stories mostly appeared in front pages or other relevant news pages while pro-GMO pieces were mostly popular science articles in the cultural section (SW does not have specific science pages) hidden within the paper. "Those [negative GMO] stories were often produced by investigative reporters supported by news editors which I cannot control," said a science editor affiliated with the Cultural Department of SW (INT20161016).

The slow reaction of scientists to cases like the unethical golden rice nutrition experiment (G. Tang et al., 2012) and illegal planting of GM crops also 


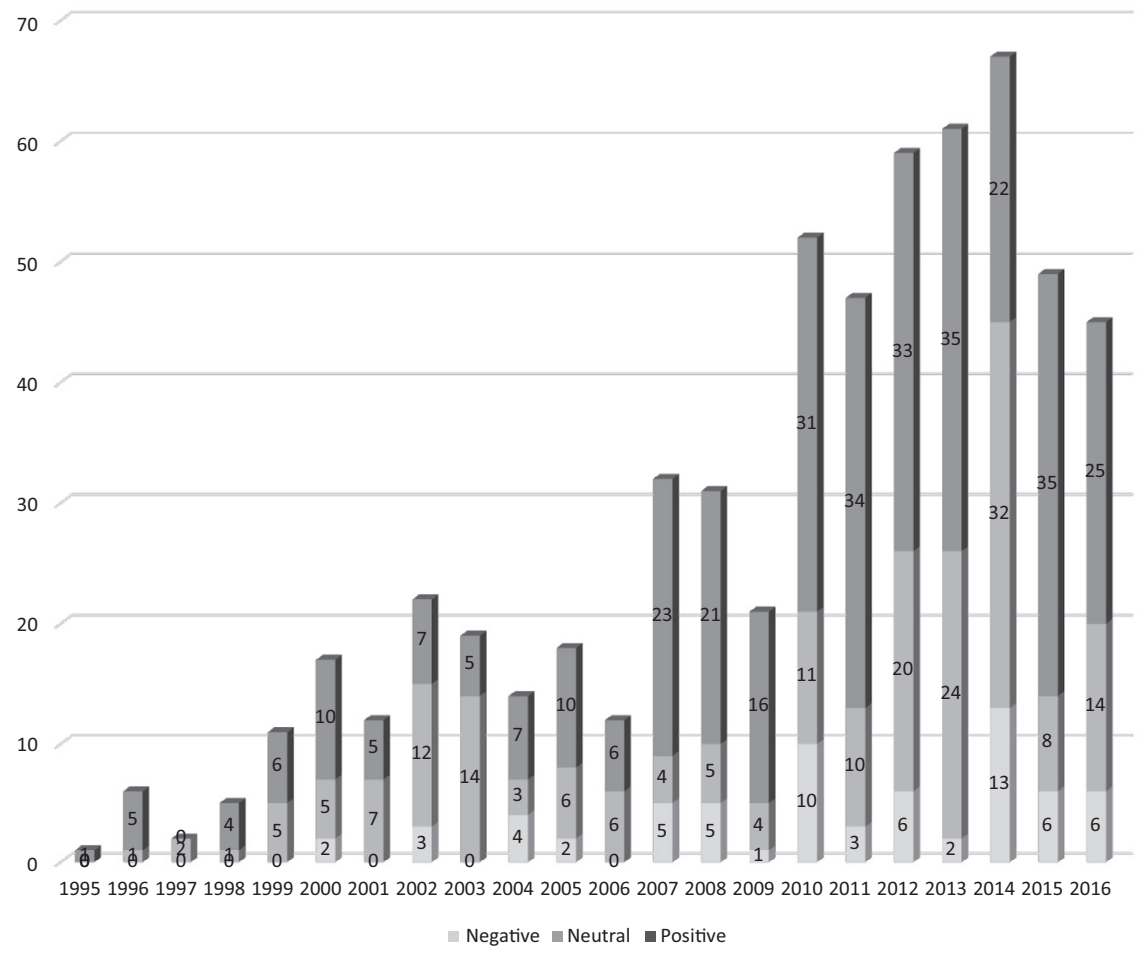

Figure 5.2 Attitude of sampled media articles to GMOs in China 1995-2016 Source: Collected and coded by author

caused an information imbalance on biotechnology in the media, similar to what Flipse and Osseweijer (2013) have observed. More than in the West, Chinese biotechnology scientists were often warned by government officials against talking to the media directly (INT20161226).

Despite the above structural disadvantages, Chinese biotechnology scientists eventually managed to improve media outlets' overall attitude to GMOs, aided to a certain degree by the communist party's publicity departments' media censorship. Figure 5.3 indicates a decreased quantity of negative coverage of GMOs by the four sampled media outlets. Although the sample may not be representative enough (GMO-friendly science and official media such as CSD and PD published most of the positive stories), scientists and pro-GMO journalists generally reflected their positive impression (INT20161115, INT20161110a, INT20161118).

However, with the decline of traditional media outlets (including print media and established online news portals) and the rise of social media, the GMO controversy remained popular, especially on social media platforms. The following subsection will explore this aspect. 


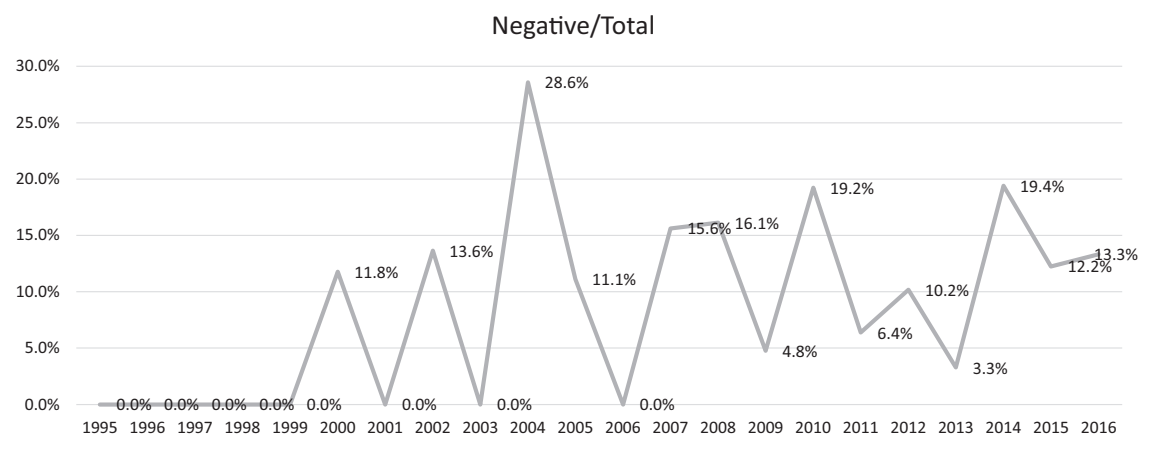

Figure 5.3 Percentage of sampled media articles adverse to GMOs in China 1995-2016 Source: Collected and coded by author

\subsubsection{GMO debate on rising social media}

While print media fueled or even triggered China's GMO controversies, it was the Internet that deeply embedded the dispute among the average Chinese public. Figure 5.4 is Baidu Index's media index (unavailable through Google), indicating the frequency of the Chinese media mentioning GMOs in their reporting from 2011 (the earliest available indexing time). Then Figures 5.5 and 5.6 present online search trends by Baidu and Google, respectively. Google's data started in 2004, but after its complete blockage in China in 2011, Google search may not accurately reflect search behavior by Chinese citizens. Luckily, Baidu's search data starting in 2011 may offset the gap. Similarly, Figure 5.1 on the number of the sampled media articles on GMO in China may somewhat fill the gap caused by Baidu's lack of pre2011 data. Figure 5.4 to Figure 5.6 were all screenshotted by the author on January 5, 2019.

Figure 5.4 indicates that traditional media reporting of GMOs has shown a declining trend. These figures show that the frequency of media

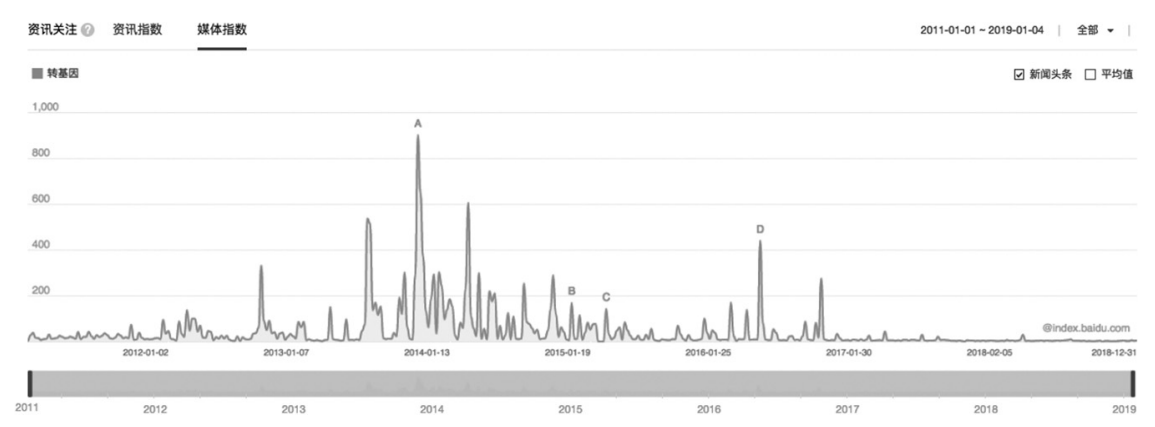

Figure 5.4 Baidu media index of GMOs in China (2011-2018)

Source: Baidu Media Index 


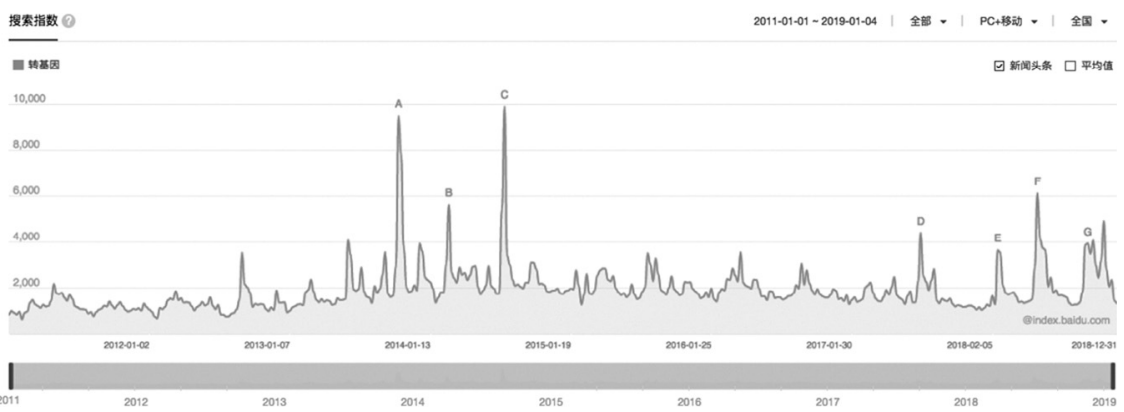

Figure 5.5 Baidu search index for GMOs in China (2011-2018)

Source: Baidu Search Index

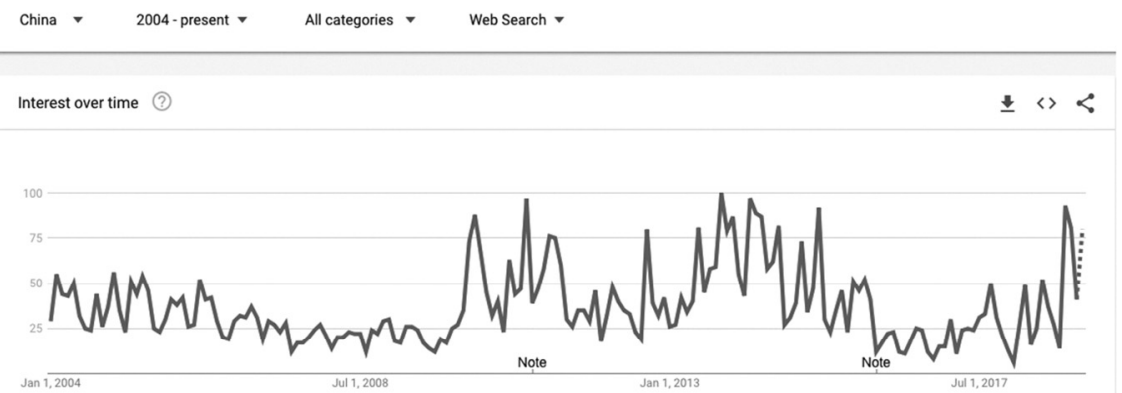

Figure 5.6 Google search index for GMOs in China (2004-2018)

Source: Google Trends

coverage of GMO issues was consistent with people's search behaviors of the keyword GMO. The consistency matches Segev and Baram-Tsabari's (2012) finding that media attention to news events was driving sciencerelated searches. The pattern indicates that media coverage (and indeed opinion leaders' social media posts) pushed people's attention to, and raised similar concerns about, GMOs.

During the period, bulletin board systems (BBS) were also frequently used. Figure 5.7 represents high-impact BBS posts (with impact defined as posts with more than 100 following comments) on Tianya.cn. The figure indicates that the year 2010, when China issued two biosafety certificates to GM rice, had a significantly higher number of impactful BBS posts.

The consistent GMO controversy is also associated with rising Internetbased media platforms, ranging from news portals and blogs to Weibo and WeChat (China's primary social media platforms). Given China's strict control of print media and their electronic versions, online portals and nonofficial 


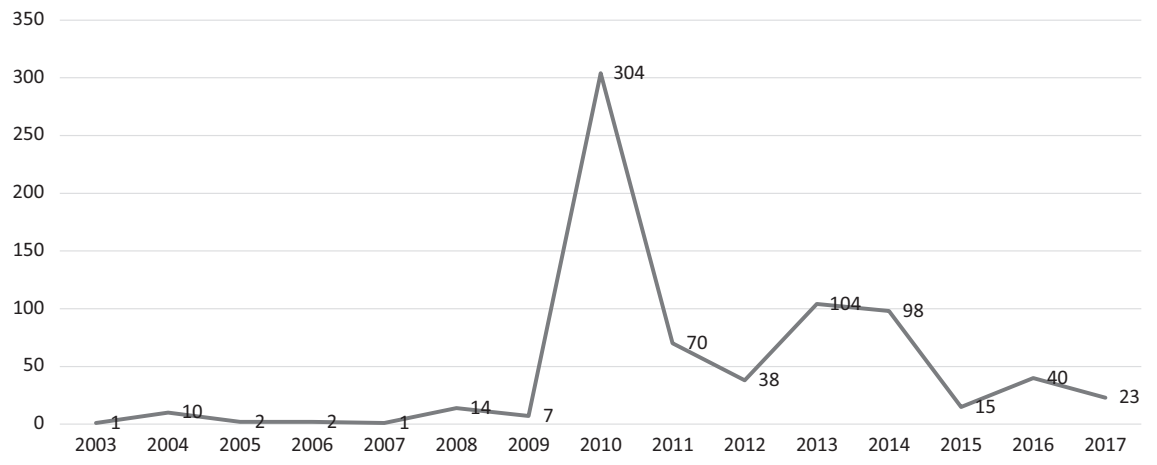

Figure 5.7 High-impact BBS posts on Tianya (2003-2017)

Source: Data collected and graphed by Kai Liu

websites, blogs, Weibo, and WeChat became the main bases for activists to launch anti-GMO campaigns.

The active role the Internet played in promoting the GMO controversy became clear when SW published in December 2004 its compelling cover story questioning commercialization of GM rice. Within days, Google search indicates that the article was reposted nearly 10,000 times (Yi \& Jia, 2008), creating enormous pressure and effectively halting the commercialization process. Several popular news portal editors admitted that they preferred to post hotly disputed GMO news to boost online visits (INT20170108, INT20170109, INT20170725).

Between the SW story in 2004 and the national protest against biosafety certificates in 2010, China experienced a booming development of the Internet, with its users surging from 94 million to 437 million, and blog use percentage growing from $0.5 \%$ to $64.4 \%$ (China Internet Network Information Center (CNNIC), 2005, 2011). The technology progress resulted in multiple online information portals for anti-GMO activism. Blogs were the most frequently used.

Searching Sina Blog, one cannot find well-archived results containing old blogs on GMOs, partly due to later intensified online censorship, though there was still available in 2018 a long list of contemporary blog articles, mostly taking an anti-GMO stance. Historically, blogs were a major anti-GMO front, and most anti-GMO activists published blog articles. With blogs, personal websites also mushroomed in China. According to the 2011 CNNIC report cited above, in December 2010, China had 1.91 million sites. Many activists, including Chen Yiwen, set up websites posting anti-GMO news.

A noticeable media advancement regarding anti-GMO activism was the emergence and development of Maoist websites, mainly the extreme leftist site Utopia (Wuyouzhixiang: wyzxwk.com), which had a particular column specifically attacking GMOs. I searched and analyzed three emerging Maoist 
websites: Utopia, Chawang (literally meaning "the site for examination," cwzg.cn), and Red Song Club (szhgh.com). Using GMO as my keyword, I found thousands of relevant articles, including Utopia's 4,340, Chawang's 234 and Red Song Club's 45,778. I read and coded the first 50 most read items from each of these websites, and found all of them, including comments, various rumor-based claims and negative news stories posted from other websites, were critical of GMOs.

Compared with blogs and websites, the arrival of Weibo and other microblogging platforms played a more significant role in spreading anti-GMO voices of non-establishment elites, amplifying people's concerns and promoting public protest (Wen et al., 2016; Q. Xu, Yu \& Song, 2018). Our previous research on the public reaction on Weibo to an unethical study led by Tufts University scientists to feed Chinese children with golden rice without properly informing procedure (G. Tang et al., 2012) revealed that social media quickly amplified the impact of GMO events, enhanced attitudinal polarization and resulted in fragmentation of public opinions (J. Fan et al., 2013). Social media has significantly increased public participation in the GMO controversy in China (Jia et al., 2014).

Anti-establishment public opinion leaders quickly utilized the widespread public concerns and the powerful communication effects of social media. Former TV anchor Cui Yongyuan, currently a central figure of China's antiGMO campaigns (INT20161110a, INT20160929, INT20161115), is such an example. After he was involved in the anti-GMO campaign in 2013, Cui masterfully handled Weibo and other social media platforms (such as Tencent's microblogging site which is now closed). He highlighted negative aspects of GMOs with the public accountability frame, activated public concerns, mobilized follow-up media reporting and carved his role as a public intellectual to defend the public interest against the infringement of biotechnology (Jia et al., 2015). With 19.5 million followers at the time this chapter was drafted (January 2019), his tweets dramatically increased the reach of anti-GMO information and public rejection of the technology.

Using an external Weibo analysis tool Weiboreach.com, Table 5.2 illustrates the massive impact of Cui by analyzing his six most commented GMOrelated tweets in the first three pages of his Weibo account that were available for visits (from December 20, 2018, to January 6, 2019). The six tweets alone produced 143 million views (Weiboreach.com defined viewing as information appearing in viewers' Weibo accounts) and over 9,300 forwards.

Based on Table 5.2, one can find that many anti-GMO messages reached millions of people, intensifying the widespread anti-GMO mentality. In addition to spreading anti-GMO information, Weibo was also utilized to produce antiGMO news stories. According to an internal report submitted to the top Chinese leaders drafted by a pro-GMO expert (INT20160922), a series of negative media stories on GMOs was first posted on Weibo by an active anti-GMO activist with the pen name Zhiyanliao (literally "speaking truth"), before the media published them. These stories claimed that planting GM corn in Shanxi and Jilin provinces 


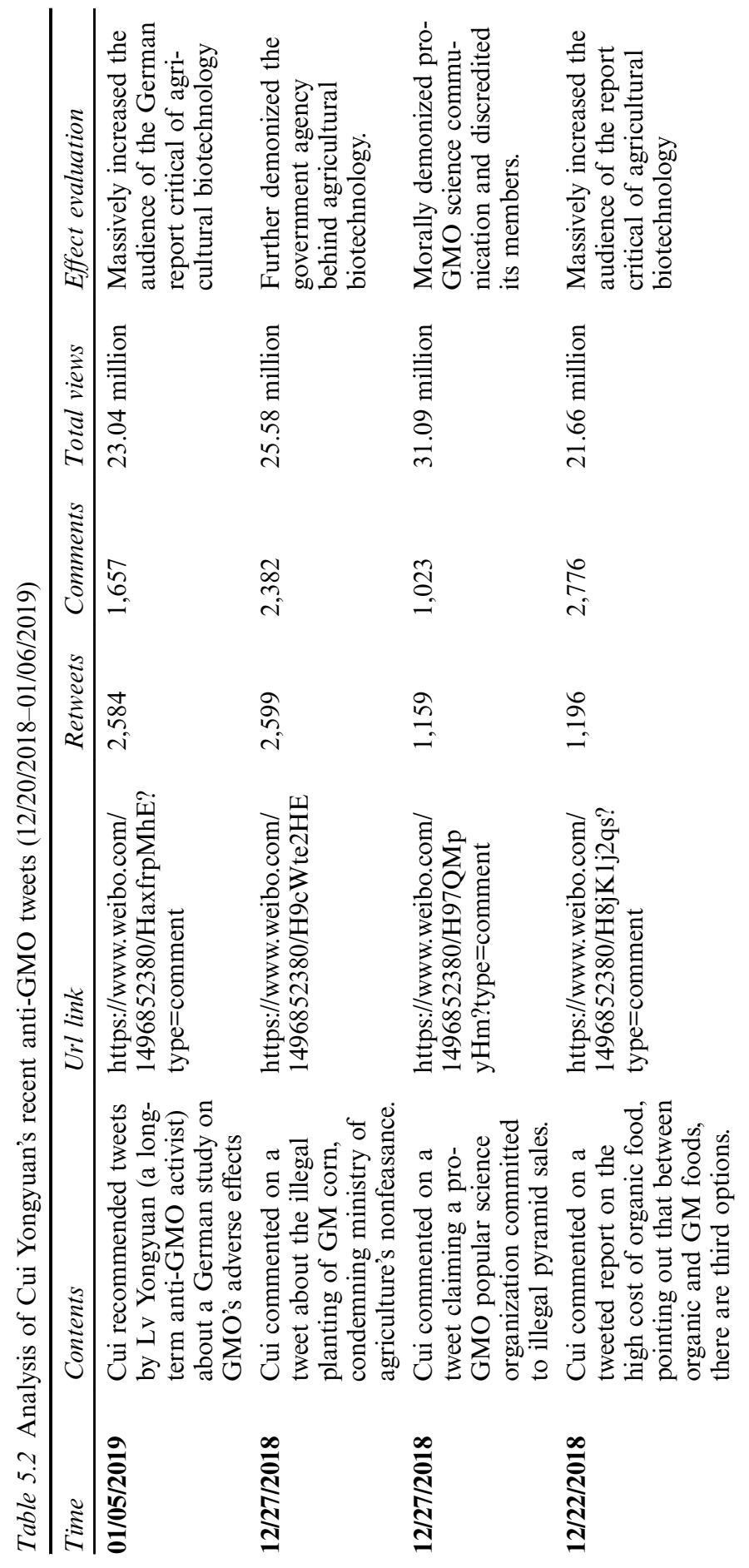


GMO controversy 115
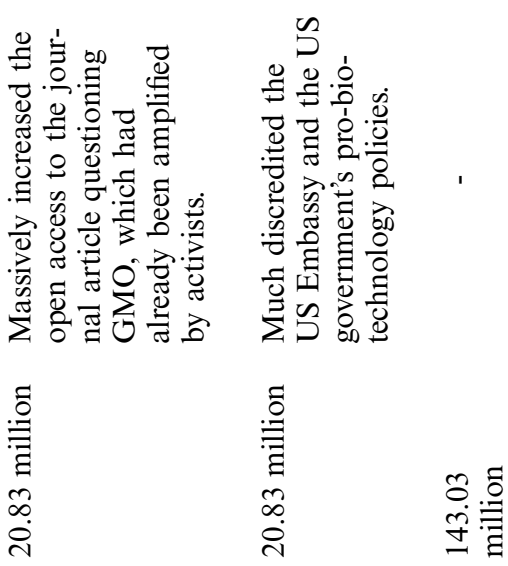

$\stackrel{n}{=}$

$\stackrel{\infty}{\infty}$

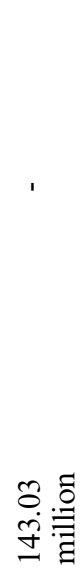

웅

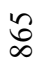

à

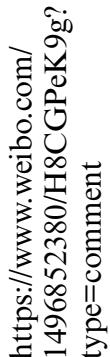

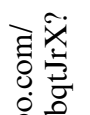

0
0
0
0
0
0
0
$\infty$
0
0
0
0
0
0
0
0
0
0
0

in

ปี

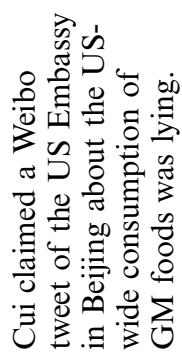

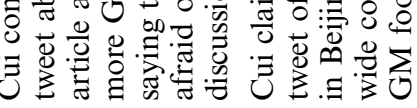

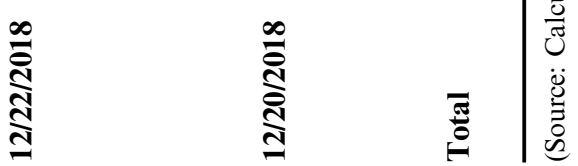




\section{6}

GMO controversy

caused abnormal swine diseases and reduction in the mouse population. The media news was then quickly tweeted by Zhiyanliao and other activists to make a public impact on social media. Our earlier study also found evidence to show that in exposing the unethical Tufts study, some opinion leaders were "assigned" to amplify Greenpeace's claim on Weibo (J. Fan et al., 2013). A separate interview with a former Weibo editor revealed that finding that GMO topics boosted visits, the social media platform often promoted such tweets in its homepage (INT20170109).

The GMO controversy also quickly spread to WeChat. Using QS Data (www.qsdata.com), I found and downloaded on January 29, 2019, the 50 most read WeChat public account articles on GMOs for coding and analysis. As expected, all WeChat articles posted by public accounts of traditional media outlets ( 8 out of the 50 items) were positive, though as a whole, more WeChat articles held a negative tone ( 25 negatives versus 22 positives).

In terms of the primary theme of the 50 sampled WeChat articles, public accountability and regulatory issues (18), food safety (11) and science communication (10) dominated the agenda. It is noticeable that controversy contents were visible even in those pro-GMO articles, particularly for public accountability-framed stories in which relevant government departments, particularly Ministry of Agriculture and Rural Affairs (MOA), responded to an accusation made by Cui Yongyuan in early December. The ministry denied Cui's claim that the ministry itself avoided GM foods for its internal food consumption. Similarly, many science communication articles defending GMO safety often had to admit controversies and then refute those adverse claims. Besides, among the top 50 viewed items, two completely embraced conspiracy theories behind GMOs and over $50 \%$ of the food safety articles quoted false information or discredited anti-GMO activists like F. William Engdahl.

Another pattern one can observe is the high diversification of public accounts that published GMO stories, ranging from news outlets (e.g., the WeChat accounts of conventional media) and popular science sites to entertainment, culture, religion and cuisine accounts. The high public attention to GMO issues was a driving force for many non-news and nonscience sites to post GMO stories so that they could win more visits, a benchmark criterion for a WeChat account to earn advertising money or impact. When discussing the diversified media morphology for the mass media to report GMOs, I described the high diversity of reporters and the media outlets in reporting GMO. The WeChat data further confirmed the pattern. I will explore its epistemic implication in the section on the knowledge-control regime.

So far, in this section, I have analyzed the communication factors underlying China's GMO controversy. Mass media liberalization and commercialization, scientists' structural disadvantage in dealing with disputes, the Internet's ability to boost public attention, social media's capacity to create and fuel alternative public opinion leaders, and people's deep concern 
about food safety and their lack of institutional trust jointly promoted the widespread rejection of plant biotechnology and GM foods.

However, just as in the hydropower controversy, the communication pattern is not enough for us to fully understand the debates of GMO issues. For example, why did the media not rely on orthodox scientists when reporting on GMOs? Why has the GMO controversy lasted much longer than other scientific controversies? More specifically, why in authoritarian China has the politically prioritized biotechnology research and development scheme been frequently disputed and discredited without receiving much censorship?

It is necessary to explore these issues further using both the social movement theory framework and several STS-oriented theories. In the subsequent section (Section 5.4), I will examine the components of social movement theories particularly of political process theory and FA framework - underlying China's GMO controversies. Following that, STS concepts such as knowledge-control regime (Hilgartner, 2017) and civic epistemology (Jasanoff, 2011b) will be probed in Section 5.5.

\subsection{Examining the GMO controversy as a social movement}

\subsubsection{Emerging political opportunity structure fueling the GMO controversy}

Tracing China's GMO controversy in the past 20 years, one can quickly identify the three drivers - a favorable political opportunity structure, robust frames, and effective mobilization - of social movements (Tarrow, 2011). Unlike in Western democracies, China lacks the institutional faces of these drivers. For example, the political opportunity structure embedded in the tension between government's executive branches, legislature, and advocacy groups which explained the fate of anti-nuclear power campaigns in Western European countries (Kitschelt, 1986) is virtually non-existent in China. However, various political opportunities linked to China's economic reform and opening-up still structurally brew, promote and sustain science and technology controversies, of which the GMO debate is a salient one.

For the political opportunity structure facilitating the GMO controversy, China's opening-up to allow the massive penetration of international civil society organizations, including Greenpeace, into Chinese society, should be counted as a primary element. The introduction of foreign NGOs resulted from Chinese agencies' effort to seek professional consultation services, as evidenced by the fact that Greenpeace came to China as a project office linked to the nature conservancy project of the then State Forestry Administration (now State Forestry and Grassland Administration of China) (Teets, 2014). However, without political tolerance, Greenpeace and other international NGOs' involvement in the authoritarian nation's environmental activism was unimaginable. Therefore, the political environment allowing Greenpeace to initiate and sustain anti-GMO campaigns in China can be safely considered a political opportunity. 
A second political opportunity favoring Greenpeace to launch its antiGMO campaign in China is the internationalization of academics. The early activities of Greenpeace in China connected it with some internationally active Chinese environmental or ecological scientists, who utilized Greenpeace's expertise and perhaps funding but meanwhile offered chances for the organization to legitimate its activities (INT20161215). The move to preserve biodiversity from challenges posed by adopting biotech crops enabled the debate to be defined as an academic dispute, tolerable to the authoritative Chinese regime (INT20170310) and echoed China's international political stance of conserving biodiversity (INT20160926).

But Greenpeace as a highly experienced social movement promoter quickly shifted its focus from low-profile biodiversity conservancy to challenging public accountability of biotechnology developers. The Chinese government's highly criticized cover-up of the SARS epidemics in 2003 legitimatized the public call for accountability and transparency.

Table 5.3 lists all major controversial events about GMOs in China in recent years. Nearly every major event was associated with the poor accountability of scientists or government officials and the lack of transparency of relevant policies.

Most of the cases listed above would not have been widely noticed without media involvement or intervention. Some milestone incidents, such as the impactful 2004 critical reporting by SW of the commercial-interest-driven effort to commercialize GM rice which effectively halted the crop's commercialization, could even be defined as media events (INT20161118) (Yi \& Jia, 2008). Others, like GM rice's biosafety certificate, could not be publicly disputed without media exposure. Thus, the media commercialization and partial liberalization examined in the previous section must be considered a central component of the political opportunity structure nurturing GMO controversy in China.

While Greenpeace and the media were the main actors at the early stage of anti-biotechnology campaigns, the issue's politicization in the late 2000s offered fresh blood to activism. In 2010, the biosafety certificate granted to HZAU and the Chinese Academy of Agricultural Sciences (CAAS) in the previous year ignited nationwide fear and anger against biotechnology. A group of princelings of the first generation of Chinese leaders, including the daughters of Mao Zedong, Ren Bishi (1904-1950, a standing member of the politburo in the 1940s), and Ye Jianying (1897-1986, military marshal) reportedly formed a small but influential group to lobby the top Chinese leader $\mathrm{Hu}$ Jintao to halt the commercialization process of GMOs. The struggle was framed as legal action by the communist offspring inheriting the socialist legacy against Deng Nan, the daughter of Deng Xiaoping (19041997) (Y. Yin, 2017). Deng Nan, who inherited her father's strong support for agricultural biotechnology (to be discussed in the next section), was the former vice minister of science and technology and then the head of China Association for Science and Technology. 


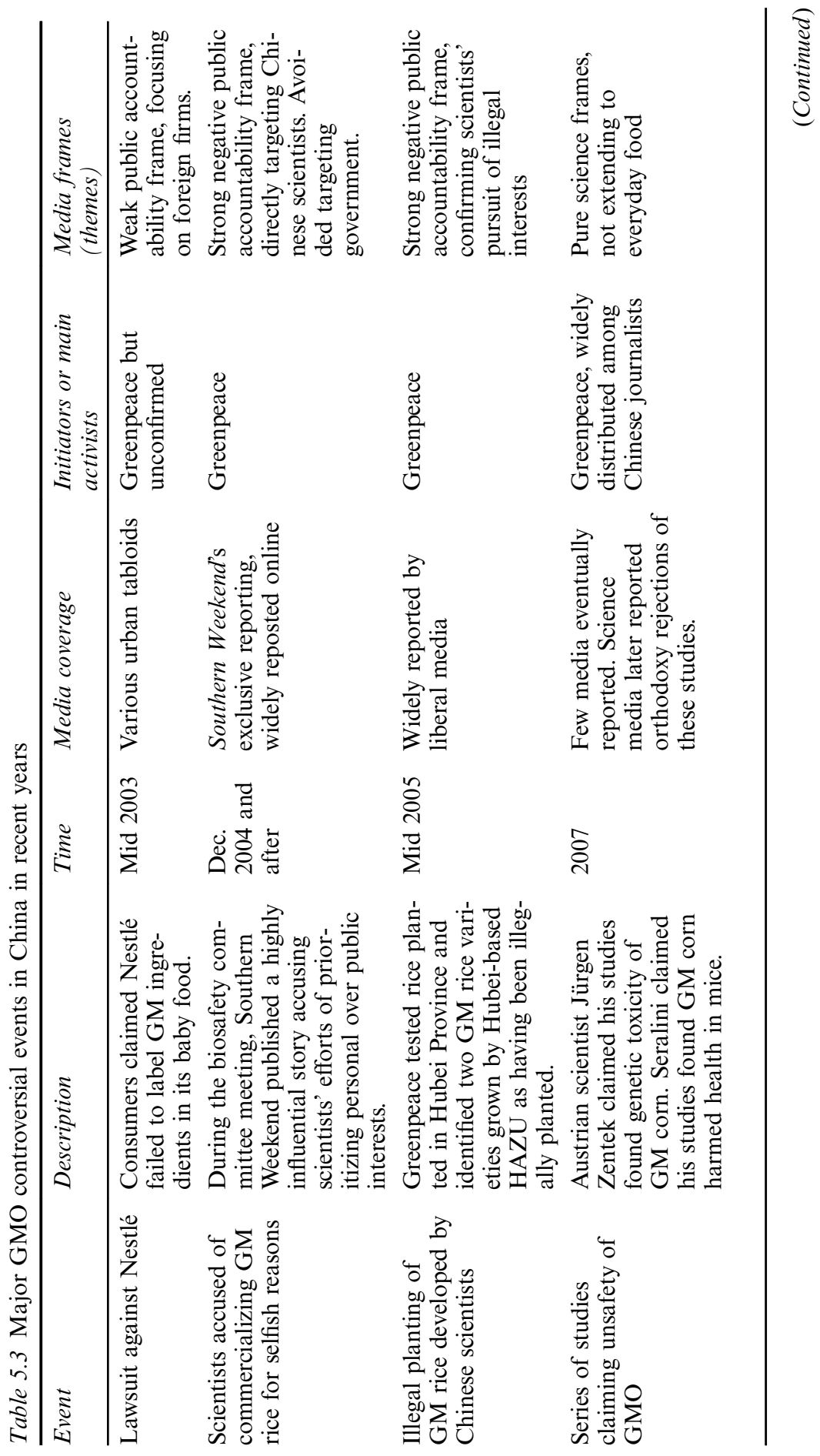




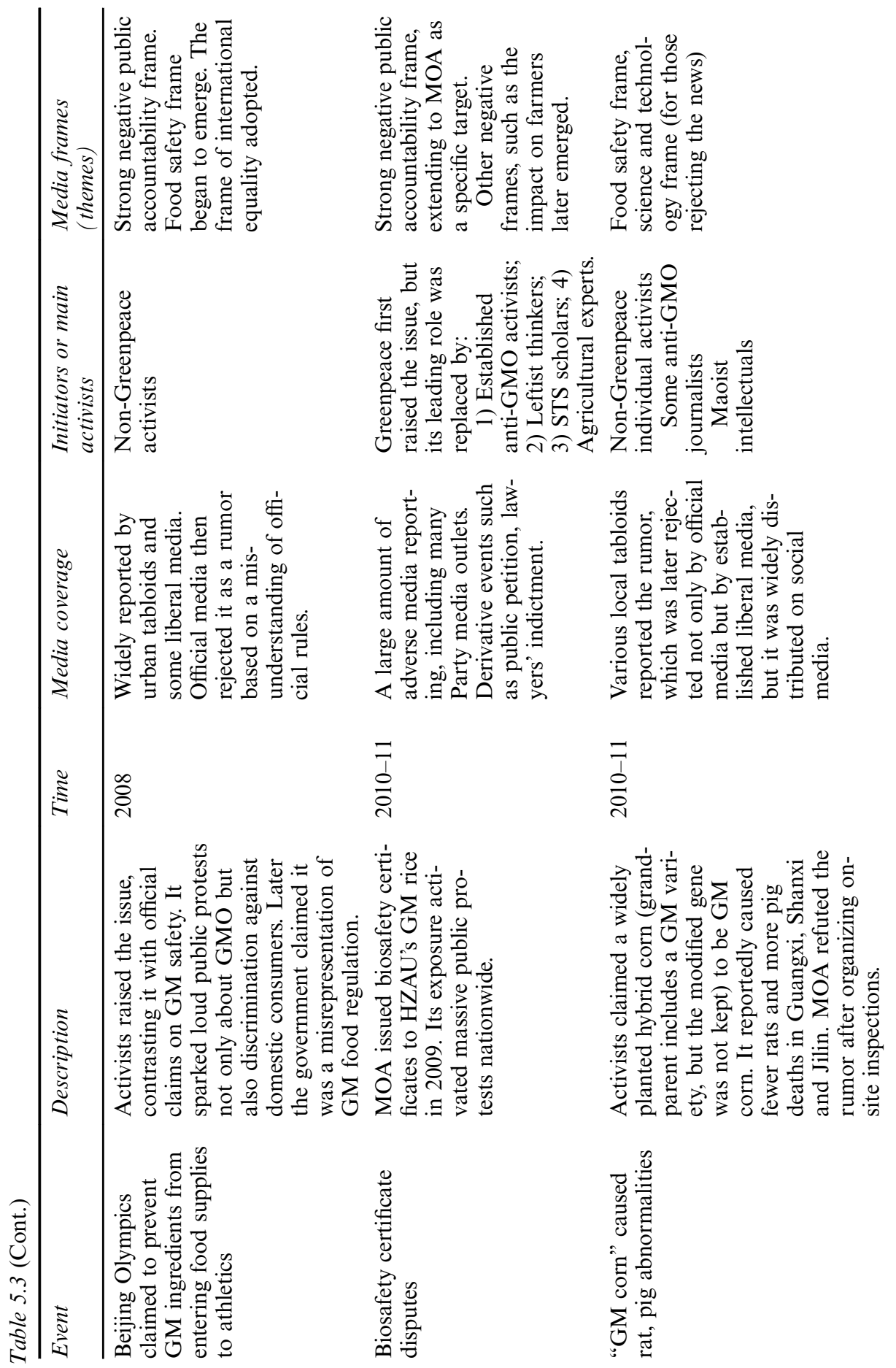




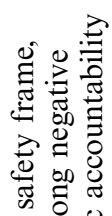

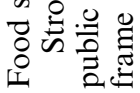
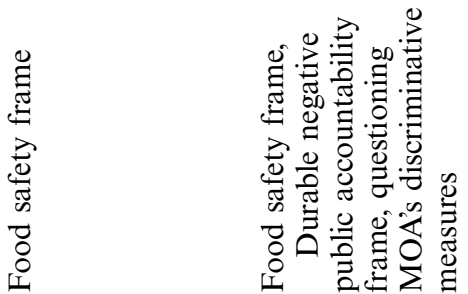

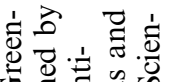

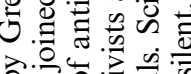

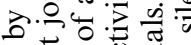

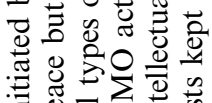

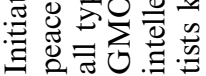

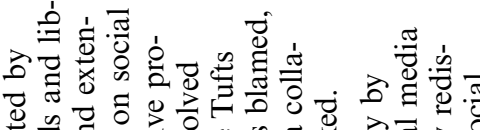

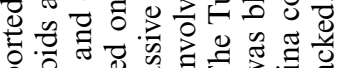

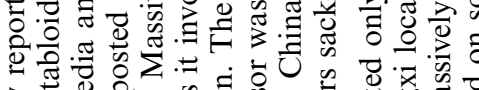

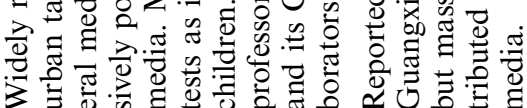

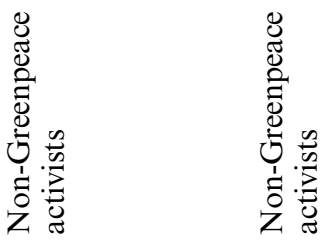

กับ

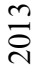

䓂

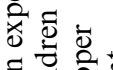

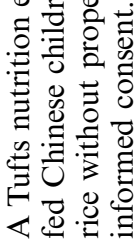

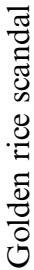

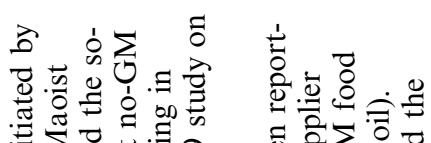

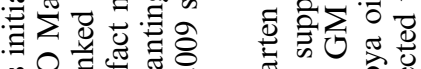

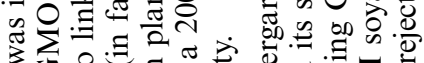

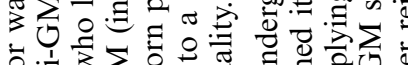

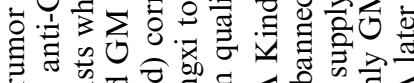

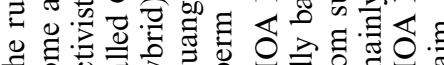

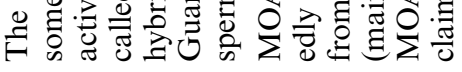

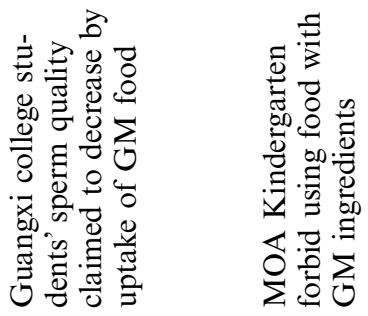




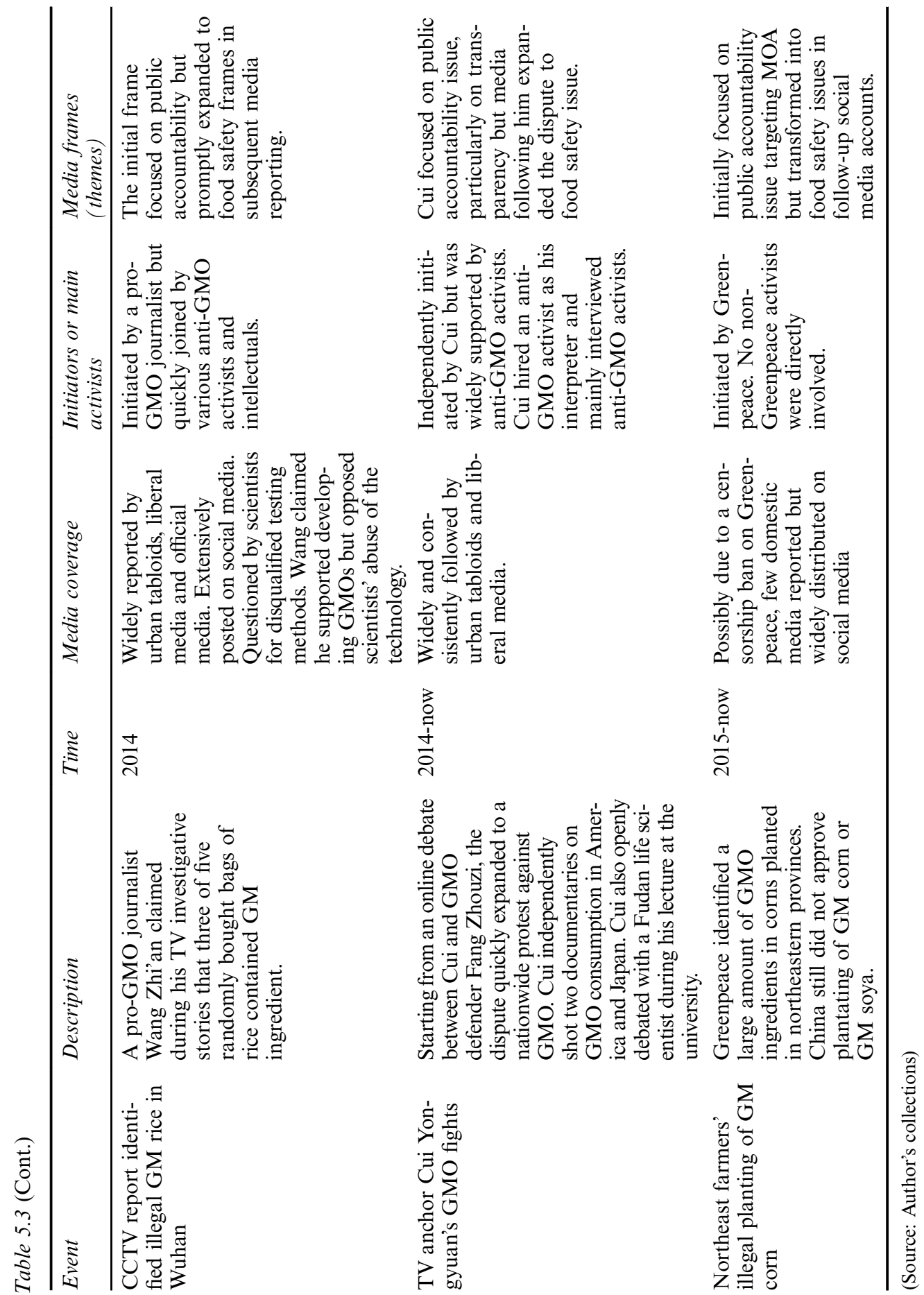


Despite China's harsh censorship, articles like Y. Yin (2017) that directly defamed Deng Nan or even Deng Xiaoping's policy stance on GMOs were still available for my study, mainly through Maoist sites such as Wuyouzhixiang (wyzxwk.com), Chawang (cwzg.cn) and Red Song Club (szhgh. com), which also posted voices reportedly from the so-called "red princelings." As analyzed in the previous section, these Maoist sites were unanimously against GMOs. Hence, the rise of Maoism and other leftist activists should be considered another factor of political opportunity structure.

We should not over-estimate Maoists' direct influence in policymaking. After all, most of the "red princelings" retired a long time ago. But their presence justified Maoist intellectuals and activists' anti-GMO stance. As active Chinese leftism theorist Li Beifang (2016) argued, leftists had a complex composition, but embracing Chairman Mao Zedong and opposing GMOs could become two basic symbols to unite Chinese leftists. Leftists actively networked with other leading public figures, such as retired generals Peng Guangqian and Mi Zhenyu, former chemical minister Qin Zhongda, and Marxism-leaning Hong Kong economic professor Larry Hsien Ping Lang to form the anti-GMO front.

Accompanying the rise of Maoists, a group of diehard left-leaning antiGMO activists emerged. Many of them, including retired economist Gu Xiulin, former CAAS researcher Tong Pingya, copywriter Zhao Hua, a military novel writer Lv Yongyan, and some crank scientists like the aforementioned Chen Yiwen, are still active today (2019). They joined the established intellectuals consisting of STS scholars, rural sociologists, Marxist economists and occasionally ecologists to question the safety of GM foods and the capitalistic nature of agricultural biotechnology. Although unlike the established scholars and generals, these activists seldom attracted media attention, their full-time devotion provided "massive gunpowder" to anti-GMO capitalism. For example, Chen Yiwen was Cui Yongyuan's English translator for the latter's investigation of GM food consumption in the United States in 2014. Other crank scientists also claimed to have provided knowledge supports to Cui. These leftleaning anti-GMO activists also frequently contributed to the Maoist websites or posted anti-GMO articles on their blogs.

The consistent effort to counter GMOs from the perspective of political ideology (as compared with Greenpeace's environmentalism stance and ordinary public's food safety concerns) seemed to have an effect. A 2016 national survey found that 40 percent of the Chinese public believed that GMOs were an American conspiracy against China (G. He et al., 2017).

Taken together, China's opening-up and introduction of NGOs, media commercialization and ideological schism constituted an emerging political opportunity structure favoring activism against GMOs. But for the actors Greenpeace, journalists and Maoists - to play their active role so powerfully as to effectively halt China's GM crop commercialization for more than a decade, this emerging political opportunity structure is not enough. At the 
policy-making end, there had to be structural opportunities that could make top policymakers, no matter how institutionalized, receive, consider and accept (at least partially) the policy options from activists. Otherwise, we cannot explain how the GMO controversy as a social protest could be sustained so long and have such widespread influence. The fragmented authoritarianism, particularly bureaucratic fragmentation and the virtually weak alliance between politics and science, which could be treated as a political opportunity structure as I did in the hydropower chapter, provides a relevant theoretical lens to examine this perspective.

\subsubsection{Fragmented bureaucrats as a political opportunity structure}

In the previous chapter, the fragmented authoritarianism (FA) framework was used to explain the victory or failure of China's anti-dam activities (Mertha, 2008). In a broader sense, the framework can be considered part of the political opportunity structure. In bureaucracy politics, the perceived relative weakness of MOA and the perceived opinion disparity among top Chinese leaders can be an indication of political and bureaucratic fragmentation that constituted an opportunity structure in which activists were encouraged to raise disputes.

During China's GMO controversy, one remarkable phenomenon is that the low-profile Ministry of Agriculture (MOA, renamed to the Ministry of Agriculture and Rural Affairs in March 2018) often displayed perceptible weakness. For example, an article in Beijing Youth Daily in October 2013 reported that Vice Agricultural Minister Li Jiayang, a senior genetic scientist and former vice-president of CAS, had been hired by Dupont to work on biotechnology, and accused $\mathrm{Li}$ of representing the interests of multinational companies by helping them promote GMOs (Y. Li, 2013). The fact that the media openly blamed a senior incumbent government official of a potentially improper foreign link was scarce in China. But it was not unique. Sun Zhengcai, a former crop scientist who was Agricultural Minister between 2006 and 2009 during which the Ministry approved the biosafety certificates of China's two types of GM rice and one type of GM corn, was also a target for open attack long before his fall as a political star in July 2017 (Unknown, 2014). Overseas observers widely thought Sun's fall a sacrifice to pave the way for Xi Jinxing's life-long tenure because he used to be considered a promising future generation of State leaders (Buckley, 2017).

Cui Yongyuan repeatedly and openly questioned MOA and its officials in his Weibo account and his CPPCC proposals (Cui ended his CPPCC membership in 2019 after retiring from CCTV), often using very humiliating words. The MOA's apparent weak strength in the authoritarian political hierarchy may be another piece of evidence implying bureaucratic fragmentation (INT20161226, INT20170823).

Lawyers and anti-biotechnology activists repeatedly sued MOA for hiding important information regarding its approval of biosafety certificates of 
both China's own GM varieties and imported soybean and corn. China Justice Online (https://wenshu.court.gov.cn), operated by the Supreme People's Court of China, recorded two lawsuits against MOA. There are certainly more such litigations as Chinese courts often refused to accept an accusation against a government agency (X. Yang, 2016). Although MOA won both lawsuits, the fact that a ministry was sued for lack of transparency by the public in authoritarian China was an indication that the ministry's authority was discounted in the public sphere and this impression encouraged more to join anti-GMO activism.

Although the perceived agency weakness encouraged activists, it does not mean the real power of the agency was low. But in the GMO case, while the MOA could dominate the technology's development agenda at early stages, the jurisdiction to make key policies went beyond the ministry's authority after it became a hot "issue" (INT20161110b, INT20161118, INT20170823). This power erosion was first reflected in 2001 when China was eager to make its GM food labeling rule to fend off the possible impact of flooding US farm imports after China's expected WTO entry.

In 2010, the biosafety certificate issuance triggered protests from red princelings, over 120 leading Chinese scholars' effort to submit a petition to NPC in March 2010 (X. Tian, 2010), and the concentrated adverse reporting by the media, including official outlets like Outlook Weekly published by Xinhua Agency. Since then, the vast sensitivity of the GMO issue has reportedly resulted in an attitude disparity among top Chinese leaders.

In March 2011, a national exhibition was held to show off the milestone achievements of the 16 mega science and technology initiatives launched in 2008. All Politburo standing members attended the event. Premier Wen went to the booth of agricultural biotechnology, reiterating his support, but $\mathrm{Hu}$ Jintao and several other members intentionally avoided stopping there (INT20161226).

Hu's avoidance of the biotechnology booth did not mean he rejected GMOs. In 2008, he inspected the Peking University College of Life Sciences and praised the GM cotton research there. In June 2011, during his inspection in Hubei Province, he specifically visited HZAU's GM rice lab, but the official Xinhua Agency story about the Hubei inspection (Zou \& Zhang, 2011) intentionally omitted this visit (Q. Zhang, 2017). Meanwhile, Premier Wen reportedly was pressured within the Politburo for his outspoken support for GM technology (INT20161110a). Hence, there was a deadlock. Top Chinese leaders constrained themselves from talking about GMOs to reduce sensitivity and avoid controversy, but activists interpreted this as a policy concession, which further encouraged activism.

Chinese scientists spared no effort to lobby policymakers (INT20170723). In 2011, scientists submitted a CAS consultative report on GMOs to the top leadership, and in 2013, a total of 61 CAS and CAE (the Chinese Academy of Engineering) academicians signed a petition to central leadership to appeal for quicker commercialization of GM rice. The effect was far from satisfactory. The CAS consultative report and academicians' petition did not 
result in any policy change (INT20161221). One leading scientist complained: "The situation was too poor. The highest official I can meet [for the GMO issue] was MOA vice minister [who was not a key decision-maker]" (INT20161009).

Despite the paramount ideological role science enjoys in China (Jia \& Liu, 2014), the science-politics alliance here appeared to be weak. "Chinese leaders pay attention to science, but it is preconditioned that they think science is free of problems. When facing strong public protest, the leaders themselves would hesitate whether the science in question is reliable," one senior science policy advisor told me. "Top Chinese leaders today are highly responsive to public opinion. They are particularly worrying that offending the public would cause social unrests" (INT20170619).

Chinese leaders' high-profiled support for science is very utilitarian (Cao, 2004). While research on GM technology is an issue of science policy, the decision to commercialize GM crops is far more complicated, involving policy considerations of international trade, intellectual property rights and public protests. Therefore, other factors seemed to play an equally significant, if not more significant, role in the policy-making process (Cao, 2018).

This subsection examines components associated with the fragmented authoritarianism (FA) framework underlying the GMO controversy in China. While FA factors generally played a role in promoting the dispute, they were different from the pattern displayed in the hydropower controversy in which bureaucratic fragmentation was salient. In the GMO controversy, although MOA did not have a robust bureaucratic challenger, the fragmentation existed among political ideologies, members of top leadership and different experts, as well as between activists and establishments. The degree to which this fragmentation existed was much broader and deeper than in the hydropower controversy and other controversies/social contentions, including the debates on nuclear power which I will explore in the next chapter.

\subsubsection{Anti-GMO framing and mobilization}

So far, I have used the political process theory to analyze China's GMO controversy as a social movement. Tarrow and other scholars maintain that political opportunity should not be considered a static social structure (Meyer \& Minkoff, 2004; Tarrow, 1996). With this theoretical leniency, we can find that on the basis of the perceived agency weakness, Chinese leaders' policy disparity and insecure science-politics alliance, China's opening to international NGOs, the shaking public confidence on food safety, the rise of Maoism in post-reform China, and media's commercialization formed a political opportunity structure favoring anti-GMO activism.

In terms of framing and cultural artifacts that Tarrow (2011) listed as the second dimension for political process theory, anti-GMO actors legitimatized 
them within this political opportunity structure by framing themselves as either defending public interests, as revealed in Table 4.2, or inheriting the legacy of socialism. Activists and dissenting experts effectively mobilized more public figures, civil resistance to GM foods through mass media, Maoist websites and other media platforms discussed in the previous section.

Ordinary Chinese people may not be motivated by abstract public accountability, but they were anxious about food safety. For years, scandals on food safety have been the No. 1 topic dominating the public opinion agenda. No other food safety issues are as concentrated in one term as GMOs, which, as Herring (2008) argued, has become an omnipotent negative frame. This frame, together with the political safety of the topic, has made anti-GMO an ideal topic for public mobilization. On the other hand, the grave public concerns with the issue also lure more and more new activists and potential opinion leaders to come to the anti-GMO front to seek public attention. My WeChat public account article analysis has revealed that in a given period, hot GMO articles spread across different types of public accounts ranging from lifestyle to cooking and religion. Similarly, while a group of diehard activists has maintained and driven the GMO controversy, one can find new anti-GMO activists, and claims chronically rose in WeChat, Weibo and other non-official platforms, resulting in a sustainable social mobilization against GMOs.

Using the above material, Figure 5.8 demonstrates the three social movement elements - political opportunity structure, framing and mobilization of the political process theory. The intersection of the three circles represents combined factors leading to China's intensified GMO controversy.

As I argued in the Introduction, social movement theories have a tremendous advantage in interpreting widespread public science controversies as they bring in actors and their strategic actions to deal with opportunities. In this process, communication factors such as the media and the Internet are instrumentally explored by activists to utilize opportunities. People's attention to the disputed topic is also an important parameter. In the GMO controversy, activists effectively used the attention and personal concern to boost public rejection of GM foods, which then brought more opinion-makers to tap the field.

But with only political and communication dimensions, one cannot fully understand why activists had the intellectual confidence and necessary knowledge to challenge the claimed scientific consensus on the safety and economic prospect of GM crops. If the activists' side did not have the fundamental belief that they could counter orthodox knowledge, they might not have been able to perceive the emerging political opportunities. On the other hand, if policymakers and the public fully accepted the knowledge maintained by mainstream scientists about GMOs, then activists might not have been able to network and mobilize mass resistance. All these questions need further scrutiny, for which social movement theories per se cannot offer a ready answer and guidelines. I will examine these aspects in terms of the knowledge-control regime and civic epistemology in the following section. 


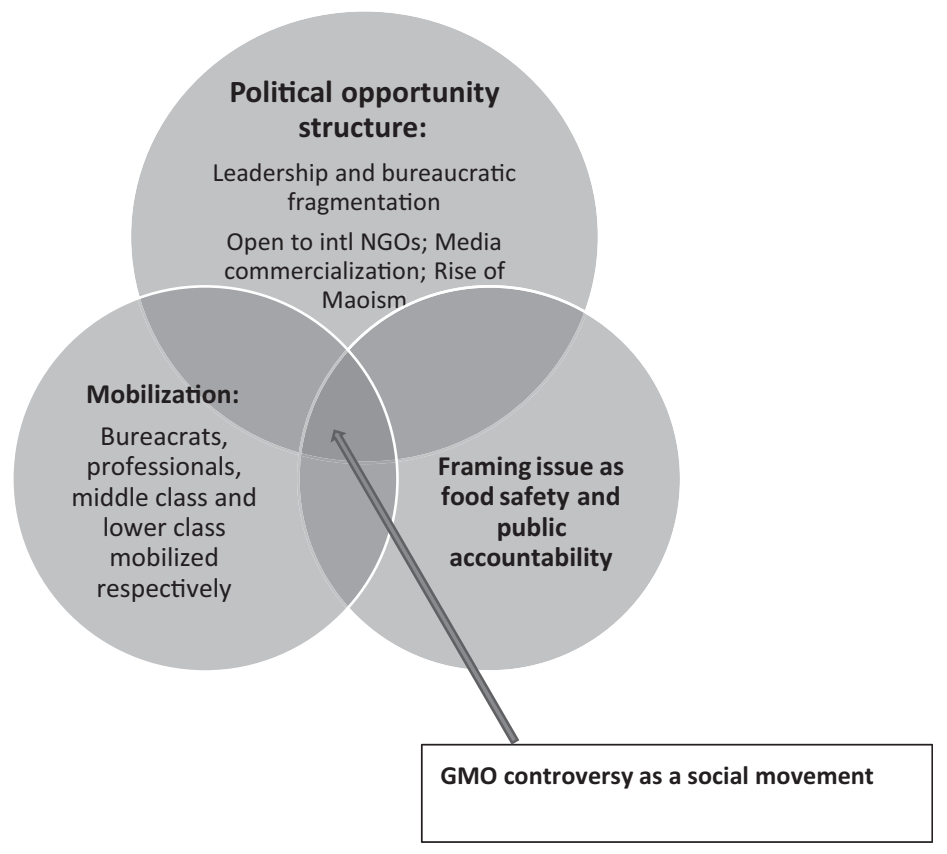

Figure 5.8 Political opportunity structure, framing and mobilization in China's antiGMO activism

Source: Drawn by the author

\subsection{Knowledge control and contention}

\subsubsection{Knowledge-control regime in China's GMO controversy}

In the previous section, I indicated the importance of knowledge in shaping political opportunities for the GMO debate. The knowledge-control regime concept clarified by Hilgartner (2017) can be highly relevant here. Although the GMO controversy took place more in public spheres than in labs, the idea of various control regimes still holds. According to Hilgartner (2017, p. 14), knowledge-control regimes do not determine action but structure the categories, routines, identities, rules, expectations, menus of options and other resources that actors draw on to interpret situations and guide action. As we can expect, for most "regular" sciences, their knowledge production and application can be routinely performed within such a structure, often supported by political power (Jasanoff, 2004a). But the widespread public controversy on GMOs toppled such "routines, identities, rules, expectations and menus of options" at the societal level of knowledge-control regime, even 
though scientists had primarily maintained their knowledge-control regime within the professional biotechnology circle.

Given agriculture's political and symbolic importance in China, China had actively developed modern agricultural biotechnology since the 1970s when it began to open the door. Deng Xiaoping even concluded that the ultimate solution to agriculture could only rely on biotechnological engineering (X. Deng, 1988/1993b). A knowledge-control regime was developed to place technical supremacy over conventional cropping (INT20161118, INT20160816). The scheme was extended to agricultural economics which calculated economic and farmers' health benefits of planting the GM cotton China commercialized in 1997 (Pray, Huang, Hu \& Rozelle, 2002) and confidently projected such benefits if China commercialized GM rice (J. Huang, Hu, Rozelle \& Pray, 2005).

At the very beginning of the regime formation, no effort was taken to deal with science and technology controversies (INT20161118). A senior science journalist put it straightforwardly. "Scientists thought they can handle political leaders and completely ignored the possible public resistance" (INT20170723). In promoting their disciplines, these scientists seemed intent to distinguish their research from conventional breeding, observed another senior science journalist who has long reported biotechnology advances in China (INT20160816).

Agricultural biotechnology scientists also ignored the effort to introduce biosafety governance pushed by ecologists and botanists (INT20161215). To social and humanities sciences, pro-biotechnology scientists even showed their contempt. "GMO scientists disdained to have a dialogue with we social science scholars," said a leading Chinese rural sociologist based at an agricultural university (INT20161114).

Indeed, what Chinese GMO scientists did was nothing more than regular science where major scientific breakthroughs are followed by an effort to model their applications and project their benefits based on an optimistically estimated adoption rate. In the process, various aspects of knowledge, such as local knowledge or hidden social structures, are routinely neglected. When there is no significant controversy, neglected knowledge may be ignored. But GMO controversies which had accompanied the technology when China began to develop it made many aspects of the neglected knowledge salient, continuously stoking the disputes, similar to the situation in the West as observed by anthropological scholars (G. D. Stone, 2010).

The aforementioned rural sociologists' studies on the structural decline of Chinese countryside in the face of labor and capital outflow to coastal manufacturing centers belonged to this type of knowledge. The worry that imported GM soy would severely impact soy farmers in northeast China (indeed, the impact had already happened) was another type of consideration largely neglected in GM scientists' analytical modeling. But in the Chinese public sphere, the salience of rural decline and impacts on farmers were at least equal to agricultural technical progress, if not more salient. In the sense of knowledge-control regime, 
at the societal level of such a regime, "routines, identities, rules, expectations and menus of options" are simply out of biotechnology scientists" control.

One cannot be an expert in every field. When these rural sociologists, international trade analysts, STS scholars, ecologists and other dissenting experts raised GMO issues, they often publicly mentioned the technology's potential risks, though most of them did not have the professional background to study its health and environmental risks. This knowledge insufficiency was often quickly taken by the biotechnology side to attack them.

As compared with their reluctance to dialogue with external knowledge, Chinese biotechnology scientists spared no effort to maintain orthodox conclusions on the safety and benefits of GM crop and food. On ScienceNet.cn, a leading website primarily targeting scientists but also publicly accessible, a social network analysis on the blog comment relationship of ScienceNet.cn users showed that a high majority of network nodes were from people supportive of GMO, with only one biotechnology-negative node, a botanist and organic farming advocate (Li \& Jin, 2019).

On ScienceNet.cn and other Chinese public platforms, articles and texts to refute the dissenting studies on GMO safety - such as the rejected Séralini et al. (2012) - were widely circulated among peer scientists and science communicators. After the 2009/2010 controversy on the biosafety certificate of GM rice, agricultural biologists' efforts to reject domestically published papers (e.g., Z. Zhang et al., 2015) were also enhanced (INT20161215, INT20170617).

Partly due to the enormous controversy surrounding GMOs, Chinese science communicators and science journalists nearly unanimously united on the probiotechnology side, many believing defending GMOs to be an essential task of maintaining the authority of science and some using support for GMOs as a distinction between true or false science communicators (journalists) (Jia \& Li, 2016).

Utilizing the report and censorship mechanism of leading social media platforms in China such as Weibo and WeChat, scientists and science communicators consistently requested that these platform operators censor the rumor posts and public account articles with false content regarding GMOs. On many occasions, the request was valid. A recent Chinese study also showed that more than $77 \%$ of WeChat-based public account articles were positive to GMOs (Jin, 2017). While my above analysis of the most recent 50 highest-read articles shows different results, Jin's (2017) result is reasonable, because it might reflect the fact that most science communicators and writers are biotechnology supporters who, together with the establishment media, produce the most significant number of GMO-related WeChat articles. But due to the widespread public concerns about GM food safety, those negative articles were more likely to attract the audience to read.

Despite the effort, polls showed public acceptance of GM food continued declining (Cui \& Shoemaker, 2018) and anti-GMO public opinions remained rampant (Jin, 2017). In a recent advance in January 2019, activists widely reported and celebrated that a classic nutrition textbook - Nutrition and Food Hygiene - newly added "negative" GMO contents (C. Zhao, 2018). The four 
pages of material (one section of the book's Chapter 9), named GM food management, did nothing more than describe the potential risks of GM food and say that therefore, labeling was needed.

Why has Chinese biotechnology scientists' successful management of the consensual statement on GMO safety not been transformed into public support and consensual statement across different disciplines? Once again, we can apply the idea of multiple knowledge-control regimes. For regular science, a consensual statement in a central professional circle may naturally transform to broad support, possibly through trade and negotiation hidden to outsiders (Galison, 1997). Modern knowledge is featured with its specification and professionalization (Adhikari \& Sales, 2001). A routine practice might include some components while excluding or ignoring minor dissenting ideas such as the ones contained in Nutrition and Food Hygiene.

But given a widely attended controversy, activists tend to grasp and amplify the differences. On the other hand, once GM food became a publicly salient issue, food nutrition experts found that to maintain the governing frame of their knowledge-control regime (in food nutrition), which means "an organized set of schemata that provides a template that actors employ to guide action and interpretation" (Hilgartner, 2017, p. 12), they had to address issues relevant to the public concerns, such as the safety of GM food. Otherwise, it could be a sign that the control of their fields was less authoritative (INT20161115).

In the GMO controversy, different knowledge branches were sooner or later enlisted in the social argumentation against GMOs. In terms of knowledgecontrol regime, the biotechnology side has no power to control the spread of anti-GMO argumentations, despite the expert consensus on GM food safety and optimistic economic prospects.

To view the GMO controversy only from this knowledge-control regime perspective, however, is not enough, for any dispute might experience a similar process, but few of them are as sustained as in GMO case. Civic epistemology offers another perspective for our understanding, especially if we place this perspective in the dynamic communication process of public science controversies.

\subsubsection{Civic epistemology and conspiracy theories}

Given the sustained civil resistance to GMOs, it is necessary to investigate the dispute from the perspective of civic epistemology (Jasanoff, 2011b), which represents the stylized, culturally specific ways in which the public expects the state's expertise, knowledge and reasoning to be produced, tested and put to use in decision-making. Due to the long historical memory of food shortages and social unrest caused by the deficiency, generations after generations of Chinese leadership placed maintaining sufficient food supplies on the top of their policy agenda. In the 1980s, and then across the first two decades of the new century, most of the annual No. 1 Documents of the CCP Central Committee, symbolically the most important policy of the year, dealt with the so-call Three 
Nong (countryside, agriculture and peasants) affairs. Although the percentage of agricultural outputs in gross domestic product (GDP) had decreased from $24.6 \%$ in the 1980 s to $18.3 \%$ in 1997 (the year when China commercialized GM cotton) and then to 7.2\% in 2018 (National Bureau of Statistics of China, 1981, 1998, 2019), the symbolic importance of agriculture did not.

For ordinary Chinese people, due to the long-time propaganda linking national prosperity and science and technology progress, most welcome hightech development of agriculture. People see parallels between the support for high-tech adoption in agricultural production, national food security and their concern about food safety. To them, it is necessary to develop science and technology to promote social progress, but the development should not threaten personal food safety, or even just bring a potential threat.

In the early days of agricultural biotechnology development in China, the public showed strong support for the technology (J. Huang et al., 2006b; L. Lü, 2009). But as a result of anti-GMO activists' continuous effort to negatively frame GMOs as morally stigmatized, public support for biotechnology as a specific high-tech solution dramatically decreased and the concern over the technology's negative impacts on food safety continuously increased.

Amidst the repeated exposure of food and plant scandals in contemporary China ranging from using industrial pigment for food to adding the industrial material melamine to milk, people of different social status developed their own "culturally specific ways" to understand GMOs. The middle class had great concern about food safety. A national poll in 2009 found that more than $50 \%$ of the middle class felt intense anxiety about food safety (Ouyang, 2010). The survey was confirmed by my interview with an organic food activist (INT20160823) and by two recent polls that found people either with graduate school degrees (Cui \& Shoemaker, 2018) or with higher biotechnology knowledge (Ren et al., 2016) had more concerns about GM foods than other social groups. Though the two subsamples may not completely match, they can represent the overall status of the middle class.

Although the middle class might have basic biotechnology knowledge or the potential to get it, they still chose to believe some rumors. The most widely circulated ones were the lists of GM fruits and vegetables in the market. Most foods in the list, such as grape tomato and colored pepper, were not genetically modified at all.

While the rich and middle class tried to avoid GM food with their money, many people in China embrace conspiracy theories. Guangxi He et al. (2017) indicated that more than $40 \%$ of the Chinese public believed that GMOs were a conspiracy of the Western powers to control China. Following the wide public protest against the biosafety certificates of GM rice and GM corn in 2010, three best-selling books - GMO War (Gu, 2011), Secrets of Freemasonry (X. He, 2011) and Unrestricted Biological War: The Conspiracy of GM Foods and Vaccines (Chai, 2011) - were published in China. They unanimously claimed that GMOs were a conspiracy of the Western ruling class to control the world (the difference is they defined different groups as Western ruling class). 
It is naive to blame the public's embrace of a GMO conspiracy on their low scientific literacy. Adopting the concept of civic epistemology, one may understand the embrace of conspiracy as the historically and culturally shaped ways for many disadvantaged people to understand GMOs. Indeed, Guangxi He et al. (2017) found those aged over 50 and those with lower education were more likely to believe a conspiracy theory in the GMO issue. Left behind in China's fast and state capitalism-driven economic growth, this group of the population was the direct followers of Maoist activists' antiGMO campaigns.

Another logic of the civic epistemology underlying the mass perception of GMO conspiracy is a political polarization specific to China. "The logic is, Chairman Mao is against the United States; GMO is thought to be a US strategy against China, so following Mao means opposing the United States and GMOs," a communication scholar told me during an interview (INT20170828).

Combining the different findings, we find a convergent public opinion to avoid using biotechnology for food production. In the above analysis of the civic epistemology of Chinese citizen regarding GMOs, a common feature is that scientific knowledge per se did not shape people's attitude to GMOs. Instead, a combination of political, socioeconomic and cultural considerations dominated both dissenting experts and ordinary people's decision-making process, echoing civic epistemology's rejection of a public understanding of science (PUS) model as a way to deal with science policies (Jasanoff, 2011b).

This civic epistemology perspective goes hand-in-hand with the knowledgecontrol regime analyzed in the previous subsection. Because the scientific community's regime failed to control knowledge production and transmission at the societal level, the public was more likely to encounter messages alien to the progress belief (e.g., that technology is an essential solution to food safety). On the other hand, when some radical experts and opinion leaders sensed the high public attention to and concerns about GMOs, they were more likely to link their publicly expressed views to the controversial technology to snatch more attention resources.

\subsection{Chapter conclusions}

This chapter examined factors triggering and sustaining the GMO controversy in China from the perspectives of communication, social movements and knowledge control. Media commercialization and the rise of social media, the political opportunity structure allowing penetration of NGOs and emerging Maoism and suffering bureaucratic fragmentation, and GM scientists' failure to monopolize knowledge-control regimes all contributed to the long-lasting GMO controversy. Meanwhile, GMOs being framed as a food safety and public accountability issue and high public attention highlighted scientific uncertainties and disparities, motivated opinion leaders and other allies with different knowledge equipment, and helped activists mobilize various resources against the technology. 


\section{GMO controversy}

To better understand China's GMO controversy, the three dimensions communication, social movements and STS scholarship - have to be integrated. The media provided an arena for contention which was made possible due to the specific political opportunity structure listed above. The media platforms contributed to the development or breakdown of knowledge-control regimes. The public knowledge arising from these regimes provided legitimacy to both biotechnology scientists and anti-GMO activists.

A specific theoretical contribution of this chapter is the communication factors in the political opportunity structure and knowledge-control regimes in the public attention market. A higher public concern of GM food safety amplified through communication channels created a broader opportunity structure for activists and other actors and mobilized more otherwise neglected "routines" to become salient. There seemed to be a positive feedback loop, making GMO controversy the most prolonged and most intensive S\&T contention in contemporary China.

\section{Note}

1 Wuyouzhixiang's website used to be wyzx.com. But it was closed by the Chinese government in 2012, possibly due to its extreme leftism. See https://www.bbc.com/ zhongwen/simp/chinese_news/2012/04/120406_china_wuyouzhixiang. Later the website moved much of its content to a new site literally called Wuyouzhixiang Online Journal at wyzxwk.com, which is still active at the time of writing. In this book, the two websites are treated identically. 


\section{The nuclear power debate in a narrow political opportunity structure}

\subsection{Introduction}

In the past 30 years, nuclear power has achieved tremendous progress in China. According to the National Energy Administration (NEA), by the end of 2017, 37 nuclear power reactors were in operation in the Chinese mainland, and 19 reactors were under construction, with a total capacity of 21.87 million kilowatts. The number of nuclear reactors under construction in China ranked first in the world (National Energy Administration, 2017).

Despite the significant progress, nuclear power also experienced controversies in China, although the intensity is far below other science and technology disputes such as GMOs, hydropower and waste incineration. Street protests halted the proposed construction of two nuclear fuel recycling facilities in Guangdong Province's Jiangmen and Jiangsu Province's Lianyungang in 2012 and 2016 respectively. Between 2016 and 2018, the Chinese government did not issue a new construction permit to any nuclear power plant (NPP).

How should we understand the situation surrounding nuclear power contention in China that is so different from patterns of GMO and hydropower controversies? Is there any political opportunity structure in the country that can fuel anti-nuclear campaigns? Has the knowledge control pattern played a role in nourishing nuclear power controversies? This chapter will examine how communication, sociopolitical and knowledge control factors jointly shape the unique situation of the social contention surrounding nuclear power.

\subsubsection{Media framing, public attitude and anti-nuclear social movements}

Partly due to its military origin, the civil use of atomic energy attracted protests worldwide from the very beginning (Gamson \& Modigliani, 1989; Rudig, 2014). The ebb of the initial protests in the 1960s can be associated with the decline of overall public concern during this decade (Kasperson et al., 1980), which was associated with the media's widespread framing of the technology as a significant scientific progress (Gamson \& Modigliani, 1989).

The public attitude toward nuclear power was both shaped by the media (Mazur, 1981, 1990) and influenced by organized social movements. In the

DOI: $10.4324 / 9781003160212-6$ 
latter half of the 1970s, anti-nuclear power campaigns became the central focus of social movements in Western Europe and the United States.

Like other science and technology controversies, the public disputes against nuclear power started with or at least echoed the internal disagreement among experts (Nelkin, 1971, 1995). Despite dissenting expert views, the regulators like the Atomic Energy Commission (AEC) seemed to favor more industrial interests due to the agency's deep links to the industry (Jasper, 1992). The policy impact of anti-nuclear movements in terms of halting or delaying proposed plant construction was often limited (Giugni, 2007; Giugni, McAdam \& Tilly, 1999).

Structural analysis showed that anti-nuclear campaigns' emergence, development and policy effect were mostly bounded within the so-called political opportunity structures. According to Kitschelt (1986), institutional arrangements and historical precedents for social mobilization of the United States, West Germany, France and Sweden resulted in different political opportunity structures, facilitating the development of protest movements in some instances but constraining them in others. For example, the more open political representation in Sweden and the United States assisted anti-nuclear activists to adopt more lobbying processes while France and Germany's more formal political structures led to more street politics (Tompkins, 2016). Political opportunity structures have also impacted the policy effects of anti-nuclear movements in the four democracies.

In former Soviet Union nations, the emergence of anti-nuclear activism was associated with a rise in nationalism and the pursuit of national independence from the control of Soviet empire (J. I. Dawson, 1995, 1996) or a revolt against the Soviet techno-bureaucracy (Schmid, 2004). However, after the collapse of the Soviet Union, the anti-nuclear movement quickly dissolved. The best explanation, according to Dawson, is that the anti-nuclear movement offered a surrogate for nationalism and anti-communism. Similarly, in Taiwan, the anti-nuclear movement became a surrogate for political struggle in the newly democratized society (M.-S. Ho, 2003).

The Chernobyl accident in 1986 was a primary trigger for anti-nuclear power activism in the former Soviet Union. Indeed, the major nuclear accidents Three Miles Island, Chernobyl and Fukushima - have severely impacted public attitudes to nuclear power (Bolsen \& Cook, 2008; Y. Kim, Kim \& Kim, 2013; Rosa \& Dunlap, 1994; Siegrist \& Visschers, 2013; Visschers \& Wallquist, 2013), but in most cases, the accidents' impacts were short-lived, and other variables, such as institutional trust and prior support, played a more constant role in deciding public attitudes (Siegrist \& Visschers, 2013; Visschers \& Wallquist, 2013). For example, Slovic, Flynn, Mertz, Poumadere and Mays (2000) found that the French nuclear plants that partly caused the higher public acceptance of nuclear power in France than in the United States were all financially supported by the State-owned sector (notably Électricité de France (EDF)) while in the United States, the dominant players were all private investors. 


\subsubsection{Nuclear controversy from the knowledge-making perspective}

Given the considerable controversy surrounding nuclear power, STS scholars and science communication academics have paid attention to the controversial technology, enabling nuclear power to dominate their research agenda for decades (Suerdem, Bauer, Howard \& Ruby, 2013). According to them, because few other technologies raise so many social costs - proliferation, terrorist abuse, routine health damage, the social perception of "low probability-high damage" accidents, civil liberties and obligations to future generations - opposition to nuclear power could be reasonable and legitimate (Bickerstaffe \& Pearce, 1980).

Wynne's (1992) classic study on the disputed contamination of Cumbrian sheep farms in England by Chernobyl disaster's radioactive pollutants can be taken as an empirical example of this direction. The study revealed that sheep farmers' lay know-how of airflow and topography triumphed over the professional knowledge of radioactive experts commissioned by the government, demonstrating the problems with the government's ban on sheep sales and breaking the knowledge monopoly by experts in the highly professional field.

In East Asia, STS scholars found that in Japan, techno-nationalism that drove Japanese elites to seek to catch up with the West in economic and military terms as rapidly as possible created the essential momentum for nuclear development (Fujigaki \& Tsukahara, 2011; Kelly, 2015). Similarly, in South Korea, the introduction of nuclear power was considered a modernizing and empowering force that would develop and strengthen the nation (Hong, 2011). As noted in the first chapter, South Korean's progressive sociotechnical imaginaries for nuclear power were sharply different from the US imaginaries that nuclear needs to be contained (Jasanoff \& Kim, 2009, 2013). There is no doubt that nuclear power enjoys similar positive sociotechnical imaginaries in China.

Anti-nuclear power campaigns have led to the stigmatization of nuclear power (Tannenwald, 2005), but Schmid (2015) found that although people widely linked the Chernobyl accident to poor management, the Soviet Union's nuclear industry workers were, in fact, a high-quality, self-disciplined and proud group. The accident was a result of a systematic failure of the technology. Schmid's depicting of high-quality nuclear power workers is relevant to the study in this chapter.

\subsubsection{Public attitude toward nuclear power in China}

Accompanying China's great leap forward in nuclear power, Chinese scholars have performed several surveys on public views about atomic energy (G. He, Mol, Zhang \& Lu, 2013, 2014; Y. Wu, 2017). Generally speaking, public acceptance of nuclear power was high, ranging from $74 \%$ of respondents in the southern Chinese city of Shenzhen in 2008 (Z. Chen, Kong \& Geng, 2009) to $72 \%$ of participants in 2015 (Y. Wu, 2017). Nearly $68 \%$ agreed that nuclear power's benefits outweigh its harm (C. Zhang, Huang \& Ren, 2016). The 
support rate was much higher than the 28\% support rate in 18 IAEA (International Atomic Energy Agency) countries and 20\% in OECD (Organization for Economic Co-operation and Development) members (Y. Wu, 2017). An earlier study on public risk perception also found that the Chinese had less concern about high-technology such as the radioactive threat from nuclear power plants (NPPs) (Xie, Wang \& Xu, 2003). However, the Chinese public had a quite low knowledge of atomic power (Y. Guo \& Ren, 2017; Yu et al., 2012), and the knowledge level had a significant impact on their acceptance of nuclear power both in general terms and in their hometown (L. Deng, Zheng \& Zhou, 2016).

As in other countries, in China the Fukushima nuclear accident dramatically decreased Chinese acceptance of nuclear power and increased their risk perception (G. He et al., 2014; L. Huang et al., 2013; C. Sun, Zhu \& Meng, 2016), but it also enhanced people's knowledge about nuclear power (L. Huang et al., 2013). Though immediately after the accident, public trust in government lowered (L. Huang et al., 2013), confidence in government and scientists to deal with a nuclear crisis remained high and showed no significant change from before the disaster (G. He et al., 2014). Several years after Fukushima, public support for nuclear power largely resumed (Y. Wu, 2017), and the Chinese public generally maintained high trust in the nuclear information provided by government (in general), nuclear regulators and scientists (L. Deng \& Tu, 2016; G. He et al., 2013, 2014; Y. Wu, 2017). Echoing the public's high trust in government was the Chinese people's more significant concern about risks that threaten social stability and economic development (Xie et al., 2003).

The general high trust in government was not always translated to actual support for nuclear facilities in one's backyard. Studies found that two NIMBY (Not In My Back Yard) campaigns that suspended a proposed NPP in Rushan, Shandong Province in 2009 and a proposed nuclear fuel recycling plant in Jiangmen city, Guangdong Province in 2013 could largely be attributed to inappropriate engagement measures by local governments and insufficient disclosure by industry (J. Dai et al., 2015; Zeng et al., 2015). In both cases, social media platforms (BBS in Rushan and Weibo in Jiangmen) played an active role in fueling the public protests (R. Huang \& Sun, 2016). Thus, well-organized public engagement and communication activities could contribute to a higher social acceptance of nuclear power (L. Deng, Zhou \& Zheng, 2016; G. He et al., 2013). On the other hand, case studies and media stories show that unlike in other NIMBY activities such as those against trash incineration facilities (Standaert, 2017) and Para-xylene plant (Jia, 2014a) where street protests dominated the agenda, some local anti-nuclear power campaigns have shown a high level of elite-led public deliberations, which are generally rare in authoritarian China (L. Deng \& Jia, 2019; D. Yan \& Li, 2014).

These studies reveal China's high public acceptance of nuclear power for the sake of national interests and a strong public belief in the government's capacity to handle nuclear safety at a time when public trust in government on food safety issues was declining (X. Lü \& Zhao, 2009). The acceptance 
and belief, possibly arising from pride in China's independent development of atomic weapons, constitute the national sociotechnical imaginaries underlying the nuclear controversy examined in this chapter.

\subsection{Contemporary nuclear contentions in China}

With the term "Two Bombs, One Satellite," the achievement of nuclear technology has long been celebrated as a source of national pride in China. Chapter 3 detailed China's nuclear power development and the contentions it has encountered in the country. Despite the national pride, nuclear power has not been free from controversies and NIMBY protests. After the Fukushima disaster, anti-nuclear power activities sprang up in Wangjiang county in Anhui Province, Lianyungang of Jiangsu Province and Jiangmen of Guangdong Province. There were other low-profile local resistance activities to nuclear power in Guangxi's Fangchenggang and Hubei Province's Xian'ning.

Yet, the anti-nuclear power activities are largely elite-driven. The main participants in the nuclear power debate, ranging from Wangjiang's Four Seniors and Wang Yinan to $\mathrm{Wu}$ Hui and other activists, can all be considered elites. Few public participants can be perceived.

Elite activists were isolated from NIMBY movements against nuclear power. In July 2013 and August 2016, street demonstrations in Jiangmen and Lianyungang resulted in the suspension of the two proposed CNNC nuclear fuel recycling facilities (Buckley, 2016b; C. Yang, 2013). No anti-nuclear elite activists were involved in these street protests, though during the Lianyungang protest local protesters were found to distribute Wu's article "Nuclear power destroys China” (INT20161011).

Elite appeals seemed to result in policy effects. In November 2016, the 13th Five-Year Plan of Power Industry released by NDRC and NEA did not mention inland NPPs. However, in spring 2018, the policy tone towards nuclear power suddenly became positive. By January 30, 2021, China became the world's third-largest player in both nuclear power reactors in operation and installed generation capacity.

Summarizing China's nuclear power controversy, one can find a very different pattern from those of hydropower and GMOs. Although the postponing of inland NPP constructions and AP1000 loading were widely considered to be associated with the challenges raised by Wang Yinan and other dissenting experts, the policy effect was limited as compared with the hydropower and GMO controversies. The nuclear dispute was also low profile and limited mainly to elite circles. Except for the Four Seniors' action in Wangjiang, the Chinese media reported few other debates. Unlike with hydropower, the nuclear power industry's reaction was overall quick, though as compared with GMO contention, which involves a large number of both activists and pro-GMO science communicators, few external experts joined the debate. 


\subsection{Media and the nuclear controversy in China}

\subsubsection{Examining conventional media reporting of nuclear power}

As discussed in the above section, China's nuclear controversy was low profile, and most of the disputes seemed not to have received intensive media reporting. Figure 6.1 charts the four sampled media outlets' coverage of nuclear power (see Chapter 2 for sampling rubrics). A striking feature was the sudden surge of media stories in 2011 when the Fukushima accident occurred. Given Fukushima's disastrous character, this is understandable but what makes nuclear power reporting different is that other than the Fukushima disaster, no other news event has significantly boosted the number of nuclear power stories.

Media outlets had different reporting strategies. As an urban tabloid in Shanghai, XEN had a low daily reporting of nuclear power before the Fukushima disaster. According to Table 6.1, before the Fukushima accident, regular XEN reporting of atomic energy was mostly in the business section, as Shanghai is a manufacturing center of nuclear power equipment. Due to nuclear power's low relevance to urban life, this may also be the only significant link between the sector and XEN. But after the accident, high concern about radioactive leaks among residents in coastal Shanghai drove XEN to increase nuclear power reporting dramatically. The dominant theme of such reporting changed to

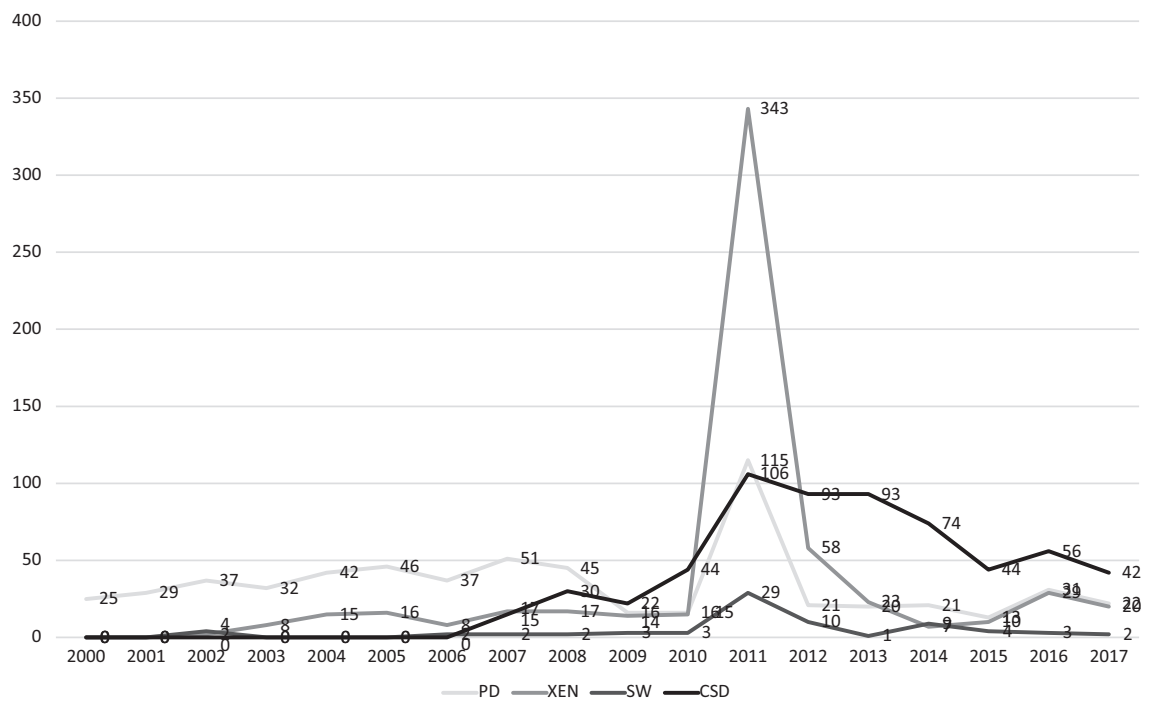

Figure 6.1 Number of the sampled media articles on nuclear power in China (2000-2017) Source: Collected and cleaned by the author; PD: 2000-2017; SW: 2002-2017; XEN: 2002-2017; CSD: 2007-2017 
Table 6.1 XEN's nuclear power coverage (2002-2017)

\begin{tabular}{lccc}
\hline & Before 2011 & After 2011 & Total \\
\hline Positive reporting & 17 & 40 & 57 \\
Negative reporting & 16 & 267 & 283 \\
Neutral & 81 & 182 & 263 \\
Nuclear power safety & 18 & 310 & 328 \\
Business \& economy & 47 & 41 & 88 \\
Development & 5 & 2 & 7 \\
Environment \& ecology & 10 & 9 & 19 \\
Engineering and technique & 10 & 7 & 17 \\
History \& culture & 3 & 13 & 16 \\
International treaty \& military nuclear & 1 & 16 & 17 \\
Science popularization & 3 & 15 & 18 \\
Politics \& national interests & 5 & 13 & 18 \\
Regulatory \& public accountability & 7 & 60 & 67 \\
Science \& technology & 5 & 3 & 8 \\
Total & 114 & 489 & 603 \\
\hline
\end{tabular}

(Source: Author's collection and coding)

nuclear safety. After the Fukushima accident, XEN's coverage of domestic atomic power remained positive or at least neutral, mostly in economic frames.

Table 6.2 shows that $\mathrm{PD}$, as a CCP mouthpiece, predominantly reported nuclear power as a symbol of China's science and technology progress, independent innovation and economic growth. The Fukushima disaster dramatically halted the tone and pushed PD to focus more on promising the safety of domestic nuclear power facilities in addition to blaming Japan's poor behaviors. However, as China began to export atomic power technologies (Masood \& Buckley, 2013), "nuclear power goes outside" became a new propaganda theme for PD to praise the sector.

My data collection of CSD, unfortunately, starts in 2007, later than the other three sampled media outlets, due to a database availability constraint. CSD focused on science and technology aspects of nuclear power, including fusion research such as ITER (International Thermonuclear Experimental Reactor) in which CAS, the publisher of CSD, has been heavily involved. The Fukushima accident seemed to increase the newspaper's interest in nuclear energy. Table 6.3 shows the themes of CSD's nuclear power reporting. Besides Fukushima-related stories, CSD intensively reported senior scientists' appeals to increase China's nuclear power development despite Fukushima and their promise of its safety. Among the four sampled outlets, if we do not consider one censored story in SW, CSD is the only medium among the four sampled 
Table 6.2 People's Daily nuclear power coverage (2000-2017)

\begin{tabular}{lrrr}
\hline & Before 2011 & After 2011 & Total \\
\hline Positive reporting & 166 & 44 & 210 \\
Negative reporting & 11 & 61 & 72 \\
Neutral & 199 & 137 & 336 \\
Nuclear power safety & 31 & 115 & 146 \\
Business \& economy & 117 & 41 & 158 \\
Development & 21 & 9 & 30 \\
Environment \& ecology & 16 & 6 & 22 \\
Engineering and technique & 63 & 11 & 74 \\
History \& culture & 18 & 6 & 24 \\
International treaty \& military nuclear & 36 & 12 & 48 \\
Science popularization & 10 & 9 & 19 \\
Politics \& national interests & 16 & 20 & 36 \\
Regulatory \& public accountability & 18 & 4 & 22 \\
Science \& technology & 30 & 9 & 39 \\
Total & 376 & 242 & 618 \\
\hline
\end{tabular}

(Source: Author's collection and coding)

Table 6.3 China Science Daily nuclear power coverage (2007-2017)

\begin{tabular}{lrrr}
\hline & Before 2011 & After 2011 & Total \\
\hline Positive reporting & 63 & 169 & 232 \\
Negative reporting & 7 & 117 & 124 \\
Neutral & 41 & 221 & 262 \\
Nuclear power safety & 6 & 88 & 94 \\
Business \& economy & 25 & 83 & 108 \\
Development & 8 & 7 & 15 \\
Environment \& ecology & 13 & 53 & 66 \\
Engineering and technique & 13 & 71 & 84 \\
History \& culture & 12 & 16 & 28 \\
International treaty \& military nuclear & 1 & 4 & 5 \\
Science popularization & 0 & 28 & 28 \\
Politics \& national interests & 1 & 5 & 6 \\
Regulatory \& public accountability & 0 & 50 & 50 \\
Science \& technology & 32 & 102 & 134 \\
Total & 111 & 507 & 618 \\
\hline
\end{tabular}

(Source: Author's collection and coding) 
newspapers to have interviewed anti-nuclear activists and dissenting experts, indicating the elite nature of the nuclear debates.

As I pointed out in previous chapters, SW as a liberal media outlet heavily reported negative aspects of hydropower development and initiated China's anti-GMO activism, but when reporting nuclear power, its style shifted. While the Fukushima accident impelled SW to include negative reporting about nuclear safety and public accountability frames, it was about Japan's nuclear power industry. When shifting back to China, SW took a neutral tone to examine competition between nuclear enterprises, nuclear waste site location and safety challenges in the business frame, rather than in its long-used public accountability frame for investigating regulatory loopholes. The liberal media did not quote any domestic anti-nuclear power activist in its news stories. On June 19, 2014, SW published a Q\&A with Wang Yinan to criticize inland nuclear power development, but Guangdong Provincial Propaganda Department censored the story (X. Hu, 2014) (INT20160923b). To balance the article, on June 20, 2014, SW published another opinion article written by a nuclear supporter to defend the industry against Wang's criticism (W. Zhang, 2014). Table 6.4 reports the basic coding results of SW nuclear articles.

Indeed, anti-nuclear activists repeatedly complained that the media could hardly report the anti-nuclear voices due to the alleged censorship as a result of the lobbying effort by nuclear power industry as a strong vested interest group (INT20160923b, INT20161229). But the claim might not be true. Besides Wu Hui's conspiracy claims, the only censored media article my field

Table 6.4 Southern Weekend nuclear power coverage (2002-2017)

\begin{tabular}{lccc}
\hline & Before 2011 & After 2011 & Total \\
\hline Positive reporting & 3 & 8 & 11 \\
Negative reporting & 2 & 20 & 22 \\
Neutral & 11 & 30 & 41 \\
Nuclear power safety & 2 & 9 & 11 \\
Business \& economy & 9 & 18 & 27 \\
Development & 1 & 5 & 6 \\
Environment \& ecology & 1 & 5 & 6 \\
Engineering and technique & 0 & 0 & 0 \\
History \& culture & 0 & 0 & 0 \\
International treaty \& military nuclear & 0 & 1 & 1 \\
Science popularization & 0 & 2 & 2 \\
Politics \& national interests & 1 & 5 & 6 \\
Regulatory \& public accountability & 0 & 12 & 3 \\
Science \& technology & 2 & 1 & 74 \\
Total & 16 & 58 & \\
\hline
\end{tabular}

(Source: Author's collection and coding) 
interviews can confirm is the SW's Q\&A with Wang, perhaps because, in Guangdong Province, the ratio of nuclear energy to total electricity supplies is the highest nationwide (reaching $11.9 \%$ by 2020) (China Energy News, 2018).

Instead of being censored, journalists have widely avoided investigative reporting of nuclear power. One senior editor of an official science and technology newspaper stressed that she had never received any censorship directive from the Central Publicity Department on nuclear power coverage. However, "journalists were reluctant to report negative news about nuclear power because they worried about the military background of the nuclear power sector, the ingrained image that nuclear represents national prosperity and the long-held belief that there was no [significant] news in the nuclear power industry" (INT20160925a). She was echoed by another senior journalist of the same newspaper who talked with me.

In a separate interview, a former science editor at a leading liberal news magazine confirmed a similar point: "An in-depth investigative story costs a lot of energy. Journalists would not touch [investigative stories of] nuclear power because they perceived there would be lack of public interest due to the small presence of nuclear power in the country" (INT20170106).

A third media source, a former environmental editor at the abovementioned Guangdong-based liberal media outlet, mostly shared the view. "We defend public interests, but there seem not many news-making events in the nuclear sector" (INT20161022).

A fourth media source, a science journalist, working with a liberal news magazine famous for its journalist professionalism (where the second source used to work), said when reporting nuclear power issues, she has insisted on high rationality to avoid amplifying the potential but highly unlikely risks associated with nuclear power. She attended a debate joined by nuclear power experts and activists. "I was reluctant to interview and quote the activists because their claims on nuclear power risks seemed too extremist while nuclear industry experts' comments seemed more reasonable and evidence-based" (INT20161217).

On the other hand, official Chinese media outlets have every reason to positively report nuclear power due to its symbolic images of national science and technology progress, independent innovation, substantial economic return and most recently China's proud international expansion. Table 6.5 below provides evidence. According to Table 6.5, most articles of the four sampled media outlets on the history of nuclear power positively eulogized Chinese nuclear scientists' devotion and contribution to national independence (before Fukushima $80 \%$ positive and post-Fukushima $75.8 \%$ ). Besides, among science and technology framed sample articles, 55\% were positive (before Fukushima $59.5 \%$ and post-Fukushima $50.5 \%$ ), and only $2 \%$ were negative.

Consistent with the media's restrained reporting of nuclear power is a restrictive media morphology. My field studies revealed that most official media outlets have a somewhat stable news team reporting the beat, either science or business and energy reporters for a long time. In the hydropower case, energy 


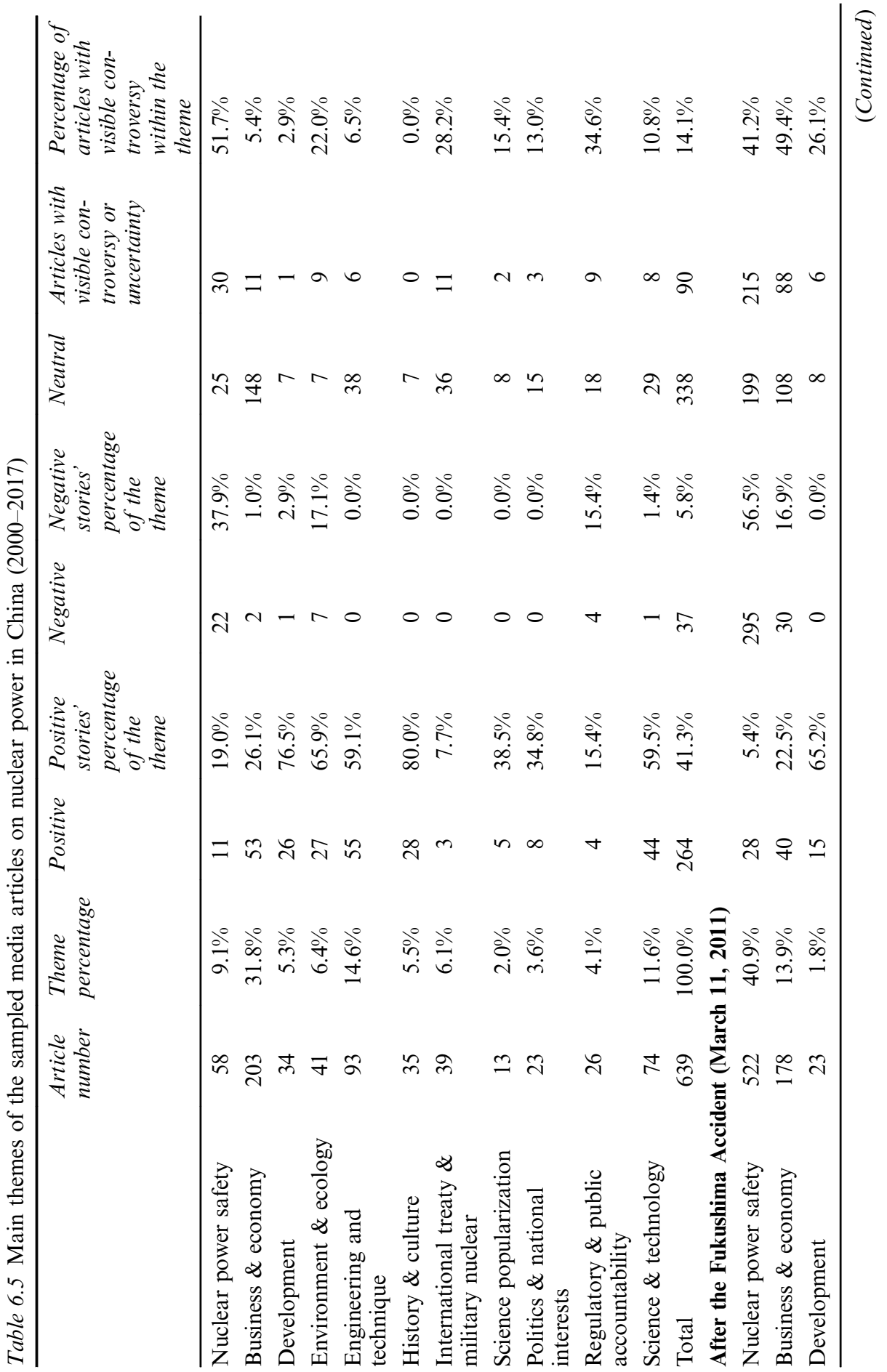


146 The nuclear power debate

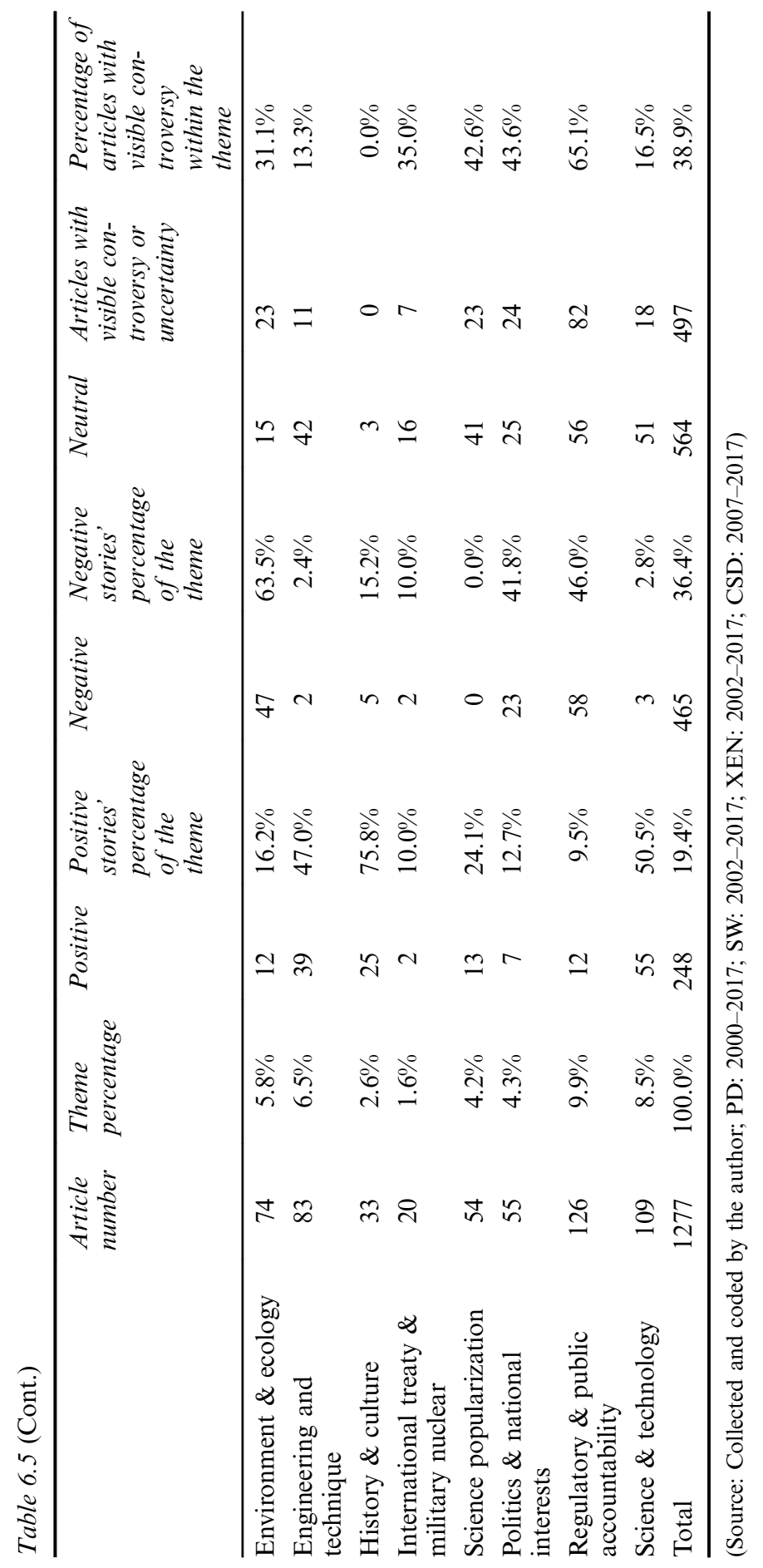


reporters tended to report the sector positively, but environmental journalists often offset and outvoiced their effort due to the media's active pursuit of environmentalism agenda.

In the nuclear power case, however, few environmental journalists were involved in reporting the nuclear power sector, for reasons indicated above (INT20161022). The implication of this low diversity will be explored in the following section examining knowledge-control regimes.

Taken together, the nuclear power industry's positive images, Chinese journalists' self-censorship partly due to their perceived limited audience interest, and the atomic industry's active public communication efforts have effectively restricted the media's role as a platform for anti-nuclear activism. Can the Internet and social media that have eroded the dominance of conventional media and decentralized the communication process topple the pattern?

\subsubsection{Nuclear power controversy in the social media era}

To examine the Internet and social media role in China's nuclear disputes, one can first investigate whether the sampled print media's reporting of nuclear power was comparable with people's online behaviors, including online searches and BBS postings. Figure 6.2 to Figure 6.6 present such information.

Data embodied in the above graphs are not entirely satisfactory. Baidu.com introduced its Baidu Index service covering media trends only after 2011, while Google does not offer a media trends service. On the other hand, Google's Chinese search data is likely minimal since 2010 when its search engine was blocked in China, and Chinese residents needed to use a virtual private network (VPN) to cross the Chinese Internet wall, hence dramatically reducing the number of Chinese users. But comparing with the Baidu Index, Google Trends can provide a chance for triangulation. Baidu search and

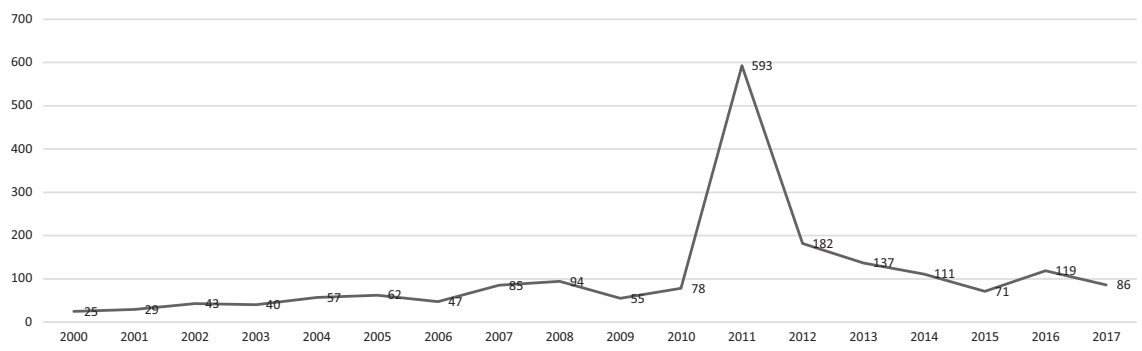

Figure 6.2 Combined four sampled Chinese media nuclear power articles (2010-2017) Source: Author's analysis; PD from 2000, CSD from 2007, XEN from 2002 and SW from 2000 
Google search seemed to have comparable morphology though their time scales were different.

All media and search data showed a high wave around March 2011 when the Fukushima accident occurred. There were several significant waves in the Baidu search data, such as in December 2014 (December 1-7) and January (January 12-18), April (April 20-26) and May 2015 (May 18-24). In terms of the weekly unit of Baidu search (Figure 6.4) and Baidu media index (Figure 6.3), the two roughly matched (e.g., they matched in three of the four periods except January 12-18, 2015). But when I manually checked the sampled media data, I found the wave crest of the sample media stories did not correspond to the waves in search results and Baidu media index.

I further searched Baidu news search engine (news.baidu.com) for the above periods (December 1-7, 2014; January 12-18, 2015; April 20-26, 2015; and May 18-24, 2015). The search returned results ranging from 47 to 85. No article reported blockbuster nuclear news, such as new disasters or anti-nuclear campaigns such as the NIMBY street protests in 2013 and 2016. Although I did not make a systematic coding, a skim was enough to judge there was nearly no adverse reporting except the tiny amount on the leftover issues of Fukushima. Instead, dominant stories were the appeal to recover nuclear power momentum before Fukushima, new technology or engineering advances, and events to celebrate the 60th anniversary of China's nuclear power industry (1955-2015). No anti-nuclear activists or dissenting experts were quoted in these articles.

Although the analysis on the data obtained from Baidu news index and Google search engine was far from systematic and representative, it confirmed the finding of my systematic coding of articles from the four sample media outlets. Nuclear power's progress and technological innovation rather than its safety

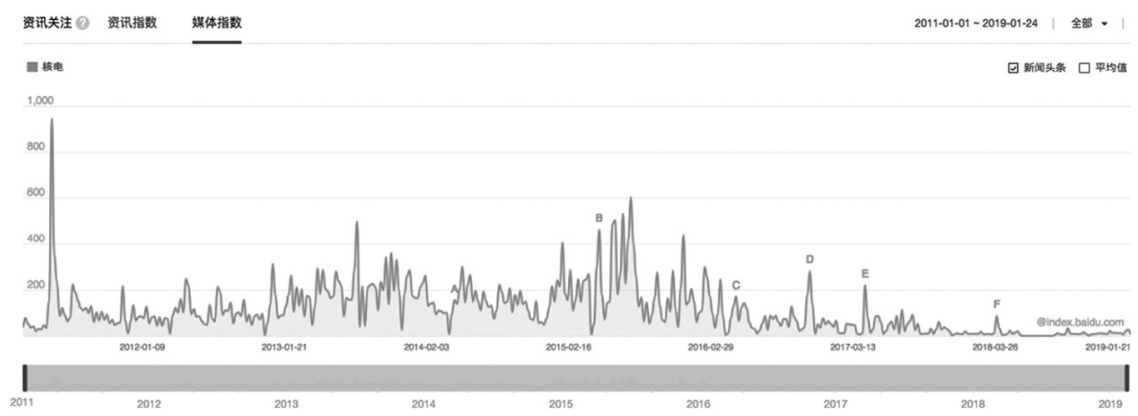

Figure 6.3 Chinese media articles mentioning nuclear power searched through Baidu Index (2011.01-2019.01)

Source: index.baidu.com, searched on January 25, 2019; Url: https://index.baidu.com/ v2/main/index.html\#/trend $/ \% \mathrm{E} 6 \% \mathrm{~A} 0 \% \mathrm{~B} 8 \% \mathrm{E} 7 \% 94 \% \mathrm{~B} 5$ ?words $=\% \mathrm{E} 6 \% \mathrm{~A} 0 \% \mathrm{~B} 8 \% \mathrm{E} 7 \%$ $94 \% \mathrm{~B} 5$ 


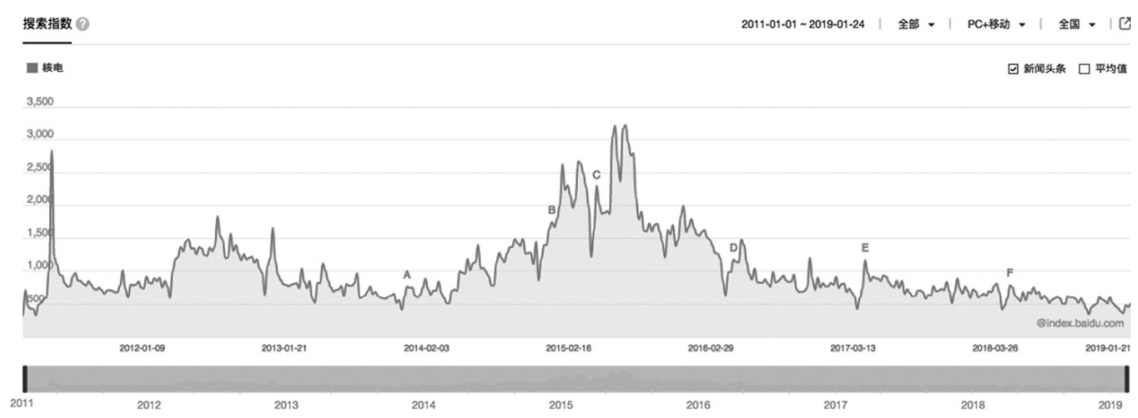

Figure 6.4 Baidu users' online search of the keyword "nuclear power" (2011-2018) Source: index.baidu.com, searched on January 25, 2019; Url: https://index.baidu.com/ v2 $/$ main/index.html $/$ trend $/ \% \mathrm{E} 6 \% \mathrm{~A} 0 \% \mathrm{~B} 8 \% \mathrm{E} 7 \% 94 \% \mathrm{~B} 5$ ? words $=\% \mathrm{E} 6 \% \mathrm{~A} 0 \% \mathrm{~B} 8 \% \mathrm{E} 7 \%$ $94 \%$ B5

concerns drove people's interest in the sector, as revealed in their online search behaviors.

However, the interest in nuclear power based on its progress seemed limited and short-lived. The Baidu search data demonstrated that the maximum daily search, including during Fukushima accident, was around 3,000, while the average daily search across the past eight years was just 1,010 . The lack of mass interest no doubt restricted the public impact of anti-nuclear power activism, which has been marginalized by the established mass media. The status also frustrated activists' efforts to utilize social media platforms ranging from blogs to Weibo and WeChat.

Searching the two major blog portals - Sina blog and BlogChina - with the key terms "nuclear power" and "nuclear energy" for bloggers returned about 330 bloggers. Known activists or dissenting experts operated none of them. Two blog accounts were linked to local anti-nuclear activism in Rushan of Shandong Province and Xinxiang of Henan Province, both with less than five

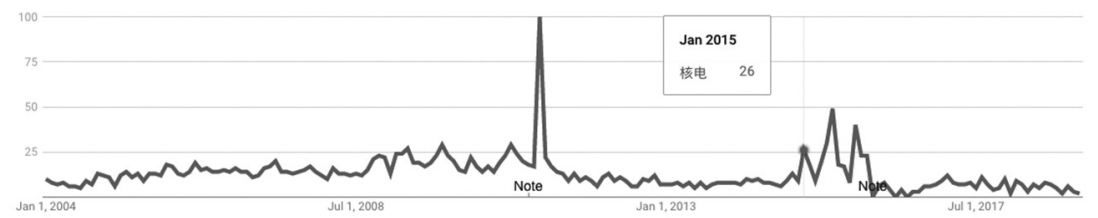

Figure 6.5 Google Trend showing the online search of the keyword "nuclear power" (in Chinese and China) (2004.01-2019.01)

Source: Google Trends; URL: https://trends.google.com/trends/explore?date=all\&geo= $\mathrm{CN} \& \mathrm{q}=\% \mathrm{E} 6 \% \mathrm{~A} 0 \% \mathrm{~B} 8 \% \mathrm{E} 7 \% 94 \% \mathrm{~B} 5$ 


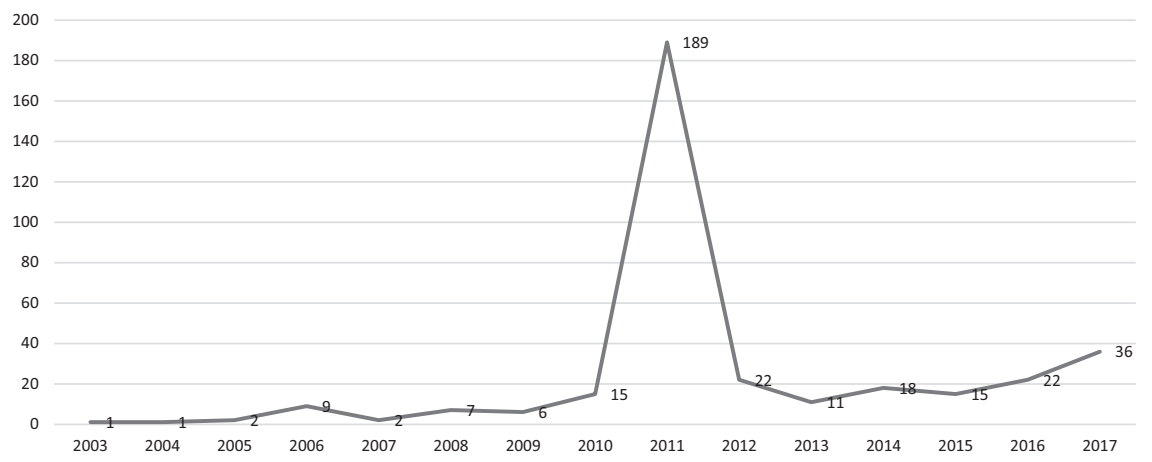

Figure 6.6 The frequency of high-impact BBS posts on "nuclear power" (in Chinese) on Tianya.com (2003-2017)

Source: bbs.tianya.cn, collected by Kai Liu

articles and stopping updates in 2008. Searching the names of crucial activists or dissenting experts, I only found blog accounts belonging to the grassroots anti-nuclear activist $\mathrm{Wu}$ Hui and the senior scientist He Zuoxiu who sharply criticized inland nuclear power. Among the 34 blog posts in the scientist's account in BlogChina.com, six were dedicated to nuclear power. As of January 26, 2019, each nuclear power articles had 4,661 views on average, and six comments per capita.

Wu posted 146 blog articles since he opened a Sina blog account in 2009 (he had another Sina blog account that was closed in 2008, without any nuclear power relevant articles), including 12 articles dedicated to anti-nuclear power, all posted after Fukushima. The average visit of these articles, as of January 26, 2019, was 4,568. The comments and republishing posts were higher, 60 and 100 respectively, partly because the activist has concentrated more on a locally relevant campaign against the proposed Taohuajiang NPP in his hometown Hunan Province. Despite the more significant number of comments, there was no evidence that his blogs have mobilized local opposition to the plant that was strongly supported by the local government.

The small number of views and comments indicate low public response to the nuclear power issue, including anti-nuclear activism, especially if we consider the fact that most blog articles were published not long after the 2011 Fukushima disaster. The low number of visits seemed not caused by little public interest in the bloggers as they also published articles on other topics, winning tens of thousands of views.

As compared with the low-profile activists in the blog world, the nuclear industry was active. Nearly all major nuclear power plants or proposed projects had their official blog accounts. Several leading public communicators of nuclear power and radioactive science, both individual and institutional, also had their presence. 
On the other hand, although in the public blogosphere little anti-nuclear activism was visible, on ScienceNet.cn, published by CAS and operated by CSD, which is noted for its blogs written by thousands of scientists (X. Huang \& Zhan, 2010), a number of severe blog articles questioning nuclear power can be found, some with more than 10,000 views. As ScienceNet.cn's primary readers are scientists whose number is much fewer than the audiences of public media, 10,000 views is a pretty high number. This fact, together with CSD articles quoting major dissenting experts on the nuclear power issue, indicates the elite, professional feature of China's anti-nuclear activism.

Moving from blogs to the more popular Weibo, one can identify more impassive public reactions to the nuclear power issue. Combining keyword searches, topic searches (with hashtag \# and the keyword "nuclear power"), and targeted search in key actors' Weibo accounts, I selected four nuclear-negative tweets among the total of (only) 12 negative tweets I found eligible for Weiboreach.com analysis (over 30 forwards) and all the four such available positive tweets. I input them for Weiboreach.com analysis. The four negative tweets produced altogether 670,000 independent views, much fewer than the four high-impact nuclear-positive tweets, whose total reader numbers reached 3 million. Although the two sets of Weibo tweets might not be genuinely comparable because they were posted at a different time in varying contexts, the big difference between the view number for the two types of tweets showed the lack of market for antinuclear debate on social media.

On the other hand, the highest viewed nuclear power topic on Weibo was worth further exploration. A former nuclear engineer with a Tsinghua master's degree started his own business of instant noodles, claiming the reason for his entrepreneurship: "Nuclear power is safe, but food safety is less satisfactory!" Since its debut in early December 2018, the Weibo topic has attracted 12.8 million views and 7,300 comments by the time of my data collection in late January 2019.

Weibo was indeed used in anti-nuclear NIMBY activities (R. Huang \& Sun, 2016), but the dominant social media platform has not become an arena for regular anti-nuclear power activism. People's anti-nuclear emotion as revealed in their Weibo tweets was far less than the industry's use of it as a promotion for nuclear power's legacy and positive image.

Finally, a brief examination of WeChat revealed similar results. My field observation on WeChat only identified two WeChat groups focused on antinuclear activism, each with only a dozen members. A January 7, 2019 search of the 100 highest read WeChat public account articles with gsdata.com found none of them had a clear anti-nuclear tone. Then I specifically searched activists and dissenting experts' names to see their WeChat public account articles. The search on January 27 returned with 14 different articles, with the earliest dates back to March 2015 (gsdata.com only supported search in recent three months from the search time). Except for one 2015 piece questioning inland nuclear power whose views reached 13,000, all other articles were read by less than 5,000 
readers. Nearly all anti-nuclear power articles were accompanied by refutations, either by official nuclear power organizations or individual atomic engineers.

Like Weibo, the lukewarm reaction to WeChat-based anti-nuclear articles reflects the low public attention to the issue. A triangulation across blogs, Weibo and WeChat showed that nuclear power is far from a hot topic most of the time in China. This low interest has led online editors to not spend their energies in promoting such tweets or posts. "Unlike GMOs, the audience's few views result in an algorithm naturally avoiding recommending this type of contents," said an editor at an algorithm-based media (INT20170725).

Although anti-nuclear power voices can be heard on social media, their low public attention, together with conventional media's friendly tone to the energy, inhibited mass mobilization against it. But the media alone cannot reach this effect. Instead, the inhibiting political opportunity structure should be the primary force curbing regular anti-nuclear activism in Chinese society.

\subsection{Examining nuclear contention as a social movement}

\subsubsection{Restrictive political opportunity structure}

Taking China's nuclear power controversy as a social movement, we can find that the three dimensions - political opportunity structure, frames and mobilization (Tarrow, 2011) - driving social movements were relatively restrictive in the case of anti-nuclear activism. Among them, the political opportunity structure plays a central role. Due to China's lack of institutionalized democratic bodies which Kitschelt (1986) found essential to Western democracies' anti-nuclear movements, we have to investigate both the political establishments and sociopolitical elements forming political channels.

Due to its unique importance, the nuclear power industry has enjoyed a much higher political status than average sectors. For example, the top leader (normally chairman and Party secretary) of CNNC has always been a member of the 200-member CCP central committee, usually consisting of ministers and governors. With political power only less than the Politburo, CCP central committee is China's main policymaking body. Fewer than ten of its members commonly come from industry, including the nation's top bank leaders, presidents of two petroleum giants, CNNC head and defense industry top executives.

Among China's political establishments, the Chinese People's Political Consultative Conference (CPPCC), China's "upper house" which plays a vital role in its consultative Leninism (Tsang, 2009), has not raised any open debate against nuclear power. My field study only identified one CPPCC delegate who openly questioned nuclear power development. However, without other delegates' support, he can hardly raise the nuclear power issue into group discussions at the political body's annual plenary meetings. Without the endorsement of more members, he had to personally submit his policy proposal to relevant agencies, such as NEA and NNSA, through their offices for 
letters and visits ${ }^{1}$, which makes it hardly possible to produce any policy impact (INT20170730).

By contrast, the nuclear power industry has a much more concentrated presence in CPPCC. In 2018, CNNC alone contributed to seven delegates to the 13 th CPPCC in its economics and science and technology groups. The appearance was complemented by business executives in CGNPC and other power firms, as well as scientist delegates who studied high-energy physics and other nuclear-related disciplines. For example, two scientists at the CAS Institute of High-energy Physics (IHEP) were elected CPPCC members (IHEP, 2018). Although the total number was small in relation to CPPCC's 2100 plus delegates, their concentration in the science and technology group (112 members) and business \& economy group (130 members) seemed enough to raise pronuclear power proposals and block any potential anti-nuclear proposal. During NPC and CPPCC annual plenary meetings, jointly held in March, the nuclear industry represented by CNNC and CGNPC often convened press conferences to brief their new CPPCC proposals or NPC motions.

CPPCC and NPC are examples of arenas where the political opportunity structure does not open wide enough for anti-nuclear activism. In a broader sense of the structure (Meyer \& Minkoff, 2004), China's specific sociopolitical and economic condition also contributes to constrained anti-nuclear activism.

In the previous section, I analyzed Chinese media's reluctance to initiate and amplify any nuclear power controversy. In terms of political opportunity structure in an undemocratic nation, this also means the lack of political channels for anti-nuclear activism.

Among other elements, the nuclear power sector's resource concentration and power monopoly, which rendered the industry a primary target of social movements in Western democracies in the 1970s and 1980s (Kasperson et al., 1980; Opp, 1986), instead have played an inhibiting role for the social movement in developmentalism-dominated China. "A nuclear power project easily reaches 30 to 50 billion yuan [in investment], which will significantly promote the local economy and tax revenues of hosting cities. Therefore, local government will try every effort to attract a nuclear power plant and then ensure its successful construction and operation," said a senior journalist affiliated with the official Xinhua Agency who has reported on the nuclear power industry for years (INT20160923a). His remark was consistent with the economic and business frame dominating Chinese media's non-Fukushima nuclear power reporting, as shown in Table 5.5. The frame accounted for $31.8 \%$ of the sampled media reporting of nuclear power before the Fukushima accident, the largest. After the Fukushima disaster, the frame's percentage decreased to $13.9 \%$, the second largest after nuclear safety's $40.9 \%$. The nuclear safety frame was mostly applied to situations related to the Fukushima accident and post-disaster impacts and rescue.

Unlike a hydropower dam which is often located in remote southwestern provinces, all NPPs in China sit in affluent coastal areas - particularly Guangdong, Zhejiang, Jiangsu and Shandong (the four richest Chinese provinces in 
terms of GDP) - where local governments have extensive resources and high capacity to advance major industrial projects. The nuclear power industry, on the other hand, does not merely wait for or rely on local host governments. According to an industry insider, while maintaining a high intensity of regular public education, the industry usually spent massive efforts making sure the planned nuclear power projects were written into the provincial five-year development plans to ensure legitimacy. After that, nuclear power investors would mobilize officials from the provincial level to host local governments. Local opinion leaders would also be invited to model atomic power plants - normally Qinshan NPP for CNNC and Dayawan NPP for CGNPC - to experience how beneficial an NPP can be to residents (INTINT20161023).

The governance structure of China's nuclear power industry further shut down organized resistance to the industry. Nuclear power safety is governed by the National Nuclear Safety Administration (NNSA) under SEPA/MEP/MEE, the most critical government agency behind environmental activism such as the antihydropower movement. It is widely acknowledged that ENGOs generally consider SEPA/MEP as one of their few government allies (Y. Sun \& Zhao, 2008) and are reluctant to turn hostile to the agency by provoking the nuclear power sector. Although most ENGO sources I interviewed did not admit this, they walked away from anti-nuclear activism. Funding could be another factor. A former China representative of a European environmental foundation said despite the organization's anti-nuclear stance in Europe, it has not introduced such activism to China or funded local ENGOs for this activity.

In addition to political opportunity structure, anti-nuclear activists in China also found it hardly possible to win the frame competition, another critical element Tarrow (1996) identified for a successful social movement. The previous section has revealed the media's cold attitude to anti-nuclear activism. But activists themselves had to avoid an overall anti-nuclear image. Instead, they either targeted inland nuclear power, or focused on the lower efficiency of the energy, or opposed the great leap forward of the NPP construction, or stressed the possible management loopholes.

Two prominent factors make it hard for anti-nuclear activists to frame their actions as legitimate: the nuclear power sector's close ties with SEPA/MEP/ MEE and its past glory and symbolic image of independent innovation. Nuclear power is strongly framed as a solution to China's environmental woes ranging from the severe haze caused by air pollution to its high carbon intensity (Zhou, 2014). The link to the environmental agency indeed corroborates the frame, as experts and officials affiliated to MEP widely endorsed the claim to place nuclear power as clean energy either in meetings, government documents and media interviews (W. Guo, 2014).

The sector's revolutionary legacy, a foundation for its positive sociotechnical imaginaries (Jasanoff \& Kim, 2009), and its image of competence in serving the public (Siegrist, Cvetkovich \& Roth, 2000) shielded nuclear power from any growing public dissatisfaction. The nuclear power industry's revolutionary legacy to successfully make an atomic bomb from scratch and its later 
development of civil nuclear power result in an image of technological competence among the public and the media. The independent innovation frame enjoyed by the nuclear power sector has won the appreciation of generations of Chinese leaders from Deng Xiaoping and Jiang Zemin to Xi Jinping and premier Li Keqiang. The latter even called the nuclear power sector a highlight card for the exports of Chinese innovation (Party Committee of CNNC, 2017).

As shown in the previous chapter, the growing leftism movement joined hands to attack GMOs, which were framed either as a conspiracy of Western powers against China, or a capitalism symbol to exploit peasants. But the revolutionary legacy of nuclear power sector makes it nearly wholly free of this stigmatized frame. "Leftists cherishes Chairman Mao. One of the most notable achievements of Mao is his determination to develop the atom bomb. So, leftism-oriented nationalists tend to link the nuclear power industry to Mao's legacy, making it free from being branded as a Western conspiracy," said a Chinese communication scholar (INT20170828).

In summary, in addition to the narrow political opportunity structure, the clean technology frame of nuclear power endorsed by the environmental agency and the sector's revolutionary and innovation images have primarily inhibited activists from negatively framing atomic energy. Meanwhile, MEP's endorsement of nuclear power has also limited established ENGOs' involvement in antinuclear activism. The absence of ENGOs, plus media workers' reluctance to make critical reporting of atomic energy, made social mobilization for antinuclear activism hardly sufficient. Figure 6.7 indicates the situation.

Despite these restrictive factors and limited impacts, there were still NIMBY events against nuclear power, even resulting in project suspensions. Activists and dissenting experts can always openly question the industry. In addition to the triggering role of the Fukushima accident, internal conflicts and fragmentation of China's nuclear governance, as revealed by the fragmented authoritarianism (FA) framework, also contributed to the occurrence of NIMBY events and controversies related to nuclear power.

\subsubsection{Fragmented authoritarianism and anti-nuclear activism.}

Although the political opportunity structure was narrow for China's anti-nuclear power activism, activists have desperately tried to exploit the fragmentation to widen the opportunity structure. Wangjiang's civil movement against Pengze NPP in Jiangxi Province is a typical example of fragmented elements that can fuel certain activities against nuclear power (L. Deng \& Jia, 2019).

As discussed above, a mighty host government can effectively constrain local protests within its jurisdiction, but Wangjiang belongs to the neighboring province of Anhui, which is on the other side of Yangtze River. After the Four Seniors raised the anti-Pengze NPP flag, Pengze county's officials requested to meet their counterparts in Wangjiang several times but were refused. Although the Chinese media are generally reluctant to tap negative news of nuclear power, two dramatic plots - Wangjiang government's official 


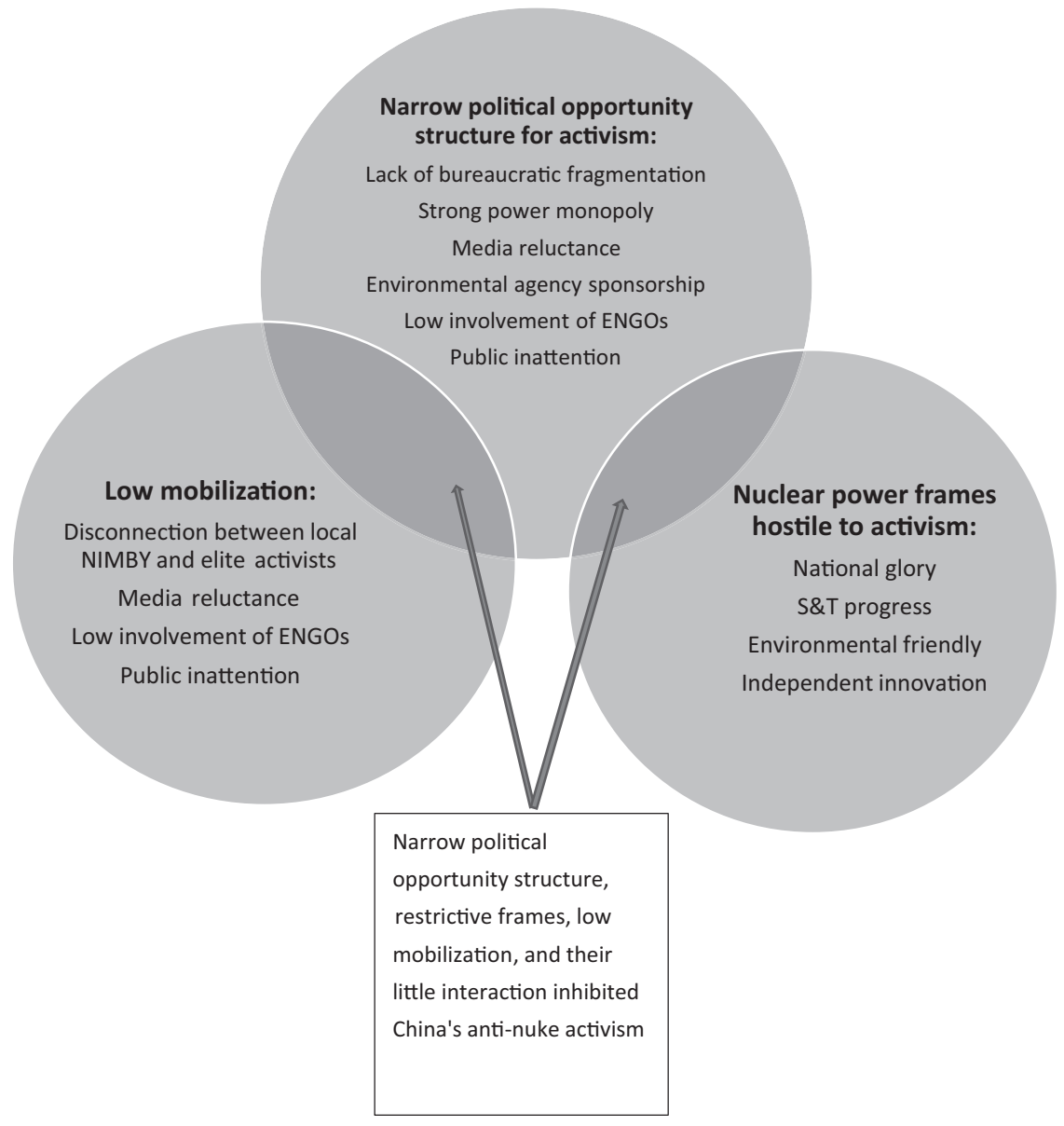

Figure 6.7 Narrow political opportunity structure, unfriendly framing and low mobilization for China's anti-nuclear activism

Source: Drawn by author

document against nuclear power and the Four Seniors' symbolic image of elite self-governance - attracted their attention (INT20161217).

On the Four Seniors' side, they effectively mobilized residents in Wangjiang's jurisdiction. Advertising boards against nuclear power were erected, and residents who worked for the preliminary construction of Pengze NPP were mobilized to inform about the advance of the nuclear project. With the support of Wangjiang residents, the Four Seniors were able to charge that Pengze NPP staffs used valuable gifts to trade for Wangjiang stakeholders' endorsement in its public consultation process (INT20161206). 
The privilege of experts who supported the Four Seniors to submit internal reports to top national leadership further enlarged the fragmentation. CAS members can directly brief top state leaders on science and technology issues. He Zuoxiu as a CAS member managed to submit relevant policy briefs to top policymakers, including President $\mathrm{Xi}$ Jinping and Premier Li Keqiang (INT20171221), a sign of China's bureaucratic fragmentation (Nathan, 1986).

By contrast, the pro-nuclear side seemed powerless in this aspect. According to an industry source (INT20170723), since 2008 when NEA was set up, CNNC and other State-owned energy giants can only report to NEA to reflect their policy appeals, apparently to limit the expanding power of stateowned energy giants. The bureaucratic fragmentation made the nuclear power industry suffer a procedural disadvantage in political debates.

Nonmainstream knowledge and expertise within the nuclear power industry were other fragmented resources that activists and dissenting experts could utilize. Activists often stressed responsible engineers and experts within the sector empowered them to identify the problems of nuclear power. According to the above industry insider (INT20170723), the nuclear fuel recycling sector within the industry could be the primary source of expertise for activists, because the latter's protests could highlight the importance of the longneglected atomic fuel recycling.

But the nuclear fuel recycling side was blindsided by NIMBY activities in Heshan and Lianyungang. The fuel recycling portion did not have as much public communication experience as their NPP counterparts. Hence, they had not surveyed public opinion nor tried to appease local opinion leaders in host regions (INT20161023). When online protests convened to push citizens to the streets (R. Huang \& Sun, 2016), they were utterly unprepared.

Local governments in some host regions, then, also become somewhat fragmented elements of nuclear power development. When developmentalism dominated the agenda, bringing in nuclear projects best satisfied local officials' desire to pursue political achievements. But since President Xi Jinping came to the center of Chinese political power, the central leadership more and more stressed the importance of maintaining social stability rather than unusual economic growth (Lampton, 2015). Facing the potential risk to trigger social unrest, some local governments of host regions became less friendly to, or at least not wholeheartedly embracing of, nuclear power projects. The quick success of NIMBY activities in Heshan and Lianyungang resulted from this bureaucratic logic. An official of Guangxi Zhuang Autonomous Region's Fangchenggang city with an ongoing six-reactor NPP reported that resident relocation for the NPP "nearly made his skin peel off" (D. Yan \& Li, 2014). "The rising risk awareness of local officials on the nuclear power project possibly causing street protests is changing their policy priority. Perhaps this is one of the policy impacts of China's anti-nuclear debates," said a Chinese communication scholar who has been following nuclear controversies across the country for several years (INT20170915). 
In summary, despite the overall restrictive political opportunity structure, fragmentation within and outside the nuclear power industry still enabled activists and dissenting experts to initiate controversies. Activists never hesitated to utilize the fragmentation. In their petition to higher government leaders against Pengze NPP, for example, the Four Seniors hinted that mounting local dissatisfaction could lead to unwanted street protests, threatening political stability. No doubt this intentional effort contributed to the possibilities brought by fragmented bureaucracy associated with nuclear power governance.

On the other hand, although bureaucratic fragmentation played a role in facilitating anti-nuclear debates, the activism and its policy impacts were shortlived and limited, hardly enough to institutionalize the capacity to mobilize both elite and grassroots support. The weak strength explained the resumed momentum of the nuclear power industry in spring 2018. Theoretically, this is an indication that the emerging FA framework existing in and beyond nuclear power sector had to be subject to the more restrictive political opportunity structure.

As illustrated above, the nuclear power sector not only linked to a constrained political power regime but also co-existed with an effective knowledge-control regime. The regime strengthened the constraints affecting antinuclear activism.

\subsection{Interpreting knowledge-making in nuclear disputes}

\subsubsection{Knowledge-control regime in China's nuclear power sector}

\section{Institutionalized knowledge monopoly}

As compared with hydropower and GMOs, the nuclear power sector has evolved a much stronger knowledge-control regime. Starting from the atom bomb development era, China's nuclear scientists and engineers concentrated in remote, mysterious Gobi bases, which made them not only far from urban prosperity, but also free of the political turmoil of the disastrous Cultural Revolution in the 1960s and 1970s.

What was isolated was not only the geographical and spatial location but also knowledge production. Nuclear science and technology education was limited to top universities such as Tsinghua, Xi'an Jiaotong and Shanghai Jiaotong universities, Hefei-based University of Science and Technology of China (USTC) and Wuhan-based Huazhong University of Science \& Technology (HUST). The research was restricted to individual CAS institutes (such as institutes of Applied Physics in Shanghai, of Theoretical Physics in Beijing and Modern Physics in Lanzhou), China Institute of Atomic Energy (CIAE) now under CNNC, Tsinghua's Institute of Nuclear Technology (which has an undergraduate wing, the Department of Engineering Physics) and USTC. Many of these institutions are veiled in mystery and named with a number. For example, Tsinghua's Institute of Nuclear Technology was named No. 200 in Changping District while CIAE is called Institute 401. 
Although since the 1970s, China began to open its door to international collaborators to commercialize nuclear power, the quasi-isolation system remains active today, partly because nuclear knowledge production and learning are highly professionalized. By the end of 2017, China Nuclear Society has only certified 18 Chinese universities' nuclear programs. Among them, Tsinghua University enjoys paramount status. In 2016, Tsinghua University's Department of Engineering Physics celebrated its 60th anniversary, announcing it had cultivated 20 generals and 32 CAS and Chinese Academy of Engineering (CAE) members. CNNC hosted 61 CAS or CAE academicians. CAS and CAE have honored a total of 2,400 academicians since 1956. CNNC announced in June 2018 that it would set up a Chinese University of Nuclear Industry in the coastal city of Tianjin.

Studies on the health impact of nuclear radiation are also concentrated in a few institutions, including the National Institute for Radiological Protection (NIRP) under the Chinese Center for Disease Control (China CDC), the Institute (Department) of Radiation Medicine under the Chinese Academy of Medical Sciences (CAMS), Beijing Institute of Radiation Medicine (BIRM) under the Chinese Academy of Military Medical Sciences (AMMS) and radiation medicine departments at a very limited number of medical universities. Although radiation medicine is now widely adopted at Chinese universities and hospitals, few of these ordinary institutions have the privilege to examine NPPs' health impacts.

The institutional concentration contributed to the monopoly in knowledge production. Unlike in the hydropower field where experts of various backgrounds can comment on environmental issues and in the GMO case where food safety concerns push the unchecked distribution of false information, nuclear power knowledge production and certification are highly controlled within the small number of institutions and top experts. According to one Chinese communication scholar who studies nuclear power controversies, a leading nuclear safety modelling expert at a top university used to tell him that when the expert failed to model the desired nuclear facility safety indices and expressed a bit of suspicion on the current safety measures, his aging advisor - a CAS academician - warned him not to become a rebel of the nuclear power industry (INT20170915).

While the anecdotal evidence cannot be independently confirmed, it is clear that professionals and knowledge production in the field are somewhat disciplined. The self-discipline echoes Schmid's (2015) observation on the former Soviet Union's nuclear power industry. In China, disciplined knowledge production is associated with industry professionals' self-confidence and their recognition of their past glory.

This past glory and its associated sociotechnical imaginaries can become a living component of the knowledge-control regime, just as it helps shield the nuclear power industry from many moralist attacks. In the knowledge-control regime, it maintains knowledge defenders' self-identity and their confidence, authorizes its legitimacy, silences dissenting voices and mobilizes necessary 
political resources when needed. Even He Zuoxiu, the senior CAS member, complained that his views questioning the feasibility of inland nuclear were not reflected in relevant CAE consultative reports and his attendance at the consultation process wasn't recognized with authorship.

\section{Knowledge control in public engagement}

While disciplining internal dissidents, the nuclear power sector is active in promoting nuclear safety ideas in the public sphere. In addition to the publicity departments of major industrial players such as CNNC and CGNPC, which are often staffed with several hundred employees to support science popularization, public relations, affected community appeasement, public and external publications, and academic sponsorship, two major industrial groups, China Nuclear Energy Association (CNEA), which mainly represents industry, and China Nuclear Society (CNS) that primarily represents academics, have proactive public publicity departments. Among the 210 national societies affiliated with CAST (which is legally the umbrella organization of all national natural science societies), CNS was one of the few organizations that continuously won CAST's annual award for science popularization.

In the early 2000s, several years before NIMBY movements began to spread across $\mathrm{China}^{2}$, media articles promoting nuclear power's safety and efficiency were widely published in the sampled media outlets, describing concerns about nuclear safety as irrational. "As compared with biotechnology experts, the nuclear power sector has a strong self-awareness in science popularization and strong organized capacity to implement it," said a leading science journalist of a Party mouthpiece (INT20170723).

He was echoed by a liberal news magazine's science editor. "Whenever I had a request or query, I can always find amiable nuclear experts to consult with" (INT20160816). The same magazine's energy reporter echoed: "Unlike other state-owned energy conglomerates, nuclear power enterprises' PRs are very capable. At news conferences, companies regularly prepared suggested questions for attending journalists. Many of these questions prepared by other industry players are nonsense. But in the question list prepared by nuclear companies' PR, you can nearly find every question a journalist wants to ask" (INT20170825).

Together with the favorable sociotechnical imaginaries that the nuclear power industry enjoyed, the cooperation regularly received friendly responses from the media, steering them to positively report the industry in standard time and balancing their reporting with the industrial voice when there were unfavorable events like the Fukushima accident or local NIMBY activities. This media orientation was corroborated by the abovementioned media morphology of keeping a stable "nuclear journalist" team for the beat. As media sociology scholarship has revealed, for both general media (Carlson, 2009) and science journalism (Schäfer, 2011), a 
closer tie between journalists and their sources produces more favorable reporting of these sources.

\section{Risk management and its socially constructed allies}

In its effort to reassure the public, the Chinese nuclear power sector, and the worldwide nuclear industry alike, adopts a strategy to admit uncertainty and potential risks but to assure the public (and particularly officials and political leaders) that the uncertainty is an unavoidable feature of industrialization; the risk associated with nuclear power is the lowest or most controllable as compared with other conventional technologies/applications such as driving cars; and the nuclear industry has the complete capacity to control the risks. The preamble of the International Atomic Energy Agency (IAEA)'s basic safety principles for NPPs claimed that "safety is never absolute in any endeavor. All of life is hazardous in some way" (International Nuclear Safety Advisory Group, 1999, p. 1).

Science studies scholars have shown that admitting uncertainties/risks but assuring effective management of them is a strategy to increase the epistemic authority of science (Shackley \& Wynne, 1996; Zehr, 1999). Nuclear power experts seek precisely this type of epistemic authority. Nearly every industry interviewee showed his/her embrace of this rationality. Correspondingly, rejecting or worrying about controllable low risk would be considered irrational.

Built on studies on the epistemic significance of uncertainty/risk management, Jia et al. (2017) further explored how the societal forces - the media, the government and policy agenda - interact with scientists' uncertainty management. In China's nuclear power case, besides sponsorship by SEPA/ MEP/MEE, journalists also helped strengthen the nuclear power sector's uncertainty/risk management, further securing its knowledge-control regime. "Nuclear power is not $100 \%$ perfect, but as compared with other energies, it is the most advantaged. Coal is heavy polluting; wind and solar energies are unstable and too expensive; hydropower cannot assure water supply in winter. There are risks, but they are under control," said an energy reporter working for a leading business news magazine (INT20170825).

The situation is similar to the US media's effort to keep the GMO controversy from escalating through the professionalization of reporting the beat (M. C. Nisbet \& Huge, 2006) or a "rational" tradeoff between potential risks and perceived benefits (Steiner \& Bird, 2008). Both M. C. Nisbet and Huge (2006) and Steiner and Bird (2008), however, neglected the role of low public attention in influencing journalists' behaviors. Above I mentioned that low public awareness led journalists to perceive reporting nuclear power as less rewarding. Meanwhile, low public attention meant a low availability of alternative sources and experts' views to journalists, leading the latter to adopt the dominating agenda and risk management paradigm of nuclear power. 
In mid-March 2011, after the Fukushima accident, widespread concern about radiation contaminants floating to China led the Chinese public to rush to buy iodized salt because taking iodine pills can reduce radiation harm. The buying rush, however, was depicted as an irrational behavior in various media and online articles, in which nuclear experts' claim of no radiation pollution from Fukushima paralleled science communication experts' comments on the public irrationality. Because salt's Chinese pronunciation (yan: 盐) is the same as "words" (言), which in Chinese are the second character of the term "rumor" (yaoyan: 谣言), a new Chinese word "rumored salt" (谣盐) was created, still pronounced as "yaoyan". The newly created term "rumored salt" was widely used in newspapers, websites, magazine, social media and public education events, vividly and satirically indicating an irrational public and its poor scientific literacy (W. Liu, 2011). The frame was so robust that it is still regularly used today to satirize the public's fear of rumored harms and its rejection of orthodox official knowledge (L. Xu, 2018).

The nuclear power sector's monopoly in knowledge production, its dominance in the public communication agenda and engaging media strategies, and its pragmatic uncertainty/risk management all resulted in (a) robust knowledge-control regime(s). When developing the concept using the example of the Human Genome Project (HGP), Hilgartner (2017) demonstrated that as compared with competing efforts, the knowledge-control regime(s) represented by HGP best matched the existing knowledge production practice, scientists' expectations and the public understanding of the genome sequencing. No doubt China's nuclear power sector had a similar situation.

Combining findings in the previous sections, one can find that the knowledge-control regime of the nuclear power sector allied with China's political power, but its epistemic authority primarily did not rely on the political power's coercive force. Instead, a whole set of societal, institutional and knowledge-making arrangements and a full set of social actors consciously and unconsciously enabled the regime to implement its knowledge control and strengthened the effect of such authority. In which case, given the high strength of the control, why can we still hear the controversies and debates raised by outsiders, even though the policy impact was relatively limited? We can understand this by tracing activists' alternative knowledge building as a way to break the knowledge-control regime of the nuclear power sector.

\subsubsection{Alternative knowledge and challenges to knowledge control}

\section{Alternative knowledge seeking}

The lack of public resistance to nuclear power does not mean the Chinese public highly embraced atomic energy. Instead, according to the idea of civic epistemology, which "refers to these culturally specific, historically and politically grounded, public knowledge-ways" (Jasanoff, 2011b, p. 249), the general public has not meaningfully examined the relevance of nuclear power and 
made rational choices about nuclear energy, due to their culturally, historically and politically bounded circumstances. The low connection of atomic energy to most ordinary people and their lack of attention to the energy/ technology further corroborated the preference. In reality, the choice was epistemologically translated to the public's tolerance of nuclear power.

The activists and dissenters, as members of the public, initially did not explicitly take up anti-nuclear activism. Their challenge to the knowledgecontrol regime of the nuclear power sector started from their encounter with knowledge different from dominant views. STS scholars have well examined this alternative knowledge and its role in counterattacking the orthodox regime (Irwin, 1995; Wynne, 1992). Chinese anti-nuclear activists adopted a similar strategy.

Among others, international sources of alternative knowledge were crucial to Chinese dissenters. Although in the early 2010s, when the Chinese actors debuted, global anti-nuclear power movements had dramatically declined (Joppke, 1991), legacies were embodied in environmentalism advocacy materials.

For example, the nuclear power knowledge of the Wangjiang Four Seniors primarily came from a series of books questioning nuclear power's promises ranging from economic efficiency to the fight against climate change after the Fukushima disaster. The book was introduced to China by the Heinrich Böll Foundation, a Germany-based anti-nuclear charity.

Similarly, an abovementioned grassroots activist heavily relied on a classic US textbook on environmental studies, Living in the Environment, authored by G. T. Miller (2007) to construct his dissident knowledge system (INT20161127). He was commissioned to translate the book that raised the nuclear waste issue. It seemed to the activist that nuclear waste had become an unsolvable issue. Later, when Maoism-oriented nationalism shaped his belief, he developed his version of a conspiracy theory: a central strategic goal of the US policy toward China is to control the latter with GMOs so that it can dump nuclear waste to China.

Disadvantaged social groups often use conspiracy theory as a tool to protest dominant knowledge (Sunstein \& Vermeule, 2009). The grassroots activist's undergraduate major was soil chemistry. He has not gone to graduate school. He found his academic training could not equip him for challenging the orthodox knowledge about nuclear power. But a conspiracy theory based on what he perceived as a widely-admitted fact (nuclear waste cannot be entirely disposed of could empower him against the dominance of orthodox nuclear power knowledge. It could counteract the atomic energy sector's risk management strategy (there are risks beyond the sector's imagination), its credibility won by historical glory (China's nuclear power industry imported technologies from the West) and its environmentally-friendly frame (nuclear waste is a non-disposable and much more severe ecological woe than regular pollution).

In contrast to the grassroots activist, a dissenting computational physicist working at a top Chinese university said his involvement in the ITER project which explores nuclear fusion as an energy solution changed his initial belief 
on atomic power (INT20170619). According to the dissenting physicist, ITER participants heavily criticized current fission technologies. "I became aware that the current fission technologies weren't a good idea, neither do the socalled next generations of nuclear power, such as traveling wave reactor promoted by Bill Gates. ITER's fusion technology cannot become a feasible energy solution either." Although not a nuclear engineer, his expertise still provided professional support to more proactive activists.

Others harvested the knowledge necessary to launch a more destructive attack: Questioning the legitimacy and reliability of the nuclear power sector. Such knowledge primarily came from the favorite alarmist book $A$ NPP Employee's Last Will written by the former Japanese anti-nuclear activist Hirai Norio, who used to be a nuclear engineer (Hirai, 2011). The book depicted how Fukushima Daiichi tried to make profits by lowering safety investments and surveillance, hiring cheap, low-qualified workers, and exposing employees to high nuclear radiation. The greedy image of Japanese NPP managers gave activists an excuse to split commercial nuclear power developers from the historically glorious military nuclear enterprises, framing the former as vested interest groups.

Another type of alternative knowledge was reflective articles and memoirs, such as the autobiography The First Nuclear Era of Alvin M. Weinberg (1915-2006), Oak Ridge National Laboratory (ORNL) former director (Weinberg, 1994, 1996), and articles of former CNNC vice president Li Yulun (1940-2018) (e.g., Y. Li, 2013) on nuclear safety management and potential risks. Both Weinberg and Li are hardly atomic energy skeptics. However, with their half-a-century working experience, both of them raised warnings against the dangers of organizational failures and human negligence. Weinberg even used the term "Faustian bargain" to describe the potential danger nuclear energy might impose on human society (Weinberg, 1994, pp. 175-200).

The alternative knowledge encouraged activists and dissenting experts to challenge the nuclear power sector's knowledge monopoly. The challenging process also provided chances for them to network with each other. Although the alternative knowledge was not enough to topple the knowledge-control regime of the nuclear power sector, it helped initiate controversies in which activists adopted various discourse strategies to shake nuclear power's knowledge dominance.

\section{Discourse strategies against knowledge control}

In the previous section which examined social movement aspects of nuclear contention in China, I briefly described the internal disputes of the nuclear power industry, particularly the tension between power generation and nuclear fuel processing, as evidence to support the FA framework.

Clearly, nuclear fuel processing engineers would not topple the whole industry when they raised the issue of higher unprocessed nuclear waste, but activists 
amplified and reframed the unharmonious voices from within the nuclear power industry, such as the potential safety management challenges, insufficient social organization to support massive atomic energy development, and accumulating nuclear wastes. The claims against potential risks raised by Weinberg, $\mathrm{Li}$, and other engineers were alarms to peers, but activists took them as a powerful weapon - both as contrary evidence against nuclear power and as a symbol that the industry's founders betrayed it.

In their debates with the nuclear power industry, activists and dissenting experts took a strategy to reject the rationale of the industry's risk management. As mentioned above, the atomic energy industry has adopted a plan to admit potential low risks but demonstrate its high controllability. Citing Fukushima NPP's management flaws exposed by Hirai (2011) and Tokyo Electric's (Fukushima NPP's owner) poor disaster handling, Wang Yinan rejected the rationale by distinguishing nuclear power safety design from management practice. "The blueprint of nuclear power is always preconditioned by on-site workers with perfect technological capacity, without discussing whether staff on site has such capacity," she wrote (Y. Wang, 2015a). She further pointed out that vulnerability of the complicated pipe arrangement in NPPs, the lack of engineering experience in safety surveillance, the inevitable human errors, the unsafe storage of spent nuclear fuel, and the unprocessed nuclear waste have made atomic energy far from reliable as boasted by industrial experts.

Based on these claimed problems, Wang further quoted Premier $\mathrm{Li}$ Keqiang's remarks to require "absolute nuclear safety" during his inspection at an HRR1000 demonstration plant in 2015 to challenge the nuclear power industry's concept of controllable risks (Y. Wang, 2015c). According to the article, absolute safety means not only theoretical modeling but also wholly reliable engineering practice and highly qualified and responsible staff.

Strictly speaking, politicians' stress on absolute nuclear safety is at a different level from the technical sense of the atomic energy industry's controllable risks. The former does not necessarily exclude manageable risks but requires risk controllers to be entirely responsible, careful and competent. However, by quoting political leaders' slogans, Wang and other activists highlighted the nuclear power industry's profit-driving behaviors, questioned and downplayed Chinese nuclear power firms' implementation capacity, and forcefully embraced new risk factors (e.g., terrorist attacks) which she claimed were neglected in the nuclear power industry's risk assessments. Thus, in terms of discourse strategy, activists utilized political discourse to overcome the scientific discourses of the nuclear power industry, breaking its knowledge monopoly in nuclear safety.

In other channels, activists and dissenting scientists also challenged the nuclear power group's hegemony in terminology. For example, in a public commentary published in bilingual environmental site China Dialogue, $\mathrm{He}$ Zuoxiu used the reactor-year (the number of years all reactors operate) calculation adopted by the nuclear power industry to refute the industry's theoretical 
probability of nuclear disaster. He argued that based on the frequency of major atomic energy disasters from Three Mile Island to Chernobyl and Fukushima and China's expansion speed to build new NPPs, China is highly likely to suffer a significant nuclear accident by 2030 (Z. He, 2013).

His calculation was refuted by the industry as a too simple and layman method, as he has not considered the technological improvement, staff quality and social characteristics. Chinese media almost did not notice the article. However, his simple and easily understandable method is another attempt to challenge the risk assessment practice dominated by nuclear power sector based on complicated models.

Thus far, in this subsection, I have summarized the alternative knowledge activists absorbed and the discourse contention they adopted to challenge the knowledge control regime of the nuclear power sector. With small networks based on WeChat chat groups, these activists and dissenting scientists exchanged their knowledge, expertise and perceived loopholes of nuclear power knowledge-control regime. The networking and knowledge exchange strengthened individual activists' knowledge base and fueled their activism. For example, a proposal by the aforementioned anti-nuclear CPPCC member submitted to energy authorities seemed precisely based on the remarkable points raised in Wang Yinan's articles against inland (Y. Wang, 2015b) and Bohai Bay NPPs (Y. Wang, 2016).

\subsection{Chapter summary}

With the alternative knowledge and their dynamic discourse strategies, activists and dissenting scientists have indeed made significant achievements in shaking the knowledge-control regime of the nuclear power sector. However, the communication, political, economic, cultural (sociotechnical) and bureaucratic resources nuclear power enjoys in China have resulted in a restrictive political opportunity structure, a competitive cultural environment and a weak network for realizing social mobilization for anti-nuclear activism. Although activists had chances emerging from fragmentation within the nuclear power industry, and sometimes between the industry and its local hosting governments, and although the FA framework associated with China's nuclear power sector has helped activism achieve specific policy effects, such as the delay of AP-1000 reactors' fuel loading and the moratorium on inland NPP construction, this fragmentation cannot topple the overall restrictive political opportunity structure in nuclear power governance. As a result, it is unlikely that the nuclear power industry will lose its expansion momentum.

If the major theories and concepts applied in this chapter can be presented synthetically, this chapter provides evidence to show that political process theory centered in political opportunity structure has the most potent explanatory role in analyzing nuclear controversies in China. The FA framework 
has a moderate role in understanding individual campaigns, but their policy impact has to be subject to the more general political opportunity structure.

China's overall authoritarian political system, in which the government ministries play the central governance role, may be blamed for causing the situation. As a result, when there isn't a deep bureaucratic schism like the one between SEPA/MEP/MEE and the water/energy departments in the case of hydropower controversy, and when nuclear power has enjoyed a much more privileged status than other science and technology topics, the fragmentation existing within the nuclear industry or between nuclear industry and hosting governments cannot facilitate the final success of anti-nuclear activism. The fragmentation cannot fuel debates on nuclear power as a widespread and long-lasting science and technology controversy either.

But without a careful calculation of the role of knowledge and communication patterns, the political/social movement side is not enough for us to understand the nuclear controversy in China. For a complicated science and technology issue deeply rooted in China's modernization dream like nuclear power, knowledge is an integral component of the political dimensions of nuclear controversy. For example, the knowledge-control regime of nuclear power is closely associated with the restrictive political opportunity structure the anti-nuclear activists encounter. On the other hand, the restrictive political opportunity structure can reinforce the knowledge-control regime. Similarly, the sociotechnical imaginaries about a progressive and proud nuclear power image also support the constraints on activism imposed by the restrictive political opportunity structure and inhibit the effect of activists' anti-nuclear framing effort. The current chapter is only an early step to explore this dynamic and interactive relationship.

\section{Notes}

1 Unlike the NPC where 30 representatives' endorsement is needed to submit a motion, CPPCC proposal does not require other members to endorse. However, a one-member proposal is often considered trivial and organizationally neglected. All government agencies in China have offices for letters and visits to deal with public complaints. Policy proposals through these offices are often unattended (Thireau \& Linshan, 2003)

2 In China, landmark NIMBY events were Guangzhou's protest against Lizhuang trash incineration plant and Xiamen's protest against a PX plant around 2008 (R. Huang \& Yip, 2012). 


\section{Why are science controversies so different?}

\subsection{Introduction}

In the preceding chapters, I traced the development of significant science and technology controversies - resistance to hydropower, the GMO controversy and the nuclear power debate - in contemporary China. I also analyzed communication, sociopolitical and knowledge-making factors underlying their emergence and evolvement. Consistent with a group of science communication and STS scholars (e.g., Irwin, 1995, 2014; Jasanoff, 2011a, 2017; Wynne, 1992), my study revealed that in China as elsewhere, primary public science and technology controversies are far more than a product of poor public understanding of science or emotional rejection of potentially hazardous technologies.

Instead, both the widespread GMO controversy and the relatively more elitist campaigns against hydropower and nuclear power resulted from a combination of factors ranging from the changing media environment, emerging political opportunities and the evolving knowledge-control regime to the strategic actions adopted by activists and the public distrust of scientific experts and officials behind them. These factors and activists' strategic efforts to utilize the opportunities associated with them lead to varying patterns of science and technology controversies in the domain of social movements that are worth communication and STS scholars' attention (Epstein, 1996, 2008).

More concretely, the public resistance to hydropower controversy was a concentrated reflection of rising environmentalism and ENGOs which have effectively utilized emerging public environmental awareness, bureaucratic fragmentation, publicity-pursuing media and the shackled knowledge-control regimes, although given the remoteness of the protesting sites and limited public attention, anti-hydropower activism did not show a high level of public participation (Tilt, 2014). The GMO controversy, on the other hand, was widespread in Chinese society, although few established civil society groups were involved, and scientists increased their efforts to maintain knowledge control. The fragile science-politics alliance, the fragmentation within central leadership and widespread public concerns all created a favorable political opportunity structure for anti-GMO activists. By contrast, the nuclear power

DOI: $10.4324 / 9781003160212-7$ 
controversy showed both narrow political opportunity structure and robust knowledge-control regimes, thanks to nuclear power's link to military purposes, its past glory and its strong business-politics alliance, as well as lack of public attention.

Below in this chapter, while addressing the working research questions, I will first re-examine the most crucial elements in the media and communication system, social movement angle and knowledge control aspect of the three sample controversies. Then a comparison of theoretically important components underlying these controversies will be provided. Finally, I will discuss the possibility of integrating different aspects of these factors to achieve a comprehensive understanding of public science and technology controversies.

\subsection{Media and science controversies}

The first set of research questions is about the role of communication elements, such as the media and Internet, in developing the GMO, hydropower and nuclear power controversies. China's media commercialization and partial liberalization have played an important, if not always central, role in promoting, amplifying, sustaining and in some case even triggering the hydropower, GMO and nuclear power controversies in the country. However, in different disputes, media involvement and communication patterns differed from each other.

In the hydropower controversy, organized resistance of ENGOs (whose early members originated from or were closely linked to the media) to dam building was consistently supported by the mass media and the anti-dam activism also enabled the media outlets to exploit environmental reporting as a symbol to fulfill the media's watchdog role for public interests. With the regular beat reporting covering the power industry succumbing to the rising environmental agenda, the developmentalism that dominated the Chinese press until the early 2000s gave way to the discourses of environment conservation and public accountability.

Similarly, Chinese media were active in reporting GMO controversies and even initiated the early debates regarding the technology. Their reporting of GMOs shared the public accountability frame they used for hydropower coverage, but food safety issues replaced the environmentalist agenda. Despite the lack of organized involvement of NGOs, widespread public concerns about food safety inspired a diversified media reporting of GM food.

The nuclear power controversy experienced an entirely different media scenario. The media stories were generous in framing atomic energy development as symbols of national honor, science and technology progress and independent innovation. Journalists structurally avoided news topics questioning nuclear power. Although the Fukushima accident brought widespread concerns on nuclear safety, this did not change the Chinese media's general tone when reporting domestic nuclear power development, and few of them offered platforms for anti-nuclear activism. 
The media performance was associated with the actors' behaviors. The hydropower industry's failure to deal with the media resulted in an imbalanced media picture, strongly favoring activists' environmentalism claims. Despite their initial impassiveness, biotechnology scientists later increased public communication, but their effort was countered by mushrooming antiGMO campaigns, mingling serious intellectual challenges with rumors and conspiracy claims. The nuclear power industry started its risk communication long before nuclear became a controversy within China. Their active public communication effort won support from most media outlets.

In both the hydropower and GMO controversies, journalists not only received messages from activists but also worked as activists, initiating disputes with their stories. However, in the debate on nuclear power, it was hardly possible to identify any journalist directly involved in the activism against nuclear power.

While the nuclear power sector has relatively made a stronger effort in media communication and public relations, the reasons for more negative reporting of hydropower and GMOs than nuclear power could be structural factors. The hydropower controversy met the media's environmentalism agenda (the inadequate response of the sector fueled the trend) while the escalated media interest in reporting GMOs was associated with the extensive public attention to food safety and the media's effort to snatch the attention. In the nuclear power case, lack of public awareness interacted with journalists' risk avoidance to produce low media attention.

Together with conventional media, the Internet also became a significant promoter of science and technology controversies. By timely distributing controversy-inducing articles from print media, highlighting and organizing debates, and collecting background information in science and technology controversies, online portals harvested visits while fueling and intensifying controversies. G. Yang and Calhoun (2007) outlined the interaction between the media, Internet and civil society groups in China's advancing green politics.

The arrival of social media intensified the communication pattern of the print media era. Strong public attention and concerns enabled the GMO controversy to remain a hot issue on Weibo and WeChat, offsetting scientists' media training efforts and the government's media censorship. Social media continued to host positive frames related to nuclear power and the general public's indifference to the topic inhibited anti-nuclear debates from spreading online.

Although hydropower, GMO and nuclear power controversies in China were not possible without the media, Chinese media's facilitating or inhibiting these controversies was often a result of the role other sociopolitical and knowledge factors played in structurally triggering and shaping science and technology controversies. Correspondingly, the media have become an integral part of the process. For example, due to the lack of institutionalized democracy in China, the media have played a role within the political opportunity structure. 


\subsection{Communication patterns}

In the previous section, I summarized the role of media in facilitating the science and technology controversies. Now I will further consider the communication patterns involved in these S\&T disputes. As examined across the empirical study chapters, public attention and the associated issue cycle are an essential backbone factor underlying science and technology controversies. Significant public awareness encourages more newcomers and more diversified topics, such as in the GMO case. In a less concentrated public attention setting, such as in the hydropower controversy, activists had to create new public problems. The necessary time and travels of activists to create these new issues regarding southwestern dams resulted in periodically hot media events. By contrast, low public attention in the nuclear power setting inhibited anti-nuclear debates from becoming a hot public issue.

Consistent with public attention was the actors' strategies for dealing with their perceived public awareness. In the nuclear power case, event-driven journalists and editors avoided investigative reporting of the nuclear power sector because of a tradeoff between high potential risks and low rewards (low public attention). The beat covering practice for highly professional areas intensified journalists' avoidance behaviors. Reporting on the less attended nuclear power sector was dominated by senior energy and science journalists preferring to ally with the industry (and academics behind it) while similar professional beat coverage of hydropower was replaced periodically by environmental journalists. During the peak time of the GMO controversy, generalist journalists replaced science journalists to become the main actors reporting the controversial technology, precisely opposite to the phenomenon revealed by M. C. Nisbet and Huge (2006) in their studies on the US elite media.

Communication technology change has profoundly shaped the pattern of science and technology controversies too. Scholars have widely recorded the impact of the fast growth of the Internet, social media and mobile communication on disputes, including the hydropower (G. Yang \& Calhoun, 2007), GMO (J. Fan et al., 2013; Q. Xu et al., 2018) and nuclear power (R. Huang $\&$ Sun, 2016) controversies in China, but my book exemplifies the interaction of this technology change with other factors such as public attention and knowledge control/monopoly patterns. The intention of Internet editors to attract more online visits promoted the initiation of online forums/special topics for hydropower and GMO debates and allowed these editors to tolerate false but sensational news on GMOs spreading online, but the same editors avoided initiating such online forums on nuclear power. Wang Yinan, the anti-nuclear elitist activist, was never involved in such debates, possibly because Internet editors shared the reward/risk logic with conventional journalists. The media behavior is also related to the knowledge-control regime that shaped public knowledge of nuclear power. 


\subsection{Tracing the sociopolitical roots of science controversies}

\subsubsection{Political opportunity structure for science controversies in China}

\section{Political opportunities arising in a gradually opening society}

The second set of research questions is about the relevance of social movement theories to China's hydropower, GMO and nuclear power controversies. Of various theoretical components, the political opportunity structure is the most crucial element.

My study indicates that science and technology controversies occurred during a period of loosening political control amidst China's gradual opening-up and market-oriented reform (Cao, 2018; Y.-W. Lei, 2018; Mertha, 2008; Zeng et al., 2015). These policy shifts created political opportunities in the sense that public science and technology controversies had apparent policy and political implications.

As early as the mid and late 1980s, the debate on Three Gorges Project (TGP) initiated the first large-scale science and technology contention in which dissenting experts, if not activists as in the more recent period, challenged the central government's decision to build the massive dam (Lee, 2013a). In the process, science and technology issues were primarily understood as a nonpolitical issue, allowing authorities to tolerate harsh debates. Throughout the contentions, few dissenting experts and activists were physically punished if they were not involved in other politically salient protests. However, this is also because most debate participants carefully maintained the boundary between science (or environment) and politics.

The loosening political atmosphere in China resulted in more participating actors. Among these actors, NGOs, the media and dissenting experts are the most important. The post-TGP hydropower controversy became a real battlefield of China's local ENGOs while Greenpeace was the most potent initiator and promoter of GMO contention in China. In the case of nuclear power, dissenting elites arose as the main actors.

The Chinese media, too, are a significant component of the political opportunity structure. In the hydropower and GMO cases, the media not only timely reported activists' challenges against dams and GM foods, but also organized and participated in various contentious events. For example, Wang Yongchen of China National Radio arranged numerous journalistic inspections along the Upper Yangtze and Yellow rivers, and these inspections accompanied activists' ongoing protests against dams in Dujiangyan, $\mathrm{Nu}$ River and Jinsha River. For GMOs, the 2004 cover story in Southern Weekend (SW) (J. Liu, 2004) questioning scientists' interests behind their effort to commercialize GM rice practically postponed GM rice commercialization in China. Many activists, such as Wang Yongchen and Liu Jianqiang of SW, author of the SW cover story, among many others, turned out to be leading activists in environmental movements (H. Wang, 2016). 
Academic allies of activists also provided fuel for public science and technology controversies, while the increasingly diversified Chinese society enabled experts directly involved in internal and professional debates to voice their concerns publicly. ENGOs often stimulated experts' views. Some academics, such as Fan Xiao of Sichuan Geological Survey, became activists themselves.

External resources were often crucial to the formation and evolution of science and technology controversies. Internationally funded Greenpeace was the central actor in activism against GMOs while international funding and expertise from partner organizations such as International Rivers and professional materials such as those in the book Silenced River (McCully, 1996) significantly supported ENGOs' anti-dam activism.

\section{Political opportunity structure and fragmented authoritarianism}

While in the circumstances of authoritarian China, loosened political control, liberalizing media, emerging ENGOs and dissenting experts can all be called political opportunities, these circumstances or their combination do not definitely constitute a political opportunity structure (Meyer \& Staggenborg, 1996). In Kitschelt (1986), a political opportunity structure is narrowly defined as a political structure for policymaking, but Tarrow (1996, 2011) seemed to take a more lenient view on the definition of political opportunity structure. In this book, I adopted an eclectic approach. As long as the political, social and knowledge opportunities, including the ones listed above, can combine to facilitate or block science and technology controversies structurally, I would apply the political opportunity structure concept for analysis.

As for structural factors underlying social movements, including science and technology controversies examined in this book, the bureaucratic fragmentation in China has played a crucial role in promoting them, due to China's authoritarian regime. Given China's authoritarian nature, the bureaucratic fragmentation should be considered an essential form of the analytical framework of fragmented authoritarianism (FA) (Mertha \& Brødsgaard, 2017), though it has been suggested that FA should embrace more actors such as journalists and activists (Mertha, 2009) and even scientists (Brødsgaard, 2017). The existence of fragmentation itself does not mean that a social movement can be naturally facilitated. The bureaucratic fragmentation has to be combined with other factors to promote or inhibit the evolution of scientific controversies.

In the hydropower controversy, the schism between the hydrological department and the environmental agency as well as hydropower developments' conflicts with construction, historical conservation, wildlife protection and agricultural agencies enabled the ENGOs' actions, helped mobilize supporters and in many cases directly halted dam construction (as in the Xiaonanhai case). But one shouldn't consider that bureaucratic antithesis was automatically translated to rejection of dam buildings. After all, most planned dams in China were constructed and put to operation. 
Instead, the bureaucratic schism offered the necessary political opportunity structure for activists to concentrate resources, exert influence and obtain knowledge to target specific hydropower projects. Indeed, what made the hydropower controversy more salient is the effect of activism. After the unsuccessful attempt against TGP, most other dams that raised intense debates - $\mathrm{Nu}$ River dams, Yangliuhu in Dujiangyan, Xiaonanhai and Tiger Leap Gorge - were suspended or halted. The bureaucratic fragmentation had to work with other elements, such as active ENGOs, effective framing and knowledge control factors to drive or block major public science and technology controversies.

In the GMO controversy, there were many minor traces of bureaucratic schisms, such as the initial struggle of SEPA/MEP/MEE to dominate biotechnology governance with the goal of implementing China's commitments to the Cartagena Protocol on Biosafety. But, as Chapter 4 examined, SEPA never put serious effort into the struggle for dominance, and anti-GMO activists did not ally with SEPA as in the hydropower case. Another internal fragmentation - the protests from Maoist princelings - also played a role by pressuring individual members within the top leadership and by legitimatizing grassroots protesters. In terms of political opportunity structure, this was a less clear structure. However, the Ministry of Agriculture (MOA)'s relatively weaker or at least perceived weaker power, as indicated by the media openly impugning its incumbent vice-minister, may be considered a sign of a less restrictive political opportunity structure. No matter whether MOA was weak, given food safety/security's supreme importance to Chinese politics and its people, any single ministry cannot withstand and control enormous public opinion pressure caused by people's widespread concerns about GM foods, enabling grassroots activists to rise to dominate anti-GMO activism.

In the nuclear power controversy, although elitist activists and dissenting experts against the nuclear power industry were visible and the debates they raised produced some policy effects, there was not a political opportunity structure friendly to anti-nuclear activism. The glorifying national sociotechnical imaginaries about nuclear power, the sector's concentrated power and resources, its military links, SEPA/MEP/MEE's alliance with the industry, media's reluctance to be involved, and stable knowledge-control regimes of nuclear power all structurally inhibited controversies from being expanded and amplified.

But the fragmentation within the nuclear power sector also provided opportunities to activists and some NIMBY activities. These opportunities can also be considered structural, as they were related to structural and institutional arrangements. However, these opportunities were offset by factors such as bureaucratic integration and the State's desire to promote nuclear power as a symbol of national innovation capacity. As a result, activism around nuclear power controversies only produced a limited policy impact. 
Examining hydropower, GMO and nuclear power controversies, one can find that putting the FA framework into the political opportunity structure has the most efficient explanatory power. Fragmentation, no matter whether it is a bureaucratic one or involves many new actors, creates essential opportunities, but it is still constrained in a macro-political structure and influenced by activists' framing strategies, the establishment's knowledge control and other sociotechnical factors.

\subsubsection{Framing and mobilization in the public attention market}

\section{Public accountability frames across settings}

Successful framing is considered by one branch of social movement scholars as a central element to social movements (Snow, 2013; Snow et al., 1986). For Tarrow and other promoters of political process theory, framing is essential but is not considered as central. According to previous chapters, framing seems an element subject to the political opportunity structure, but this does not mean it is less critical. Instead, within a specific political opportunity structure, framing can still play a crucial role.

In the hydropower, GMO and nuclear controversies, activists framed these controversies primarily as public credibility issues. Hydropower companies, GMO scientists and the nuclear industry were framed as vested interest groups, putting public interests at risk. Correspondingly, the media frequently adopted a public accountability frame when reporting GMO and hydropower topics. But the frame was not so useful in the nuclear controversy due to journalists' self-censorship to avoid risk, the positive national sociotechnical imaginaries of nuclear power, and the knowledge-control regime of the nuclear power sector (to be discussed below).

Under the umbrella of a public accountability frame, environmentalism agendas dominated anti-hydropower efforts while GMOs were predominantly considered a food safety issue. As analyzed in Chapter 3, most media articles that framed hydropower as an environmental issue showed a negative tone or visible controversy. This framing was related to the fact that the main antihydropower force was ENGOs, which effectively mobilized the media. It was also caused by China's increasing embrace of environmentalism in its rapid economic progress that caused severe environmental woes. On the other hand, nuclear power was free from the attack of environmentalism frames. SEPA/ MEP's alliance with the nuclear power sector largely exempted the industry from being attacked by ENGOs as well as environmentalism frames.

For GMOs, the early effort against the technology, initiated by Greenpeace and supported by other more elitist international groups such as Third World Network, framed it as an environmental issue, threatening biodiversity. However, activists soon found the frame was not appealing in China. Utilizing the broad public concerns about food safety and the general dissatisfaction with government transparency, anti-GMO activists forcibly adopted a public 
accountability frame and reached their desired effect. In addition to food safety concerns, Maoist activists further stigmatized agricultural biotechnology with a conspiracy theory, claiming GMO was a US conspiracy to control or conquer China. This frame, though logically ridiculous, was even accepted by $40 \%$ of the population (G. He et al., 2017).

\section{Social mobilization during controversies}

With the invincible public accountability frame, activists achieved effective social mobilization in the hydropower and GMO debates. SEPA/MEP/MEE's relatively friendly attitude to a civil society fueled the development of ENGOs, which mobilized environmental and ecological research organizations and scientists against dam building. Frequent expert seminars targeting journalists, and regular journalists' field inspections in the Yangtze and Yellow rivers guided and joined by environmental, geological and wildlife protection experts united to form an amplified anti-dam tone. A mobilization network of activists-experts-journalists-environmental officials created strong and consistent public opinion pressure on the hydropower side.

The mobilization of anti-GMO forces demonstrated an entirely different scenario. GMO debates were participated in by a large proportion of the population, though established local ENGOs were generally less involved. Greenpeace initiated the discussion, involved the ecological scholars and consistently provided debate material with its surveillance of illegal planting of the first GM rice in central China and then GM corn in northeast Chinese provinces.

Following Greenpeace, Chinese STS scholars questioned the credibility of biotechnology science, legitimatized public concerns and mobilized dissenting experts (including a few scientists and much more agricultural economists and rural sociologists). Maoist activists expanded the anti-GMO fronts by engaging red princelings, some military generals and leftist organizations and continuously generated anti-GMO messages often stuffed with conspiracy theories. Fast-developing Internet and mobile communication enabled various activists to cross-refer and modify different sources of information (such as grafting a conspiracy claim onto Séralini's retracted study on GM corn (2012)) to expand their influence. As a result, the Chinese government postponed commercialization of all GM crops after GMOs became a widespread public controversy.

Compared with hydropower and GMOs, the mobilization of anti-nuclear activism was far less successful. There is no organization involved at the national level. The impromptu organizers of NIMBY events never connected to anti-nuclear activists or dissenting experts. These activists and experts' voices were seldom amplified by the media to recruit more new participants. The established Chinese ENGOs were not involved in any anti-nuclear activity, either in terms of producing and transmitting articles or in actual operations. Although activists and dissenting experts had a chance to submit their 
appeals to the top leadership, the lack of social protests as a result of poor mobilization did not exert any pressure, so that the leadership could still make its decisions based on professional judgment primarily offered by the nuclear power sector.

\section{Public attention as a movement moderator}

Examining the framing and mobilization process involved in hydropower, GMO and anti-nuclear controversies, one can find public recognition was also a factor which can hardly be neglected. Here the Downs (1972) issue-attention cycle, which describes cyclical waves in media attention and historical shifting among different frames of an issue (M. C. Nisbet \& Huge, 2006), can be borrowed to help illustrate the phenomenon.

In developmentalism-dominated China, an environmental agenda has trouble attracting public attention. Utilizing the black-and-white image of dam building proved successful in attracting public attention. However, at the time of rising anti-dam activism, nearly all dam building was located in remote southwestern China, so protesting dams and organizing journalists to report the protest involved much time and resources. This situation resulted in a highly periodical issue cycle and significant issue concentration (primarily focused on environmental and ecological affairs) in the hydropower controversy. The lack of public attention and high involvement costs also inhibited the participation of average public citizens. As a result, only the targeted dam projects were halted, while most hydropower developments that have not been problematized continued.

When activists successfully framed the GMO controversy as a food safety issue, the public began to devote much more attention to it. These grave public concerns and perceived public awareness triggered more and more actors to get involved, and their involvement brought increasingly diversified topics and events, ranging from protesting vested interest groups to complaints against lack of transparency. The claims that MOA-affiliated kindergartens did not use oil made from GM crops and that at the 2008 Beijing Olympics GM food ingredients were forbidden were all topics brought in by grassroots protesters. The escalated public attention thus resulted in the consistent controversy on GM foods, with new material repeatedly being brought into the debates.

The nuclear power controversy suffered the lowest public attention given its closed nature, elitist agenda and little perceivable environmental impact. The situation could explain the reluctance of the media to devote investigative reporting in the area. The Fukushima accident temporarily changed the lowattention status, but the public attention quickly faded as there was no report of irradiation contamination from Japan to China. Together with the fading public awareness is the diversion of some public intellectuals, such as STS scholar Jiang Xiaoyuan, from the field. Thus, only a few diehard activists and dissenting experts remained in the area. Although some activists and experts had channels to submit reports to the central leadership so that the 
controversy could be maintained in the policy domain, the controversy's public impact remained low. The low public attention enabled policymakers to make decisions based primarily on professional suggestions.

The above summary of framing strategy and mobilization effort in hydropower, GMO and nuclear power controversies show that in public science and technology controversies, activists' framing and mobilization strategies are often associated with perceived public attention. The interaction of these elements within specific political opportunity structures has shaped the different evolution patterns of science and technology, which I will summarize below.

\subsection{Examining knowledge-control regimes}

The third set of research questions is about the relevance of various STS concepts, such as knowledge-control regimes, civic epistemology and national sociotechnical imaginaries, to China's hydropower, GMO and nuclear power controversies. Of the various ideas, the knowledge-control regime is used most widely in this book.

Knowledge stands in a central position in science and technology controversies. The public debates about any controversial science and technology issue, including hydropower, GMO and nuclear power examined in this book, are primarily about the credibility of individual knowledge claims, the claimmakers and the claimed application of the knowledge in question (Jasanoff, 2017). However, without taking consideration of social movement angles, scholars may lose sight of how actors' actions promote, reject, maintain and diffuse this knowledge credibility (Breyman et al., 2017; Epstein, 1996).

Using the hydropower, GMO and nuclear power controversies as case studies, this book finds that major STS concepts regarding knowledge, particularly knowledge-control regimes (Hilgartner, 2017), civic epistemology (Jasanoff, 2011b) and national sociotechnical imaginaries (Jasanoff \& Kim, 2009), are deeply embedded in the controversy process. Meanwhile, the strategic actions by actors of both sides to mobilize various knowledge resources to overcome knowledge barriers profoundly influence the development of controversies.

For hydropower development, the publicly visible knowledge-control regime was mainly embodied in the hydropower industry's effort to maintain developmentalism discourse (Lee, 2014), ensure engineering credibility and publicize technological achievements. In terms of the knowledge of engineering side (including sediment and hydrological studies), post-TGP the hydropower sector has maintained an active control, but the industry seemed to make only a minimal effort in environment-related knowledge production in the 1980s and early 1990s. However, during the southwest hydropower debates starting in 2003, environmental knowledge became the main debating point. Emerging ENGOs avoided engineering knowledge and mobilized broad environmental expertise in the debates on dams' impacts on ecology, biodiversity, fish habitats, earthquake and local households. Because of the increasing salience environmental studies enjoyed in contemporary China, 
environmentalism triumphed over the developmentalism and engineering credibility of the hydropower side in the public sphere.

The knowledge control strength of the hydropower sector was rather weak in the public domain. Like other State-owned conglomerates, hydropower companies maintained a good relationship with reporters covering the beat of hydropower and water resources. These journalists regularly reported on the engineering achievements and developmentalism embodied in them. However, within media outlets, hydropower controversies were dominated by environmental or public affair journalists rather than energy reporters. When the anti-dam campaign became a nationally hot media event, environmentalists often had a more prominent platform to speak within the media outlets.

Compared with hydropower, nuclear power's knowledge-control regime has enjoyed a more favorable condition. Nuclear science's sophisticated requirements of knowledge production, higher safety concerns and the sector's military link caused natural isolation in its education and knowledge production system. Meanwhile, the vast quantities of nuclear science-related senior academicians, as represented by CAS and CAE members, helped the sector win a dominant role in the knowledge production system, which was supported by the sociotechnical national imaginaries of nuclear power as a symbol for science and technology progress, independent innovation and national prosperity. SEPA/MEP's role as a nuclear safety regulator resulted in an alliance between environmental governance and the nuclear power industry both in policymaking and knowledge production. Together with the keen publicity awareness of the nuclear power sector, these factors jointly maintained nuclear power's reliable, safe, innovative and clean images in China's public sphere. Chinese journalists' avoidance of launching investigative reporting of the nuclear power industry due to the low perceived rewards of such reporting further increased the strength of the nuclear power sector's knowledge-control regime.

Similarly to hydropower and the nuclear power sector, China's biotechnology scientists also attempted to set up a knowledge-control regime by seeking political allies. Meanwhile, its promoters meticulously maintained and highlighted a scientific consensus. However, when activists rose to challenge GMOs from the perspective of public accountability in the food safety issue, the scientific consensus quickly paled amidst attacks ranging from questioning scientists' credibility (and hence the credibility of the scientific consensus the defamed scientists insisted on) and worrying about the fate of peasants (suffering the impact of imported GM corn and soy) to conspiracy theories and various rumors linking GMOs to health harms.

In the view of civic epistemology, food safety, the "US conspiracy," and peasants' fate were considered by the public as much more important than the scientific consensus on GMOs and science and technology progress embodied by biotechnology. It turned out that the science-politics alliance, as well as the knowledge-control regime endorsed by such an alliance, could be easily broken when politicians felt the massive pressure from public protests. 
The continued and intensified public attention to food issues, which can be traced to the long historical memory of famines and disasters, also allowed various new actors to bring various debating issues into GMO controversies, further inhibiting the ought-to-be power of scientific consensus.

Summarizing this section's discussion, one can see that the knowledgecontrol regime has played an essential role in facilitating or inhibiting public debates on science and technology issues. However, the effect of this regime was also influenced by macro political factors, civic epistemology and sociotechnical imaginaries of the science in question, the sciencemedia relationship and the level of public attention and participation.

\subsection{Comparing different patterns}

In the above sections, I summarized the evolution of hydropower, GMO and nuclear power controversies from the perspectives of social movement theory and STS frameworks such as knowledge control and national sociotechnical imaginaries. Clearly, each of these theoretical frameworks can explain part of the patterns of these controversies. Based on the above analysis, I present their variant patterns per different academic traditions.

Table 7.1 shows that within different theoretical frameworks, the hydropower, nuclear and GMO controversies present different patterns. Using these frameworks - social movement theories, knowledge-control regime and fragmented authoritarianism - one can "predict" the result of these controversies. For example, in both the hydropower and GMO cases, activists enjoyed a favorable political opportunity structure for their activism while such structure was highly closed or unfriendly to anti-nuclear controversies. Compared with the hydropower controversy, the GMO controversy experienced a more significant number of political opportunities, loosely defined. As a result, anti-hydropower activism succeeded in halting nearly all targeted projects but the hydropower controversy as a whole elapsed quickly. Anti-GMO activists did better to stop the commercialization of all GM crops. By contrast, anti-nuclear power activities could only achieve minimal, unsystematic success by halting new NPP construction for three years.

Meanwhile, when applied in the hydropower, nuclear and GMO controversies, theories of different traditions were entirely consistent with each other, so that one can be used to supplement others in making "predictions." For example, the nuclear power sector's stronger knowledge-control regime is coherent with the narrow political opportunity structure for antinuclear activists while the hydropower sector's lower level of knowledge control in the environmental area seemed to link to the bureaucratic fragmentation between the hydropower sector and environmental agencies, fueling anti-dam activities. In the case of GMO, biotechnology science enjoyed high scientific consensus on GM food safety, but the knowledgecontrol regime for scientific conclusions was dwarfed by mass protects 
Table 7.1 Different patterns of hydropower, GMOs and nuclear power controversies

\begin{tabular}{llll}
\hline & Hydropower & GMOs & Nuclear power \\
\hline Basic patterns of & Collective efforts & Long-lasting and & Low-profile \\
controversies & of ENGOs to & massive public & internal elite \\
& resist hydro- & rejection. & $\begin{array}{l}\text { strife. No orga- } \\
\text { nized anti- } \\
\text { power projects }\end{array}$ \\
& & & $\begin{array}{l}\text { nuclear } \\
\text { campaigns }\end{array}$
\end{tabular}

Social causes of S\&T controversies

The level of public trust in orthodoxy science (and technology)

Media factors: Mass media

Internet and Social Media

$\begin{array}{ll}\text { STS } & \begin{array}{l}\text { Knowledge } \\ (\mathrm{kn}) \text {-control }\end{array} \\ \text { regimes } \\ \text { Sociotechnical } \\ \text { imaginaries } \\ \text { and civic } \\ \text { epistemology }\end{array}$

Growing public concerns about uncontrolled technologies; Competing for knowledge claims; the rise of environmentalism and civil society; the rise of mass media, Internet and social media; Scientists' slow response to public concerns. Decreased public trust in the government and official science.

Low Low

Media actively
reported hydro-
power con-
troversies to
highlight its
environmental
agenda.

News portal edi- News portal editors actively promoted hydropower controversies. Social media debates on hydropower were inactive.

Moderate

No universal sociotechnical imaginaries of hydropower
Media actively reported GMO controversies to win public attention. tors actively promoted GMO controversies. Social media diversified public rejection of GMOs and intensified controversies.

Moderate to weaker

Sociotechnical imaginaries of food more for substance than for innovation
Generally high except the short period after Fukushima accident

Media positively reported domestic nuclear power, refusing to offer platforms for controversies.

Few news portal editors promoted nuclear power controversies. Social media debates on nuclear power were untraceable.

Strong

Sociotechnical imaginaries of atomic power as national independence, social prosperity and S\&T progress 
Table 7.1 (Cont.)

\begin{tabular}{|c|c|c|c|c|}
\hline & & Hydropower & GMOs & Nuclear power \\
\hline \multirow[t]{4}{*}{$\begin{array}{l}\text { Social } \\
\text { move- } \\
\text { ments }\end{array}$} & $\begin{array}{l}\text { Political } \\
\text { opportunities } \\
\text { and political } \\
\text { opportunity } \\
\text { structure }\end{array}$ & $\begin{array}{l}\text { Moderate } \\
\text { opportunities } \\
\text { and favorable } \\
\text { structure for } \\
\text { activism. }\end{array}$ & $\begin{array}{l}\text { Many opportu- } \\
\text { nities and moder- } \\
\text { ate structure for } \\
\text { activism }\end{array}$ & $\begin{array}{l}\text { Few opportu- } \\
\text { nities and unfa- } \\
\text { vorable structure } \\
\text { for activism }\end{array}$ \\
\hline & $\begin{array}{l}\text { Activists' } \\
\text { frames of tar- } \\
\text { geted S\&T } \\
\text { subjects }\end{array}$ & $\begin{array}{l}\text { Lack of public } \\
\text { accountability in } \\
\text { the environment. }\end{array}$ & $\begin{array}{l}\text { Lack of public } \\
\text { accountability in } \\
\text { food safety. }\end{array}$ & $\begin{array}{l}\text { Avoidance of a } \\
\text { robust anti- } \\
\text { nuclear frame; } \\
\text { public account- } \\
\text { ability frame not } \\
\text { dominant in the } \\
\text { media. }\end{array}$ \\
\hline & $\begin{array}{l}\text { Mobilization } \\
\text { of activists }\end{array}$ & $\begin{array}{l}\text { Periodically } \\
\text { effective mobili- } \\
\text { zation among } \\
\text { elites and } \\
\text { activists }\end{array}$ & $\begin{array}{l}\text { Successful mass } \\
\text { mobilization }\end{array}$ & $\begin{array}{l}\text { Unsuccessful } \\
\text { mobilization }\end{array}$ \\
\hline & $\begin{array}{l}\text { Fragmented } \\
\text { authoritarian- } \\
\text { ism (FA) } \\
\text { framework }\end{array}$ & $\begin{array}{l}\text { Broad FA fra- } \\
\text { mework, with } \\
\text { visible bureau- } \\
\text { cratic fragmen- } \\
\text { tation between } \\
\text { hydropower and } \\
\text { environmental } \\
\text { agencies }\end{array}$ & $\begin{array}{l}\text { Bureaucratic frag- } \\
\text { mentation less } \\
\text { salient, but actors' } \\
\text { massive participa- } \\
\text { tion brings exten- } \\
\text { sive fragmentation }\end{array}$ & $\begin{array}{l}\text { Only minor } \\
\text { bureaucratic } \\
\text { fragmentation, } \\
\text { and little FA } \\
\text { within the } \\
\text { industry }\end{array}$ \\
\hline \multicolumn{2}{|c|}{$\begin{array}{l}\text { Results of S\&T con- } \\
\text { troversies as social } \\
\text { protests }\end{array}$} & $\begin{array}{l}\text { Successfully } \\
\text { halted targeted } \\
\text { dams. }\end{array}$ & $\begin{array}{l}\text { Entirely successful } \\
\text { in halting com- } \\
\text { mercialization of } \\
\text { all GM crops in } \\
\text { China. }\end{array}$ & $\begin{array}{l}\text { Initiated con- } \\
\text { troversies but } \\
\text { achieved limited } \\
\text { success (delayed } \\
\text { new construction } \\
\text { permits for three } \\
\text { years) }\end{array}$ \\
\hline
\end{tabular}

(Source: Author's summary)

featuring various claims from both different expert groups and grassroots activists. As a whole, the knowledge-control regime was weakened, resulting in GMO activism's most significant success among the three controversies in question. So, the knowledge-control regime can be used together with social movement theories to "predict" activism results.

But I used quotation marks for "predict/prediction" here because unlike quantitative research which tries to measure every variable "exactly," the application of either social movement theories or STS concepts in the controversies studied is rather context-dependent. For example, the FA framework in hydropower was mainly reflected as a bureaucratic fragmentation while in the GMO case, the less salient bureaucratic fragmentation gave way 
to an enormous fragmentation across the society. This fragmentation existed among different knowledge claim makers (e.g., between scientists and STS scholars and rural sociologists), different interest holders (agricultural biotech firms versus organic farmers) and various political lines (Maoists are diehard anti-GMO members as compared with other political groups). So, both GMO and hydropower enjoyed a high level of FA, but their FAs were different. 


\section{Synergy of different theoretical traditions in a comparative lens}

\subsection{Pattern difference and theoretical development}

In the previous chapter, we saw that the three controversies demonstrated apparent differences in all theoretical frameworks -communication patterns, social movement theories and knowledge-control regime - adopted in this book. As a result, they had different consequences. In the hydropower case, activists successfully suspended all controversial dams; in the GMO controversy, no new GM crop has been commercialized since 2007; yet in the nuclear power case, the construction of new NPPs resumed in 2019, after three years' pause.

Did the different fates perfectly reflect the predictions suggested by the adopted theories, or were they primarily a result of various characteristics of the selected cases? One may say anti-GMO debates are so salient simply because people are worried about their food, while nuclear power's low impact on their life because of its low visibility, and the periodical hydropower controversy is associated with the remote location of dams.

Throughout this monograph, I have not denied the case differences and their role in causing differing evolution patterns of the controversies. For example, the relationship of the disputes to people's daily life results in different public attention, which is an essential component in both social movement theories and the framework of the knowledge-control regime. However, the case difference alone cannot sufficiently explain their different consequences. As indicated in the first chapter, other similar controversies have not resulted in a similar outcome to the studied ones. For example, Chinese citizens also have a widespread concern about food additives, but this has never been translated to a massive controversy in the same way as GMOs. Meanwhile, ordinary people living in cities feel equally little impact from hydropower and nuclear power, yet hydropower has experienced much more severe disputes than nuclear power.

The reasons for the different case consequences include the actors involved, their different sociopolitical situations and the various knowledge-making processes. All these elements are theoretically relevant. In previous chapters, I have repeatedly examined how different factors identified by theory result in

DOI: $10.4324 / 9781003160212-8$ 
different evolution patterns of the cases. I will not repeat these arguments. One point to be stressed here, however, is that the case characteristics interact with the case's sociopolitical situations, its knowledge-making ways and the actors involved in the case.

The previous chapter shows that different theoretical frameworks are consistent with each other in "predicting" the development of the selected controversy cases - the anti-hydropower movement, the GMO controversy and nuclear power debates. Indeed, these variant frameworks are not only mutually supplemental but also interact with each other. Only by tracing interactions among sociopolitical, knowledge and communication factors underlying public science and technology controversies and by combining different theoretical traditions, can we deeply understand the specific evolution pattern of various disputes. I will explore this point below to deepen the application of interdisciplinary theoretical exploration and to illustrate a significant academic contribution of this book.

\subsection{Interactions of different theoretical frameworks}

\subsubsection{Interaction of different theoretical components in China}

So far, I have examined China's hydropower, nuclear and GMO controversies (plus some minor controversies as background) using communication, social movement and STS theories. Components from communication studies, social movement theories and STS concepts interact with and strengthen each other, suggesting that they should not be separated. For example, in the hydropower case, activists organized journalists to carry out Yangtze and Yellow rivers inspections with the guide of ecology and environmental scholars. In the process, activists, journalists, and ecological and environmental experts formed a mobilization network against hydropower development or individual dams. This process represents an essential aspect of Tarrow's (2011) political process theory. Meanwhile, the networking activities were closely associated with the effort of competing with the hydropower establishments' knowledge-control regime. On the other hand, as analyzed in Chapter 4, the relative openness and salience of environmental knowledge-making also helped weaken the knowledge-control regime of the hydropower establishments. The weakened regime no doubt encouraged activists and journalists to adopt more offensives against dam-building when necessary.

Nuclear power offers another, yet reverse example. The stronger knowledge-control regime of the nuclear power sector cannot be separated from its stronger political power and hierarchic governance structure. The latter can relatively easily inhibit social movements against the nuclear power sector as it can both mobilize coercive forces against activism and cut off potential internal allies from external activists. Nuclear-friendly media outlets offered another example. Journalists' reluctance to made investigative reporting into nuclear power was both caused by lack of public attention to nuclear power, the inhibiting political power, and real and perceived knowledge monopoly. 
In the GMO controversy, the high scientific consensus on GM food safety did not translate to a stronger knowledge-control regime, because without the endorsement of political power, the biotechnology sector has a low capacity to control knowledge in the public sphere. In 2015 when the propaganda department decided to manage adverse reporting of GMOs, the rise of social media platforms and widespread rumors offset the policy effect. Hence, media change further weakened the knowledge-control regime for GMOs.

There are many other examples across the three cases showing the interaction between communication, social movement and knowledge factors. It is interesting to notice that although these factors are categorized differently, they overall are consistent or mutually strengthening rather than mutually offsetting. To better understand their interaction, we will also need to consider how different theoretical frameworks interact with each other.

\subsubsection{Interaction of different theoretical frameworks}

The call to utilize social movement theories to investigate controversial science and technology issues has been made for up to three decades (Breyman et al., 2017; Epstein, 1996; Hess et al., 2008; Martin \& Groth, 1991), and in the first chapter of this book, I also set this as a goal for my research. The study here justified this call while bringing fresh evidence and material to the scholarship.

Based on the three controversy case studies, one can safely conclude that social movement studies first of all help solve the question of why given similar low public knowledge of science, some controversies can grow out of academic circles to produce social impacts while others remained hidden from public attention. They also address the question of why, among those publicly salient science and technology controversies, some can produce significant policy impacts (such as GMOs) and others go relatively unnoticed by policymakers (such as nuclear power concerns). The three cases - hydropower, nuclear and GMO - are all in the public domain, but the three cases can be combined to compare with other controversies, such as nanotechnology, which has never raised media attention and produced significant policy impact in China.

Taking account of social movement theories can also enable STS scholars to deeply observe how actors involved in public science and technology controversies perceive, utilize, or miss macro political opportunities. Moreover, this approach also illustrates how actors use cultural resources to frame themselves and their opponents. Delborne's (2008) study of UC (University of California) Berkeley scientist Ignacio Chapela's strategic consideration of protesting strategies after his controversial Nature paper on Mexican maize's GMO contamination was retracted is precisely one of these cases.

At their core, science and technology controversies are about the credibility of knowledge and have been widely examined by STS scholars using various concepts including Hilgartner's (2017) knowledge-control regime. It is well known that such knowledge-control regimes are about power; but using social movement theories, one can more dynamically examine the role of power in 
knowledge-control controversies. The current book makes an initial effort for the dynamic examination of such a regime.

Meanwhile, STS and communication studies on knowledge can contribute to social movement theories as well. Compared with STS scholars, conventional social movement scholars remain less interested in examining knowledge issues (Breyman et al., 2017), just as 30 years ago when Martin and Groth (1991) made such a claim. Yet nearly all social movements/controversies involve knowledge issues, though the knowledge may not be about a narrowly defined science.

In the cases in this book, hydropower and GMOs were widespread public controversies in China, and many actors without any science background or any link to the science community have been involved, but from the very beginning, without internal dissenting scientists/experts' widely broadcasted critical views, they might not have become controversies at all. Chapter 3 found that the southwestern hydropower debates started from dissenting experts' seminars on the Dujiangyan and $\mathrm{Nu}$ Rivers. Chapter 4 demonstrated that the concerns about biodiversity loss caused by GM crops initiated the GMO controversies that continued and later focused on food safety. In the social contention process, no matter whether the dispute is about narrowly defined science, certification and decertification form a pair of mechanisms widely involved in the social movement (McAdam et al., 2001), and these mechanisms are related to knowledge.

My study of the nuclear power protests' less successful fate also involved knowledge factors, one of which being the nuclear power sector's firm knowledge-control regime. The successful knowledge-control regime of the industry isolated activists from potential supporters, such as the journalists.

Other STS concepts, such as national sociotechnical imaginaries, also play an essential role in influencing or even shaping social movements. If such imaginaries are full of the expectation for science and technology progress and national independence, as the nuclear power case shows, or full of modernist imaginations of convenience and immediacy, such as mobile phones, controversial concerns such as mobile phones' potential health harms may never become a real public controversy. Frames, which are vital for mobilization in social movements, are also contingent on knowledge and its production and distribution (e.g., whether a grassroots activist has a chance to utilize particular expertise claims to develop his/her frame against controversial science and technology items).

The discussion here is not to try to set up an all-inclusive model to enlist all sociopolitical and knowledge factors one by one in all circumstances. Contexts matter. Disciplinary boundaries are inevitable. But the current discussion and the empirical studies in this book can pave the way for a more systematic calculation of sociopolitical, knowledge and other factors such as economic forces. 


\section{Conclusion}

\subsection{Generalizing findings}

This book traced the hydropower, GMO and nuclear power controversies in contemporary China and identified a body of interactive sociopolitical, knowledge and communication factors that have jointly shaped the evolution of these controversies. One major conclusion is that, just like other social and political disputes, public science and technology controversies can be considered social movements, with actors actively and strategically seeking political opportunities - which are structurally caused by a batch of sociopolitical and economic factors - to expand their impact or the impact of their viewpoints.

The second conclusion is that the control of knowledge, conceptualized as the knowledge-control regime, in a controversial case is central in enhancing or inhibiting the public controversy's evolution, but the regime is not just about knowledge. Instead, it is the product of a collection of sociopolitical and epistemic factors, which vary in different controversy settings. On the other hand, the knowledge-control regime, its effect in controlling the knowledge production and flow, and activists' perception of the regime are all critical portions of the political opportunity structure.

The third conclusion is that communication factors - including public attention to controversial issues, media and journalists' roles in promoting public debates, and the rise of new media - are essential to both political opportunity structures and knowledge control. These factors are structurally embedded in the evolution of controversy. For example, in the nuclear power case, the Chinese media were either active in positively framing the energy or reluctant to produce investigative reporting of the sector. This action increased the effect of the knowledge-control regime of the nuclear power sector and resulted in a relatively more restrictive political opportunity structure.

As revealed in Chapter 6, Chinese media and journalists' reluctance to report negative news on China's domestic nuclear power industry was partially related to the perceived military link of the nuclear power industry, resulting in journalists' risk avoidance behaviors. This finding, like many others in this book, highlights the authoritarian nature of the Chinese regime.

DOI: $10.4324 / 9781003160212-9$ 
Further, this raises the question of the generalizability of this study's findings and conclusions.

In a sense, the question is legitimate. China's authoritarian regime enables macro political power to play a more significant role in fueling the science and technology controversies examined in this book than might have been true in less authoritarian countries. However, the essence of the above conclusions is not about the degree to which political power was involved in science and technology disputes, but that these controversies should be treated like other social movements that interact with knowledge factors. This finding is highly generalizable and consistent with previous findings on scientific dissenters' strategies for entering controversies (Delborne, 2008; Martin, 1998, 2010).

Another generalizable finding is the role of sociopolitical factors in constituting the knowledge-control regimes of the controversy cases. In different instances, sociopolitical factors involved in forming knowledge-control regimes may vary, but what remains unchanged is that the type of knowledge control also depends on a combination of sociopolitical and epistemic factors.

A third generalizable finding is that the communication factors listed above have to be regularly considered in the pattern or dynamics of science and technology controversies (Martin, 2014). Not all scientific debates demonstrate the same dynamics. Actors adapt their behaviors depending on the audience attention and the media agenda.

Although these findings are internationally generalizable, the three controversy cases systematically examined in this monograph are not enough to reveal the more detailed generalizable mechanisms underlying controversies. The nature of the three studied cases as significant public science and technology controversies also prevents us from directly applying the conclusions to more elitist scientific disputes. We need more research in this direction.

\subsection{Limitations and future studies}

This book's first limitation lies in its research focus on China. Indeed, China has a sharply different political system and environment from the Western democracies on which both the mainstream STS and science communication scholarships are built, which makes some theoretical findings of this book challenging to generalize.

I admit this limitation, though would not frame it as a problem. Instead, I want to justify my research conclusions despite the limitation. First, across all three science and technology controversies I examined, a heavy influence of political institutions can be easily identified. For example, activists and orthodox scientists alike in the hydropower, GMO and nuclear cases tried their best to brief top leadership. However, if we set aside the surface differences, we can compare this with policy lobbying in Western democracies. The difference is not that Chinese science and technology controversies are political while the West's are not. The difference is that politics in Chinese cases are less institutional and occur with much less transparency. So, while the effort to re-examine 
the application of this book's conclusions in different contexts is necessary, it does not mean these conclusions are not applicable. Similarly, while the efforts of actors to depoliticize the frames for controversies may come from their widespread concern about political prosecution that does not apply in nonauthoritarian nations, yet the pursuit of political correctness is everywhere. Therefore, behaviors caused by the concerns about political challenges can be compared with a similar effort in the West for political correctness.

For the second limitation, the development stage of China and its political system bring up priorities different from the West. For example, except for Greenpeace's initial attempts, the GMO issue was not framed as an environment/ecology/biodiversity issue. Food safety and science and technology progress were the two dominant frames with different directions in terms of framing the disputed biotechnology. The first is related to many generations' memory in China of hunger and famines, and the latter is associated with Chinese people's eagerness to achieve national strength. The other side of the coin for this is widespread belief in a Western conspiracy. But my justification for claiming generalizability is that although the frames are different, we may consider their similar impacts on social movements and knowledge-control regime.

As with all qualitative studies, there are other limitations. As a whole, the discussions on embracing transferability versus generalizability by many qualitative study methodologists (Lincoln \& Guba, 1985; Tracy, 2010) point to issues relevant for my study.

Another major limitation is that, despite my extensive interviews, I still feel a lack of access to many data and sources, such as State and ministerial leaders or top industrial executives. I tried my best to understand their intentions. I also tried to triangulate my observations as much as possible. Sometimes I was lucky to have two separate sources to compare, for example, in the case of attitude to GMOs among top leadership in the Hu Jintao-Wen Jiabao era. But on most other occasions, I did not have such luck. I tried to avoid making any definitive remarks.

\subsection{Concluding remarks}

So far in this concluding chapter, I have summarized the communication factors, social movement theories and various knowledge-related concepts' application in interpreting China's hydropower, GMO and nuclear power controversies; compared the different evolution patterns of these controversies; discussed the integration of social movement theories and STS concepts in understanding social contentions; and explored the relevance of communication patterns to these controversies. A general conclusion seems redundant here: public science and technology disputes are the results of a body of interactive sociopolitical, knowledge and communication factors. We should consider public science and technology controversies as social movements, with actors actively and strategically seeking political opportunities to expand their impact. The control of knowledge, resulting from epistemic, 
communication and sociopolitical factors, allows or inhibits the evolution of public scientific controversies.

Underlying these claims is my goal to push ahead the application of social movement theories and STS concepts in offering a broad interpretation to knowledge-related social unrest. Communication studies are necessary to support this interpretation.

The theoretical significance of this book is therefore embodied in the elaboration of various theoretical components and their combined application in understanding complex reality rather than developing a theory. For this latter task, further research based on the current book is definitely needed. 


\section{Appendix}

There are a total of 103 interviewees recorded in this table. The table is grouped by the category of interviewees' primary role in this book, which can be a formal profession (activists, scientists, social science researchers etc.) but not limited to this profession, particularly in the case of activists who may have other established professions. Within each category, interviewees are chronologically ranked in accordance with the interview code, which is coded with the date of the interview they received. The interview code, in the format of INT+YYYY+MM+DD, was used in the text as an in-text reference. When there were multiple interviews on the same date, a letter $(a, b$, or $c)$ is added at the end of the code. Within each category, a number is added before the description just for reference. When the same person was interviewed more than once, Ibid is used to replace his/her description.

\section{Interviewee description and code}

\begin{tabular}{|c|c|c|c|c|c|}
\hline No. & $\begin{array}{l}\text { Profession or } \\
\text { description }\end{array}$ & $\begin{array}{l}\text { Location of } \\
\text { the interviewee }\end{array}$ & Age range & $\begin{array}{l}\text { Interview } \\
\text { time }\end{array}$ & Interview code \\
\hline \multicolumn{6}{|c|}{ Activists } \\
\hline 1 & $\begin{array}{l}\text { Journalist- } \\
\text { turned anti- } \\
\text { GMO activist, } \\
\text { founder of an } \\
\text { organic food } \\
\text { group in } \\
\text { Beijing }\end{array}$ & Beijing & $40-50$ & $\begin{array}{l}\text { Tuesday, } \\
\text { August 23, } \\
2016\end{array}$ & INT20160823 \\
\hline \multirow[t]{2}{*}{2} & $\begin{array}{l}\text { Anti-nuclear } \\
\text { activist, energy } \\
\text { policy } \\
\text { researcher }\end{array}$ & Beijing & $40-50$ & $\begin{array}{l}\text { Friday, } \\
\text { September } \\
23,2016\end{array}$ & INT20160923b \\
\hline & Ibid & Beijing & $40-50$ & $\begin{array}{l}\text { Second } \\
\text { interview: } \\
\text { December } \\
29,2016\end{array}$ & INT20161229a \\
\hline
\end{tabular}




\begin{tabular}{|c|c|c|c|c|c|}
\hline No. & $\begin{array}{l}\text { Profession or } \\
\text { description }\end{array}$ & $\begin{array}{l}\text { Location of } \\
\text { the interviewee }\end{array}$ & Age range & $\begin{array}{l}\text { Interview } \\
\text { time }\end{array}$ & Interview code \\
\hline & Ibid & Beijing & $40-50$ & $\begin{array}{l}\text { Third: } \\
\text { interview: } \\
\text { December } \\
21,2017\end{array}$ & INT20171221 \\
\hline 3 & $\begin{array}{l}\text { Journalist- } \\
\text { turned environ- } \\
\text { mental activist, } \\
\text { former interna- } \\
\text { tional ENGO } \\
\text { member }\end{array}$ & Beijing & $30-40$ & $\begin{array}{l}\text { Monday, } \\
\text { September } \\
26,2016\end{array}$ & INT20160926 \\
\hline 4 & $\begin{array}{l}\text { Environmental } \\
\text { activist, inter- } \\
\text { national } \\
\text { ENGO } \\
\text { member }\end{array}$ & Beijing & $30-40$ & $\begin{array}{l}\text { Tuesday, } \\
\text { September } \\
27,2016\end{array}$ & INT20160927 \\
\hline 5 & $\begin{array}{l}\text { Anti-GMO } \\
\text { activist, self- } \\
\text { described } \\
\text { scientist }\end{array}$ & Beijing & $70-80$ & $\begin{array}{l}\text { Thursday, } \\
\text { September } \\
29,2016\end{array}$ & INT20160929 \\
\hline 6 & $\begin{array}{l}\text { Head of a } \\
\text { nationally lead- } \\
\text { ing ENGO }\end{array}$ & Beijing & $30-40$ & $\begin{array}{l}\text { Tuesday, } \\
\text { November } \\
22,2016\end{array}$ & INT20161120 \\
\hline 7 & $\begin{array}{l}\text { Activist and } \\
\text { activist-turned- } \\
\text { journalist }\end{array}$ & Beijing & $30-40$ & $\begin{array}{l}\text { Sunday, } \\
\text { November } \\
27,2016\end{array}$ & INT20161122 \\
\hline 8 & $\begin{array}{l}\text { Anti-GMO \& } \\
\text { anti-nuclear } \\
\text { activist, leftist }\end{array}$ & South China & $40-50$ & $\begin{array}{l}\text { Saturday, } \\
\text { December } \\
3,2016\end{array}$ & INT20161127 \\
\hline 9 & $\begin{array}{l}\text { Anti-nuclear } \\
\text { activist, retired } \\
\text { local official }\end{array}$ & East China & $70-80$ & $\begin{array}{l}\text { Tuesday, } \\
\text { December } \\
6,2016\end{array}$ & INT20161206a \\
\hline 10 & $\begin{array}{l}\text { Anti-nuclear } \\
\text { activist, retired } \\
\text { local official }\end{array}$ & East China & $60-70$ & $\begin{array}{l}\text { Tuesday, } \\
\text { December } \\
6,2016\end{array}$ & INT20161206b \\
\hline 11 & $\begin{array}{l}\text { Anti-nuclear } \\
\text { activist, retired } \\
\text { local official }\end{array}$ & East China & $70-80$ & $\begin{array}{l}\text { Wednes- } \\
\text { day, } \\
\text { December } \\
7,2016\end{array}$ & INT20161207a \\
\hline 12 & $\begin{array}{l}\text { Anti-nuclear } \\
\text { activist, retired } \\
\text { local official }\end{array}$ & East China & $70-80$ & $\begin{array}{l}\text { Wednes- } \\
\text { day, } \\
\text { December } \\
7,2016\end{array}$ & INT20161207b \\
\hline 13 & $\begin{array}{l}\text { Anti-hydro- } \\
\text { power activist, } \\
\text { former liberal }\end{array}$ & Beijing & $60-70$ & $\begin{array}{l}\text { Thursday, } \\
\text { December } \\
8,2016\end{array}$ & INT20161208a \\
\hline
\end{tabular}




\begin{tabular}{|c|c|c|c|c|c|}
\hline No. & $\begin{array}{l}\text { Profession or } \\
\text { description }\end{array}$ & $\begin{array}{l}\text { Location of } \\
\text { the interviewee }\end{array}$ & Age range & $\begin{array}{l}\text { Interview } \\
\text { time }\end{array}$ & Interview code \\
\hline 14 & $\begin{array}{l}\text { Journalist- } \\
\text { turned environ- } \\
\text { mental activist }\end{array}$ & East China & $40-50$ & $\begin{array}{l}\text { Tuesday, } \\
\text { December } \\
13,2016\end{array}$ & INT20161213 \\
\hline 15 & $\begin{array}{l}\text { Journalist- } \\
\text { turned anti- } \\
\text { dam activist. } \\
\text { Head of local } \\
\text { ENGO }\end{array}$ & Beijing & $60-70$ & $\begin{array}{l}\text { Sunday, } \\
\text { December } \\
18,2016\end{array}$ & INT20161215 \\
\hline 16 & $\begin{array}{l}\text { Environmental } \\
\text { activist }\end{array}$ & Shanghai & $30-40$ & $\begin{array}{l}\text { Thursday, } \\
\text { December } \\
15,2016\end{array}$ & INT20161217 \\
\hline 17 & $\begin{array}{l}\text { Environmental } \\
\text { anti-dam acti- } \\
\text { vist, self- } \\
\text { claimed scien- } \\
\text { tist. Head of } \\
\text { local ENGO }\end{array}$ & $\begin{array}{l}\text { Southwest } \\
\text { China }\end{array}$ & $50-60$ & $\begin{array}{l}\text { Thursday, } \\
\text { December } \\
22,2016\end{array}$ & INT20161221 \\
\hline 18 & $\begin{array}{l}\text { Environmental } \\
\text { anti-dam acti- } \\
\text { vist, local } \\
\text { scientist }\end{array}$ & $\begin{array}{l}\text { Southwest } \\
\text { China }\end{array}$ & $60-70$ & $\begin{array}{l}\text { Thursday, } \\
\text { December } \\
22,2016\end{array}$ & INT20161222 \\
\hline 19 & $\begin{array}{l}\text { Journalist- } \\
\text { turned environ- } \\
\text { mental activist. } \\
\text { Head of local } \\
\text { ENGO }\end{array}$ & $\begin{array}{l}\text { Southwest } \\
\text { China }\end{array}$ & $50-60$ & $\begin{array}{l}\text { Friday, } \\
\text { December } \\
23,2016\end{array}$ & INT20161223 \\
\hline 20 & $\begin{array}{l}\text { Scholar-turned } \\
\text { environmental } \\
\text { activist. Head } \\
\text { of local ENGO }\end{array}$ & $\begin{array}{l}\text { Southwest } \\
\text { China }\end{array}$ & $50-60$ & $\begin{array}{l}\text { Sunday, } \\
\text { December } \\
25,2016\end{array}$ & INT20161225 \\
\hline 21 & $\begin{array}{l}\text { Young environ- } \\
\text { mental activist }\end{array}$ & Beijing & $20-30$ & $\begin{array}{l}\text { Wednes- } \\
\text { day, Jan- } \\
\text { uary 11, } \\
2017\end{array}$ & INT20170111 \\
\hline 22 & $\begin{array}{l}\text { Young environ- } \\
\text { mental activist }\end{array}$ & Beijing & $20-30$ & $\begin{array}{l}\text { Friday, } \\
\text { January } \\
13,2017\end{array}$ & INT20170113 \\
\hline 23 & $\begin{array}{l}\text { Journalist- } \\
\text { turned environ- } \\
\text { mental activist, } \\
\text { former interna- } \\
\text { tional ENGO } \\
\text { member }\end{array}$ & East China & $40-50$ & $\begin{array}{l}\text { Friday, } \\
\text { March 10, } \\
2017\end{array}$ & INT20170310 \\
\hline
\end{tabular}




\begin{tabular}{|c|c|c|c|c|c|}
\hline No. & $\begin{array}{l}\text { Profession or } \\
\text { description }\end{array}$ & $\begin{array}{l}\text { Location of } \\
\text { the interviewee }\end{array}$ & Age range & $\begin{array}{l}\text { Interview } \\
\text { time }\end{array}$ & Interview code \\
\hline 24 & $\begin{array}{l}\text { Environmental } \\
\text { activist, former } \\
\text { international } \\
\text { ENGO } \\
\text { member, } \\
\text { former head of } \\
\text { a nationally } \\
\text { leading NGO }\end{array}$ & Overseas & $40-50$ & $\begin{array}{l}\text { Monday, } \\
\text { May 15, } \\
2017\end{array}$ & INT20170515 \\
\hline 25 & $\begin{array}{l}\text { Anti-nuclear } \\
\text { activist, } \\
\text { CPPCC } \\
\text { member, a } \\
\text { billionaire }\end{array}$ & South China & $60-70$ & $\begin{array}{l}\text { Sunday, } \\
\text { July } 30 \text {, } \\
2017\end{array}$ & INT20170730 \\
\hline \multicolumn{6}{|c|}{ Government officials (including retired officials) } \\
\hline 1 & $\begin{array}{l}\text { Incumbent } \\
\text { agricultural } \\
\text { official }\end{array}$ & Beijing & $40-50$ & $\begin{array}{l}\text { Thursday, } \\
\text { November } \\
10,2016\end{array}$ & INT20161110b \\
\hline 2 & $\begin{array}{l}\text { Promoter of } \\
\text { hydro project, } \\
\text { former scien- } \\
\text { tist, retired } \\
\text { senior official }\end{array}$ & East China & $60-70$ & $\begin{array}{l}\text { Monday, } \\
\text { January 9, } \\
2017\end{array}$ & INT20170109 \\
\hline 3 & $\begin{array}{l}\text { Incumbent pro- } \\
\text { paganda } \\
\text { official }\end{array}$ & Beijing & $40-50$ & $\begin{array}{l}\text { Thursday, } \\
\text { January } \\
12,2017\end{array}$ & INT20170112 \\
\hline 4 & $\begin{array}{l}\text { Former agri- } \\
\text { cultural official }\end{array}$ & Beijing & $60-70$ & $\begin{array}{l}\text { Wednes- } \\
\text { day, } \\
\text { August 23, } \\
2017\end{array}$ & INT20170823 \\
\hline \multicolumn{6}{|c|}{ Industry sources } \\
\hline 1 & $\begin{array}{l}\text { PR official of a } \\
\text { nuclear giant }\end{array}$ & South China & $40-50$ & $\begin{array}{l}\text { Sunday, } \\
\text { October } \\
23,2016\end{array}$ & INT20161023 \\
\hline 2 & $\begin{array}{l}\text { Engineer of a } \\
\text { nuclear giant }\end{array}$ & South China & Unknown & $\begin{array}{l}\text { Sunday, } \\
\text { October } \\
23,2016\end{array}$ & INT20161023b \\
\hline 3 & $\begin{array}{l}\text { Engineer of a } \\
\text { nuclear giant }\end{array}$ & South China & Unknown & $\begin{array}{l}\text { Sunday, } \\
\text { October } \\
23,2016\end{array}$ & INT20161023c \\
\hline 4 & $\begin{array}{l}\text { Engineer of a } \\
\text { nuclear } \\
\text { research } \\
\text { institute }\end{array}$ & Shanghai & $30-40$ & $\begin{array}{l}\text { Tuesday, } \\
\text { December } \\
20,2016\end{array}$ & INT20161219 \\
\hline 5 & $\begin{array}{l}\text { Head of local } \\
\text { medical website }\end{array}$ & Shanghai & $40-50$ & $\begin{array}{l}\text { Tuesday, } \\
\text { December } \\
20,2016\end{array}$ & INT20161220 \\
\hline
\end{tabular}




\begin{tabular}{|c|c|c|c|c|c|}
\hline No. & $\begin{array}{l}\text { Profession or } \\
\text { description }\end{array}$ & $\begin{array}{l}\text { Location of } \\
\text { the interviewee }\end{array}$ & Age range & $\begin{array}{l}\text { Interview } \\
\text { time }\end{array}$ & Interview code \\
\hline 6 & $\begin{array}{l}\text { PR official of a } \\
\text { nuclear giant }\end{array}$ & Beijing & $40-50$ & $\begin{array}{l}\text { Thursday, } \\
\text { December } \\
29,2016\end{array}$ & INT20161229b \\
\hline 7 & $\begin{array}{l}\text { Nuclear engi- } \\
\text { neer-turned } \\
\text { nuclear PIOs }\end{array}$ & Shanghai & $30-40$ & $\begin{array}{l}\text { Thursday, } \\
\text { December } \\
29,2016\end{array}$ & INT20161229c \\
\hline 8 & $\begin{array}{l}\text { The main } \\
\text { spokesperson } \\
\text { of hydropower } \\
\text { industry }\end{array}$ & Beijing & $50-60$ & $\begin{array}{l}\text { Friday, } \\
\text { January 6, } \\
2017\end{array}$ & INT20170106 \\
\hline 9 & $\begin{array}{l}\text { Nuclear power } \\
\text { senior } \\
\text { executive }\end{array}$ & Shanghai & $50-60$ & $\begin{array}{l}\text { Second } \\
\text { interview: } \\
\text { June 15, } \\
2017\end{array}$ & INT20170615 \\
\hline 10 & $\begin{array}{l}\text { PR official of a } \\
\text { nuclear giant }\end{array}$ & Beijing & $40-50$ & $\begin{array}{l}\text { Friday, } \\
\text { June 16, } \\
2017\end{array}$ & INT20170616 \\
\hline 11 & $\begin{array}{l}\text { Engineer and } \\
\text { VP of a nuclear } \\
\text { plant }\end{array}$ & East China & $50-60$ & $\begin{array}{l}\text { Friday, } \\
\text { June 16, } \\
2017\end{array}$ & INT20170616b \\
\hline \multicolumn{6}{|c|}{ Journalists } \\
\hline 1 & $\begin{array}{l}\text { Science } \\
\text { journalist }\end{array}$ & Beijing & $40-50$ & $\begin{array}{l}\text { Tuesday, } \\
\text { August 16, } \\
2016\end{array}$ & INT20160816 \\
\hline 2 & $\begin{array}{l}\text { Former science } \\
\text { journalist }\end{array}$ & Beijing & $30-40$ & $\begin{array}{l}\text { Saturday, } \\
\text { August 20, } \\
2016\end{array}$ & INT20160820 \\
\hline 3 & $\begin{array}{l}\text { Science } \\
\text { journalist }\end{array}$ & Beijing & $30-40$ & $\begin{array}{l}\text { Monday, } \\
\text { September } \\
19,2016\end{array}$ & INT20160919 \\
\hline 4 & $\begin{array}{l}\text { Environmental } \\
\text { journalist }\end{array}$ & Beijing & $30-40$ & $\begin{array}{l}\text { Wednes- } \\
\text { day, Sep- } \\
\text { tember } 21 \text {, } \\
2016\end{array}$ & INT20160921a \\
\hline 5 & $\begin{array}{l}\text { Science } \\
\text { journalist }\end{array}$ & Beijing & $40-50$ & $\begin{array}{l}\text { Wednes- } \\
\text { day, Sep- } \\
\text { tember } 21 \text {, } \\
2016\end{array}$ & INT20160921b \\
\hline 6 & Journalist & Beijing & $50-60$ & $\begin{array}{l}\text { Friday, } \\
\text { September } \\
23,2016\end{array}$ & INT20160923a \\
\hline 7 & $\begin{array}{l}\text { Science } \\
\text { journalist }\end{array}$ & Beijing & $40-50$ & $\begin{array}{l}\text { Sunday, } \\
\text { September } \\
25,2016\end{array}$ & INT20160925 \\
\hline
\end{tabular}




\begin{tabular}{|c|c|c|c|c|c|}
\hline No. & $\begin{array}{l}\text { Profession or } \\
\text { description }\end{array}$ & $\begin{array}{l}\text { Location of } \\
\text { the interviewee }\end{array}$ & Age range & $\begin{array}{l}\text { Interview } \\
\text { time }\end{array}$ & Interview code \\
\hline 8 & $\begin{array}{l}\text { Science } \\
\text { journalist }\end{array}$ & Beijing & $40-50$ & $\begin{array}{l}\text { Sunday, } \\
\text { September } \\
25,2016\end{array}$ & INT20160925 \\
\hline 9 & $\begin{array}{l}\text { Science } \\
\text { journalist }\end{array}$ & Guangzhou & $40-50$ & $\begin{array}{l}\text { Sunday, } \\
\text { October } \\
16,2016\end{array}$ & INT20161016 \\
\hline 10 & $\begin{array}{l}\text { Science } \\
\text { journalist }\end{array}$ & Guangzhou & $40-50$ & $\begin{array}{l}\text { Saturday, } \\
\text { October } \\
22,2016\end{array}$ & INT20161022 \\
\hline 11 & $\begin{array}{l}\text { Former senior } \\
\text { journalist }\end{array}$ & Shenzhen & $60-70$ & $\begin{array}{l}\text { Wednes- } \\
\text { day, } \\
\text { November } \\
2,2016\end{array}$ & INT20161102 \\
\hline 12 & $\begin{array}{l}\text { Science } \\
\text { journalist }\end{array}$ & Beijing & $40-50$ & $\begin{array}{l}\text { Thursday, } \\
\text { November } \\
17,2016\end{array}$ & INT20161115 \\
\hline 13 & $\begin{array}{l}\text { Science jour- } \\
\text { nalist \& web } \\
\text { editor }\end{array}$ & Beijing & $40-50$ & $\begin{array}{l}\text { Friday, } \\
\text { December } \\
16,2016\end{array}$ & INT20161216 \\
\hline 14 & $\begin{array}{l}\text { Science } \\
\text { journalist }\end{array}$ & Beijing & $30-40$ & $\begin{array}{l}\text { Saturday, } \\
\text { December } \\
17,2016\end{array}$ & INT20161217 \\
\hline 15 & $\begin{array}{l}\text { Science } \\
\text { journalist }\end{array}$ & Hangzhou & $50-60$ & $\begin{array}{l}\text { Monday, } \\
\text { December } \\
19,2016\end{array}$ & INT20161218 \\
\hline 16 & $\begin{array}{l}\text { Former science } \\
\text { journalist }\end{array}$ & Hangzhou & $40-50$ & $\begin{array}{l}\text { Monday, } \\
\text { December } \\
\text { 19, } 2016\end{array}$ & INT20161219 \\
\hline 17 & $\begin{array}{l}\text { Former science } \\
\text { journalist }\end{array}$ & Hangzhou & $40-50$ & $\begin{array}{l}\text { Sunday, } \\
\text { January } 8, \\
2017\end{array}$ & INT20170106 \\
\hline 18 & $\begin{array}{l}\text { Former science } \\
\text { journalist }\end{array}$ & Beijing & $30-40$ & $\begin{array}{l}\text { Monday, } \\
\text { January 9, } \\
2017\end{array}$ & INT20170108 \\
\hline 19 & $\begin{array}{l}\text { Former news } \\
\text { portal \& social } \\
\text { media science } \\
\text { editor }\end{array}$ & Beijing & $30-40$ & $\begin{array}{l}\text { Monday, } \\
\text { January 9, } \\
2017\end{array}$ & INT20170109 \\
\hline 20 & $\begin{array}{l}\text { Environmental } \\
\text { journalist }\end{array}$ & Beijing & $20-30$ & $\begin{array}{l}\text { Tuesday, } \\
\text { January } \\
10,2017\end{array}$ & INT20170110 \\
\hline 21 & $\begin{array}{l}\text { Former science } \\
\text { journalist }\end{array}$ & Beijing & $30-40$ & $\begin{array}{l}\text { Saturday, } \\
\text { January } \\
14,2017\end{array}$ & INT20170114 \\
\hline
\end{tabular}




\begin{tabular}{|c|c|c|c|c|c|}
\hline No. & $\begin{array}{l}\text { Profession or } \\
\text { description }\end{array}$ & $\begin{array}{l}\text { Location of } \\
\text { the interviewee }\end{array}$ & Age range & $\begin{array}{l}\text { Interview } \\
\text { time }\end{array}$ & Interview code \\
\hline 22 & $\begin{array}{l}\text { Science } \\
\text { journalist }\end{array}$ & Beijing & $20-30$ & $\begin{array}{l}\text { Saturday, } \\
\text { July 23, } \\
2016\end{array}$ & INT20170723 \\
\hline 23 & $\begin{array}{l}\text { Science } \\
\text { journalist }\end{array}$ & Beijing & $20-30$ & $\begin{array}{l}\text { Saturday, } \\
\text { July 23, } \\
2016\end{array}$ & INT20170723 \\
\hline 24 & $\begin{array}{l}\text { Former science } \\
\text { journalist }\end{array}$ & Beijing & $30-40$ & $\begin{array}{l}\text { Tuesday, } \\
\text { July 25, } \\
2017\end{array}$ & INT20170725 \\
\hline 25 & $\begin{array}{l}\text { Energy } \\
\text { journalist }\end{array}$ & Beijing & $30-40$ & $\begin{array}{l}\text { Friday, } \\
\text { August 25, } \\
2017\end{array}$ & INT20170825 \\
\hline 26 & $\begin{array}{l}\text { Environmental } \\
\text { journalist }\end{array}$ & Beijing & $50-60$ & $\begin{array}{l}\text { Wednes- } \\
\text { day, } \\
\text { August 30, } \\
2017\end{array}$ & INT20170830 \\
\hline \multicolumn{6}{|c|}{ Science communication professionals } \\
\hline 1 & $\begin{array}{l}\text { PIO1 of a } \\
\text { research } \\
\text { institute }\end{array}$ & Beijing & $30-40$ & $\begin{array}{l}\text { Sunday, } \\
\text { August 21, } \\
2016\end{array}$ & INT20160821 \\
\hline 2 & $\begin{array}{l}\mathrm{PIO} 2 \text { of a } \\
\text { research } \\
\text { institute }\end{array}$ & Beijing & $40-50$ & $\begin{array}{l}\text { Sunday, } \\
\text { September } \\
25,2016\end{array}$ & INT20160925c \\
\hline 3 & $\begin{array}{l}\text { Science com- } \\
\text { munication } \\
\text { expert }\end{array}$ & Beijing & $30-40$ & $\begin{array}{l}\text { Wednes- } \\
\text { day, Sep- } \\
\text { tember } 28 \text {, } \\
2016\end{array}$ & INT20160928 \\
\hline 4 & $\begin{array}{l}\text { PIO3 of a } \\
\text { research } \\
\text { institute }\end{array}$ & Central China & $40-50$ & $\begin{array}{l}\text { Tuesday, } \\
\text { December } \\
27,2016\end{array}$ & INT20161226 \\
\hline 5 & $\begin{array}{l}\text { Science com- } \\
\text { munication } \\
\text { expert }\end{array}$ & Beijing & $50-60$ & $\begin{array}{l}\text { Friday, } \\
\text { December } \\
30,2016\end{array}$ & INT20161230 \\
\hline \multicolumn{6}{|c|}{ Social science researchers } \\
\hline 1 & STS professor & Beijing & $50-60$ & $\begin{array}{l}\text { Tuesday, } \\
\text { September } \\
20,2016\end{array}$ & INT20160920 \\
\hline 2 & $\begin{array}{l}\text { Senior science } \\
\text { policy } \\
\text { researcher }\end{array}$ & Beijing & $50-60$ & $\begin{array}{l}\text { Thursday, } \\
\text { September } \\
22,2016\end{array}$ & INT20160922 \\
\hline 3 & $\begin{array}{l}\text { Senior } \\
\text { researcher, sci- } \\
\text { ence commu- } \\
\text { nication }\end{array}$ & Beijing & $40-50$ & $\begin{array}{l}\text { Tuesday, } \\
\text { October } \\
11,2016\end{array}$ & INT20161011 \\
\hline
\end{tabular}




\begin{tabular}{|c|c|c|c|c|c|}
\hline No. & $\begin{array}{l}\text { Profession or } \\
\text { description }\end{array}$ & $\begin{array}{l}\text { Location of } \\
\text { the interviewee }\end{array}$ & Age range & $\begin{array}{l}\text { Interview } \\
\text { time }\end{array}$ & Interview code \\
\hline & Ibid & Beijing & $40-50$ & $\begin{array}{l}\text { Second } \\
\text { interview: } \\
\text { September } \\
15,2017\end{array}$ & INT20170915 \\
\hline 4 & $\begin{array}{l}\text { Senior agri- } \\
\text { cultural policy } \\
\text { researcher }\end{array}$ & Beijing & $50-60$ & $\begin{array}{l}\text { Monday, } \\
\text { November } \\
14,2016\end{array}$ & INT20161114 \\
\hline 5 & STS professor & East China & $40-50$ & $\begin{array}{l}\text { Saturday, } \\
\text { November } \\
19,2016\end{array}$ & INT20161117 \\
\hline 6 & STS professor & Beijing & $50-60$ & $\begin{array}{l}\text { Sunday, } \\
\text { November } \\
20,2016\end{array}$ & INT20161119 \\
\hline 7 & $\begin{array}{l}\text { Risk commu- } \\
\text { nication } \\
\text { scholar }\end{array}$ & Beijing & $50-60$ & $\begin{array}{l}\text { Monday, } \\
\text { November } \\
28,2016\end{array}$ & INT20161128 \\
\hline 8 & STS professor & Beijing & $30-40$ & $\begin{array}{l}\text { Thursday, } \\
\text { December } \\
8,2016\end{array}$ & INT20161208b \\
\hline & Ibid & Beijing & $30-40$ & $\begin{array}{l}\text { Second } \\
\text { interview: } \\
\text { July 15, } \\
2017\end{array}$ & INT20170715 \\
\hline 9 & $\begin{array}{l}\text { Communica- } \\
\text { tion scholar, } \\
\text { ENGO intern }\end{array}$ & Beijing & $20-30$ & $\begin{array}{l}\text { Monday, } \\
\text { January 9, } \\
2017\end{array}$ & INT20170109 \\
\hline 10 & $\begin{array}{l}\text { Senior } \\
\text { researcher, sci- } \\
\text { ence policy }\end{array}$ & Ningbo/UK & $50-60$ & $\begin{array}{l}\text { Monday, } \\
\text { April 24, } \\
2017\end{array}$ & INT20170424 \\
\hline 11 & STS professor & Beijing & $50-60$ & $\begin{array}{l}\text { Monday, } \\
\text { May 15, } \\
2017\end{array}$ & INT20170515 \\
\hline 12 & STS professor & Beijing & $50-60$ & $\begin{array}{l}\text { Thursday, } \\
\text { May 18, } \\
2017\end{array}$ & INT20170518 \\
\hline 13 & STS professor & Beijing & $50-60$ & $\begin{array}{l}\text { Saturday, } \\
\text { May 20, } \\
2017\end{array}$ & INT20170520 \\
\hline 14 & STS professor & Beijing & $30-40$ & $\begin{array}{l}\text { Sunday, } \\
\text { June 18, } \\
2017\end{array}$ & INT20170618 \\
\hline 15 & $\begin{array}{l}\text { Senior science } \\
\text { policy } \\
\text { researcher }\end{array}$ & Beijing & $50-60$ & $\begin{array}{l}\text { Monday, } \\
\text { June 19, } \\
2017\end{array}$ & INT20170619 \\
\hline
\end{tabular}




\begin{tabular}{|c|c|c|c|c|c|}
\hline No. & $\begin{array}{l}\text { Profession or } \\
\text { description }\end{array}$ & $\begin{array}{l}\text { Location of } \\
\text { the interviewee }\end{array}$ & Age range & $\begin{array}{l}\text { Interview } \\
\text { time }\end{array}$ & Interview code \\
\hline 16 & STS professor & UK & $40-50$ & $\begin{array}{c}\text { Friday, } \\
\text { July 21, } \\
2017\end{array}$ & INT20170721 \\
\hline 17 & $\begin{array}{l}\text { Communica- } \\
\text { tion scholar }\end{array}$ & Beijing & $30-40$ & $\begin{array}{l}\text { Thursday, } \\
\text { September } \\
28,2017\end{array}$ & INT20170828 \\
\hline \multicolumn{6}{|c|}{ Scientists (natural science) } \\
\hline 1 & $\begin{array}{l}\text { Senior agri- } \\
\text { cultural } \\
\text { scientist }\end{array}$ & Central China & $60-70$ & $\begin{array}{l}\text { Sunday, } \\
\text { October 9, } \\
2016\end{array}$ & INT20161009 \\
\hline 2 & Chemist & Nanjing & $50-60$ & $\begin{array}{l}\text { Wednes- } \\
\text { day, } \\
\text { March 9, } \\
2016\end{array}$ & INT20160309 \\
\hline 3 & $\begin{array}{l}\text { Senior agri- } \\
\text { cultural scien- } \\
\text { tist, former } \\
\text { CPPCC } \\
\text { member }\end{array}$ & Beijing & $60-70$ & $\begin{array}{l}\text { Wednes- } \\
\text { day, } \\
\text { November } \\
9,2016\end{array}$ & INT20161110a \\
\hline 4 & $\begin{array}{l}\text { Senior agri- } \\
\text { cultural } \\
\text { scientist }\end{array}$ & Beijing & $50-60$ & $\begin{array}{l}\text { Friday, } \\
\text { November } \\
18,2016\end{array}$ & INT20161118 \\
\hline 5 & $\begin{array}{l}\text { Ecology } \\
\text { scientist }\end{array}$ & Beijing & $50-60$ & $\begin{array}{l}\text { Thursday, } \\
\text { December } \\
15,2016\end{array}$ & INT20161215 \\
\hline 6 & $\begin{array}{l}\text { Senior life } \\
\text { scientist }\end{array}$ & Beijing & $60-70$ & $\begin{array}{l}\text { Wednes- } \\
\text { day, } \\
\text { December } \\
21,2016\end{array}$ & INT20161221 \\
\hline 7 & $\begin{array}{l}\text { Senior environ- } \\
\text { mental scientist }\end{array}$ & $\begin{array}{l}\text { Southwest } \\
\text { China }\end{array}$ & $70-80$ & $\begin{array}{l}\text { Friday, } \\
\text { December } \\
23,2016\end{array}$ & INT20161222 \\
\hline 8 & $\begin{array}{l}\text { Senior environ- } \\
\text { mental scientist }\end{array}$ & Central China & $70-80$ & $\begin{array}{l}\text { Monday, } \\
\text { December } \\
26,2016\end{array}$ & INT20161227 \\
\hline 9 & $\begin{array}{l}\text { Anti-nuclear } \\
\text { physicist }\end{array}$ & Beijing & $80-90$ & $\begin{array}{l}\text { Friday, } \\
\text { December } \\
30,2016\end{array}$ & INT20161230 \\
\hline 10 & $\begin{array}{l}\text { Senior hydro- } \\
\text { power scientist }\end{array}$ & Beijing & $50-60$ & $\begin{array}{l}\text { Wednes- } \\
\text { day, Jan- } \\
\text { uary 11, } \\
2017\end{array}$ & INT20170111 \\
\hline 11 & $\begin{array}{l}\text { Senior environ- } \\
\text { mental scientist }\end{array}$ & Beijing & $50-60$ & $\begin{array}{l}\text { Friday, } \\
\text { February } \\
10,2017\end{array}$ & INT20170210 \\
\hline
\end{tabular}


Appendix 201

\begin{tabular}{|c|c|c|c|c|c|}
\hline No. & $\begin{array}{l}\text { Profession or } \\
\text { description }\end{array}$ & $\begin{array}{l}\text { Location of } \\
\text { the interviewee }\end{array}$ & Age range & $\begin{array}{l}\text { Interview } \\
\text { time }\end{array}$ & Interview code \\
\hline 12 & $\begin{array}{l}\text { Space scientist } \\
\text { and active sci- } \\
\text { ence } \\
\text { communicator }\end{array}$ & Guangzhou & $50-60$ & $\begin{array}{l}\text { Tuesday, } \\
\text { March 28, } \\
2017\end{array}$ & INT20170328 \\
\hline 13 & $\begin{array}{l}\text { Ecology } \\
\text { scientist }\end{array}$ & Beijing & $50-60$ & $\begin{array}{l}\text { Saturday, } \\
\text { June 17, } \\
2017\end{array}$ & INT20170617 \\
\hline 14 & $\begin{array}{l}\text { Anti-nuclear } \\
\text { physicist }\end{array}$ & Beijing & $50-60$ & $\begin{array}{l}\text { Monday, } \\
\text { June 19, } \\
2017\end{array}$ & INT20170619 \\
\hline 15 & $\begin{array}{l}\text { Senior hydro- } \\
\text { power scientist }\end{array}$ & Beijing & $50-60$ & $\begin{array}{l}\text { Friday, } \\
\text { June 30, } \\
2017\end{array}$ & INT20170630 \\
\hline
\end{tabular}




\section{References}

Adhikari, K., \& Sales, A. (2001). Introduction: New directions in the study of knowledge, economy and society. Current Sociology, 49(4), 1-25. doi:10.1177/ 0011392101049004002 .

Adler, P. A., \& Adler, P. (1994). Observational techniques. In N. K. Denzin \& Y. S. Lincoln (Eds.), The SAGE Handbook of Qualitative Research (pp. 377-391). Thousand Oaks, CA: Sage.

Akin, H., \& Scheufele, D. A. (2017). Overview of the science of science communication. In K. H. Jamieson, D. Kahan, \& D. A. Scheufele (Eds.), Oxford Handbook on the Science of Science Communication (pp. 25-33). New York, NY: Oxford University Press.

Albæk, E. (2011). The interaction between experts and journalists in news journalism. Journalism, 12(3), 335-348.

Anderson, A. A., \& Huntington, H. E. (2017). Social media, science, and attack discourse: How Twitter discussions of climate change use sarcasm and incivility. Science Communication, 39(5), 598-620. doi:10.1177/1075547017735113.

Anderson, W. (2012). Asia as method in science and technology studies. East Asian Science, Technology and Society, 6(4), 445-451.

Antilla, L. (2005). Climate of scepticism: US newspaper coverage of the science of climate change. Global Environmental Change: Human and Policy Dimensions, 15(4), 338-352.

Augoustinos, M., Crabb, S., \& Shepherd, R. (2010). Genetically modified food in the news: media representations of the GM debate in the UK. Public Understanding of Science, 19(1), 98-114.

Baram-Tsabari, A., \& Segev, E. (2011). Exploring new web-based tools to identify public interest in science. Public Understanding of Science, 20(1), 130-143.

Barbagallo, F., \& Nelson, J. (2005). Report: UK GM dialogue: Separating social and scientific issues. Science Communication, 26(3), 318-325.

Bauer, M. W. (2002). Controversial medical and agri-food biotechnology: A cultivation analysis. Public Understanding of Science, 11(2), 93-111.

Berkow, J. (2009). Chinese press finally covers story that Zipingpu reservoir may have induced deadly quake. Probe International. Retrieved from https://journal.probeinterna tional.org/2009/02/20/chinese-press-finally-covers-story-zipingpu-reservoir-may-have-in duced-deadly-quake/.

Bickerstaffe, J., \& Pearce, D. (1980). Can there be a consensus on nuclear power? Social Studies of Science, 10(3), 309-344.

Bijker, W. E. (2007). Dikes and dams, thick with politics. Isis, 98(1), 109-123. doi:10.1086/512835. 
Bloor, D. (1991). Knowledge and Social Imagery. Chicago: University of Chicago Press.

Bolsen, T., \& Cook, F. L. (2008). The polls-trends: public opinion on energy policy: 1974-2006. Public Opinion Quarterly, 72(2), 364-388.

Bonny, \& Sylvie. (2003). Why are most Europeans opposed to GMOs?: Factors explaining rejection in France and Europe. Electronic Journal of Biotechnology, 6(1), $50-71$.

Boykoff, M. T., \& Boykoff, J. (2004). Balance as bias: Global warming and the US prestige press. Global Environmental Change: Human and Policy Dimensions, 14(2), $125-136$.

Branigan, T. (2011, July 25). Chinese anger over alleged cover-up of high-speed rail crash. The Guardian, p. HS2. Retrieved from https://www.theguardian.com/world/ 2011/jul/25/chinese-rail-crash-cover-up-claims.

Breyman, S., Campbell, N., Eubanks, V., \& Kinchy, A. (2017). STS and social movements: Pasts and futures. In U. Felt, R. Fouche, C. A. Miller, \& L. Smith-Doerr (Eds.), Handbook of Science and Technology Studies (4th edition) (pp. 289-317). Cambridge, MA: The MIT Press.

Brødsgaard, K. E. (Ed.) (2017). Chinese Politics as Fragmented Authoritarianism: Earthquakes, Energy and Environment. Abingdon, Oxon and New York, NY: Routledge.

Brossard, D. (2009). Media, scientific journals and science communication: Examining the construction of scientific controversies. Public Understanding of Science, 18(3), 258-274.

Brossard, D. (2013). New media landscapes and the science information consumer. Proceedings of the National Academy of Sciences, 110(Suppl. 3), 14096-14101.

Brossard, D., \& Nisbet, M. C. (2007). Deference to scientific authority among a low information public: Understanding US opinion on agricultural biotechnology. International Journal of Public Opinion Research, 19(1), 24-52.

Buckley, C. (2016a, August 10). Chinese city backs down on proposed nuclear fuel plant after protests. The New York Times, p. A8. Retrieved from http://www.nytim es.com/2016/08/11/world/asia/china-nuclear-fuel-lianyungang.html.

Buckley, C. (2016b, August 9). Thousands in eastern Chinese city protest nuclear waste project. The New York Times, p. A6. Retrieved from https://www.nytimes. com/2016/08/09/world/asia/china-nuclear-waste-protest-lianyungang.html.

Buckley, C. (2017, July 22). From political star to "a sacrificial object" in China. The New York Times, p. A8. Retrieved from https://www.nytimes.com/2017/07/22/ world/asia/china-xi-jinping-sun-zhengcai-chongqing-.html.

Buesgen, M. (2008). Environmental NGOs' role in expanding social spaces - diversification with Chinese characteristics: A case study of ENGOs' opposition to the Nujiang dam in China's Yunnan Province. China Journal of Social Work, 1(2), 160-171. doi:10.1080/17525090802086380.

Cairns, C. M. (2017). China's Weibo Experiment: Social Media (Non-)Censorship and Autocratic Responsiveness. Cornell University, Ithaca, NY. Retrieved from http://www. chrismcairns.com/uploads/3/0/2/2/30226899/cairns_dissertation_draft_3.19.17.pdf.

Cao, C. (2004). China's Scientific Elite. London and New York: Routledge.

Cao, C. (2014). The universal values of science and China's Nobel Prize pursuit. Minerva, 52(2), 141-160.

Cao, C. (2018). GMO China: How Global Debates Transformed China's Agricultural Biotechnology Policies. New York: Columbia University Press.

Carlson, M. (2009). Dueling, dancing, or dominating? Journalists and their sources. Sociology Compass, 3(4), 526-542. 


\section{4}

References

CBCGDF. (2021, January 27). The research department of China Biodiversity Conservation and Green Development Foundation (CBCGDF) suggested not to pass the land use plan of Poyang Lake Water Facility. The Paper. Retrieved from https://www. thepaper.cn/newsDetail_forward_10963047. (In Chinese).

Chai, W. (2011). Unrestricted Biological War: The Conspiracy of GM Foods and Vaccines. Beijing: China Development Press. (In Chinese).

Chan, J. M., \& Qiu, J. L. (2002). China: Media liberalization under authoritarianism. In M. E. Price, B. Rozumilowicz, \& S. G. Verhulst (Eds.), Media Reform: Democratizing the Media, Democratizing the State (pp. 27-46). London and New York: Routledge.

Chang, M. (2013, May 17). Thousands protest Kunming PX plan. Global Times. Retrieved from https://www.globaltimes.cn/content/782252.shtml.

Chen, H., Yang, X., \& Xiang, Z. (2006). The whole process of the debates and policymaking on the Three George Project. Party History World, (2), 24-28. (In Chinese).

Chen, H.-H. (2011). Does legal justice meet scientific fact? A view on law, science and society through the Daubert controversy. Taiwanese Journal for Studies of Science, Technology and Medicine (科技, 醫療與社會), 12, 17-60. (In Chinese).

Chen, Y. (2009). Did the reservoir impoundment trigger the Wenchuan earthquake? Science in China Series D: Earth Sciences, 52(4), 431-433.

Chen, Y. (2010). Mass media, collective action and environmental issues in contemporary China: A case study of the conflict on the building of a waste incineration plant in Fanyu. Journal of International Communication, 32(7), 43-49. (In Chinese).

Chen, Z., Kong, J., \& Geng, M. (2009). Study on public acceptance of nuclear power in Guangdong Province. China Electricity Power Education (s1), 48-52. (In Chinese).

Chin-Fu, H. (2013). Citizen journalism and cyberactivism in China's anti-PX plant in Xiamen, 2007-2009. China: An International Journal, 11(1), 40-54.

China Energy News. (2015, April 6). General status of world's dam building and hydropower development. China Energy News. Retrieved from http://paper.people. com.cn/zgnyb/html/2015-04/06/content_1551213.htm.

China Energy News. (2018). Guangdong coal power installed capacity will decrease to 47.8 by the end of 13th Five-year Plan (2020). Retrieved from http://www.nea.gov. $\mathrm{cn} / 2018-01 / 22 / \mathrm{c} \_136914904 . \mathrm{htm}$.

China Internet Network Information Center (CNNIC). (2005). The 15th Statistical Report on Internet Development in China. Retrieved from Beijing: http://www.cac. gov.cn/files/pdf/hlwtjbg/hlwlfzzkdctjbg015.pdf (In Chinese).

China Internet Network Information Center (CNNIC). (2011). The 27th Statistical Report on Internet Development in China. Retrieved from Beijing: http://www.cac. gov.cn/files/pdf/hlwtjbg/hlwlfzzkdctjbg027.pdf (In Chinese).

China Internet Network Information Center (CNNIC). (2017). The 39th Statistical Report on Internet Development in China. Retrieved from http://www.cnnic.net.cn/ hlwfzyj/hlwxzbg/hlwtjbg/201701/P020170123364672657408.pdf.

Chryssochoidis, G., Strada, A., \& Krystallis, A. (2009). Public trust in institutions and information sources regarding risk management and communication: Towards integrating extant knowledge. Journal of Risk Research, 12(2), 137-185.

Chu, D. (2018, June 10). Russia and China sign nuclear deal. Global Times. Retrieved from http://www.globaltimes.cn/content/1106388.shtml.

Chu, L. L. (1994). Continuity and change in China's media reform. Journal of Communication, 44(3), 4-21.

Collins, H. M. (1981). Introduction: Stages in the empirical programme of relativism. Social studies of science, 11(1), 3-10. 
Conrad, P. (1992). Medicalization and social control. Annual Review of Sociology, 18(1), 209-232.

Cook, G., Pieri, E., \& Robbins, P. T. (2004). "The scientists think and the public feels": Expert perceptions of the discourse of GM food. Discourse \& Society, 15(4), 433-449.

Cook, G., Robbins, P. T., \& Pieri, E. (2006). "Words of mass destruction": British newspaper coverage of the genetically modified food debate, expert and non-expert reactions. Public Understanding of Science, 15(1), 5-29.

Corbett, J. B., \& Durfee, J. L. (2004). Testing public (un)certainty of science media representations of global warming. Science Communication, 26(2), 129-151.

Crawley, C. E. (2007). Localized debates of agricultural biotechnology in community newspapers: A quantitative content analysis of media frames and sources. Science Communication, 28(3), 314-346.

Creswell, J. W. (2007). Qualitative Inquiry and Research Design: Choosing Among Five Approaches (2nd edition). Thousand Oaks, CA: Sage.

Cui, K., \& Shoemaker, S. P. (2018). Public perception of genetically-modified (GM) food: A Nationwide Chinese consumer study. npj Science of Food, 2(1). doi:10.1038/ s41538-018-0018-4.

Cuppen, E., Hisschemöller, M., \& Midden, C. (2009). Bias in the exchange of arguments: The case of scientists' evaluation of lay viewpoints on GM food. Public Understanding of Science, 18(5), 591-606.

Cyranoski, D. (2017, August 3). Authors retract controversial NgAgo gene-editing study. Nature. doi:10.1038/nature.2017.22412.

Da Silva, P. P., \& Rothman, F. D. (2011). Press representation of social movements: Brazilian resistance to the Candonga hydroelectric dam. Journal of Latin American Studies, 43(4), 725-754.

Dai, J., Zeng, F., \& Huang, S. (2015). Risk communication in the shadow of nuclear panic-An analysis based on trust construction. Shanghai Journalism Review, (4), 56-63. (In Chinese).

Dai, Q. (Ed.) (1989). Yangtze, Yangtze: Debates on the Three Gorge Project. Guiyang: Guizhou People's Press. (In Chinese).

Davies, S. R., \& Hara, N. (2017). Public science in a wired world: How online media are shaping science communication. Science Communication, 39(5), 563-568. doi:10.1177/1075547017736892.

Dawson, J. I. (1995). Anti-nuclear activism in the USSR and its successor states: A surrogate for nationalism? Environmental Politics, 4(3), 441-466. doi:10.1080/ 09644019508414215.

Dawson, J. I. (1996). Eco-Nationalism: Anti-Nuclear Activism and National Identity in Russia, Lithuania, and Ukraine. Durham, NC: Duke University Press.

Delborne, J. A. (2008). Transgenes and transgressions: Scientific dissent as heterogeneous practice. Social studies of science, 38(4), 509-541.

Delborne, J. A. (2011). Constructing audiences in scientific controversy. Social Epistemology, 25(1), 67-95.

DeLuca, K. M., Brunner, E., \& Sun, Y. (2016). Constructing public space: Weibo, WeChat, and the transformative events of environmental activism in China. International Journal of Communication, 10, 321-339.

Deng, L., \& Jia, H. (2019). The potentials and limits of stakeholder contestation as macro deliberation: A case study on Wangjiang Four Seniors' contention of Jiangxi Pengze nuclear power project, China. Communication \& Society, 49, 141-174. 
Deng, L., \& Tu, S. (2016). Research on college students' perception of nuclear power and attitudes toward it: A survey at Guangzhou University City. Studies on Science Popularization, 11(1), 69-74. (In Chinese).

Deng, L., Zheng, X., \& Zhou, Z. (2016). Objective and subjective knowledge: Knowledge level of the college students on nuclear energy and its impact toward their attitudes. Science and Society, (2), 85-109. (In Chinese).

Deng, L., Zhou, Z., \& Zheng, X. (2016). Exploring the impact of risk-benefit perception on public acceptance of nuclear power - Based on a survey at Guangzhou University City. Journal of University of South China (Social Science Edition), 17(4), 5-13. (In Chinese).

Deng, Q. (2013, January 31). Hydropower resumed in Nu River of Yunnan, geological experts used to jointly petition for opposition. Time Weekly. Retrieved from http:// news.sina.com.cn/c/sd/2013-01-31/020426162737.shtml.

Deng, X. (1988/1993a). China must secure a position in the world's high-tech fields. In The Collected Works of Deng Xiaoping: Volume 3 (1982-1992) (pp. 279-280). Beijing: People's Publishing House. (In Chinese).

Deng, X. (1988/1993b). Science and technology are the first productivity. In The Collected Works of Deng Xiaoping: Volume 3 (1982-1992) (pp. 274-276). Beijing: People's Publishing House. (In Chinese).

Diao, F. (2021, January 8). Jiangxi publicly announced: Poyang Lake Dam listed as a national key water project; will adjust water supply in dry seasons. The Paper. Retrieved from https://www.thepaper.cn/newsDetail_forward_10705790 (In Chinese)

Ding, J. (2014, July 1). Why are PM2.5 source appointment so different? China Science Daily, p. 1.

Downs, A. (1972). Up and down with ecology: The issue-attention cycle. In P. Peretz (Ed.), The Politics of American Economic Policy Making (pp. 48-59). Armonk, NY and London: M E Sharpe.

Einsiedel, E. F. (2002). GM food labeling: The interplay of information, social values, and institutional trust. Science Communication, 24(2), 209-221.

Ellis, C. (2007). Telling secrets, revealing lives: Relational ethics in research with intimate others. Qualitative Inquiry, 13(1), 3-29.

Epstein, S. (1996). Impure Science: AIDS, Activism, and the Politics of Knowledge. Berkeley, CA: University of California Press.

Epstein, S. (2008). Inclusion: The Politics of Difference in Medical Research. Chicago: University of Chicago Press.

Eyerman, R., \& Jamison, A. (1989). Environmental knowledge as an organizational weapon: The case of Greenpeace. Information (International Social Science Council), 28(1), 99-119.

Fadaee, S. (2016). Understanding Southern Social Movements. London: Routledge.

Fairbank, J. K., \& Goldman, M. (2006). China: A New History. Cambridge, MA: Harvard University Press.

Fan, C. (2010). Public and social should have higher participation in GM staple food policymaking. Democracy and Science, (2), 38-43. (In Chinese).

Fan, F.-T. (2007). East Asian STS: Fox or hedgehog? East Asian Science, Technology and Society, 1(2), 243-247.

Fan, F.-T. (2012). Doing East Asian STS is like feeling an elephant, and that is a good thing. East Asian Science, Technology and Society, 6(4), 487-491.

Fan, J., Jia, H., Peng, G., \& Zhang, F. (2013). A study on scientific controversies in social media - Genetically modified golden rice communication in Chinese Weibo. Journalism \& Communication, (11), 106-116. (In Chinese). 
Fan, X. (2009). Chinese geologist says Zipingpu dam reservoir may have triggered China's deadly quake, calls for investigation. Probe International. Retrieved from https://journal.probeinternational.org/2009/01/26/chinese-geologist-says-zipingp u-dam-reservoir-may-have-triggered-chinas-deadly-quake-calls-investigation/.

Fang, K., \& Repnikova, M. (2017). Demystifying "Little Pink": The creation and evolution of a gendered label for nationalistic activists in China. New Media \& Society, 20(6), 2162-2185. https://doi.org/10.1177/1461444817731923.

Financial Times. (2016, December 21). China province bans GMO crops for five years. Financial Times. Retrieved from https://www.ft.com/content/a221fb5e-c750-11e6-8f299445cac8966f.

Fishery Resources Management Committee (China), \& World Wide Fund for Nature. (2013). Report for 2013 Joint Scientific Inspection in Upper Yangtze River. WWF China. Retrieved from http://www.wwfchina.org/content/press/publication/2013/p ublication-20130814-yangtze.pdf.

Flaherty, D. K. (2011). The Vaccine-Autism Connection: A Public Health Crisis Caused by Unethical Medical Practices and Fraudulent Science. Annals of Pharmacotherapy, 45(10), 1302-1304. doi:10.1345/aph.1Q318.

Flick, U. (2009). An Introduction to Qualitative Research. Thousand Oaks, CA: Sage Publications.

Flipse, S. M., \& Osseweijer, P. (2013). Media attention to GM food cases: An innovation perspective. Public Understanding of Science, 22(2), 185-202.

Foucault, M. (1978). The History of Sexuality, Volume 1: The Will to Knowledge. New York: Vintage.

Frewer, L. J., Lassen, J., Kettlitz, B., Scholderer, J., Beekman, V., \& Berdal, K. G. (2004). Societal aspects of genetically modified foods. Food and Chemical Toxicology, 42(7), 1181-1193. https://doi.org/10.1016/j.fct.2004.02.002.

Frewer, L. J., Miles, S., \& Marsh, R. (2002). The media and genetically modified foods: Evidence in support of social amplification of risk. Risk Analysis, 22(4), 701-711.

Fu, D. (2007). How far can East Asian STS go? A position paper. East Asian Science, Technology and Society, 1(1), 1-14.

Fujigaki, Y., \& Tsukahara, T. (2011). STS Implications of Japan's 3/11 Crisis. East Asian Science, Technology and Society, 5(3), 381-394.

Gahalaut, K., \& Gahalaut, V. K. (2010). Effect of the Zipingpu reservoir impoundment on the occurrence of the 2008 Wenchuan earthquake and local seismicity. Geophysical Journal International, 183(1), 277-285.

Galison, P. (1997). The trading zone: Coordinating action and belief. In Image and Logic: A Material Culture of Microphysics (pp. 781-844). Chicago: University of Chicago Press.

Gamson, W. A., \& Modigliani, A. (1989). Media discourse and public opinion on nuclear power: A constructionist approach. American Journal of Sociology, 95(1), 1-37.

Ge, S., Liu, M., Lu, N., Godt, J. W., \& Luo, G. (2009). Did the Zipingpu Reservoir trigger the 2008 Wenchuan earthquake? Geophysical Research Letters, 36(20). doi:10.1029/2009GL040349.

Giugni, M. (2007). Useless protest? A time-series analysis of the policy outcomes of ecology, antinuclear, and peace movements in the United States, 1977-1995. Mobilization: An International Quarterly, 12(1), 53-77.

Giugni, M., McAdam, D., \& Tilly, C. (1999). How Social Movements Matter. Minneapolis and London: University of Minnesota Press. 
Glaser, B. G., \& Strauss, A. L. (1967). The Discovery of Grounded Theory: Strategies for Qualitative Research. New York: Aldine de Gruyter.

Glaser, B. G., \& Strauss, A. L. (2009). The Discovery of Grounded Theory: Strategies for Qualitative Research. Piscataway, NJ: Transaction Publishers.

Gu, X. (2011). GMO War: The War to Protect China's Food Security in the 21st Century. Beijing: Intellectual Property Press. (In Chinese).

Guo, F. (1987). We must pay importance to studies on environmental impacts of TGP. In F. Tian, F. Lin, \& A. C. Ling (Eds.), Treatises on Macro Policymaking on the Three Gorge Project (pp. 268-273). Changsha: Hunan Science and Technology Press. (In Chinese).

Guo, W. (2014). Nuclear Power, Haze and You. Beijing: Peking University Press. (In Chinese).

Guo, Y., \& Ren, T. (2017). When it is unfamiliar to me: Local acceptance of planned nuclear power plants in China in the post-Fukushima era. Energy Policy, 100, 113-125.

Gupta, N., Fischer, A. R., \& Frewer, L. J. (2012). Socio-psychological determinants of public acceptance of technologies: A review. Public Understanding of Science, 21(7), 782-795.

Gutteling, J. M., Olofsson, A., Fjaestad, B., Kohring, M., Goerke, A., Bauer, M. W., \& Rusanen, T. (2002). Media coverage 1973-1996: Trends and dynamics. In M. W. Bauer \& G. Gaskell (Eds.), Biotechnology - the Making of a Global Controversy (pp. 95-128). Cambridge, UK and New York: Cambridge University Press.

Han, H. (2013). China's policymaking in transition: A hydropower development case. The Journal of Environment \& Development, 22(3), 313-336.

Han, H., Swedlow, B., \& Unger, D. (2014). Policy advocacy coalitions as causes of policy change in china? Analyzing evidence from contemporary environmental politics. Journal of Comparative Policy Analysis: Research and Practice, 16(4), 313334. doi:10.1080/13876988.2013.857065.

Han, S. (2016). Lessons drawn from Lianyungang's anti-nuclear event. Caijing Magazine. Retrieved from https://www.sohu.com/a/110073665_119738 (In Chinese)

Hansen, L. L. G. (2017a). Bargaining science: Negotiating earthquake. In K. E. Brødsgaard (Ed.), Chinese Politics as Fragmented Authoritarianism: Earthquakes, Energy and Environment (pp. 120-134). Abingdon, Oxon and New York: Routledge.

Hansen, L. L. G. (2017b). Triggering Earthquakes in Science, Politics and Chinese Hydropower. (Doctoral thesis). Copenhagen Business School, Copenhagen.

Hao, J., Lin, Z., \& Chung, J. (Eds.). (1994). Changing Central-local Relations in China: Reform and State Capacity. Boulder, CO: Westview Press.

Harwit, E. (2016). WeChat: Social and political development of China's dominant messaging app. Chinese Journal of Communication, 10(3), 312-327. doi:10.1080/ 17544750.2016 .1213757$.

He, G., Liao, M., Shi, C., Zhang, W., \& Zhao, Y. (2017). Investigation report of the Chinese public's understanding of and its attitude to GMOs. In P. Li, G. Chen, \& Y. Zhang (Eds.), Blue Book of China's Society: Analysis and Forecast 2017 (pp. 189-209). Beijing: Social Science Academic Press. (In Chinese).

He, G., Mol, A. P., Zhang, L., \& Lu, Y. (2013). Public participation and trust in nuclear power development in China. Renewable and Sustainable Energy Reviews, 23, $1-11$.

He, G., Mol, A. P. J., Zhang, L., \& Lu, Y. (2014). Nuclear power in China after Fukushima: understanding public knowledge, attitudes, and trust. Journal of Risk Research, 17(4), 435-451. doi:10.1080/13669877.2012.726251. 
He, X. (2011). Who Rule the World: Unraveling the Secret Freemasonry. Beijing: China Book Publishing House. (In Chinese).

He, Z. (2013). Chinese nuclear disaster "highly probable" by 2030. China Dialogue. Retrieved from https://www.chinadialogue.net/article/show/single/en/5808-Chinesenuclear-disaster-highly-probable-by-2-3-.

Herring, R. J. (2008). Opposition to transgenic technologies: Ideology, interests and collective action frames. Nature Reviews Genetics, 9(6), 458-463.

Herring, R. J. (2010a). Epistemic brokerage in the bio-property narrative: Contributions to explaining opposition to transgenic technologies in agriculture. New Biotechnology, 27(5), 614-622.

Herring, R. J. (2010b). Framing the GMO: Epistemic brokers, authoritative knowledge and diffusion of opposition to biotechnology. In R. K. Givan, K. M. Roberts, \& S. A. Soule (Eds.), The Diffusion of Social Movements: Actors, Mechanisms, and Political Effects (pp. 78-96). New York: Cambridge University Press.

Hess, D. J., Breyman, S., Campbell, N., \& Martin, B. (2008). Science, technology, and social movements. In E. J. Hackett, O. Amsterdamska, M. Lynch, \& J. Wajcman (Eds.), The Handbook of Science and Technology Studies (3rd edition) (pp. 473499). Cambridge, MA: The MIT Press.

Hilgartner, S. (2017). Reordering Life: Knowledge and Control in the Genomics Revolution. Cambridge, MA and London: The MIT Press.

Hilgartner, S., \& Bosk, C. L. (1988). The rise and fall of social problems: A public arenas model. American Journal of Sociology, 94(1), 53-78.

Hirai, N. (2011). Nuclear Staff's Last Testament: Disaster Report 15 Years Before Fukushima Accident. Beijing: People's Literature Press. (In Chinese).

Ho, M.-S. (2003). The politics of anti-nuclear protest in Taiwan: A case of partydependent movement (1980-2000). Modern Asian Studies, 37(3), 683-708.

Ho, P., Vermeer, E. B., \& Zhao, J. H. (2006). Biotechnology and food safety in China: Consumers' acceptance or resistance? Development and Change, 37(1), 227-254.

Hong, S. (2008). The Hwang Scandal that "shook the world of science". East Asian Science, Technology and Society, 2(1), 1-7.

Hong, S. (2011). Where is the nuclear nation going? Hopes and fears over nuclear energy in South Korea after the Fukushima disaster. East Asian Science, Technology and Society, 5(3), 409-415.

Hou, X. (1987). TGP must consider ecological, environmental and resource issues. In F. Tian, F. Lin, \& C. Ling (Eds.), Treatises on Macro Policymaking on the Three Gorge Project (pp. 268-273). Changsha: Hunan Science and Technology Press. (In Chinese).

Hu, A. Y. (2006). Swimming Against the Tide: Tracing and Locating Chinese Leftism Online. (Masters thesis). School of Communication-Simon Fraser University, Vancouver, Canada.

Hu, H., Li, X., Nguyen, A. D., \& Kavan, P. (2015). A critical evaluation of waste incineration plants in Wuhan (China) based on site selection, environmental influence, public health and public participation. International Journal of Environmental Research and Public Health, 12(7), 7593-7614. doi:10.3390/ijerph120707593.

$\mathrm{Hu}, \mathrm{X}$. (2014). Wang Yinan: I am astonished by the public opinion about inland nuclear power. IFeng Finance. Retrieved from http://finance.ifeng.com/a/20140806/ 12873200_0.shtml. (In Chinese).

Huang, J., Hu, R., Rozelle, S., \& Pray, C. (2005). Insect-resistant GM rice in farmers' fields: Assessing productivity and health effects in China. Science, 308(5722), 688-690. doi:10.1126/science. 1108972 . 
Huang, J., Qiu, H., Bai, J., \& Pray, C. (2006). Awareness, acceptance of and willingness to buy genetically modified foods in Urban China. Appetite, 46(2), 144-151.

Huang, L., Zhou, Y., Han, Y., Hammitt, J. K., Bi, J., \& Liu, Y. (2013). Effect of the Fukushima nuclear accident on the risk perception of residents near a nuclear power plant in China. Proceedings of the National Academy of Sciences of the United States of America, 110(49), 19742.

Huang, R., \& Sun, X. (2015). Issues and place: the hyperlink network of homeowner forums and implications for collective action. Chinese Journal of Communication, 8(2), $119-141$.

Huang, R., \& Sun, X. (2016). Dynamic preference revelation and expression of personal frames: How Weibo is used in an anti-nuclear protest in China. Chinese Journal of Communication, 9(4), 385-402. doi:10.1080/17544750.2016.1206030.

Huang, R., \& Yip, N.-M. (2012). Internet and activism in urban China: A case study of protests in Xiamen and Panyu. Journal of Comparative Asian Development, 11(2), 201-223.

Huang, X., \& Zhan, Y. (2010). Scientific content analysis of scientific researchers' blog: Blogs in ScienceNet.cn as examples. Studies on Science Popularization, 5(2), 24-29. (In Chinese).

IHEP. (2018, February 28). Four IHEP scientists elected as 13th NPC deputies and CPPCC delegates. CAS Institute of High-energy Physics (IHEP). Retrieved from http://www.ihep.ac.cn/xwdt/gnxw/2018/201802/t20180228_4968586.html.

International Nuclear Safety Advisory Group. (1999). Basic Safety Principles for Nuclear Power Plants. International Atomic Energy Agency (IAEA). Retrieved from https://www-pub.iaea.org/MTCD/Publications/PDF/P082_scr.pdf.

Irwin, A. (1995). Citizen Science: A Study of People, Expertise and Sustainable Development. London and New York: Routledge.

Irwin, A. (2001). Constructing the scientific citizen: Science and democracy in the biosciences. Public Understanding of Science, 10(1), 1-18.

Irwin, A. (2014). From deficit to democracy (re-visited). Public Understanding of Science, 23(1), 71-76.

Irwin, A., \& Wynne, B. (Eds.). (1996/2003). Misunderstanding Science?: The Public Reconstruction of Science and Technology. Cambridge, UK: Cambridge University Press.

ISAAA. (2021). Global Status of Commercialized Biotech/GM Crops in 2019: Biotech Crop Adoption Surges as Economic Benefits Accumulate in 24 Years. Ithaca, NY: The International Service for the Acquisition of Agri-biotech Applications (ISAAA).

Jackson, J. (2012). Earthquake hazards and large dams in Western China. Probe International. Retrieved from http://probeinternational.org/library/wp-content/uploa ds/2012/04/JohnJacksonFinalReport.pdf.

Jacos, A. (2012, March 15). Party ousts Chinese regional chief, halting his rise. The New York Times. Retrieved from https://www.nytimes.com/2012/03/16/world/asia/ bo-xilai-ousted-from-communist-party-post-in-china.html.

Jasanoff, S. (1996). Beyond epistemology: Relativism and engagement in the politics of science. Social Studies of Science, 26(2), 393-418.

Jasanoff, S. (2004a). The idiom of co-production. In S. Jasanoff (Ed.), States of Knowledge: The Co-production of Science and the Social Order (pp. 1-12). London and New York: Routledge.

Jasanoff, S. (2004b). Ordering knowledge, ordering society. In S. Jasanoff (Ed.), States of Knowledge: The Co-production of Science and the Social Order (pp. 13-45). London and New York: Routledge. 
Jasanoff, S. (2005). In the democracies of DNA: Ontological uncertainty and political order in three states. New Genetics and Society, 24(2), 139-155.

Jasanoff, S. (2011a). Cosmopolitan knowledge: Climate science and global civic epistemology. In J. S. Dryzek, R. B. Norgaard, \& D. Schlosberg (Eds.), The Oxford Handbook of Climate Change and Society (pp. 129-143). Oxford, UK: Oxford University Press.

Jasanoff, S. (2011b). Designs on Nature: Science and Democracy in Europe and the United States. Princeton, NJ and Oxford, UK: Princeton University Press.

Jasanoff, S. (2017). Science and democracy. In U. Felt, R. Fouche, C. A. Miller, \& L. Smith-Doerr (Eds.), Handbook of Science and Technology Studies (4th edition) (pp. 259-287). Cambridge, MA: The MIT Press.

Jasanoff, S., \& Kim, S.-H. (2009). Containing the atom: Sociotechnical imaginaries and nuclear power in the United States and South Korea. Minerva, 47(2), 119-146.

Jasanoff, S., \& Kim, S.-H. (2013). Sociotechnical imaginaries and national energy policies. Science as Culture, 22(2), 189-196.

Jasanoff, S., \& Kim, S.-H. (2015). Dreamscapes of Modernity: Sociotechnical Imaginaries and the Fabrication of Power. Chicago: University of Chicago Press.

Jasper, J. (1992). Three nuclear energy controversies. In D. Nelkin (Ed.), Controversy: Politics of Technical Decisions (pp. 91-111). Newbury Park, CA: Sage.

Jia, H. (2007). Global warming, science communication and public participation: An analysis of climate change communication in China. Studies on Science Popularization, 2(3), 39-45. (In Chinese).

Jia, H. (2014a). Para-xylene plants face uphill struggle for acceptance in China. Chemistry World, 11(4). Retrieved from https://www.chemistryworld.com/news/para -xylene-plants-face-uphill-struggle-for-acceptance-in-china/7275.article.

Jia, H. (2014b). Pollution research sparks car control debate in China. Chemistry World, 11(3). Retrieved from http://www.rsc.org/chemistryworld/2014/01/pollu tion-research-sparks-car-control-debate-china.

Jia, H. (2016a, October 31). Ambitious nuclear plan backfired in China. Chemistry World, https://www.chemistryworld.com/news/new-nuclear-faces-public-suspicion-inchina-/1017622.article. Retrieved from https://www.chemistryworld.com/news/newnuclear-faces-public-suspicion-in-china-/1017622.article.

Jia, H. (2016b). Debate on China's super collider heats up. Nature Index. Retrieved from https://www.natureindex.com/news-blog/debate-on-chinas-super-collider-heats-up.

Jia, H., Fan, J., \& Peng, G. (2014). Public engagement of science and social media's challenges to science communication. Studies on Science Popularization, 9(2), 1119. (In Chinese).

Jia, H., Fan, J., \& Yan, J. (2015). The interaction of knowledge, trust and value in risk communication: Examining the example of GMO controversy. Contemporary Communication, (3), 99-101. (In Chinese).

Jia, H., Jayaraman, K. S., \& Louët, S. (2004). China ramps up efforts to commercialize GM rice. Nature Biotechnology, 22, 642. doi:10.1038/nbt0604-642.

Jia, H., Lewenstein, B. V., \& Yan, J. (2017). When scientific uncertainty came to media: Interpretative flexibility and Beijing's air pollution controversy. Paper presented at the 2017Annual Conference of International Communication Association, San Diego, CA.

Jia, H., \& Li, X. (2016). How has the GMO issue split Chinese society? The Intellectual. Retrieved from http://news.sina.com.cn/z1/2016-07-03/doc-ifxtsatm1247138. shtml (In Chinese). 


\section{References}

Jia, H., \& Liu, L. (2014). Unbalanced progress: The hard road from science popularisation to public engagement with science in China. Public Understanding of Science, 23 (1), 32-37.

Jia, H., \& Liu, Z. (2009). The separation of propaganda about science research and mass media: Quantitative and qualitative analysis of science institutions in China. Studies on Science Popularization, 4(1), 17-23. (In Chinese).

Jia, H., \& Wang, L. (2017). Peering into China's thick haze of air pollution. Chemical and Engineering News, 95(4), 19-22.

Jiang, T. (2013). The historical contribution of Mao Zedong to China's strategic nuclear weapon. People.com.cn. Retrieved from http://dangshi.people.com.cn/n/ 2013/1113/c85037-23527142-4.html (In Chinese)

Jiang, X. (2014). Cultural principle for contemporary science controversy: With GM staple food as example. Book City, (4), 8-9. (In Chinese).

Jin, J. (2017). Misunderstanding in the public opinions about GMOs. Science and Technology Journalism Studies, (2), 41-45. (In Chinese).

Johnson, T., Lora-Wainwright, A., \& Lu, J. (2018). The quest for environmental justice in China: citizen participation and the rural-urban network against Panguanying's waste incinerator. Sustainability Science, 13(3), 733-746. doi:10.1007/s11625-018-0545-6.

Joppke, C. (1991). Social movements during cycles of issue attention: The decline of the anti-nuclear energy movements in West Germany and the USA. British Journal of Sociology, 42(1), 43-60.

Kahan, D. M., Jenkins-Smith, H., \& Braman, D. (2011). Cultural cognition of scientific consensus. Journal of Risk Research, 14(2), 147-174.

Kasperson, R. E., Berk, G., Pijawka, D., Sharaf, A. B., \& Wood, J. (1980). Public opposition to nuclear energy: Retrospect and prospect. Science, Technology, \& Human Values, 5(2), 11-23.

Kelly, D. (2015). Ideology, society, and the origins of nuclear power in Japan. East Asian Science, Technology and Society, 9(1), 47-64.

Kerr, R. A., \& Stone, R. (2009). A human trigger for the great quake of Sichuan? Science, 323(5912), 322-322.

Khagram, S. (2004). Dams and Development: Transnational Struggles For Water and Power. Ithaca, NY: Cornell University Press.

Kim, T.-H. (2008). How could a scientist become a national celebrity? Nationalism and Hwang Woo-Suk scandal. East Asian Science, Technology and Society, 2(1), $27-45$.

Kim, Y., Kim, M., \& Kim, W. (2013). Effect of the Fukushima nuclear disaster on global public acceptance of nuclear energy. Energy Policy, 61, 822-828.

King, G., Pan, J., \& Roberts, M. E. (2013). How censorship in China allows government criticism but silences collective expression. American Political Science Review, 107(2), 326-343.

Kitschelt, H. P. (1986). Political opportunity structures and political protest: Anti-nuclear movements in four democracies. British Journal of Political Science, 16(1), 57-85.

Klose, C. D. (2008, December 2008). The 2008 M7.9 Wenchuan earthquake: Result of local and abnormal mass imbalances? Paper presented at the American Geophysical Union Fall Meeting Abstracts, 89(53), U21C-08, San Francisco, California.

Klose, C. D. (2012). Evidence for anthropogenic surface loading as trigger mechanism of the 2008 Wenchuan earthquake. Environmental Earth Sciences, 66(5), 1439-1447.

Klose, C. D. (2013). Mechanical and statistical evidence of the causality of humanmade mass shifts on the Earth's upper crust and the occurrence of earthquakes. Journal of Seismology, 17(1), 109-135. 
Lam, H.-M., Remais, J., Fung, M.-C., Xu, L., \& Sun, S. S.-M. (2013). Food supply and food safety issues in China. The Lancet, 381(9882), 2044-2053.

Lampton, D. M. (2015). Xi Jinping and the National Security Commission: Policy coordination and political power. Journal of Contemporary China, 24 (95), 759-777.

Lang, G., \& Xu, Y. (2013). Anti-incinerator campaigns and the evolution of protest politics in China. Environmental Politics, 22(5), 832-848.

Lee, Y.-C. B. (2013a). Development as governing tactics: The Three Gorges Dam and the reproduction and transformation of state power in Dengist China. (Doctoral thesis). The University of Chicago, Chicago. (UMI 3557419)

Lee, Y.-C. B. (2013b). Global capital, national development and transnational environmental activism: Conflict and the Three Gorges Dam. Journal of Contemporary Asia, 43(1), 102-126.

Lee, Y.-C. B. (2014). Water power: The "hydropower discourse" of China in an age of environmental sustainability. ASIANetwork Exchange: A Journal for Asian Studies in the Liberal Arts, 21(1), 1-10.

Leem, S. Y., \& Park, J. H. (2008). Rethinking women and their bodies in the age of biotechnology: Feminist commentaries on the Hwang Affair. East Asian Science, Technology and Society, 2(1), 9-26.

Lei, X. (2011). Possible roles of the Zipingpu Reservoir in triggering the 2008 Wenchuan earthquake. Journal of Asian Earth Sciences, 40(4), 844-854.

Lei, X., Ma, S., Wen, X., Su, J.-R., \& Du, F. (2008). Integrated analysis of stress and regional seismicity by surface loading: A case study of Zipingpu Reservoir. Seismology and Geology, 30(4), 1046-1064.

Lei, Y.-W. (2011). The political consequences of the rise of the Internet: Political beliefs and practices of Chinese netizens. Political Communication, 28(3), 291-322.

Lei, Y.-W. (2018). The Contentious Public Sphere: Law, Media, and Authoritarian Rule in China. Princeton, NJ and Oxford, UK: Princeton University Press.

Leibold, J. (2011). Blogging alone: China, the internet, and the democratic illusion? The Journal of Asian Studies, 70(4), 1023-1041.

Levidow, L., \& Boschert, K. (2011). Segregating GM crops: Why a contentious "risk" issue in Europe? Science as Culture, 20(2), 255-279.

Lewenstein, B. V. (1995). From fax to facts: Communication in the cold fusion saga. Social Studies of Science, 25(3), 403-436.

Lewenstein, B. V. (2017). Science controversies: Can the science of science communication provide management guidance or only analysis? In K. H. Jamieson, D. Kahan, \& D. A. Scheufele (Eds.), Oxford Handbook on the Science of Science Communication (pp. 73-78). New York, NY: Oxford University Press.

Li, B. (2016). Comments on Sima Nan. Travel and Observation (WeChat public account). Retrieved from http://www.szhgh.com/Article/opinion/xuezhe/2016-06-29/ 116316.html (In Chinese).

Li, J. (2016, November 28). China's eco-warriors make last stand against Poyang Lake dam. South China Morning Post. Retrieved from http://www.scmp.com/news/china/poli cies-politics/article/2049630/chinas-eco-warriors-make-last-stand-against-poyang-lake.

Li, Y. (2013). Policy study on China's nuclear power development and safety risk. In The International Forum for Clean Energy (Macao) (Ed.), Blue Book of Clean Energy: Annual Report on Development of International Clean Energy (pp. 62-87). Beijing: Social Science Academic Press. (In Chinese). 


\section{References}

Li, Y. (2013, October 31). Vice Agricultural Minister Li Jiayang was hired by American firm to promote GMOs. Beijing Youth Daily. Retrieved from http://finance.sina.com. cn/china/20131031/031017172171.shtml (In Chinese).

Li, Y., \& Jin, J. (2019). Polarization of online public opinion and its impact on scientists' intention to engage the public. Modern Communication, 41(3), 32-37,42. (In Chinese).

Liang, D., Guo, R., \& Wang, L. (2019). Characteristics and countermeasures of NIMBY in waste incineration project in China. Tianjin Science and Technology, 46(4), 92-95. (In Chinese).

Lieberthal, K., \& Lampton, D. M. (1992). Bureaucracy, Politics, and Decision Making in Post-Mao China. Berkeley, CA; Los Angeles; Oxford, UK: University of California Press.

Lin, T.-C. (2007). Environmental NGOs and the anti-dam movements in China: A social movement with Chinese characteristics. Issues \& Studies, 43(4), 149-184.

Lin, Y.-P. (2011). After death of some electronic workers: The health risk controversies of organic solvents. Taiwanese Journal for Studies of Science, Technology and Medicine, (12), 61-112. (In Chinese).

Lincoln, Y. S., \& Guba, E. G. (1985). Naturalistic inquiry. In N. K. Denzin \& Y. S. Lincoln (Eds.), The SAGE Handbook of Qualitative Research (1st edition) (pp. 289-331). Beverly Hills, CA: Sage Publications.

Listerman, T. (2010). Framing of science issues in opinion-leading news: International comparison of biotechnology issue coverage. Public Understanding of Science, 19(1), $5-15$.

Liu, J. (2004, December 9). GM Rice: The interest suspense behind staple food for 1.3 billion people. Southern Weekend, p. 1. Retrieved from http://news.sina.com.cn/c/ 2004-12-09/12104480154s.shtml (In Chinese).

Liu, J. (2013). How Tiger Leaping Gorge was saved. China Dialogue. Retrieved from https://www.chinadialogue.net/culture/5923-How-Tiger-Leaping-Gorge-was-saved/en.

Liu, J. (2016). Digital media, cycle of contention, and sustainability of environmental activism: the case of anti-PX protests in China. Mass Communication and Society, 19(5), 604-625.

Liu, W. (2011, March 24). "Rumored salt" and crowd. Time Weekly. Retrieved from http://news.ifeng.com/opinion/sixiangpinglun/detail_2011_03/24/5339867_0.shtml.

Lofland, J., Snow, D., Anderson, L., \& Lofland, L. H. (2006). Analyzing Social Settings: A Guide to Qualitative Observational Research (4th edition). Belmont, CA: Wadsworth Publishing.

Lu, J., \& Qiu, Y. (2013). Microblogging and social change in China. Asian Perspective, $37(3), 305-331$.

Lü, L. (2009). The value of the use of biotechnology: public views in China and Europe. Public Understanding of Science, 18(4), 481-492.

Lü, X., \& Zhao, Y. (2009). China's modernity, mass media, and the reconstruction of publicity. Paper presented at the Fudan Forum: Communication and China. Retrieved from https://wap.cnki.net/touch/web/Conference/Article/FDXX200912001036 (In Chinese).

Luo, H. (2014, 6-20). Nuclear power is not a necessary demon: An interview with Wang Yinan, a senior research fellow at the Development Research Center of the State Council. Southern Weekend. Retrieved from http://news.ifeng.com/a/20140621/ 40835121_0.shtml (In Chinese).

Ma, L. (2012). Eight Thoughts in Contemporary China. Beijing: Social Sciences Academic Press. (In Chinese). 
Ma, Y., \& Zhao, Y. (2009). Public satisfaction with food safety and determining factors in Beijing. Beijing Social Science, (3), 17-20. (In Chinese).

Magee, D., \& McDonald, K. (2006). Beyond Three Gorges: Nu River hydropower and energy decision politics in China. Asian Geographer, 25(1-2), 39-60.

Marks, L. A., Kalaitzandonakes, N., Allison, K., \& Zakharova, L. (2003). Media coverage of agrobiotechnology: Did the butterfly have an effect? Journal of Agribusiness, 21 (1), 1-20.

Marks, L. A., Kalaitzandonakes, N., Wilkins, L., \& Zakharova, L. (2007). Mass media framing of biotechnology news. Public Understanding of Science, 16(2), 183-203.

Martin, B. (1998). Strategies for dissenting scientists. Journal of Scientific Exploration, 12(4), 605-616.

Martin, B. (2004). Dissent and heresy in medicine: Models, methods, and strategies. Social Science \& Medicine, 58(4), 713-725.

Martin, B. (2010). How to attack a scientific theory and get away with it (usually): The attempt to destroy an origin-of-AIDS hypothesis. Science as Culture, 19(2), 215-239.

Martin, B. (2014). The Controversy Manual. Sparsnäs, Sweden: Irene Publishing.

Martin, B., \& Groth, E. (1991). Scientific Knowledge in Controversy: The Social Dynamics of the Fluoridation Debate. Albany, NY: State University of New York Press.

Masood, S., \& Buckley, C. (2013, November 26). Pakistan breaks ground on nuclear plant project with China. The New York Times, p. A12. Retrieved from https:// www.nytimes.com/2013/11/27/world/asia/pakistan-breaks-ground-on-nuclear-p ower-plant-project-with-china.html.

Maxwell, J. A. (1996). Qualitative Research Design: An Interactive Approach. Thousand Oaks, CA: Sage.

Mazur, A. (1981). Media coverage and public opinion on scientific controversies. Journal of Communication, 31(2), 106-115.

Mazur, A. (1990). Nuclear power, chemical hazards, and the quantity of reporting. Minerva, 28(3), 294-323.

Mazur, A. (2016). How did the fracking controversy emerge in the period 2010-2012? Public Understanding of Science, 25(2), 207-222.

McAdam, D. (1982). Political Process and the Development of Black Insurgency, 1930-1970. Chicago: University of Chicago Press.

McAdam, D., Tarrow, S., \& Tilly, C. (2001). Dynamics of Contention. Cambridge, UK and New York: Cambridge University Press.

McCarthy, J. D., \& Zald, M. N. (1973). The Trend of Social Movements in America: Professionalization and Resource Mobilization. Morristown, NJ: General Learning Corporation.

McCarthy, J. D., \& Zald, M. N. (1977). Resource mobilization and social movements: A partial theory. American Journal of Sociology, 82(6), 1212-1241.

McCormick, S. (2006). The Brazilian anti-dam movement: Knowledge contestation as communicative action. Organization \& Environment, 19(3), 321-346.

McCormick, S. (2007a). Democratizing science movements: A new framework for mobilization and contestation. Social Studies of Science, 37(4), 609-623. doi:10.1177/0306312707076598.

McCormick, S. (2007b). The governance of hydro-electric dams in Brazil. Journal of Latin American Studies, 39(2), 227-261. Retrieved from http://www.jstor.org/stable/ 4491810.

McCormick, S. (2010). Damming the Amazon: Local movements and transnational struggles over water. Society and Natural Resources, 24(1), 34-48. 


\section{References}

McCully, P. (1996). Silenced Rivers: The Ecology and Politics of Large Dams. London: Zed Books.

McInerney, C., Bird, N., \& Nucci, M. (2004). The flow of scientific knowledge from lab to the lay public: The case of genetically modified food. Science Communication, 26(1), 44-74.

Mei, Y. (2021). Over 1.7 billion investment, Wujiang waste incinerator Phase II to be finished by the end of 2021. solidwaste.com.cn. Retrieved from http://www.solidwa ste.com.cn/news/319658.html (In Chinese).

Mertha, A. (2008). China's Water Warriors: Citizen Action and Policy Change. Ithaca, NY: Cornell University Press.

Mertha, A. (2009). "Fragmented authoritarianism 2.0": Political pluralization in the Chinese policy process. The China Quarterly, 200, 995-1012.

Mertha, A., \& Brødsgaard, K. E. (2017). Introduction. In K. E. Brødsgaard (Ed.), Chinese Politics as Fragmented Authoritarianism: Earthquakes, Energy and Environment (pp. 1-14). Abingdon, Oxon; New York: Routledge.

Meyer, D. S., \& Minkoff, D. C. (2004). Conceptualizing political opportunity. Social Forces, 82(4), 1457-1492.

Meyer, D. S., \& Staggenborg, S. (1996). Movements, countermovements, and the structure of political opportunity. American Journal of Sociology, 101(6) 1628-1660.

Miller, G. T. (2007). Living in the Environment (13th edition). Belmont, CA: Cengage Learning.

Miller, H. L. (1996). Science and Dissent in Post-Mao China: The Politics of Knowledge. Seattle, WA: University of Washington Press.

Moore, K. (2009). Disrupting Science: Social Movements, American Scientists, and the Politics of the Military, 1945-1975. Princeton, NJ: Princeton University Press.

Moore, M. (2012, March 15). Top Chinese leader Bo Xilai purged, one day after criticism. The Daily Telegraph. Retrieved from https://www.telegraph.co.uk/news/worldnews/asia/ china/9144860/Top-Chinese-leader-Bo-Xilai-purged-one-day-after-criticism.html.

Moore, S. M. (2014). Modernisation, authoritarianism, and the environment: the politics of China's South-North Water Transfer Project. Environmental Politics, 23(6), 947-964.

Motta, R. (2014). Social disputes over GMOs: An overview. Sociology Compass, 8(12), $1360-1376$.

Nathan, A. J. (1986). Chinese Democracy. Berkeley, CA and Los Angeles: University of California Press.

National Bureau of Statistics of China. (1981). Statistical Bulletin of National Economy and Social Development in 1980. Retrieved from http://www.stats.gov.cn/tjsj/ tjgb/ndtjgb/qgndtjgb/200203/t20020331_29993.html.

National Bureau of Statistics of China. (1998). Statistical Bulletin of National Economy and Social Development in 1997. Retrieved from http://www.stats.gov.cn/tjsj/ tjgb/ndtjgb/qgndtjgb/200203/t20020331_30011.html.

National Bureau of Statistics of China. (2019). Statistical Bulletin of National Economy and Social Development in 2018. Retrieved from http://www.stats.gov.cn/tjsj/ zxfb/201902/t20190228_1651265.html.

National Energy Administration. (2017). China's nuclear reactors under construction lead the world. Chinese Government Web. Retrieved from http://www.gov.cn/xinwen/ 2017-10/31/content_5235794.htm\#2.

Nelkin, D. (1971). Nuclear Power and its Critics: The Cayuga Lake Controversy. Ithaca, NY: Cornell University Press. 
Nelkin, D. (1987). Controversies and the authority of science. In H. T. Engelhardt \& A. L. Caplan (Eds.), Scientific Controversies: Case Studies in the Resolution and Closure of Disputes in Science and Technology (pp. 283-294). New York: Cambridge University Press.

Nelkin, D. (1995). Science controversies: The dynamics of public disputes in the United States. In S. Jasanoff, G. E. Markle, J. C. Petersen, \& T. Pinch (Eds.), Handbook of Science and Technology Studies (1st edition) (pp. 444 456). Thousand Oaks, CA: Sage Publications.

Nisbet, E. C., Cooper, K. E., \& Garrett, R. K. (2015). The partisan brain: How dissonant science messages lead conservatives and liberals to (dis)trust science. The Annals of the American Academy of Political and Social Science, 658(1), 36-66.

Nisbet, M. C., \& Huge, M. (2006). Attention cycles and frames in the plant biotechnology debate: Managing power and participation through the press/policy connection. The Harvard International Journal of Press/Politics, 11(2), 3-40.

Nisbet, M. C., \& Lewenstein, B. V. (2002). Biotechnology and the American media: The policy process and the elite press, 1970 to 1999. Science Communication, 23(4), 359-391.

Nucci, M. L., \& Kubey, R. (2007). "We begin tonight with fruits and vegetables": Genetically modified food on the evening news 1980-2003. Science Communication, 29(2), 147-176.

Obar, J. A., \& Wildman, S. S. (2015). Social media definition and the governance challenge: An introduction to the special issue. Telecommunications Policy, 39(9), 745-750.

Opp, K.-D. (1986). Soft incentives and collective action: Participation in the antinuclear movement. British Journal of Political Science, 16(1), 87-112.

Ouyang, H. (2010). China safety and better-off index in 2009-2010 is 69.4: A general survey on Chinese safety perception. Better-off, (7), 56-59. (In Chinese).

Palmer, D. A. (2007). Qigong Fever: Body, Science, and Utopia in China. New York: Columbia University Press.

Party Committee of CNNC. (2017). Make the national name card for nuclear power's going global strategy. Qiushi, (1), 54-56. (In Chinese).

Pietz, D. A. (2015). Yellow River: The Problem of Water in Modern China. Cambridge, MA: Harvard University Press.

Pin, R. R., \& Gutteling, J. M. (2009). The development of public perception research in the genomics field. Science Communication, 31(1), 57-83.

Pin, R. R., Gutteling, J. M., \& Kuttschreuter, M. (2009). Determinants of reactions to gene technology: a generic approach. New Genetics and Society, 28(1), 51-65.

Pinch, T. J. (2015). Scientific controversies. In J. D. Wright (Ed.), International Encyclopedia of the Social \& Behavioral Sciences (2nd edition) (pp. 281-286). Amsterdam: Elsevier.

Pinch, T. J., \& Leuenberger, C. (2006). Researching scientific controversies: The S\&TS perspective. Paper presented at the Proceedings of EASTS Conference "Science, Controversy and Democracy", National Taiwan University, Taiwan.

Pray, C. E., Huang, J. K., Hu, R. F., \& Rozelle, S. (2002). Five years of Bt cotton in China - the benefits continue. Plant Journal, 31(4), 423-430. doi:10.1046/j.1365313X.2002.01401.X.

Price, M. E., Rozumilowicz, B., \& Verhulst, S. G. (2003). Media Reform: Democratizing the Media, Democratizing the State. London and New York: Routledge. 


\section{References}

Priest, S. H. (2001). Misplaced faith communication variables as predictors of encouragement for biotechnology development. Science Communication, 23(2), 97-110.

Pritchard, S. B. (2011). Confluence: The Nature of Technology and the Remaking of the Rhône. Cambridge, MA and London: Harvard University Press.

Pritchard, S. B. (2012). From hydroimperialism to hydrocapitalism: "French" hydraulics in France, North Africa, and beyond. Social studies of science, 42(4), 591-615. doi: $10.1177 / 0306312712443018$.

Qian, G., \& Bandurski, D. (2011). China's emerging public sphere: The impact of media commercialization, professionalism, and the Internet in an era of transition. In S. L. Shirk (Ed.), Changing Media, Changing China (pp. 38-76). Oxford, UK and New York: Oxford University Press.

Qiu, H., Huang, J., Pray, C., \& Rozelle, S. (2012). Consumers' trust in government and their attitudes towards genetically modified food: empirical evidence from China. Journal of Chinese Economic \& Business Studies, 10(1), 67-87.

Rainie, L., Funk, C., \& Anderson, M. (2015). How Scientists Engage the Public. Pew Research Center. Retrieved from http://www.pewinternet.org/2015/02/15/how-scien tists-engage-public/.

Rauchfleisch, A., \& Schäfer, M. S. (2015). Multiple public spheres of Weibo: A typology of forms and potentials of online public spheres in China. Information, Communication \& Society, 18(2), 139-155.

Ren, L., Gao, H., \& Huang, L. (2016). On Chinese public awareness and attitudes towards genetically modified technology. Studies on Science Popularization, 11(3), 59-64. (In Chinese).

Rogers, S., Barnett, J., Webber, M., Finlayson, B., \& Wang, M. (2016). Governmentality and the conduct of water: China's South-North Water Transfer Project. Transactions of the Institute of British Geographers, 41(4), 429-441.

Rogers, S., \& Crow-Miller, B. (2017). The politics of water: A review of hydropolitical frameworks and their application in China. Wiley Interdisciplinary Reviews: Water, 4(6). doi:10.1002/wat2.1239.

Rosa, E. A., \& Dunlap, R. E. (1994). Poll trends: Nuclear power: Three Decades of Public Opinion. Public Opinion Quarterly, 58(2), 295-324.

Rudig, W. (2014). Antinuclear power movements (In general). In D. A. Snow, D. D. Porta, B. Klandermans, \& D. McAdam (Eds.), The Wiley-Blackwell Encyclopedia of Social and Political Movements. Hoboken, NJ: John Wiley \& Sons.

Saich, T. (2011). Governance and Politics of China (3rd edition). Basingstoke, UK: Palgrave Macmillan.

Schäfer, M. S. (2011). Sources, characteristics and effects of mass media communication on science: A review of the literature, current trends and areas for future research. Sociology Compass, 5(6), 399-412.

Schmid, S. D. (2004). Transformation discourse: Nuclear risk as a strategic tool in late Soviet politics of expertise. Science, Technology \& Human Values, 29(3), 353-376.

Schmid, S. D. (2015). Producing Power: The Pre-Chernobyl History of the Soviet Nuclear Industry. Cambridge, MA: MIT Press.

Schuldt, J. P., Konrath, S. H., \& Schwarz, N. (2011). "Global warming" or "climate change"? Whether the planet is warming depends on question wording. Public Opinion Quarterly, 75(1), 115-124.

Schurman, R., \& Munro, W. (2006). Ideas, thinkers, and social networks: The process of grievance construction in the anti-genetic engineering movement. Theory \& Society, 35(1), 1-38. 
Schurman, R., \& Munro, W. A. (2010). Fighting for the Future of Food: Activists Versus Agribusiness in the Struggle over Biotechnology. Minneapolis, MN: University of Minnesota Press.

Schutz, A., \& Luckmann, T. (1973). The Structure of the Life-World. Evanston, IL: Northwestern University Press.

Scoones, I. (2008). Mobilizing against GM crops in India, South Africa and Brazil. Journal of Agrarian Change, 8(2-3), 315-344.

Segev, E., \& Baram-Tsabari, A. (2012). Seeking science information online: Data mining Google to better understand the roles of the media and the education system. Public Understanding of Science, 21(7), 813-829.

Séralini, G.-E., Clair, E., Mesnage, R., Gress, S., Defarge, N., Malatesta, M., ... De Vendômois, J. S. (2012). RETRACTED: Long term toxicity of a Roundup herbicide and a Roundup-tolerant genetically modified maize. Food and Chemical Toxicology, 50(11) 4221-4231.

Shackley, S., \& Wynne, B. (1996). Representing uncertainty in global climate change science and policy: Boundary-ordering devices and authority. Science, Technology \& Human Values, 21(3), 275-302.

Shambaugh, D. L. (2008). China's Communist Party: Atrophy and Adaptation. Berkeley, CA; Los Angeles and Oxford, UK: University of California Press.

Shi, J. (2009, May 12). Geologist defies ban to discuss possible link between the disaster and a hydroelectric dam. South China Morning Post. p. 9.

Shi, Y., \& Rao, Y. (2010). China's research culture. Science, 329(5996), 1128-1128.

Shirt, S. L. (Ed.) (2011). Changing Media, Changing China. Oxford, UK and New York: Oxford University Press.

Sieber, J. E. (1997). Planning ethically responsible research. In L. Bickman \& D. J. Rog (Eds.), The Sage Handbook of Applied Social Research Methods (pp. 127-156). Thousand Oaks, CA: Sage.

Sieber, J. E. (2009). Planning ethically responsible research. In L. Bickman \& D. J. Rog (Eds.), The SAGE Handbook of Applied Social Research Methods (2nd edition) (pp. 106-142). Thousand Oaks, CA: Sage.

Siegrist, M. (1999). A causal model explaining the perception and acceptance of gene technology. Journal of Applied Social Psychology, 29(10), 2093-2106.

Siegrist, M., Cvetkovich, G., \& Roth, C. (2000). Salient value similarity, social trust, and risk/benefit perception. Risk Analysis, 20(3), 353-362.

Siegrist, M., \& Visschers, V. H. (2013). Acceptance of nuclear power: The Fukushima effect. Energy Policy, 59, 112-119.

Slovic, P., Flynn, J., Mertz, C., Poumadere, M., \& Mays, C. (2000). Nuclear power and the public. In O. Renn \& B. Rohrmann (Eds.), Cross-Cultural Risk Perception: A Survey of Empirical Studies (pp. 55-102). Dordrecht, Germany; Boston, MA: Kluwer Academic.

Small, M. L. (2009). How many cases do I need? On science and the logic of case selection in field-based research. Ethnography, 10(1), 5-38.

Smith, L. M., Zhu, L., Lerman, K., \& Kozareva, Z. (2013). The role of social media in the discussion of controversial topics. Paper presented at the Social Computing (SocialCom), 2013 International Conference.

Snow, D. A. (2013). Framing and social movements. In D. A. Snow, D. della Porta, B. Klandermans, \& D. McAdam (Eds.), The Wiley-Blackwell Encyclopedia of Social and Political Movements. Hoboken, NJ: John Wiley \& Sons. 
Snow, D. A., \& Benford, R. D. (1988). Ideology, frame resonance, and participant mobilization. International Social Movement Research, 1(1), 197-217.

Snow, D. A., RochfordJr, E. B., Worden, S. K., \& Benford, R. D. (1986). Frame alignment processes, micromobilization, and movement participation. American Sociological Review, 51(4), 464-481.

Standaert, M. (2017). As China pushes waste-to-energy incinerators, protests are mounting. YaleEnvironment360. Retrieved from https://e360.yale.edu/features/a s-china-pushes-waste-to-energy-incinerators-protests-are-mounting.

Steiner, L., \& Bird, N. (2008). Reporters see indifference on genetically modified food. Newspaper Research Journal, 29(1), 63-76.

Steinhardt, H. C., \& Wu, F. (2016). In the name of the public: Environmental protest and the changing landscape of popular contention in China. The China Journal, 75 (1), 61-82.

Stone, G. D. (2010). The anthropology of genetically modified crops. Annual Review of Anthropology, 39, 381-400.

Stone, R. (2008). Plant science. China plans \$3.5 billion GM crops initiative. Science, 321(5894), 1279-1279.

Stone, R. (2009). Some unwelcome questions about big dams. Science, 324(5928), 714.

Suerdem, A., Bauer, M. W., Howard, S., \& Ruby, L. (2013). PUS in turbulent times II: A shifting vocabulary that brokers inter-disciplinary knowledge. Public Understanding of Science, 22(1), 2-15.

Sullivan, J. (2012). A tale of two microblogs in China. Media, Culture \& Society, 34(6), $773-783$.

Sun, C., Zhu, X., \& Meng, X. (2016). Post-Fukushima public acceptance on resuming the nuclear power program in China. Renewable and Sustainable Energy Reviews, 62, 685-694.

Sun, Y., \& Zhao, D. (2008). Environmental campaigns. In K. J. O’Brien (Ed.), Popular Protest in China (pp. 144-162). Cambridge, MA: Harvard University Press.

Sun, Y.-S. (1920/2014). Guidelines for Nation Building. Beijing: Joint Publishing.

Sun, Z. (2013). A Study on China's Nuclear Safety Governance. (Doctoral thesis). Shandong University, Jinan. (In Chinese).

Sunstein, C. R., \& Vermeule, A. (2009). Conspiracy theories: Causes and cures. Journal of Political Philosophy, 17(2), 202-227.

Tai, Z., \& Sun, T. (2007). Media dependencies in a changing media environment: The case of the 2003 SARS epidemic in China. New Media \& Society, 9(6), 987-1009.

Tang, B. (2017). How safe must nuclear power be to avoid destroying China? ifeng. com Think Tank. Retrieved from https://pit.ifeng.com/a/20171108/53065275_0. shtml (In Chinese).

Tang, G., Hu, Y., Yin, S.-A., Wang, Y., Dallal, G. E., Grusak, M. A., \& Russell, R. M. (2012). $\beta$-Carotene in Golden Rice is as good as $\beta$-carotene in oil at providing vitamin A to children. The American Journal of Clinical Nutrition, 96(3), 658-664.

Tang, L., \& Sampson, H. (2012). The interaction between mass media and the internet in non-democratic states: The case of China. Media, Culture \& Society, 34(4), 457-471.

Tang, Y., \& Wang, D. (2016). How far are nonprofessional researchers from science? People's Weekly, (5), 50-51. (In Chinese).

Tannenwald, N. (2005). Stigmatizing the bomb: Origins of the nuclear taboo. International Security, 29(4), 5-49.

Tarrow, S. (1994). Power in Movement: Social Movements, Collective Action and Politics. New York: Cambridge University Press. 
Tarrow, S. (1996). States and opportunities: The political structuring of social movements. In D. McAdam, J. D. McCarthy, \& M. N. Zald (Eds.), Comparative Perspectives on Social Movements (pp. 41-61). Cambridge, UK and New York: Cambridge University Press.

Tarrow, S. (2011). Power in Movement: Social Movements and Contentious Politics (Revised \& updated 3rd edition). New York: Cambridge University Press.

Teets, J. C. (2013). Let many Civil societies bloom: The rise of consultative authoritarianism in China. China Quarterly, 213(213), 19-38.

Teets, J. C. (2014). Civil Society under Authoritarianism: The China Model. New York: Cambridge University Press.

Teets, J. C. (2018). The power of policy networks in authoritarian regimes: Changing environmental policy in China. Governance, 31(1), 125-141.

Thireau, I., \& Linshan, H. (2003). The moral universe of aggrieved Chinese workers: Workers' appeals to arbitration committees and letters and visits offices. The China Journal, 50, 83-103.

Tian, F. (Ed.) (1989). Second Collection of Treatises on Macro Policymaking on the Three Gorges Project. Changsha: Hunan Science and Technology Press. (In Chinese).

Tian, F., Lin, F., \& Ling, C. (Eds.). (1987). Treatises on Macro Policymaking on the Three Gorges Project. Changsha: Hunan Science and Technology Press. (In Chinese).

Tian, S. (2003). Perpetuum Mobile and Goldbach's Conjecture: Science in Grassroots. Shanghai: Shanghai S\&T Press Publishers. (In Chinese).

Tian, S. (2010). Promoting GM technology is, first of all, not an issue of science. Dushu (Reading), (7), 57-66. (In Chinese).

Tian, S. (2012). Be cautious of science and technology superstition. Dushu (Reading), (4), 98-105. (In Chinese).

Tian, X. (2010, March 11). Over 100 scholars jointly petition National People's Congress to revoke biosafety certificate of GM rice. Youth Times, p. 1. Retrieved from http://finance.ifeng.com/news/special/lianghui2010/industry/20100311/1912686.shtml.

Tilly, C. (1978). From Mobilization to Revolution. New York: McGraw-Hill.

Tilly, C., \& Tarrow, S. (2015). Contentious Politics (2nd edition). Kindle Edition. Oxford, UK: Oxford University Press.

Tilt, B. (2014). Dams and Development in China: The Moral Economy of Water and Power. New York: Columbia University Press.

Tompkins, A. S. (2016). Better Active Than Radioactive!: Anti-nuclear Protest in 1970s France and West Germany. Oxford, UK: Oxford University Press.

Tracy, S. J. (2010). Qualitative quality: Eight "big-tent" criteria for excellent qualitative research. Qualitative Inquiry, 16(10), 837-851.

Tsang, S. (2009). Consultative Leninism: China's new political framework. Journal of Contemporary China, 18(62), 865-880.

Unknown. (2014). Clearing legacy of Bo Xilai and sunk to plot, Sun Zhengcai was supported by two politburo standing member. DW News. Retrieved from https:// www.backchina.com/news/2014/11/25/331744.html (In Chinese).

Vermeer, E. B. (2011). The benefits and costs of China's hydropower: Development or slowdown? China Information, 25(1), 3-32.

Vermeer, E. B., \& Ho, P. (2004). Food safety concerns and biotechnology: Consumers' attitudes to genetically modified products in urban China. AgBioForum, 7(4), 158-175.

Visschers, V. H., \& Wallquist, L. (2013). Nuclear power before and after Fukushima: The relations between acceptance, ambivalence and knowledge. Journal of Environmental Psychology, 36, 77-86. 
Wakefield, A. J., Murch, S. H., Anthony, A., Linnell, J., Casson, D. M., Malik, M., ... Harvey, P. (1998). RETRACTED: Ileal-lymphoid-nodular hyperplasia, non-specific colitis, and pervasive developmental disorder in children. The Lancet, 351(9103), 637-641.

Wang, C. (2009, February 20). "God's damnation” or China's dream: scientific debate on reservoir-quake link. Xinhua News Agency.

Wang, C. (2017). On Xi Jinping's thoughts on S\&T and innovation. Science and Technology Review, 35(18), 13-19. (In Chinese).

Wang, H. (2016). The Transformation of Investigative Journalism in China: From Journalists to Activists. Lanham, MD: Rowman \& Littlefield.

Wang, X., \& Gu, B. (2016). The communication design of WeChat: Ideological as well as technical aspects of social media. Communication Design Quarterly Review, 4(1), 23-35.

Wang, Y. (2015a). Japanese nuclear experts' 10 reflections on Fukushima accident. China Economic Weekly, 33, 72-76. Retrieved from http://www.ceweekly.cn/2015/ 0824/124726.shtml (In Chinese).

Wang, Y. (2015b). Whether to restart inland nuclear projects depends on answers to 10 essential questions. China Economic Weekly, 39, 70-73. (In Chinese).

Wang, Y. (2015c). Why does the premier require nuclear power to have "absolute safety?". China Economic Weekly, 24, 15-16. Retrieved from http://www.sm.gov.cn/ zw/ztzl/hdzt/zjshd/201606/t20160629_336609.htm (In Chinese).

Wang, Y. (2016). NPP is not appropriate in Bohai Bay. China Economic Weekly, 41, 77. Retrieved from http://www.ceweekly.cn/2016/1024/167986.shtml (In Chinese).

Webber, M. (2012). The political economy of the Three Gorges Project. Geographical Research, 50(2), 154-165.

Webber, M., Crow-Miller, B., \& Rogers, S. (2017). The South-North water transfer project: Remaking the geography of China. Regional Studies, 51(3), 370-382.

Wei, Y. (2013). Planting GM corn made rats disappear and sows abort? Experts: Lies. S\&T Column, People.cn. Retrieved from http://scitech.people.com.cn/n/2013/0709/ c1007-22133532.html (In Chinese).

Weinberg, A. M. (1994). The First Nuclear Era: The Life and Times of a Technological Fixer. New York: American Institute of Physics Press.

Weinberg, A. M. (1996). The First Nuclear Era: The Life and Times of a Technological Fixer (Chinese translation) (Y. Lv, Trans.). Beijing: Atomic Energy Press.

Wen, N., Hao, X., \& Han, X. (2016). Examining the Role of Mobile Media in Public Engagement with GMO Foods Among Chinese Consumers. In R. Wei (Ed.) Mobile Media, Political Participation, and Civic Activism in Asia (pp. 103-121). New York: Springer.

Wikipedia. (n.d.). Websites blocked in mainland China. Retrieved from https://en. wikipedia.org/wiki/List_of_websites_blocked_in_mainland_China.

Wittfogel, K. A. (1957). Oriental Despotism: A Comparative Study of Total Power. New Haven, CT: Yale University Press.

World Commission on Dams. (2000). Dams and Development: A New Framework for Decision-Making. London and Sterling, VA: Earthscan Publications Ltd.

Wu, F. (2009). Environmental civil society in China: 15 years in review. Harvard-Yenching Institute Working Paper Series. Retrieved from https://www.researchgate.net/publication/ 297345772_Environmental_Civil_Society_in_China_15_Years_in_Review?enrichId=rgr eq-99a08d21d10f535e523c82887790372d-XXX\&enrichSource=Y292ZXJQYWd1OzI5N zM0NTc3MjtBUzozMzcyNjUwNjM2Nzc5NTJAMTQ1NzQyMTY2NTc3Mg\%3D $\%$ 3D\&el=1_x_3\&_esc=publicationCoverPdf. 
Wu, H. (2018, February 04). China's inland nuclear power has been beheaded. Great Border in Sohu Blog. Retrieved from https://www.sohu.com/a/220883427_642098 (In Chinese).

$\mathrm{Wu}, \mathrm{Y}$. (2017). Public acceptance of constructing coastal/inland nuclear power plants in post-Fukushima China. Energy Policy, 101, 484491.

Wynne, B. (1992). Misunderstood misunderstanding: Social identities and public uptake of science. Public Understanding of Science, 1(3), 281-304.

Xiang, Q., Chu, Y., \& Jin, J. (2015). Scientists in public trust framework: An evidencebased study. Modern Communication, 37(6), 46-50. (In Chinese).

Xiao, Q. (2011). The battle for the Chinese Internet. Journal of Democracy, 22(2), 47-61.

Xie, X., Wang, M., \& Xu, L. (2003). What risks are Chinese people concerned about? Risk Analysis, 23(4), 685-695.

$\mathrm{Xu}, \mathrm{L}$. (2018). "Rumored salt" again. What is potassium ferrocyanide in edible salt? Is it edible? ThePaper.cn. Retrieved from http://www.chinanews.com/life/2018/08-27/ 8611491.shtml (In Chinese).

$\mathrm{Xu}$, Q., Yu, N., \& Song, Y. (2018). User engagement in public discourse on genetically modified organisms: The role of opinion leaders on social media. Science Communication, 40(6), 691-717.

Yan, D., \& Li, Y.-I. (2014, July 24). Local people's congress "reject nuclear power," four sides' rotten tails, and escalating "nuclear fight". Southern Weekend. Retrieved from http://www.infzm.com/content/102572 (In Chinese).

Yan, X. (2015). CNNC has signed two HRR1000 export contracts. China News Agency. Retrieved from http://finance.china.com.cn/industry/energy/fcgny/20150507/ 3103854.shtml.

Yan, Y. (2009). An overview of Chinese media's anti-dam effort. Science News Magazine, 19, 10-14. Retrieved from http://www.science-weekly.cn/skhtmlnews/2009/10/ 707.html?id=707 (In Chinese).

Yan, Y. (2012). Food safety and social risk in contemporary China. The Journal of Asian Studies, 71(3), 705-729.

Yang, C. (2013, July 22). With Jiangmen 37 billion yuan nuclear fuel project aborted, has the144 million yuan financial investment been wasted? National Business Daily. Retrieved from http://www.nbd.com.cn/articles/2013-07-22/759902.html (In Chinese).

Yang, G. (2005). Environmental NGOs and institutional dynamics in China. The China Quarterly, 181, 46-66.

Yang, G. (2009). The Power of the Internet in China: Citizen Activism Online. New York: Columbia University Press.

Yang, G., \& Calhoun, C. (2007). Media, civil society, and the rise of a green public sphere in China. China Information, 21(2), 211-236.

Yang, J. (2012). Tombstone: The Great Chinese Famine, 1958-1962. Basingstoke, UK: Macmillan.

Yang, X. (2016). Closer to people's life than G20: Beijing Supreme Court did not deal with MOA and Monsanto, refused to register the lawsuit when government was involved. People's Food Sovereignty. Retrieved from http://www.shiwuzq.com/porta 1.php?mod=view\&aid=348 (In Chinese).

Yi, R., \& Jia, H. (2008). Who blocks the commercialization of GM rice? Science News Magazine (Supplement 1). Retrieved from http://www.science-weekly.cn/skhtm lnews/2008/11/28.html?id=28.

Yin, R. K. (2009). Case Study Research: Design and Methods (4th edition). Thousand Oaks, CA: Sage Publications. 


\section{References}

Yin, Y. (2017). Vivid Marxism or Dengist revisionism GMOs? Red Lilly Net. Retrieved from http://www.awzhhw.com/list.asp?id=12236 (In Chinese).

Yu, N., Zhang, Y., Wang, J., Cao, X., Fan, X., Xu, X., \& Wang, F. (2012). Knowledge of and attitude to nuclear power among residents around the Tianwan Nuclear Power Plant in Jiangsu Province of China. International Journal of Medical Sciences, 9(5), 361.

Zehr, S. C. (1999). Scientists' representations of uncertainty. In S. M. Friedman, S. Dunwoody, \& C. L. Rogers (Eds.), Communicating Uncertainty: Media Coverage of New and Controversial Science (pp. 3-21). London \& New York: Routledge.

Zeng, F., Dai, J., \& Wang, Y. (2015). Technological risks vs. risk perception: Communication process and social amplification of risk. Modern Communication, 37(3), 40-46. (In Chinese).

Zhang, B. (2011). China's democracy and debates on TGD. ScienceNet.cn blog. Retrieved from http://blog.sciencenet.cn/blog-295826-452247.html (In Chinese).

Zhang, C., Huang, L., \& Ren, L. (2016). Chinese public perception of and attitude to nuclear energy. Studies on Science Popularization, 3(11), 53-58. (In Chinese).

Zhang, J. Y. (2015). The "credibility paradox" in China's science communication: Views from scientific practitioners. Public Understanding of Science, 24(8), 913-927.

Zhang, J. Y., \& Barr, M. (2013). Green Politics in China: Environmental Governance and State-Society Relations. London: Pluto Press.

Zhang, Q. (2017). Zhang Qifa: The trend of biotechnology seeding. Agrogene.cn. Retrieved from http://wap.agrogene.cn/info-4045.shtml (In Chinese).

Zhang, R., Jing, J., Tao, J., Hsu, S.-C., Wang, G., Cao, J., ... Zhao, Y. (2013). Chemical characterization and source apportionment of PM 2.5 in Beijing: seasonal perspective. Atmospheric Chemistry and Physics, 13(14), 7053-7074.

Zhang, W. (2014, June 20). Nuclear power: Necessary devil: Discussing with Prof. Wang Yinan. Southern Weekend. Retrieved from http://www.infzm.com/content/ 101623 (In Chinese).

Zhang, Z., Yuan, L., Liu, Q., Cai, B., Li, X., Zhao, H., ... Zhao, L. (2015). Biosafety assessment of genetically modified foods based on the toxicology of the chiral D-amino acid. Scientia Sinica Chimica, 45(1), 98-108. doi:10.1360/N032014-00048-152 (In Chinese).

Zhao, C. (2018). Hygiene and management of GM food. In C. c. e. Sun, W. Ling, G. Huang, L. Liu, \& Y. Li (Eds.), Nutrition and Food Hygiene (8th edition) (pp. 413-416). Beijing: People's Medical Publishing House. (In Chinese).

Zhao, C., Zhou, R., Mao, Y., \& Wang, M. (2016). CNEA's responses to Wang Yinan's view on inland nuclear power. China Nuclear Energy Association. Retrieved from http://www.sm.gov.cn/zw/ztzl/hdzt/zjshd/201606/t20160629_336609.htm (In Chinese).

Zheng, Y. (2007). De facto Federalism in China: Reforms and Dynamics of Centrallocal Relations. Singapore: World Scientific Press.

Zhong, Y. (2015). Local Government and Politics in China: Challenges from Below. London: Routledge.

Zhou, Z. (2014). Haze pressures to accelerate nuclear power development. China News Weekly, (13), 56-57. (In Chinese).

Zhu, Q., \& Horst, M. (2019). Science communication activism: Protesting traditional Chinese medicine in China. Public Understanding of Science, 28(7), 812-827.

Zhu, X. (2013). The Rise of Think Tanks in China. London and New York: Routledge. 
Zhuang, P. (2019, July 5). Thousands keep up protest over waste incinerator. South China Morning Post. Retrieved from https://www.scmp.com/news/china/society/a rticle/3017386/thousands-protest-central-china-over-waste-incineration-plant.

Zou, S., \& Zhang, Z. (2011). Hu Jintao inspected Hubei, planted corns with farmers. Xinhua News. Retrieved from http://www.chinanews.com/gn/2011/06-03/3090303. shtml (In Chinese). 


\section{Index}

Page numbers in italics refer to figures, those in bold indicate tables.

AEC (Atomic Energy Commission) 136 air pollution controversies $12-13,154$ alternative knowledge 27, 69, 91-3, 99-100, 163-4, 166

America see United States

analysis: government documents 33 ; interview data 27; mass media data 28-32; nuclear controversies in China 167; social media data 32-3; social movement theories 9-10; Weibo and GMO (Genetically Modified Organisms) 113

anonymity 34,52

anti-biotechnology activism 107, 118, 124 anti-dam movements $12,45,67,71$, 84,92

anti-GMO activism: differing science controversies $168,170,174-6,180$; framing and mobilization $126-8$; and hydropower controversies 101-4, 104-5; knowledge control and contention 131-3, 134; and media landscape 107; and nuclear power debate 143; science controversies and political opportunities 14; and social media 112-16, 114-15; as a social movement 118, 120-3, 121-2;

transitional China 51, 54-8; WeChat (Chinese social media platform) 25-6 anti-hydropower movements: comparative theoretical traditions 185; differing science controversies 168, 175, 180; hydropower, fragmentation and knowledge-making 70, 74, 77, 83-4, 92, 96; science controversies and political opportunities 12-13, 13-15, 17; transitional China 36, 51 anti-incinerator movements 59-60, 65 anti-nuclear activism: alternative knowledge and knowledge control 163-4, 166-7; campaigns 46-54, 117, 137, 138; conventional media reporting 143; differing science controversies 169, 174, 176; social media reporting $147-8,150-2$; as a social movement 135-6, 152-4, 155-8, 156; transitional China 49, 51, 53; Weibo data 25 anti-PM2.5 movements 12-13, 62-3 article attitudes 28, 94-5, 107, 109, 110 see also media themes authoritarian regimes: conclusions 188-90; differing science controversies 173-5, 180, 182; GMO controversies 117-18, 124-6; hydropower, fragmentation and knowledge-making $67,81,82-4,84$; nuclear power debate 138, 155-8, 167; research methods and data 19; science controversies and political opportunities $1,5,10-11,17$; transitional China 33, 38, 50, 56

Baidu Baike 61

Baidu Index 23, 110-11, 147-9

Bauer, M. W. 3

BBS (Bulletin Board Systems) posts:

GMO controversies 112; hydropower controversies in China 78-80, 79; nuclear power debate 147, 150; research methods and data 23-4, 32; transitional China 49, 60, 65

Bijker, W. E. 66

biodiversity: conclusions 190; differing science controversies 175,178 ; differing theoretical traditions 187 ; 
GMO controversies 118; hydropower controversies in China 70, 84, 93; transitional China 40, 42-3, 55

biosafety certificates: biotechnology governance 174; contemporary GMO controversies in China 104; GMO controversy as a social movement 118-20, 124-5; GMO social media debate 112; knowledge-control and contention 129-30, 132; transitional China 56

blogs: GMO controversies 112-13, 123, 130; hydropower controversies in China 78; nuclear power debate 150-2; research methods and data 24,32 ; science controversies and political opportunities 11; transitional China $52,56,60,65$

Britain see UK

CAAS (Chinese Academy of Agricultural Sciences) 56, 118, 123

Calhoun, C. 170

CAS (Chinese Academy of Sciences): controversies in transitional China 43, 47, 51, 56-7, 62-3; differing science controversies 179; GMO controversies 108, 124, 126; hydropower controversies in China 82-5, 97-8; newspaper data 21; nuclear power debate 141, 151, 153, 157, 159-60

CAST (China Association for Science and Technology) 82, 84, 108, 123, 160

CCP (Chinese Communist Party): controversies in transitional China 38, 40, 44, 51, 65; GMO controversies 132; hydropower controversies in China 73; nuclear power debate 141, 152; sampled newspaper data 21 ; science controversies and political opportunities 10

CGNPC (China General Nuclear Power Corporation) 47, 49, 53, 153-4, 160

Chernobyl accident 49, 136-7, 166

China Association for Science and Technology (CAST) see CAST (China Association for Science and Technology)

China General Nuclear Power Corporation (CGNPC) 47, 49, 53, 153-4, 160

China Institute of Atomic Energy (CIAE) 47, 158

China Internet Network Information Center (CNNIC) 54, 112-13
China National Nuclear Corporation (CNNC) see CNNC (China National Nuclear Corporation)

China Nuclear Energy Association (CNEA) 52, 160

China Science Daily (CSD): GMO controversies 106-7, 109; hydropower controversies in China 72, 95; nuclear power debate 140-1, 146-7, 151; research methods and data $21-\mathbf{2}, 34 \mathrm{n} 1$

China Society for Hydropower Engineering (CSHE) 71

China's nuclear dream 46-8

Chinese Academy of Agricultural Sciences (CAAS) see CAAS (Chinese Academy of Agricultural Sciences)

Chinese Academy of Sciences (CAS) see CAS (Chinese Academy of Sciences)

Chinese Communist Party (CCP) see CCP (Chinese Communist Party)

Chinese People's Political Consultative Conference (CPPCC) see CPPCC

Chinese regime 11, 65, 188

CIAE (China Institute of Atomic Energy) 47, 159

civic epistemology see also epistemic issues: differing science controversies 178-80; in GMO controversy 103-4, $117,128,131-3$; in hydropower controversies 80, 87-93, 88-90, 92, 99-100; nuclear power debate 163; science controversies and political opportunities 4-7, 17

CNEA (China Nuclear Energy Association) 52, 160

CNNC (China National Nuclear Corporation): contentions in China 139; controversies in transitional China 47, 49, 53-4; knowledge in nuclear disputes 159-60, 164; nuclear contention as a social movement $152-5,157$

CNNIC (China Internet Network Information Center) see China Internet Network Information Center (CNNIC) communication patterns: conclusions 184 , 190; differing science controversies 169 , 170, 171; GMO controversies 117; hydropower controversies in China 71-80; nuclear controversy in China 167; social media data 23-4 communication studies 185, 187, 191 comparing theoretical traditions 184-5, $185-7$ 


\section{Index}

confidentiality 34

conspiracy theories: conclusions 190; controversies in transitional China 52 , 56; differing science controversies 170 , 176, 179; GMO controversies 104, $116,123,131-3$; nuclear power debate $143,155,163$; research methods and data $30-1$

consultative authoritarianism 10-11 contemporary GMO controversies in China 104-5

contemporary nuclear controversies in China 139

Controversy Manual (Martin) 2 controversy visibility $28,31-3,63,95$, 107, 184

Cornell University 21, 34, 38, 47, 81

CPPCC (Chinese People's Political Consultative Conference): controversies in transitional China 38, 50, 53, 57; GMO controversies 104, 124; hydropower controversies in China 68, 80-1, 84-6, 92, 98; nuclear power debate $153,166,167 \mathrm{n} 1$; science controversies and political opportunities 14

Creswell, J. W. 19

CSD (China Science Daily) see China Science Daily (CSD)

Cui Yongyuan 25, 57, 104-5, 113-14, $116,122-4$

Dayawan NPP (Nuclear Power Plant) 47-9, 154

Delborne, J. A. 186

Deng Xiaoping: GMO controversies 123, 129; hydropower controversies in China 67; nuclear power debate 155; science controversies in transitional China 36-7, 47, 49

Design on Nature (Jasanoff) 4

differing science controversies 168-83; communication patterns 171 ; examining knowledge control regimes 178-80; introduction 168-9; media and science controversies 169-70; pattern comparisons 180-3, 181-2; sociopolitical roots of science controversies 172-3, 173-5, $175-8$

discourse strategies against knowledge control 165-6

disintegrated knowledge-making 93-9, 95, 97-8

Downs, A. 177 earthquakes 44-5, 69-70, 71, 91, 97, 178

East Asia 2, 7, 55, 66, 137

EIA (Environmental Impact Assessment) Law: conceptualizing hydropower debates in the STS landscape 87-9, 91, 94, 96; contemporary hydropower controversies in China 70; media reporting of hydropower controversies 71, 78; social movements and hydropower controversies $68, \mathbf{8 5}, 87$; transitional China 40-1

ENGOs (Environmental Non-Governmental Organizations): differing science controversies 168-9, 172-4, 175-6, 178; GMO controversies 105, 107; hydropower controversies in China 66, 68, 70-1, 78, 80, 82-92, 96-7; nuclear power debate 154-6; research methods and data 34 ; science controversies and political opportunities 1, 10-11, 12-13, 13-14, 18 ; science controversies in transitional China 36, 39, 41-6, 58, 60

environmental activism see also anti-GMO activism; anti-hydropower movements; anti-nuclear activism: controversies in transitional China 42 , 45 , 60; ethical issues 34; hydropower controversies in China 78, 84, 99; nuclear power debate 154

Environmental Impact Assessment (EIA) Law see EIA (Environmental Impact Assessment) Law environmental journalism 39-40, 76-7, $83,107,147,169,171$

environmental knowledge production 94, 96

Environmental Non-Governmental Organizations (ENGOs) see ENGOs (Environmental Non-Governmental Organizations)

epistemic issues see also civic epistemology: conclusions 188-9, 190; GMO controversies 101, 117; hydropower controversies in China 93, 99, 100; nuclear power debate 161-2; science controversies and political opportunities 2, 4-6, 9; transitional China 39, 63

Epstein, S. 4, 9

ethics: data analysis 29-31, 33-4; epistemic roots of $\mathrm{S} \& \mathrm{~T}$ controversies 4; GMO controversies 57, 102-3, 107, $108,113,116$ 
ethics and Pandora frame 30-1, 107 experts fueling hydropower controversies 84-7, 85-6

FA (Fragmented Authoritarianism) framework: differing science controversies 180, 182; GMO controversies 117, 124-6; hydropower controversies in China 68-9, 80, 82-4, 87,100 ; nuclear power debate $155-8$, 167; and political opportunity structure 173-5; research methods and data 19; science controversies and political opportunities 10-11, 17

Fan Xiao 44-5, 70, 91, 173

fish: controversies in transitional

China 42-4, 46; differing science controversies 178; hydropower controversies in China 70, 84, 89-91, 94, 96, 97-8

food safety: comparing theoretical traditions 186-7; conclusions 190; differing science controversies 169-70, 174-7, 179-80; GMO controversies 106-7, 116-17, 120-3, 126-8, 130-4; mass media data analysis $30-\mathbf{1}$; nuclear power debate 138, 151, 159; science controversies and political opportunities 9, 12, 14; transitional China 63-4

Foucault, M. 5

Four Seniors 50-1, 139, 156-8, 163

framing analysis see also public accountability frames: conclusions 188, 190; differing science controversies $169,174-5,175-8$; GMO controversies 14, 102, 126-8; government documents 33; hydropower controversies in China 92, 99; mass media data 28-9, 31; nuclear power debate 135-6, 155-6, 164, 167; research methods and data 19; state power 8-10

framing and mobilization 126-8, 175-6, $176-7,177-8$

France 47, 66, 136

Fukushima accident: differing science controversies 169, 177, 181; nuclear power debate 138-9, 140-1, 143-5, 147-51, 153-5, 161-2, 163-6; science controversies and political opportunities 14-15; transitional China 49-51

future studies 189-90
Germany 4, 55, 103, 136, 163

GM (Genetically Modified) crops: contemporary hydropower controversies in China 105; differing science controversies 176-7, 180, 182; GMO controversies as a political movement 124, 126-7; knowledge-control regimes 130; media landscape of GMO controversies in China 107-8; roots of GMO contentions 101; science controversies and political opportunities 13-14, 18; theoretical traditions 184, 187; transitional China 54-5, 57

GMO controversies 101-34 see also GM (Genetically Modified) crops; conclusions 133-4; contemporary hydropower controversies in China 104-5; controversies in transitional China 54-8; differing science controversies 169-70, 180-1; introduction 101-2, 102-3, 103-4; knowledge control and contention 128-31, 131-3; media landscape 105-10, 110-17; nuclear power debate 139; and political opportunities 1-2, 2-3, 9-10, 12-16, 14, 16-17, 17-18; research methods and data $21-2,23-6$, $30-3,31,33-4$; as a social movement 117-24, 119-22, 124-6, 126-8; theoretical traditions 187

golden rice 57, 108, 113, 121

Google Trends 23, 78-80, 79, 148-9

Great Britain see UK

Great Famine (1960) 37

Greenpeace: conclusions 190; differing science controversies 172-3, 175-6; GMO controversies 104, 105, 116, 117-24; hydropower controversies in China 84; science controversies and political opportunities 13-14; science controversies in transitional China 55-8 Groth, E. 187

Guidelines for Nation Building (Sun) 37

health hazards: differing science controversies 179; GMO controversies 119, 129-30; nuclear power debate 137, 159; science controversies and political opportunities 2, 18; theoretical traditions 187; transitional China 59, 63-4

heritage sites $39,41,69-70, \mathbf{8 8}$

Herring, R. J. 9, 102, 127 
HGP (Human Genome Project) 6-7, 104,162

high-speed trains 14,16

Hilgartner, S.: GMO controversies 104, 128; hydropower controversies in China 93, 96; interaction of theoretical frameworks 186; knowledge-control regimes 6-7; nuclear power debate 162

Hong Kong 47, 49, 55, 123

HPR1000 technology 48, 54

Huge, M. 77, 103, 108, 161, 171

Human Genome Project (HGP) 6-7, 104,162

hydropower controversies in China 66-100; communication patterns of hydropower controversies 71-6, 72, 73-5, 76-80, 79; comparing theoretical traditions 182; conceptualizing hydropower debates in the STS landscape 87-93, 88-90, 92, 93-9, 95, 97-8; conclusions 99-100; contemporary hydropower controversies in China 69-71; differing science controversies 168, 169-71, 172-4, 177, 179-81; GMO controversies 117, 126; introduction 66-7, 67-9; nuclear power debate 135, 167; research methods and data 21-2, 31; science controversies and political opportunities 12-16, 14, 18; social movement theories and hydropower controversies 80-2, 82-4, 84-7, 85-6; transitional China 37-8, $39-45,45-6,65$

IAEA (International Atomic Energy Agency) 138, 161

institutionalized knowledge monopoly $158-62$

institutions fueling hydropower controversies 84-7, 85-6

interactions of theoretical frameworks 185-6, 186-7

International Atomic Energy Agency (IAEA) 138, 161

International Thermonuclear Experimental Reactor (ITER) 141, 164

Internet: comparing theoretical traditions 186; differing science controversies 169-70, 171, 176, 181; GMO controversies 110, 112, 117, 127; hydropower controversies in China 76-80, 79; nuclear power debate 147; research methods and data 23; science controversies and political opportunities 1, 11, 16; transitional China 52, 55, 60, 61

Iran 30,51

issue-attention cycle 177

Japan 7, 137, 141, 143, 164, 177

Jasanoff, S. 4-6, 91, 103

Jinsha River controversy 41, 85, 87, 88-9, 172

Kim, S.-H. 5

Kitschelt, H. P. 117, 136, 152, 173

knowledge contention 12, 87-93, 88-90, 92, 94, 128-33

knowledge-control regimes: comparing theoretical traditions 184, 185-6, 186-7; conclusions 188-9, 190; differing science controversies 168-9, 171, 174, 175, 178-80, 180, 182; GMO controversies 103-4, 117, 128, 131, 134; hydropower controversies 69 , 76-7, 80, 93-9, 99-100; nuclear power controversies $147,158-60,160-1$, 161-2, 163-4, 165-6; science controversies and political opportunities 4-7, 17

knowledge-making: comparing theoretical traditions 184-5; differing science controversies 168; GMO controversies 103; hydropower controversies in China 93-9, 95, 97-8; nuclear power debate $137,158-62$, 163-4, 165-6; science controversies and political opportunities 7, 9, 13

Lewenstein, B. V. 29-30

limitations 18, 189-90

Liu Jianqiang 105, 172

Liulitun protests 59, 61

Living in the Environment (Miller) 163

Lofland, J. et al. 19

macropolitics 7

main themes of media articles $73, \mathbf{7 6}, 92$, 95, 106-7, 145-6

Mao Zedong (Chairman Mao): controversies in transitional China 64; GMO controversies 56, 118, 123, 133; hydropower controversies in China 36, 37, 67; nuclear power debate 47, 155 Maoism: differing science controversies 174, 176, 183; GMO controversies 
104, 113, 123-4, 127-8, 133; nuclear power debate 163 ; research methods and data 26, 33, 35n 3 ; science controversies in transitional China $52-3,56,58$

Martin, B. 2, 187

mass media: differing science controversies 169, 181; GMO controversies 101, 105, 116-17, 127; hydropower controversies in China 71 , 78, 82, 87; nuclear power debate 149; research methods and data $21-3$, 23-4, 28-32, 31, 32-3; transitional China 45

McAdam, D. 2, 8

McCormick, S. 69

media and science controversies 169-70

media attention: anti-incinerator movements 60; differing science controversies 170, 177; GMO controversies 103, 111, 123; hydropower controversies in China 68, 84; science controversies and political opportunities 3; theoretical traditions 186

media commercialization: differing science controversies 169; GMO controversies $105,118,124,128,133$; hydropower controversies in China 99 media content analysis of GMO controversies 106

media coverage see media reporting media framing 33, 135-6

media landscape of GMO controversy in China 105-17, 107

media liberalization 105-10, 106, 107, 109

media reporting see also negative reporting: case selection 12; differing science controversies 169; GMO controversies 107, 111-12, 113, 119-22; hydropower controversies in China 71-6, 72, 73-5, 78, 80, 83, 86; nuclear controversies in China 139 , 140-7, 141-3, 145-6, 154; research methods and data $20-1,21-3,28,32$, 33 ; science controversies and political opportunities 3; transitional China 39, 41, 43-4, 51, 56-7, 63

media role in GMO controversies 102-3 media themes 30-1, 73, 76-7, 95, 106-7,

145-6 see also article attitudes

MEE (Ministry of Ecology and

Environment of China), earlier SEPA, then MEP 40, 154, 161, 167, 174
MEP (Ministry of Environmental Protection), earlier SEPA, later MEE: conceptualizing hydropower debates in the STS landscape 89, 91-2, 96, 99; contemporary hydropower controversies in China 70, 71; controversies in transitional China 40 , 43-4, 46, 48; dam debates and fragmented authoritarianism 82-3; differing science controversies 174 , 176; media coverage in hydropower controversies in China 75, 78; nuclear power debate 154-5, 161, 167

Mertha, A. 10, 68-9, 82

Miller, G. T. 163

Ministry of Agriculture (MOA), later Ministry of Agriculture and Rural Affairs see MOA (Ministry of Agriculture)

Ministry of Ecology and Environment of China (MEE), earlier SEPA, then MEP see MEE (Ministry of Ecology and Environment of China), earlier SEPA, then MEP

Ministry of Environmental Protection (MEP), earlier SEPA, later MEE see MEP (Ministry of Environmental Protection), earlier SEPA, later MEE

MOA (Ministry of Agriculture), later Ministry of Agriculture and Rural Affairs: controversies in transitional China 43, 54-6; differing science controversies 174, 177; GMO controversies 105, 116, 120-2, 124-6; hydropower controversies in China 89, 91, 98

Munro, W. 103

National Development and Reform Commission (NDRC) see NDRC (National Development and Reform Commission)

National Energy Administration (NEA) see NEA (National Energy Administration)

National Forestry Administration (NFA) 55

National Nuclear Safety Administration of China (NNSA) 48, 52, 153-4

National People's Congress of China (NPC) see NPC (National People's Congress of China)

national sociotechnical imaginaries see sociotechnical imaginaries 
NDRC (National Development and

Reform Commission): hydropower controversies in China 82, 88, 94, 98; nuclear power debate 139; transitional China 39-40, 41, 46, 53

NEA (National Energy Administration): controversies in transitional China 53; hydropower controversies in China 94, 98; nuclear power debate 135,139 , 153,157

negative reporting $\mathbf{7 7}, 94-\mathbf{5}, 99,106$, 141-3, 170

Nelkin, D. 2

news portals $11,32,52,77-8,112,181$

newspaper data 21-2

NFA (National Forestry Administration) 55

NGOs (Non-Governmental

Organizations): controversies in transitional China 39, 46, 53, 58, 59; differing science controversies 169,172 ; GMO controversies 102, 117-18, 124, 126, 128, 133; hydropower controversies in China 68, 84; science controversies and political opportunities 3, 10-11, 14

NIMBY (Not In My Back Yard) protests: controversies in transitional China 58; differing science controversies 174, 176; fragmented authoritarianism (FA) and the nuclear power debate 155-8, 156; knowledge-control in public engagement 160-1; landmark protests 167n2; public attitudes to nuclear power 138, 139; science controversies and political opportunities 13-14; social media and the nuclear power debate 148,151

Nisbet, M. C. 29-30, 77, 102-3, 108, 161, 171

NNSA (National Nuclear Safety Administration of China) 48, 52, $153-4$

Non-Governmental Organizations (NGOs) see NGOs (Non-Governmental Organizations)

North Korea 30, 51

Not In My Back Yard (NIMBY) protests see NIMBY (Not In My Back Yard) protests

NPC (National People's Congress of China): controversies in transitional China 38, 56; GMO controversies 125; hydropower controversies in China
84-5; nuclear power debate 153 , 167n1; research methods and data 27 NPPs (Nuclear Power Plants) see also Dayawan NPP (Nuclear Power Plant); Pengze NPP (Nuclear Power Plant): background 135; controversies in transitional China 47-53; differing science controversies 180 ; knowledge-making perspectives on nuclear controversy 159, 161, 164-6; nuclear contention as a social movement 154, 156-8; nuclear controversy and social media 150; public attitudes to nuclear power 138-9; theoretical traditions 184

$\mathrm{Nu}$ River: controversies in transitional China 39-41, 46; differing science controversies 172, 174; hydropower controversies in China 66, 68, 70, 73, $75,82-3,85-6$; research methods and data 21; theoretical traditions 187

nuclear controversies in China see nuclear power debate

nuclear power debate 135-67; conclusions 166-7; contemporary nuclear contentions in China 139; controversies in transitional China 52-3; differing science controversies 181-2; introduction 137-9; knowledge-making 158-62, 163-4, 165-6; and the media 140-7, 141-3, 145-6, 147-52, 148-50; research methods and data 22, 31; science controversies and political opportunities 12-13, 14; as a social movement 135-6, 152-5, 155-8, 156; theoretical traditions 185

Nuclear Power Plants (NPPs) see NPPs (Nuclear Power Plants)

Nutrition and Food Hygiene (Huang \& Li) 131

OECD (Organization for Economic Co-operation and Development) 138

Pandora 28-9, 30-1, 107

Paraxylene (PX) protests 12, 14, 60-2, 64-5, 167n2

partisan websites 26-7, 33

pattern comparisons 180-3, 181-2, 184-5

PD (People's Daily) see People's Daily (PD)

Pengze NPP 50, 155-8

People's Daily (PD): controversies in transitional China 38, 40, 51; GMO 
controversies 107, 109; hydropower controversies in China 72-5, 82-3, 92, 95; nuclear power debate $140-1, \mathbf{1 4 2}$, 146-7; research methods and data 21-2, 31

Pietz, D. A. 94

policy impacts: case selection 12 ; comparing theoretical traditions 186 ; controversies in transitional China 54; differing science controversies 174; nuclear power debate $136,153,158$, 162,167

political censorship 11, 99

political control 2, 5-6, 34, 92, 172, 173

political opportunity structures:

conclusions 188; differing science controversies 168-70, 172-3, 173-5, 178, 180, 182; GMO controversies 117-24, 124-6, 126-8, 133-4; hydropower controversies in China 80-2, 82-4, 87-90, 99; nuclear power debate 135-6, 152-5, 155-8, 156, 166-7; research methods and data 19 ; science controversies and political opportunities $2,8-9,10,16-18$; theoretical traditions 184 political process theories: differing science controversies 175; GMO controversies 117, 126-7; hydropower controversies in China 80, 87; nuclear power debate 167; science controversies and political opportunities $2,8,17$; theoretical traditions 185

Poyang Lake controversy 45-6, 70-1, 90 PR (Public Relations) 49, 77, 105, 160-1, 170

print media see also social media; traditional media: differing science controversies 170; GMO controversies 109, 110, 112; hydropower controversies in China 77-8; nuclear power debate 147; research methods and data 23,32

propaganda: controversies in transitional China 57-8; GMO controversies 105-6, 108, 132; hydropower controversies in China 73-4, 81; nuclear power debate 141, 143; research methods and data 31 ; theoretical traditions 186 public accountability frames $143,175-6$ public attention: conclusions 188; differing science controversies 168-9,
170, 171, 175-6, 177-8, 180-1; GMO controversies 105, 116-17, 127, 133-4; hydropower controversies in China 76-80, 79; nuclear power debate 152 , 162; political opportunities 14 ; theoretical traditions $184-5,186$; transitional China 40, 55, 64 public attitudes 3, 16, 101, 104, 135-6, 137-9

public engagement and knowledge control 160-1

public health 6

public intellectuals 52, 97-8, 113, 177

public protests: differing science controversies 179; GMO controversies 113, 126, 132; nuclear power debate 138; science controversies and political opportunities 10, 12, 14; transitional China 49, 55, 58, 59, 60-2

public reactions 23, 25, 80, 113, 151

Public Relations (PR) 49, 77, 105, $160-1,170$

Public Understanding of Science (PUS) model 5, 133

PX (Paraxylene) protests 12, 14, 60-2, 64-5, 167n2

Qigong debate 10, 12-13, 36

QS Data 26, 33, 116

qualitative interviews $20-1$

qualitative research 19, 23, 28, 33, 102,190

research methods and data 19-35; data collection and description 20-1, 21-3, 23-6, 26-7; ethical considerations 33-4; introduction 19-20; multilevel data analysis $27-8,28-32,31,32-3$; research questions $16-17$

resource mobilization theory $4,8-9$

risk management 161-2, 164, 165

Rushan 13, 49, 138, 149

SACH (State Administration of Cultural Heritage) 82

Schmid, S. D. 137, 159

Schurman, R. 103

Science 44

science communication scholarship 1-2, 3-4, 16, 189

science controversies and political opportunities 1-18; book outline 17-18; GMO, hydropower and nuclear controversies in China 12-16, 14; 


\section{Index}

introduction 1-2; literature review 2-4, 4-7, 8-10, 10-11; research questions $16-17$

science controversies in transitional

China 36-65; general observations 63-5; GMOs (Genetically Modified Organisms) 54-8; hydropower 37-8, 39-45, 45-6; introduction 36-7; nuclear power 46-8, 48-54; public controversies 59-60, 60-2, 62-3

science in movements: comparing theoretical traditions 184-7; conclusions 188-91; differing science controversies 168-83; GMO controversies 101-34; hydropower controversies in China 66-100; nuclear power debate 135-67; research methods and data 19-35; science controversies and political opportunities 1-18; science controversies in transitional China 36-65

science in movements conclusions 188-9, 190-1

science-society-state interaction 2 seismic belts 40,70

seismology 40, 44-5, 50, 69-70, 96 SEPA (State Environmental Protection Administration), later MEP, then MEE: conceptualizing hydropower debates in the STS landscape 88-9, 91-2, 96, 99; controversies in transitional China 40-1, 43, 48; differing science controversies 174-6, 179; media and hydropower controversies 71, 75; nuclear power debate 154, 161, 167; social movement theories and hydropower controversies $82-3,85,87$

Sieber, J. E. 33-4

Snow, D. A. 9, 19

SNWTP (South-North Water Transfer Project) 67

social institutions 4,5

social media see also print media; social media platforms; traditional media: controversies in transitional China 52, $56-8,62,63,65$; data 23-6, 32-3; differing science controversies 170-1; GMO controversies 104, 109-10, 110-17, 130, 133; hydropower controversies in China 78; nuclear power debate 138, 147-52, 148-50, 162 ; research methods and data 20 ; science controversies and political opportunities 11-12; theoretical traditions 186

social media platforms: GMO controversies 110, 112-13, 116, 130; hydropower controversies in China 78; nuclear power debate $52,138,150-1$; research methods and data $20,23-4$; theoretical traditions 186

social media reporting $147-52$

social mobilization: differing science controversies 176-7; GMO controversies 127 ; hydropower controversies in China 69, 92; nuclear power debate $136,155,166$ social movement theories: conclusions 190; differing science controversies 172 , 180, 182; GMO controversies 101-2, $117,127-8$; hydropower controversies in China 66, 67-9, 80, 87, 88-90, 99-100; nuclear power debate $135-6,152-5$, 155-8, 156; science controversies and political opportunities 2, 4, 8-10; theoretical traditions 184-7

sociology of scientific knowledge (SSK) scholars 4

sociopolitical factors: conclusions 188-9, 190-1; controversies in transitional China 64; differing science controversies $168,170,172-8$; differing theoretical traditions 184-5, 187; GMO controversies 101, 104, 118; hydropower controversies in China 67, 81; nuclear power debate $135,152-3$; research methods and data 34 ; science controversies and political opportunities $2,7,16,18$

sociotechnical imaginaries: controversies in transitional China 47; differing science controversies 174-5, 178, 180-1; hydropower controversies in China 80, 92, 100; nuclear power debate 137, 139, 155, 160-1, 167; research methods and data 19, 27, 33; science controversies and political opportunities 5, 17-19; theoretical traditions 187

South Korea 5, 7, 137

South-North Water Transfer Project (SNWTP) 67

Southern Weekend (SW): controversies in transitional China 41, 55-6; differing science controversies 172; GMO controversies 105-8, 106, 107, 112, 118; hydropower controversies in 
China 72-6, 73, 95; nuclear power debate $140-1,142,143-4,146-7$; research methods and data $21-\mathbf{2}, 31$ southwestern hydropower controversies: conceptualizing hydropower debates in the STS landscape 91, 97-8, 99; contemporary hydropower controversies in China 70; controversies in transitional China 42; media role in hydropower controversy in China 71; science controversies and political opportunities 18; social movement theories and hydropower controversies 80,82

Soviet Union 38, 47, 136-7, 159

State Administration of Cultural Heritage (SACH) 82

State Environmental Protection Administration (SEPA), later MEP, then MEE see SEPA (State Environmental Protection Administration), later MEP, then MEE state power 7

street protests: controversies in transitional China 53,59, 61; nuclear power debate 135, 138-9, 148, 158

STS (Science and Technology Studies): conclusions 189, 190-1; controversies in transitional China 56; differing science controversies 168, 176-7, 178, 180-3; GMO controversies 101, 104, 117, 123, 130,134 ; hydropower controversies in China 66, 68-9, 77, 80, 82, 87-99; nuclear power debate 137,163 ; research methods and data 20,27; science controversies and political opportunities 1-2, 4, 7, 9-10, 16, 17; theoretical traditions $185,186-7$

Sun Yat-sen 37

SW (Southern Weekend) see Southern Weekend (SW)

Sweden 136

Taiwan 7, 37, 48, 136

Tarrow, S.: differing science controversies 173, 175; GMO controversies 126-7; nuclear power debate 154; science controversies and political opportunities 2 , 8-9; theoretical traditions 185

TGP (Three Gorges Dam Project) see Three Gorges Dam Project (TGP) themes of media articles 73, 76, 92, 95, 106-7, 145-6 see also article attitudes; media themes theoretical developments 64, 100, 184-5

theoretical sampling 19

theoretical traditions 184-5, 185-7

Three Gorges Dam Project (TGP): contemporary hydropower controversies in China 69-70, 71; controversies in transitional China 36-7, 37-8, 39-40, 42-3, 45, 64; differing science controversies 172 , 174, 178; introduction 66-8; media and hydropower controversies in China 75, 77; public intellectuals against hydropower 97-8; research methods and data 21, 27; science controversies and political opportunities 10, 13, 14; social movement theories and hydropower controversies 80-2, 87-8

Tiananmen Square 38, 82

Tianya (Chinese BBS website) 24, 78-9, 112, 150

Tiger Leaping Gorge controversy 41-2, $70,75,86, \mathbf{8 8}$

Tilly, C. 2, 8-9

traditional Chinese medicine 63

traditional media see also print media; social media: GMO controversies 109, 111,126 ; hydropower controversies in China 74; research methods and data 25; science controversies and political opportunities 11; transitional China 58,65

transitional China see science controversies in transitional China

trash incineration: controversies in transitional China 36, 48, 58, 60; nuclear power debate $138,167 \mathrm{n} 2$; science controversies and political opportunities 10, 12, 14

triangulation $20-1,23,27,28,147,152$

Tufts University 57, 113, 116, 121

tweets (Weibo): controversies in transitional China 61; GMO controversies 113-16, 114-15; nuclear power debate 151-2; research methods and data $24-5,32,35 \mathrm{n} 2$

Twitter 23-4, 25, 35n2, 50

UK 3-4, 48, 102-3

UNESCO (United Nations Educational, Scientific and Cultural Organization) $39,41,68-9,84,88$

United Kingdom see UK 


\section{Index}

United Nations Educational, Scientific and Cultural Organization (UNESCO) 39, 41, 68-9, 84, 88

United States: controversies in transitional China 51-2, 54, 57; differing science controversies 171, 176, 179; GMO controversies 102-4, 108, 115, 123 , 125,133 ; hydropower controversies in China 66; nuclear power debate 136-7, 162-3; science controversies and political opportunities 4-5, 9,14

US see United States

visibility of controversies $28,31-2,63$, 95, 107, 184

Wang Yinan 51-3, 139, 143-4, 165-6, 171 Wang Yongchen 39, 64, 77-8, 86, 172 Wangiiang 50-1, 53, 139, 155-7, 163 WCD (World Commission on Dams) 91, 96 WeChat (Chinese social media platform): controversies in transitional China 52, 60,65 ; differing science controversies 170; GMO controversies 112, 116, 127, 130; hydropower controversies in China 78 ; nuclear power debate $150,152,166$; research methods and data 20,23, 24, 25-6, 32-3; science controversies and political opportunities 11

Weibo (Chinese social media platform): controversies in transitional China 50 , $56,60,65$; differing science controversies 170; GMO controversies 112-13, 115-16, 124, 127, 130; hydropower controversies in China 78; nuclear power debate 138, 150-2; research methods and data $24-5,32$, $35 \mathrm{n} 2$

Wen Jiabao 40, 51, 56, 83

Wenchuan Earthquake 44-5, 69-71, 91

Western democracies: conclusions 189; GMO controversies 117; nuclear power debate 152-3; partisan website data 26; science controversies and political opportunities $1,5,10$

Wise Search 21

World Commission on Dams (WCD) 91, 96
World Trade Organization (WTO) 36, 54,125

World Wildlife Fund (WWF) 43-4, 46, 70, 84, 89-91

WTO (World Trade Organization) 36, 54,125

Wu Hui 52-3, 139, 143, 150

WWF (World Wildlife Fund) 43-4, 46, 70, 84, 89-91

XEN (Xinmin Evening News) see Xinmin Evening News (XEN)

Xi Jinping: controversies in transitional China 43, 54, 57, 59, 65; GMO controversies 104, 124; hydropower controversies in China 90; nuclear power debate 155,157

Xiamen protests $60-2,167 \mathrm{n} 2$

Xiaonanhai controversy: differing science controversies 174; hydropower, fragmentation and knowledge-making $70,77,84-\mathbf{5}, \mathbf{8 9}, 91$; research methods and data 25; transitional China 43-4

Xinhua Agency 83, 125, 153

Xinmin Evening News (XEN): GMO controversies 106-7; hydropower controversies in China 72-6, 74, 95; nuclear power debate $140-\mathbf{1}, \mathbf{1 4 6}-7$; research methods and data $21-2$

Yang, G. 11, 170

Yangliuhu Hydraulic Facility 39, 68, 73, $77,88,174$

Yangtze River: conceptualizing hydropower debates 90, 97-8; differing science controversies 172, 176; hydropower controversies in China 70, 81; institutions and experts fueling hydropower controversies in China 85-6; media and hydropower controversies in China 71, 76-7; nuclear power debate 156; science controversies and political opportunities 13; theoretical traditions 185; transitional China 38, 41, 43-4, 45-6, 50

Yin, R. K. 19, 27

Zhang, R. et al. 62-3

Zipingpu Dam 39, 44-5, 69-70 